Portland State University

PDXScholar

Spring 6-9-2014

\title{
Some Neglected Aspects of the Rococo: Berkeley, Vico, and Rococo Style
}

\author{
Bennett Gilbert \\ Portland State University
}

Follow this and additional works at: https://pdxscholar.library.pdx.edu/open_access_etds

Part of the Art and Design Commons, and the European History Commons Let us know how access to this document benefits you.

\section{Recommended Citation}

Gilbert, Bennett, "Some Neglected Aspects of the Rococo: Berkeley, Vico, and Rococo Style" (2014). Dissertations and Theses. Paper 1872.

https://doi.org/10.15760/etd.1872

This Thesis is brought to you for free and open access. It has been accepted for inclusion in Dissertations and Theses by an authorized administrator of PDXScholar. Please contact us if we can make this document more accessible: pdxscholar@pdx.edu. 
Some Neglected Aspects

of the Rococo:

Berkeley, Vico, and Rococo Style

by

Bennett Bruce Gilbert

A thesis presented in partial fulfillment of the requirements for the degree of

Master of Arts

in

History

Thesis Committee:

Thomas Luckett, Chair

Richard Beyler

John S. Ott

Portland State University

2014 


\begin{abstract}
The Rococo period in the arts, flourishing mainly from about 1710 to about 1750, was stylistically unified, but nevertheless its tremendous productivity and appeal throughout Occidental culture has proven difficult to explain. Having no contemporary theoretical literature, the Rococo is commonly taken to have been a final and degenerate form of the Baroque era or an extravagance arising from the supposed careless frivolity of the elites, including the intellectuals of the Enlightenment. Neither approach adequately accounts for Rococo style.

Naming the Rococo raises profound issues for understanding the relations between conception and production in historical terms. Against the many difficulties that the term has involved in accounting for an immense but elusive cultural movement, this thesis argues that some of the chief philosophical conceptions of the period clarify the particular character and significance of Rococo production. Rococo production is here studied chiefly in decor, architecture, and the plastic arts. This thesis also makes an extended general argument for the value of intellectual history. Rococo style is a group of visual effects of which the central character is atectonicity. This is established by a synthesizing overview of Rococo ornamental motifs. Principal theorists of post-Cartesian thought have failed to see how these
\end{abstract}


distinguish Rococo style from both Baroque and Enlightenment culture. The analysis addresses the historical narratives of Benjamin, Adorno, Foucault, Deleuze, and others about Baroque and Enlightenment culture. The core historical claim of this thesis is that Rococo atectonic effects are visual forms of the anti-materialist, idealist ontology of George Berkeley and of the metaphysics and ontology in the early work of Giambattista Vico. Close readings of important passages from works of both philosophers published in 1710 develop the relationship between atectonics and idealist ontology. Both men rejected the Baroque hierarchical cosmology in favor of finitude as the key to human understanding. The readings center on the issue of causality, including Berkeley's views of the perfect contingency of the world and on Vico's theories of truth and ingenium.

A reading of Diderot's critique of the Rococo, which led the reaction to it, shows that he recognized the power of idealist ontology in the Rococo cultural production. The larger force in the rejection of Rococo is the emergence of the sublime as a morally fearful feature of physical nature. Montesquieu's aesthetic work also shows the transition to a more rigidly determined view of existence, which was expressed but constrained in the little-recognized lattice motif in Rococo arts.

The result of these readings is the influence during and after the Rococo period of the concept of continuous creation, in which the memory and imagination of the human subject relays God-given powers of creation into the production of 
culture. Continuous creation also suggested a human capability to animate material nature. Rococo style displays this as pre-cinematic effects that represent the nonmaterial, non-causal deep structure of reality. 
For Damien Jack 
There is a square; there is an oblong. The players take the square and place it upon the oblong. They place it very accurately; they make a perfect dwelling-place. Very little is left outside. The structure is now visible; what is inchoate is here stated; we are not so various or so mean; we have made oblongs and stood them upon squares. This is our triumph; this is our consolation. 
Gratitude

The Department of History of Portland State University has shown me nothing but kindness. I am in debt to every member of this faculty for their willingness to nurture cross-disciplinary studies that raise difficult theoretical problems.

I am deeply grateful to Prof. Thomas Luckett, my advisor, for his support, care, and advice in the writing of this thesis and throughout my time at PSU. Prof. John S. Ott is an irreplaceable part of my education. Prof. Richard Beyler encourage me in every way and provoked some of the most important questions in the course of this inquiry.

Prof. Vanessa Lyon at Reed College led me into the Baroque, an experience from which the need to do this thesis sprung.

I also thank the Resources Sharing staff of Millar Library. They are heroic.

I owe the greatest debts of gratitude to Damien Jack, my partner in life, and to my dear friend Alexander Pierson; and to many friends, chief among them Nicholas Begley, Tommy Bourgeois, Janis Carpenter, Rocco Harris, Davia Larson, Lacey Legel, Keith Macomber, Kevin McCullough, Jack and Amy Meyers, and Aaron Vienghkou and Jen Chow. 
Table of Contents
Abstract
Page i-iii
Chapter 1. Some Neglected Aspects of the Rococo
Pages 1-29
Chapter 2. Interdisciplinary Intellectual History
Pages 30-65
Chapter 3. Rococo Style
Pages 66-96
Chapter 4. Rococo Variations
Pages 97-127
Chapter 5. Berkeley's Creation
Pages 128-152
Chapter 6. Vico's Imagination
Pages 153-175
Chapter 7. Rococo Ontology
Pages 176-194
Chapter 8. Continuous Creation
Pages 195-223
Chapter 9. Diderot's Decision
Pages 224-240
Chapter 10. Rocaille and Lattice
Pages 241-253
Illustrations
Pages 254-266
Bibliography
Pages 267-290 
Chapter 1: Some Neglected Aspects of the Rococo

This thesis concerns the relations of Rococo style in the arts in Europe from to some of the leading conceptions in philosophy from 1690 or 1700 through 1750 or 1760. These conceptions are fundamental ideas in the works of George Berkeley (1685-1753) and of Giambattista Vico (1668-1744). Linking Rococo style and contemporary philosophy deepens historical understanding of how much Rococo style contributed to and can tell us about the development of Occidental thought in the long period of cultural invention impelled by Baroque and Enlightenment ideas. So far as I am aware, the expression of ideas found in Berkeley's and Vico's philosophy in the Rococo arts has not been studied. Indeed, historians of ideas have hardly ever linked Berkeley and Vico to one another. In this chapter I shall first summarize the conclusions of the inquiry the reader is about to read, then begin to give the reader a point of view on Rococo style, describe a passage of conceptions in intellectual history of the periods that precedes and follows the Rococo, and explain the plan of this thesis.

The work of this thesis is to explore a major though neglected similarity between the artistic style called Rococo and some major philosophical conceptions advanced at or near the start of the success of Rococo style among its producers, 
including patrons and artists in nearly every visual craft. The thesis is anchored to the year 1710, in which the works of Berkeley and Vico that it examines were both first published. Other concepts from other philosophers also are part of this scene, but Berkeley and Vico did the richest, best work of the age along the lines here under consideration. Research for the thesis has focused on the decor and the plastic arts and crafts, including architecture, although paintings have been included in both research and the small group of examples herein illustrated and discussed. Rococo production was so vast that some limit of research is practical, ${ }^{1}$ but the desire to decorate space was decisive in the application of ideas to materials among the producers of Rococo. Within these limits, the reader will find here a network of links between philosophical conception and artistic production that afford us greater understanding of each in the light of the other. These links are just a few of the many fields of close relations between the supremely carnal arts of this period and contemporary philosophy that attempts to revolutionize concepts of materiality. The

\footnotetext{
${ }^{1}$ I have excluded the direct consideration of literature, music, and the performing arts. Whether or not European literature of the period is properly described as Rococo is a very vexed problem, in which the usual difficulty of analogy among the arts is greatly compounded. The literary output of the age is in any case beyond the scope of this project. As to the music of the period the case is clear: it defines and exemplifies what Rococo is nearly as much as anything in the visual arts. Stage and set design, discussed in Chapter 8, was inspired by the same concepts that inspired visual arts in this period, and the stage in turn greatly contributed to Rococo architecture and art. Thus contemporary opera and ballet certainly were part of the Rococo. It is the immensity of this fact that puts the domain of music outside of this project, which strains to link just one large category of the arts to philosophy. Nonetheless, an interdisciplinary history of Rococo ideas that ranges over music as well as visual and decorative art, and over literature too, is feasible and highly desirable.
} 
logical and emotional complexity of the situation in the Rococo period that these analogies expose is best approached in the material developed in the following nine chapters. $^{2}$

The network of connections that I develop in this thesis are links between philosophical and artistic conceptions. By "link" in this thesis I mean perspicacious comparisons showing that human persons likely used the linked conceptions, at varying levels of awareness, in some domain of actual human creative activity. Like linked items in a network, concepts work together, although not identical to one another; then the linked use of them adds to their similarity, though differences remain; and they can be and often are used in connection with other concepts to produce quite different results. People use analogy, metaphor, symbolism, allegory, paradox, and enigma to find fruitful similarities and differences among concepts. Intellectual historians study these practices by looking at what the logic of ideas affords and constrains or by seeking evidence of actual influence or by combinations of these approaches. In this inquiry I uncover the network links solely through analysis of the directions concepts allow, but I do look at both texts and objects to make the analysis.

Here is a summary of the leading concepts I analyze in what follows.

1. Idealism is the ontological claim that "ideas" in minds constitute reality

\footnotetext{
${ }^{2}$ This summary that follows does not represent the order in which the topics of this thesis are developed.
} 
rather than matter. Thus, idealism is frequently anti-materialist, but more limited forms express the claim that the sole object of our direct knowledge is the contents of the human mind.

2. Contingency is the condition in which one entity requires something from another entity in order to exist or to function in general or in specified ways. To say, as Berkeley does, that the world is contingent on God is to say that nature has no stability or regularity of its own.

3. Atectonicity (or atectonics) is a term borrowed from architecture. ${ }^{3}$ It is the name for elements of a structure that do not appear to be sufficiently supported so as not to fall. It describes the visual effect in which the actual relation of load and bearing is not obscured and the apparent relation looks impossible to sustain. By extension an atectonic effect poses a question or doubt about the senses in which conventional structural relations in any material object are or are not real.

Architectural atectonic effects were adapted by other arts and crafts; they resemble a-causal views of reality by analogy.

4. Continuous creation comprises two concepts: first, the doctrine known as occasionalism, according to which God intervenes in physical nature instantaneously at every infinitesimal instant in order to sustain or to conserve its operation, nature being devoid of any lawfulness of its own or some non-natural agency such as human

${ }^{3} \mathrm{I}$ am sorry to say that the OED has not yet included either word. 
persons, or both; and second, that God (or providence), or human persons, or both add to the original divinely created world by their activities, which create reality in their every sphere.

The thesis of this inquiry is that in the period circa 1710 in Occidental thought some philosophical concepts roughly grouped as idealism and a very large body of artistic work in all media called the Rococo both questioned the mechanical and other naturalistic explanations of the universe, the philosophers by their critique of conceptions and the artists by their interrogation of materials; that these diverse activities were part of an object of historical inquiry legitimately assigned to interdisciplinary intellectual history, and also that the specific situation circa 1710 was a singularly strong expression of the issues around the practice of intellectual history; and that this questioning yielded thoughts about the deeper structure of reality that have been exceedingly fruitful and important in later developments of Occidental and worldwide culture, though the story of this influence has not been told in the terms in which it is here presented.

In most scholarship the distinct nature of Rococo style has gone unrecognized in favor of identifying it with the Baroque either by reducing it to the economic and social conditions in which it was patronized or by devaluing it according to modern aesthetic and social critique. It is also occasionally identified with a type of closeobserving interest in nature associated with aspects of the Enlightenment. As to 
identifying it with the Baroque, Rococo style was obviously different to most contemporaries. It is a blatant style, in appearance impossible to overlook, invasive, demanding, and showy in varying manners and to varying degrees. On the other hand, production stopped and started, now in one city and now in another country, here retreating in one decade and there exploding in another. Some pieces mix Rococo elements with Baroque style; others, particularly after 1760, have Rococo elements attached to neo-Classical design. Discerning these can be difficult and a subtle art for us, yet to its critics what was Rococo was all too patent. As to the Enlightenment, I will argue that Rococo, though retaining shadows of the Baroque, was in certain key respects one of the Enlightenments, both more and less forwardthinking than the progressive-scientific Enlightenment.

Approaching the Rococo by way of conceptual context and content exposes its specific nature, clarifying it in relation to earlier and later artistic developments. At the same time this approaches challenges scholarly analysis by wholly localized conditions of production. Devaluing the Rococo, both in its own time and now, is, I suggest, part of the motive for subsuming Rococo style into other style and for describing its style solely in terms of production. Placing the Rococo in intellectual history re-values it. The impulse to devalue it grows from conceptual conflicts in which observers have engaged on account of moral anxieties that this bizarre and counter-intuitive style has provoked from the start. 
Following the rejection of Rococo style led by Denis Diderot (1713-1784), the most effective critic of Rococo style, in favor of a form of neo-Classicism, a commonplace of modernity formed that regards the arts of the Rococo period as false, powdered, doomed, foolish amidst danger, and wasteful. This commonplace is tempered a bit when addressed to the greatest monuments of Rococo architecture, particularly the southern German and Austrian churches on account of their impressive statements of faith. It is less tempered when critiquing the Rococo palaces in Prussia and Savoy because of the abusive monarchical politics that is close to the surface for most modern observers.

The history of this judgment passes from the Enlightenment through high modernism. In 1910 Adolph Loos in "Ornament is a Crime" said that because decorative styles both drive and are driven by advances in knowledge, designers and artists were obliged to support and contribute to the progress of knowledge. If they adhered to decedent styles they failed to do this. Ornament had fallen along with the age of absolutism, in his view; its shattered bits reproduced for mass consumption, ornaments fed ignorance and reaction, caused indolence and stupidity, and helped produce reaction and crime. ${ }^{4}$ In Loos's view, the arts affect society or they are piffle; unless they are piffle, they cause progress or they cause decay. ${ }^{5}$

\footnotetext{
${ }^{4}$ Adolf Loos, "Ornament and Crime," Ornament and Crime: Selected Essays, edited by Adolf Opel (Riverside, CA: Ariadne Press, 1998), 166-176.

${ }^{5} \mathrm{~A}$ different approach to ornament that has not received sufficient attention as such is in Georges Bataille, The Accursed Share: An Essay on General Economy, translated by Robert
} 
Under the tremendous pressure of consciousness of the urgent, people

sometimes simplify moral battles in ways that degrade their sensitivity to the issues

and later must be regretted. Great present stakes lead one to make a judgment on

large areas of experience quickly enough to fit one's view of the history and current

state of things. In this way one tries to secures one's position in reality by filling it

with faces representing things morally approved or disapproved in pointed summary.

Ernst Gombrich saw this as an especially modern way of unthoughtfully thinking

about art:

When Zola wrote that what he seeks in a work of art is a man rather than a painting, he may only have articulated what others felt. To use a shorthand formula, art has become physiognomized. Just as we categorize our acquaintances as sympathetic or unpleasant, describing some as good-natured and others as pompous, so we can adopt an attitude in which we assign to every work of art a character of its own, which enlists our sympathy or arouses our hostility. I would not claim that such reactions were entirely unknown to earlier centuries. The physiognomic difference between Raphael and Michelangelo, after all, was a commonplace, but as long as most works of art had a function as devotional images, portraits, or decorations, this physiognomic reaction remained within bounds. ${ }^{6}$

Hurley (Cambridge: Zone Books, 1988), 63-87: since alternating austerity and prodigiality is a natural pattern, "growth has its limits, and it is necessary to dissipate the excess that cannot be accumulated"; this is an explanation of certain periods of intensified ornamentation in the plastic and visual arts. David Harvey extends some of this in The Condition of Postmodernity: An Enquiry into the Origins of Cultural Change (Oxford: Blackwell, 1989), referring to the material factors that build and then conclude as "regimes of accumulation" (122ff.) and noting that each such regime is a frozen state the must change (206). Llewelyn Negrin, "Ornament and the Feminine," in Feminist Theory, vol. 7, no. 2 (2006): 219-235, argues the feminist critique of opposition to ornament.

${ }^{6}$ Ernst Gombrich, "Back from Oblivion” (review of Frances Haskell, Past and Present in Art and Taste: Selected Essays [New Haven: Yale University Press, 1987]), New York Review of Books, June 25, 1987. He also discusses this idea in his The Sense of Order ( Ithaca: Cornell 
He suggests that this emotional reaction replaces more careful moral response and that this type of aesthetics is at least in part derived from exactly the modernist disdain for ornament that Loos expressed. One of the tasks of historians is to open up the fear and anxiety behind our creating "physiognomies" of the past and then to replace these falsely enlarged opinions with accounts both more particularized, in being as complex as human affairs are, and more universally true, being freer of our own particular present oblivion and more comprehending of the lives of others. To do this is partly a matter of exposing facts; and it also a matter of seeking, beyond our rapid emotions, truer understanding of meaning in historical time.

The farther an age fades into the past the more likely we are to see it solely in large characters, as if squinting to see the largest letterforms on a far-away billboard we drive rapidly past. As if by reaction, we look with greater awareness of conflict at what is nearer because that which is nearer is, or seems to be, more consequential, as well as more legible, even to the degree of threatening our existence. It is easy to do this until historians intervene. The nearer seems to be, at any rate, more useful. Of the more recent past, such as the century of early modernism from 1850 to 1950, the polemic is more current, and we have more at stake in its fissures. We defend our own lives by plunging right into the conflicts near at hand. We think there is no time for old battles and that it is better to write the old stories in the clear colors of

University Press, 1979), 202. 
physiognomy: medieval monks were grim, absurdly, and the increasing crowds of the nineteenth century newly rich were shallow and frivolous, ridiculously.

Our desire, whether hasty or theorized, to dismiss differences between people in the past and ourselves comes in part from fear of finding lost and troubling parts of ourselves. The similarities between them in the past and us in the present are frightening, even after they have been obscured, and enlarged rather than diminished by our knowledge of outcomes. If we decide to use our present knowledge to increase the profundity of response to the past, rather than to diminish it, the strange drama of the confrontation of Occidental peoples in the Rococo years with profound, weird, and disturbing changes in their production of their culture becomes something bigger, even something heroic, as well as sometimes comic. Rococo style is one of the sources of the existential challenges we today face, still a ribbon of living tissue in the thick foliage we have put out in the most recent seasons of history. Our everintensifying historicization of events, in the sense of understanding them in as full a range of diachronic context as the facts and our wits provide, disturbs the easy physiognomizing of arts from past eras. We are anxious as to what history will show us and are afraid to feel the original heat from fires we either hope to have extinguished or altogether forgotten, even though they now might require our urgent attention to control. While the artisanship in Rococo style might seem to be the model of the passé, the conceptions that explain its production deeply concern the 
growth of conception in the cultural and social production in our own, as well as in other, eras. ${ }^{7}$

Beyond the vice-squad charges against the Rococo years in the arts-that the society's pleasures doomed it—one finds a second range of anxiety about Rococo style. Words like lightness and softness, and related names and descriptors in French, Italian, and German — the languages of the lands in which, along with Britain, the Rococo arts flourished-words otherwise innocent, here paint Vanitas onto the Rococo. The word Vanitas (vanity) is used to make Rococo one-dimensional by way of a caricature of its patrons. It and other words accuse the Rococo of being the emblem of emptiness because it was interested in masks and of being nothing but face-powder because it was interested in cosmetics. One of portraits of Madame de Pompadour details the labeled drawers of her make-up table, ${ }^{8}$ yet we most certainly

${ }^{7}$ I have borrowed this phrase from the philosopher Suzanne Langer (1895-1985), a pupil of philosopher and historian of the Enlightenment Ernst Cassirer (1874-1945). In her Feeling and Form. A Theory of Art (New York: Scribner, 1953) she wrote that "the aim of philosophy is the growth of conception" (6). One can ask a great many questions about her statement. Taking it here as a straightforward account of the work of philosophy and leaving complications aside, it readily becomes a reliable and useful description of what the history of philosophy is - the growth of conceptions. In part A of Chapter 2 I discuss the definitions of this and other phrases that this thesis uses.

${ }^{8}$ This is François-Hubert Drouais' (1727-1775) Madame de Pompadour (1763-1764), at the National Gallery, London, online at http://www.nationalgallery.org.uk/paintings/francois-hubert-drouais-madame-depompadour-at-her-tambour-frame. One of François Boucher's (1703-1770) portraits of Pompadour, "Madame de Pompadour at Her Toilette" (1750-1760), in the Fogg Art Museum at Harvard online at http://www.harvardartmuseums.org/art/303561, along with the Drouais painting are examined for the rich range of their artistic and cultural association by Melisssa Hyde in Making Up the Rococo: François Boucher and His Critics (Los Angeles: Getty Research Institute, 2006) and her earlier paper, “The 'Makeup' of the Marquise: Boucher's 
know that she was more than a mask of rouge. ${ }^{9}$ The attraction and repulsion of makeup and masks is of course hardly simple. ${ }^{10}$ Frederick the Great, one of the most munificent and persistent patrons of Rococo on the very grandest scale, was, though vain, hardly simple. His thoughts about life's problems, almost as frank and as clear as we today often are, show a highly complex understanding of areas such as sex and gender, the morality of war, and power in society. ${ }^{11}$ If words of judgment and the notions behind them are to be part of our response to the Rococo, then we are obliged to recognize that Vanitas is only one part of the fraught Rococo aesthetic effect.

In order to understand the complexity of the actual Rococo, and therefore of its actual and complex effect on subsequent developments, one must seek out the distinctively conceptual part of the Rococo years. I shall return to the theoretical justification of a history of conceptions in Chapter 3. In the present chapter I direct the reader's attention to a pattern of conceptions before and after the years in which

Portrait of Pompadour at Her Toilette," in The Art Bulletin, vol. 82, no. 3 [2000]: 453-475).

${ }^{9}$ See Nancy Mitford, Madame de Pompadour (New York: New York Review of Books, 2001). Mitford, who wrote this book in 1953, says that 'The Marquise [Pompadour] and her brother controlled all the artists in France...." Research since her writing shows that although this is not true in the sense that bourgeois men commissioned a lot of Rococo art, it is true in the senses that Pompadour's style of femininity vastly influenced the arts and that her ideas and taste combined with her influence over state patronage was a decisive part of the age.

${ }^{10}$ For a relevant study see Terry Castle, "The Culture of Travesty: sexuality and masquerade in eighteenth-century England," in Sexual Underworlds of the Enlightenment, edited by G. S. Rousseau and Roy Porter (Chapel Hill: University of North Carolina Press, 1988), 156-180.

${ }^{11}$ The easy recognizability of Frederick's sentiments is one of the things that makes reading Nancy Mitford's Frederick the Great (New York: New York Review of Books, 2013) such a pleasure. She gives us an insight into the emotions and desires of a monarch in commissioning Rococo palaces that is, as far as I've found, unparalleled. 
Rococo flourished that is so sophisticated and far-reaching as to introduce the question of regarding Rococo style as conceptually profound in contrast with judgments of it as immoral or amoral. Two centuries of art history have so internalized these judgments that even knowledgeable observers resist philosophizing the Rococo. ${ }^{12}$

In the decades during and after the flood-tide of Rococo production philosophers turned their attention to the sublime for the first time in the modern era. The sublime arose, at least in part, because the issue of perfection in a work of art very readily suggested the distance between human imperfection and whatever might occupy the realm of the perfect. ${ }^{13}$ Alexander Baumgarten (1714-1762) applied to the arts a notion of regulative, logically derivable perfection, based on Leibniz's logic and

\footnotetext{
${ }^{12}$ For example, from an earlier generation of eighteenth-century studies, Robert Halsband wrote in 1985: "The topic of rococo book illustration seems so contradictory as to be selfdestructing. For the rococo is a style of decoration, external and ornamental; book illustration is primarily internal and essential, a pictorial translation of a verbal text. Can these different functions be combined? Then too, in general the rococo as decoration has been only grudgingly extended to the other arts ("The Rococo in England: Book Illustrators, Mainly Gravelot and Bentley," in The Burlington Magazine, vol. 127, no. 993 [December, 1985], 870).

${ }^{13}$ For an account of the context of Kant's thinking see Melissa McBay Merritt, “The Moral Source of the Kantian Sublime," in The Sublime From Antiquity to the Present, edited by Timothy Costelloe (Cambridge: Cambridge University Press, 2012), 37-49.
} 
metaphysics. ${ }^{14}$ For Burke and Mendelssohn, both in works published $1757,{ }^{15}$ this perfection overwhelms our senses, presenting to us something alien by virtue first of magnitude, then of power inscribed as perfection, and then of awe. We are in conflict with that of which we are in awe: we worship it or fear it. Burke contrasts our simplicity in loving beauty—our sense of being at home with beauty—with the infinite forces around us. ${ }^{16}$ The year 1757 is toward the end of the Rococo years, and something seems to have slipped the leash by then.

In 1790, in his Critique of Judgment, Immanuel Kant brought the perplexity of the sublime to full contrast to the beautiful. Straight off the sublime "displeases us" and "is repugnant to charms," yet we "RESPECT" it because it is infinite. ${ }^{17}$ Infinity is always headache-making for "us" in Kant's view. It takes away our self-assurance, our feelings of adequacy and strength; until we understand that it truly is the moral law

\footnotetext{
${ }^{14}$ Baumgarten was the first modern to use the word "aesthetica" in relation to an audience's emotional reception of a poem in his thesis of 1735, "Meditationes philosophicae de nonnullis ad poema pertinentibus." He devoted a section of his Metaphysica in 1739 to aesthetics and finally a book, Aesthetica, in 1750, to the subject.

${ }^{15}$ Edmund Burke (1730-1797) in his A Philosophical Enquiry into the Origin of our Ideas of the Sublime and Beautiful; and Moses Mendelssohn (1729-1786) in his essay "Considerations on the Sources and the Connections of Fine Arts and Sciences," revised and renamed in 1761 as "On the Main Principles in the Arts and Sciences" ("Ueber die Hauptgrundsätze der schönen Künste und Wissenschaften"), which is now its usual title.

${ }^{16}$ Amy Schmitter, "17 $7^{\text {th }}$ and $18^{\text {th }}$ Century Theories of Emotions," in the Stanford Encyclopedia of Philosophy (online at (http://plato.stanford.edu/entries/emotions-17th18th/), section 2.3, points out that for Burke "the experience of the sublime transgresses categories of pain and pleasure" and is therefore out of the control over our motions that beauty enables.

${ }^{17}$ Immanuel Kant (1724-1804), The Critique of Judgment, translated by James Creed Meredith (Oxford: Clarendon, 1969) 257, 245. The small capitals are Kant's.
} 
that makes for all the good that we can do, it does not comfort our finitude in return for its disturbing demands. Kant aims the "deduction of pure aesthetic judgment" at the goal of finding safety in what has been terrifying, for the moral law is "pure and unconditioned intellectual delight." ${ }^{18}$ But before we arrive at this happy destination, Kant presents to us a thorough account of the immeasurable might of nature and of everything outside our selves and our communities, ${ }^{19}$ which is the travail of existence within the sensory realm. A step outside this reality can lead to immortality or to extinction. Because of this danger, Kant helpfully advises us to conceive of the sublime in relation to "our way of thinking" rather than in relation to the reality of which it is a version.

We have no reason to fear that the feeling of the sublime will suffer from an abstract presentation like this, which is altogether negative as to what is sensuous. For though the imagination, no doubt, finds nothing beyond the sensible world to which it can lay hold, still this thrusting aside of the sensible barriers gives it a feeling of being unbounded; and that removal is thus a presentation of the infinite. As such it can never be more than a negative presentation—but still it expands the soul. ${ }^{20}$

The untamed infinite is like a graven idol (which the "Jewish people, in their moral period," forbad by divine commandment ${ }^{21}$ ). Therefore must Kant lay taste, and universal taste at that, upon the wild infinite sensuous, in order to lay the good upon

\footnotetext{
${ }^{18}$ Kant, Critique, 271.

${ }^{19}$ Kant, Critique, 260-266.

${ }^{20}$ Kant, Critique, 274. The italics are Kant's.

${ }^{21}$ Loc. cit.
} 
the real. Hegel, too, thought the good must meet the real; Schopenhauer and Benjamin were sure that it did not, just the opposite; Plato had raised the question for all time in the mouth of Socrates. ${ }^{22}$

For the purposes of this thesis I take the sublime to be that quality of the natural world which most forcefully challenges our understanding of the place of human persons and all humankind in its order. It comprises the perceptions, feelings, and thoughts that the conflict of finitude with infinity arouses. The infinite includes both the virtually limitless, at least partially quantifiable or formalizable, energies, processes, and materials of nature, and also the awareness we feel of the unquantifiable, unavoidable, humanly obligating forces comprising events we regard as conflicts of morally better with morally worse, of just and right with their opposites, or of good and evil. Kant wrote that the greatest objects of our "admiration and reverence" precipitate the greatest conflicts in our thoughts. He says these are "the starry heavens above me and the moral law within me." ${ }^{23}$ This makes the sublime the supreme object of reflection, holding that both material processes, such as our artifactual production, and ideal processes, such as the moral deliberation and the growth of conception, cross together in sublimity.

In this thesis I shall not more broadly examine the eighteenth-century study

\footnotetext{
${ }^{22}$ In The Republic, 6.490c.

${ }^{23}$ The Critique of Practical Reason, translated by Lewis White Beck (Indianapolis: BobbsMerrill, 1956), 5:161-2. The italics are Kant's.
} 
of the sublime. ${ }^{24}$ I present it here because I wish the reader to recall the importance of the sublime and then to consider what episodes in the history of ideas might account for Kant's anxiety about the untamed sensuous-by what growth of conception it appeared to him to be necessary to subjugate the infinite and to find rules to gird unlimited imagination. Burke and Kant spotted ideas in the productions that the culture presented to them. Rococo productions imaginatively invaded sensuous space during that period. These productions, having reached out into each other by drawing from and adding to the stylistic movement among craftsmen, patrons, and the society at large, in their whole mass, seen as paintings, churches, palaces, chairs, settees, porcelain tea services, candlesticks, soup tureens, opera, comedy, and drama, uncurled contemporary thought into a region that seemed to be feckless. It looked like causality replaced by chaos. Representation took on the infinite through transgressing the bounds of sensuality. Here was one of the unstable grounds that Kant's thinking moved toward checking in all its aspects, from the ontological straight through the aesthetic to the moral. If this is true, it suggests that deep conceptual growth was afoot within Rococo production, issuing from it as it dispersed or ended in the 1750s and subsequent decades and influencing the

\footnotetext{
${ }^{24}$ For a larger picture of eighteenth century philosophy of art, see Paul Guyer,"18th Century German Aesthetics," in The Stanford Encyclopedia of Philosophy, online at: http://plato.stanford.edu/cgi-bin/encyclopedia/archinfo.cgi?entry=aesthetics-18th-german; and Jacques Morizot, "18th Century French Aesthetics," in The Stanford Encyclopedia of Philosophy, online at: http://plato.stanford.edu/entries/aesthetics-18th-french/.
} 
culminating philosophical project of the era.

Under this view Rococo style was a phase in a much older inquiry as to the nature of reality, its relation to the good, and the means of demonstrating its claim upon us through the work of art. I shall show that it was a fully competent participant in this discourse. To begin to understand this, we must examine some of the philosophical and aesthetic responses to the morally challenging notion of infinity that preceded the years of Rococo production.

The matter of "what is incomparably great" ${ }^{\text {"25 }}$ disturbed us inhabitants of the world long before we thought of the sublime, long before Occidental people, at least, had sought for a way between the finite here and the infinite there, and long before Kant hoped that we might make the best of our position by being citizens of the world. ${ }^{26}$ We can draw closer to the Rococo itself by considering changes in conceptions of finitude and infinitude out of which Rococo artisans might have drawn some of their ideas. The proximate origin of the conceptions of infinite power and wisdom — that is, of divinity — relevant to this study is in some developments in religious philosophy in the eleventh-century monastic reform and the creation of Scholastic philosophy in the next centuries. St. Anselm (1033-1109) described a way of understanding that which is immeasurably greater and more perfect than we

\footnotetext{
${ }^{25}$ Kant, Critique of Judgment, 245.

${ }^{26}$ The phrases "inhabitant of the world" and "citizen of the world" are in Kant, Opus Posthumum, translated by Eckart Förster and Michael Rosen (Cambridge: Cambridge University Press, 1993), 27.
} 
through a dense ideational structure commonly labeled the ontological (sometimes the "Anselmian") argument for the existence of God. Inside this structure our intellect repeatedly recoils from its limits in intuitively familiar ways. An affirmation concerning the meaning of finitude accompanies each recoil. For this to happen, the thinking subject must create an assertive notion of finitude, which each moment of self-awareness re-enforces, building, as it were, a bastion out of the fortress confining us at every point of the circumference, rather than succumbs to the recoil. The result can be the conception of God as a being Who shapes space and time perfectly to enclose us.

Around the time of invention and diffusion of the perspectival method in art in the mid-fifteenth century, Nicholas of Cusa (1401-1464) advanced the old notion of divine capability to shape reality I have briefly described in a very striking and puzzling form. Perspective tended to reverse our subjection to God through His creation by shaping space and form from our point of view, subjecting it to us. Nicholas argued that infinitude, being unbounded, must extend into finitude. Even our finite realm was, in some consciousness far different from our own, infinite, and the infinite was finite by the same stroke. At the same time God, being present even in finitude, is absent even from infinitude by virtue of His infinite capabilities or being. We try to see the form of reality, but ...where you behold this sight you find no name which can be named by us 
with complete truth and complete distinctness.... [No] name which is nameable or understandably by us befits that Beginning. ${ }^{27}$

"Beginning" (illi principio) means the divine creation of all things. Our consciousness confronts the infinite possibilities that God has the power to execute as unstable names for ever-changing forms, not mapped and labeled. In trying to grasp this divine capability we come to call it the creation of all things Vision, Cusa elsewhere says, peers into this "hyper-light," as if infinitely mirrored; also this a darkness; it is the conceptual domain in which Cusa pursues the doctrine of "learned ignorance" so as to encounter God. His conceptions of infinitely varying perspective onto infinitely intermixed light and dark are intentionally difficult to grab hold of, and it is through these Nicholas called reality itself an enigma. In this case, everything created, everything constituting history, and everything we ourselves do or invent is enigmatic. Infinitely varying perspective in conjunction with God's unlimited and continuing power to create will be important ideas later in this thesis.

A very old enigma stands in the core of this: the problem of change as revealed to us by the failures of our perception and understanding. As perspective-makers, we extend space outward from us, channeled so as to aid us in understanding boundaries near and far. Our movements change our perspective. The horizon therefore seems to be a tool at the subject's disposal, but for all our willing it does what a horizon

${ }^{27}$ Nicholas of Cusa, A Concise Introduction to the Philosophy of Nicholas of Cusa (Trialogus de Possest), translated by Jasper Hopkins (Minneapolis: University of Minnesota Press, 1978), sec. 26, developed further in sec.s 62 and 66. 
does: it stops us by presenting finitude. The category of the sublime was first an indirect and finally, in Kant, an explicit way to control the horizon, placing it just so in respect to the position of mundane humankind. Kant erected a powerful conceptual defense of the importance of our species, in spite of our limits. Although its logical and spiritual roots are deep, it was in conflict with the materialist trend of Kant's century and its posterity. This, if true, helps explain one aspect of developments in optics from the mid-seventeenth onwards.

When the horizon asserts its control despite the power and freedom perspective offered hope of, the response of Occidental natural philosophers was to feel themselves to have been tricked by the authority of perspective they had credited, which now weakens; and finitude obliged them to think of our smallness over and over again. At this point some people invent tricks to fight back.

Like perception puzzles, devices to create visual tricks are ancient. They apparently were used in making paintings for some centuries before the period here under review. In the seventeenth century various insights into the details of perception inspired the fabrication of more and more complicated devices to create these tricks, and the devices in turn enabled those interested in the matter to use them to ask questions about the forms that we find the world presents to our senses and our understanding. One of these tricks was anamorphosis of images, created by 
copying a form as distorted in a conical mirror. ${ }^{28}$ Only that mirror will reconstitute the copied image into legible form. It was, as far as I can see, an unprecedented mechanical capacity assisting human control in re-shaping the world by changing images passing through perception according to our will. By its means perspective seemed multiple rather than monopunctual and shifting rather than still.

Pluripunctuality appears as a distorted kind of infinity; and, what is more, in it we ourselves are the creators and destroyers of stable finitude. Emptiness and its terrors, as well as its reassurances, pours in through the jagged horizon. Embodied, stuck in space and time, people found some illusions that were also not delusory. Plurality perturbed what had been quiet. This result was implicated in most profound developments in conceptions of self and world, identity and similarity, and the beautiful and the sublime.

Anamorphosis was a wide-spread and complex practice that flourished in original and in reproduction, in high and in popular art, from the 1640s into the succeeding decades. Around 1700 to 1710 production of anamorphic images almost stopped, surviving as the manufacture of toys. To say that it "went out of fashion" is only to ignore the significance of the change, since children's toys are a strong

\footnotetext{
${ }^{28}$ The literature on anamorphosis is fine and always growing. Beside my own observation of anamorphic images, my chief guide has been Lyle Massey, Picturing Space, Displacing bodies: Anamorphosis in Early Modern Theories of Perspective (University Park, PA: Pennsylvania State University Press, 2007). A discussion of anamorphosis in pages 21-30 of Marian Hobson's The Object of Art. The Theory of Illusion in Eighteenth-Century France (Cambridge: Cambridge University Press, 1982) is also relevant to this thesis.
} 
indicator of ideational activity in a society, not to mention the cycles of discovery and denial associated with fashion. The change was very marked, and it happened in the same period in which the Rococo emerged.

The illusionist kinetics of Baroque perspective before the Rococo period and the abundant interest in the sublime before during and after the Rococo years tell us that ideas were passing and changing throughout these periods. This thesis holds that one of the most important paths through which Europeans conducted ideas in this period was the earliest development of the ontology and philosophy that later philosophers and historians came to call "idealist" in the sense of this word used by Kant, Hegel, and thinkers in the last two centuries. Further, this thesis argues that a meaningful relation obtains between this passage in philosophy and the course of European arts in this period. One of the reasons it ought to interest us that it includes paths of thought to which thinkers and artists have returned at intervals and that it includes paths not taken.

Rococo style came in without a theory or doctrine or even a name, spreading vigorously through France, Italy north and south, Catholic Germany, Bohemia, Spain, Portugal, Britain, and some of the colonial possessions of these countries in the Americas. It stretched out in the growth of conceptual tentatives to describe the contest between finitude and infinitude, specifically between our anamorphic capability and the breaking-point of reality. I shall argue that the superficial 
brilliance of Rococo style was, at least in great part, the artistic expression of an attempt to mediate these two powers, to locate humankind somewhere between them. The location to which the metaphysics of Berkeley and Vico both pointed was a conception that Leibniz consolidated from diverse earlier notions: continuous creation. "Continuous creation" means first and foremost that God maintains the reality He created. He sustains (or conserves) its existence by exercise of His powers. Why He does this and how He does this differs according to different developments of the concept. In Berkeley's and Vico's accounts, "continuous creation" also means that beings created with those bits of divinity commonly called spirits or souls act in the world by virtue of or in cooperation with divine creative power. The principal claim that this thesis will develop is that this idea of human creative ability, which both thinkers carefully combined with notions of the moral life of persons, comprises the core intellectual history of Rococo style.

Consider the console, or "hunting table" illustrated as figure $3{ }^{29}$ If you aspire

\footnotetext{
${ }^{29}$ Some intellectual history looks only at abstractions. John Milbank's excellent book on Vico's philosophical theology, The Religious Dimension in the Thought of Giambattista Vico 1688-1744 (Lewiston, NY: Mellen, 1991) is a fine example of this approach to issues centrally important to this thesis. The method of intellectual history I pursue in this thesis involves interrogating artifacts (or "things") in a context of the growth of conceptions. Because this is not a thesis in disciplinary art history, the 13 illustrations of Rococo objects that I use herein ought not be taken to be a group balanced as to artist, type of object, recognizability, etc., or as conclusively probative. They simply illustrate my arguments. I choose them out of the thousands of truly beautiful and interesting objects I looked at reproduced in print or online (plus those I have seen in person) because these, among others, most stimulated my visual and critical responses and could be usefully discussed in this thesis.
} 
to be a Rococo table, this is the table you want to be. It was made for Louis XV, the presiding spirit of French Rococo, in the choice year of 1736. It was made for the palace of Versailles, to which it has returned after the dispersal of royal furniture and bibelots by a year-long auction following the Revolution. The mount climbs across the edges of the table-top and crowds it out of sight, but note also that the mount is pierced and open. It is more airy window than gilt wall. Nonetheless, it hides the joins between the tablet below the marble top and the support structure that is the actual function of the legs and tablet surrounds. The table's legs are not straight but in the form of an S-curve, which hides the relation of load to support. Further curling and folding elements cover the four S-curves themselves with cartouche-like shapes that seem to frame more emblems, more signifiers, or more tiny but lively decor. Other Rococo tables take this even further. A sketch for a table by JusteAurèle Meissonier (1695-1750), illustrated as figure 9, shows the legs and understructure in advanced stage of disregard for the expression of function..$^{30}$ Closely observed, there is something disturbing about the form of this table.

As a Rococo table you could not desire to be in a better place than next to this wall. Gilt carved wood (or stucco) ornament completely covering white walls is utterly satisfying theatrical absorption. The corners of the panels above the table are not squared off but curved because for some reason wreathed shells block the drive to

\footnotetext{
${ }^{30}$ I rerurn to Meissonier's table from another point of view in Chapter 9.
} 
rectangularity, and even the concave space is filled by forms that somehow answer to the shells as well as to panel decor and resonate with their kindred ornaments elsewhere around the large and small panels. The panels below the table-top have different visual themes. They combine strong lines with rounded, protruding strips of foliage within rules. Table and wall together are bright and busy.

At the center of the table-where the eye of the observer of this photograph is drawn despite its not being the center of the shot - the table displays the Bourbon arms. This is more what is "on" the table than anything to be put on the top of the table. Anyone of the time in the room would have noticed this part of the table as the first or among the first impressions of the furnishings. And yet this blazon is strangely presented: it is tilted clockwise to the side and forward at the top. The same artisans made it projecting but not titled in an earlier hunting table for Louis made about 1730, and another artisan snapped it back into sober alignment in a console made once neo-Classicism had set in. ${ }^{31}$ The coat of arms is as if in motion, as if about to twist further. The legs indeed do twist further in the other table of 1730 , curving angles so extreme that the table seems barely able to stay upright.

\footnotetext{
${ }^{31}$ Pierre Verlet makes the comparison of the sequence of three consoles in his Le Mobilier Royal Française. Meubles de la Couronne Conservés en France (Paris: Plon, 1955), no.s 1922. It is more accessibly illustrated (and in better color), along with many interesting related objects, in Penelope Hunter-Stiebel's essay on "Louis XV Style" in Sarah Coffin, Gail Davidson, Ellen Lupton, and Penelope Hunter-Stiebel, Rococo: The Continuing Curve, 1730 2008 (New York: Cooper-Hewitt National Design Museum, 2008), 74-75, fig.s 106.
} 
The ornamental motifs of the table are different from those on the wall to which it is adjacent. The topography of the wall paneling meets the table's form solely at the level of the table top, which in a rational world might be the central horizontal plane of a painting. But here it is an accident. Color unifies the wall and the table, but more than color it is tone and inspiration that seem to make of this mishmash—a contemporary German word for Rococo was mischmasch—something that demands, intrigues, and retains our attention. One of the specific features that causes this effect is that the table is so near to being animated that the observer might, with a little imagination, think herself about to see the hallucination of a solid object morph or melt. One of the conclusions of this thesis will be that Rococo style created pre-cinematic effects.

The console exhibits great freedom of invention. Also, it shows no fear of nature, neither of the natural nor of the moral sublime, because it twists up representations of natural forms in any way the designer chooses, yet it never simplifies the mystery or intricacy of natural forms. It is a picture of imaginative freedom. Rococo is, as Jean Starobinski argued, part of "the invention of liberty."

\footnotetext{
${ }^{32}$ Jean Starobinski, The Invention of Liberty, 1700-1789, translated by Bernard C. Swift (Geneva: Skira, 1964), 22-23ff., affirms Rococo as a period of freedom but characterizes it largely as freedom from Baroque order-a breakdown in visual masses and volumes, likewise a breakdown in values and beliefs, with the result that forms, having lost the significance in which they had been anchored, now floated freely according to the imagination and boldness of artists. This is partially true, but the present inquiry will show what did replace earlier beliefs, quickly arising from them, and what positive conceptions guided Rococo arts. The art historian Michael Levey in his Rococo to Revolution. Major trends in Eighteenth-
} 
But liberty is only one part of the story of Rococo. The console is a fragile dustcatcher. From grime it came and to junk many like it have returned. It is a thing less useful than a glass of water or a pliers. Why did people make it this way? What conception of the cosmos did it fit? What does this table affirm or negate? The artists who made the table had great imagination and superb visual observation, not to mention stunning skill and perseverance. Occidental civilization has increased these tools many fold since 1736. Accordingly our understanding of human and other persons has been enriched, although personhood remains full of mystery. Rococo objects are aggressive, intrusive, seductive, addictive, and confident. In all these and their other qualities they puncture our resistance to their naughtiness. Our modern resistance to them is a tell that somehow these ridiculous things raise disturbing issues. What was that quick moment, in different years at different places and diving in and out of sight, between Baroque and Enlightenment and also simultaneous with these two phases of Occidental civilization? What do the productions from the Rococo moment tell us about how people conceived of their agency in the world?

In the following chapter I shall consider some of the issues that arise when we speak of the influence of some ideas upon other ideas and of the relation of

Century Painting (London: Thames and Hudson, 1977), writes a very insightful long account (15-119) of Rococo painting as a brief window of real and consequential freedom of taste, having reached its height in the work of Boucher and Tiepolo then turned its"grand manner" into "airy shapes almost of tinted steam" in the work of Fragonard (89). It ended as "a palace of art which rising national forces destroyed, and which was long to remain neglected and unvisited" (119). 
philosophical conception to other types of thought (Chapter 2). I shall then characterize the Rococo style following my observations of the objects and the ideas of art historians, bringing up some of the quandaries in this area and defining the qualities central to the Rococo effect that I shall discuss in terms of intellectual history (Chapter 3). Next, looking at some theories of the Baroque and of the Enlightenment, I present the framework of philosophical conceptions that specifically explain Rococo style (Chapter 4). From that point forward this thesis will study the Rococo forms as representations of the growth of conception and turn to ideas of the two philosophers best associated with this, George Berkeley and Giambattista Vico, looking closely at central texts (Chapters 5 and 6) and linking the work of these two together in the history of ideas (Chapter 7). I shall then examine these ideas together in the light of the key notion of continuous creation (Chapters 8) and as illuminated by contrast to Diderot's critique of Rococo style (Chapter 9). 
Chapter 2: Interdisciplinary Intellectual History

A. Intellectual history in relation to the Rococo and definitions of terms.

Intellectual history is a highly consequential though neglected way of looking at the Rococo era. In fact, the Rococo is highly valuable in forming a defensible theory for intellectual history. This is because European philosophy written during the Rococo decades was principally concerned with the problem of what thought is, and what nature is, and what are their connections. It entered the domain of inquiry into how ideas grow and was a time of tremendous production of aesthetic objects that themselves interrogated intellectual matters in terms of material matters. In order to claim that a relationship between some philosophy around 1710 and Rococo arts obtains, it is necessary to describe in general what relations that obtain between conception and production are the province of intellectual history and why intellectual history is a worthwhile and valid way of accounting for such relations. This thesis argues that one valid way to describe these relations in the present case is this: that the materiality of Rococo production questioned the nature and utility of conceptions. I shall emphatically return to this point in discussing various topics in every chapter of this thesis.

Toward that end, this chapter defends intellectual history from certain major 
criticisms and affirmatively argues for intellectual history as a valid and worthwhile way of accounting for meaning in historical time. One of its chief valuable qualities is true interdisciplinarity, which I claim to be of its essence. By intellectual history I mean study of the history of the growth of conception. I take the history of ideas to be a rather broader term, rather than a different kind of inquiry, useful for taking social, cultural, political, and even popular history into conspectus with the growth of conception. I try roughly to observe this usage because it is practical one, but one of the issues always at stake is to what degree the historical developments of conception and of production are similar, as their contexts are always identical at some level of generality. Justification of intellectual history entails justification of its place in the history of ideas.

Because the word "idea" has a special place in eighteenth-century philosophy and a technical meaning in philosophical discourse, I do not use it in this thesis to refer to our thoughts about things. I do not use it in the broad sense in which it is used in the phrase "history of ideas" itself—except that I retained "ideas" in this phrase because it is a common idiom. I use the word "notion" to refer to what we commonly call "ideas" — more or less definite thoughts in our heads, either abstract or concrete, such as the claim that art ought to represent nature. My use of "notion" does not connote anything inferior or smaller-scale. Though my uncommonly frequent use of "notion" might seem odd, it will serve the reader and me well . 
"Concept" will refer to quite well-formed general ideas both abstract and concrete.

These near-synonyms having been distinguished for their use in this thesis, "conception" remains as the most important kind of thought in the terminology of the present inquiry. I take a conception to be a high-order and abstract claim devised through perspicacious thought for the purpose of answering fundamental questions in the practice of philosophy, especially as metaphysics, ontology, and epistemology: for example, the claim that divine intervention explains causality. Conceptions also include non-disciplinarily philosophical notions that are or can be stated as answers to fundamental philosophical questions. Conceptions are usually puzzling: they are so complicated that they border nearly on different or even contrary propositions, and they contain seeds of further developments in their growth. Conceptions change quickly in small ways, from one thinker to another. But their instability does not mean that they are not identifiable. It means that thinking about them, debating about them, and changing them are of their essence.

The word historiography commonly refers to construal of the body of writing by scholars on an historical topic, but by extension it often also denotes the body of theory applied to history, including very abstract theory supposedly classified as the philosophy of history. As a practical matter it is very difficult to separate the meanings of these two words with strict consistency. In the following I try to observe the denotative difference but also use the lexical range of both words. 
Similarly, usage really does not rigidly separate moral philosophy from philosophical ethics, although many times people write as if the strong distinction clear to them must surely be the objectively correct distinction. In truth the two words have similar lexical ranges. I use them both but use moral philosophy more often by preference.

B. History of conceptions versus the logic of conceptions.

In Chapter 1 I attempted to defamiliarize Rococo art in the view of the reader. I asked the reader to move her attention from the superficiality associated with the Rococo to ponderous ideas of sublimity and infinity in connection with the Rococo. Nevertheless it is easy for most of us to feel that many Rococo objects are ugly and that something was wrong with the people who found the style irresistibly beautiful and surrounded themselves with it and even with later writers who are comfortable with the légèreté of the era. Frivolity is no more devoid of depth than comedy is devoid of tragedy, but between the sensuous and the conceptual sides of Rococo one notices the gap not only between what conceptions are and what productions are but also between material reality and our sense that it "contains" thoughts, offers moral example, or teaches moral truths. One might feel this in thinking about any artifact, but because suggesting that Rococo style reflects on existential issues is rather fresh one strongly feels the gap in this instance. Also, the economic conditions, the social 
history, the development of artisan and artistic practice, the wonder of objects particular to the study of the material culture might be elided in this gap. It seems that a focus on conceptions shuts out much of the color and all the contingency of history.

The contingency that seems lacking is the causal motions of historical change, which are easier to see in social facts and public events. How does intellectual history give us valuable accounts of the constant changes on every level of life that occupy historians' attention? $?^{33}$

A common hasty theoretical justification of intellectual history, in the face of more concrete cultural history and its theory, distinguishes causal accounts from explanatory accounts. ${ }^{34}$ This approach, however, is not of much help. The word "explanatory" here does not explain anything because it refers to anything other than the causal without having considered what that might be. On the other hand, the adjective "causal" doesn't help, because although one has known forever that there are four traditional kinds of cause (efficient, material, formal, and final) one finds oneself assuming that this causality is efficient causality; and one then rapidly knows

\footnotetext{
${ }^{33}$ Paisley Livingston, "History of the Ontology of Art," in The Stanford Encyclopedia of Philosophy (2011), online at: http://plato.stanford.edu/entries/art-ontology-history/, is a basic primer in the subject. As always, Tom Rockmore, in "Subjectivity and the Ontology of History," in The Monist, vol. 74, no. 2 (April, 1991): 187-206, has the topic well in hand.

${ }^{34}$ For a really good academic philosopher's take on the idea of historiographic narrativity see David Velleman, "Narrative Explanation," in The Philosophical Review, vol. 112, no. 1 (January, 2003): 1-25. Velleman allows historians some freedom so long as they admit that emotions ought to submit to logic.
} 
that this is inadequate to the description of meaning in historical time except on a fully reductive materialist account. Even a small tolerance of any reality other than that which is within the conception of strict materialism unleashes formal and material causes, although final causality might remain excluded. ${ }^{35}$ The notion of the other-than-causal explanatory account is an excuse rather than a reason. It in not adequate to the conviction that human events and artifacts are unintelligible if construed as boulders knocking other boulders. It does not add positive content to the notion of explanatory accounts. Every historian relies on explanatory accounts and has some theory of what constitutes such accounts and what they accomplish, but in order to explain explanatory accounts historians need robust philosophizing about the how understanding relations between conception and production helps them to establish meaning in historical time.

Furthermore, the four classical types of causality more likely obscure than exhaust the question of human agency. Since the expansion of the human sciences through hermeneutics, phenomenology, sociology, and critical thought (all of which I call here in summary "cultural theory" or "theory of culture"), causality in the philosophy of history means merely "other-than-non-causal-explanation." The nowdoubly obscured area is one of the utmost importance to historians and theorists. It is the entire gap in which they have worked to find a way to understand meaning in

\footnotetext{
${ }^{35}$ As in the Velleman paper cited in the previous footnote.
} 
historical time that respects positivities but is adequate to the problem. Even some positivists have looked for this, and even some of those theorists concerned with polyvalence argue that human faculties are not adequate to the task, either because nature is too vast or because the world is unintelligible without the super-natural.

Michel Foucault (1926-1984) once offered list of a-causal logical modes for historical understanding, including "implication, exclusion, transformation."36 The pragmatist philosopher Hillary Putnam engages a parallel project by describing the ways in which persons meaningfully express non-factual matters, primarily moral commitments, by concepts other than "ought." ${ }^{37}$ Comparison between Foucault's concern and Putnam's concern is instructive. Putnam as a disciplinary philosopher bore down on disposing of the "is/ought," or fact/value, distinction and of all ontology connected to it. Foucault did so as a cultural theorist and an interdisciplinary historian of ideas, whose chief topic in this matter was the whole body of theory devised for the human sciences to bridge the gap I have mentioned—very much the familiar "explanatory gap" - both before it and after the power of analysis with which Kant's anthropology endowed Occidental thought.

The first thinkers in the Occidental philosophical tradition to address

\footnotetext{
${ }^{36}$ Michel Foucault interviewed by M. G. Foy, "Who are you, Professor Foucault?" in Michel Foucault, ed. Jeremy R. Carrette, Religion and Culture (New York: Routledge, 1999), 91-92 (87-105).

${ }^{37}$ In his Ethics Without Ontology (Cambridge, MA: Harvard University Press, 2004).
} 
subjectivity and non-propositional thought as the source for explaining meaning in human affairs, capable of attaining truths different from those that scientific thought attained, were the two philosophers of the first half of the eighteenth century whom I have mentioned, George Berkeley and Giambattista Vico, during the Rococo era in European artistic culture. The study of the history of philosophy also began in this period, though over a leisurely century stretching from the late Renaissance and Baroque polyhistors, such as Konrad Gesner in the 1540s to Johan Morhof who died in 1691 at the very start of the Rococo, who broke from doxographic method. ${ }^{38}$ The issue for historians yesterday, today, and tomorrow, of what beneficial and valid account of human affairs they might offer, is part of the heritage of the Rococo era.

Three issues, addressed by philosophers either systematically or as part of big specialized literatures, are the heart of debate over most theoretical matters in historiography and the philosophy of history. ${ }^{39}$

\footnotetext{
${ }^{38}$ Recently described by Luciano Malusa, "Renaissance Antecedents to the Historiography of Philosophy," in Models of the History of Philosophy: From Its Origins in the Renaissance to the 'Historia Philosophica'," edited by C. W. T. Blackwell (Dordrecht: Kluwer, 1993) 3-85.

${ }^{39}$ I formed these three questions for explaining intellectual history in connection with a study of the Rococo based on review of wide-ranging literature in recent philosophy of history. In general, intellectual history has gained ground since the polemic of the 1970s, although until the last few years it has not been the object of much direct attention. Some of the books I read (though often in disagreement) that have greatly contributed to the favorable climate and that also have stimulated many areas of thoughtful historiography are: Robert Doran, ed., Philosophy of History After Hayden White (London: Bloomsbury, 2013); Ian Hacking, Historical Ontology (Cambridge: Harvard University Press, 2002); Mogens Lærke, Justin E. H. Smith, and Eric Schliesser, eds., Philosophy and its History: Aims and Methods in the Study of Early Modern Philosophy (Oxford: Oxford University Press, 2013); and Azeviel Tucker, Our Knowledge of the Past: a philosophy of historiography (Cambridge: Cambridge University Press, 2004). Daniel Brewer's Brewer, Daniel. The Enlightenment Past:
} 
The first is whether philosophical issues are best studied as really being formalized logical proofs or whether they are better understood as including nonlogical and non-discursive forms of thought and feeling, such as world-views, personal dispositions, material textuality, and social conditions. The question is, so to speak, whether philosophical ideas are more like flesh-and-blood living organisms or more like the skeleton of a body alone. In arguing the legitimacy of intellectual history, one takes this question as the challenge of proving that explaining the relation of conceptions to one another in historical time is an historiographic practice necessary to understanding meaning in historical time.

The second issue, close kin of the first, concerns how we are to think about logical discourse itself in respect to the plurality of history, leaving aside where it stands in relation to thought as a whole. There are three basic positions on this. Some think that philosophical issues are perennial and therefore best studied as argument free of social and historical contingencies. Some think that the issues are entirely conditioned by situation. Others, by contrast, think that because they are perennial they thereby illuminate historicized context. This requires an understanding of "perennial" that is opposite to that of those holding the first basic position I described, and these two versions of this concept are rather close to the

Recovering Eighteenth-Century French Thought (Cambridge: Cambridge University Press, 2008), 4-8, gives an excellent summary account of the 1970s-1980s controversy over intellectual history. 
division between those who regard the valid, best thinking as strictly logical and those who, often holding that thought never can be strictly logical, hold that our best thinking involved faculties other than the faculty of logic. The third basic position is that philosophical issues are not perennial but particularized — that they are virtually meaningless quā conceptions but do illuminate historical objects and events. ${ }^{40}$ The historiographic problem here is how best to use the range of response to the question of how conceptions or ideas relate to human production and agency.

The third issue is the nature of time, which in this context is the field of the ontology of history because it addresses temporal succession, progression, and simultaneity. This field concerns diachronesis: the manner in which past things exist in the passage of time and at times other than their own; whether they intermittently perdure, endlessly endure, or cease to exist; what parts of them are fact or value or imagination; what unities or multiplicities constitute an event or object of

\footnotetext{
${ }^{40}$ It takes some doing to untangle the two opposite ways in which the notion that "traditional" philosophical problems remain interesting and consequential (for which I use the word "perennial") develop. One sense of their enduring importance leads to the conclusion that the "older" treatments must be discarded on account of their having been replaced by newer frontiers and methods, and the other sense of their enduring importance leads to the position that this importance lies in their precise historical forms. This latter position usually requires philosophers to read the problem in question wholly and thoroughly in its precise linguistic historical context. This is the position of Quentin Skinner. Ian Hacking's delicately nuanced position (which he calls "dynamic nominalism) in Historical Ontology, 30-57ff., holds that philosophical problems have been dissolved in their traditional form but that they persist as human issues made evident in the domain of histoical study. A superb paper exploring these issues is Justin E. H. Smith, “The History of Philosophy as Past and as Process: Ways of Writing History of Philosophy" in Philosophy and its History...., edited by Mogens Lærke, et al., 30-49; see also the three editors' "Introduction" to this collection.
} 
historiographic study; and what if any laws obtain in historical time. ${ }^{41}$ One finds the question of the ideal, real, or other nature of time itself in each of these problems. ${ }^{42}$ Even within the natural sciences, especially in physics, and within analytic philosophy the problems of time remains extremely sharp. Ontological positions determine historiographic method, much as they do moral philosophy—a link I shall pursue again in connection with Diderot in Chapter 9. When seeking to view parts of a culture or cultures as analogues to one another, historians of both ideas and of material and social culture are led to the question of what historiography may rightly say about similarities or regularities in different fields of production.

C. The necessity of intellectual history: the objection from naturalism.

Before examining these three issues in the light of what they offer to this thesis, I wish to state a general line of defense for intellectual history and then to answer objections to intellectual history on this basis.

Here is my general view of the path that historiography takes from its direct study of topics to reflecting, one day or another, on philosophical commitments. When we seek to understand persons, events, and objects, and our narratives about these, we require ourselves to recognize their social and historical contexts. After

\footnotetext{
${ }^{41}$ See Hacking, Historical Ontology, 48, 67, et passim; and Tucker, Our Knowledge, 185ff. ${ }^{42}$ See Timothy Sprigge, "Whitehead and Santayana," in Process Studies, vol. 28, no. 102 (Summer, 1999): 43-55.
} 
particularization, or as part of it, the conscientious inquirer applies her larger theoretical commitments to the objects she studies. Thus the history of the growth of conception is part of the historian's thinking and will form a valuable part of her historiography.

Her reply will be that the natural facts self-evidently and fully constitute as much as we can understand the moral nature of the object study to be and that therefore the history of conception is not an importantly comprehensive account of the particulars of historical events. If she naturalizes them, in the sense of understanding them to be intelligible without an "essentialist" notion of individual or collective human agency, and then stops at the physical and social facts, having accepted them as sufficient causal or explanatory account of historical time, she greatly risks failing to satisfy her own moral commitments and those of the pursuit of knowledge, even if her moral commitment is to the bracing and truth-giving value of naturalistic explanations.

Consider that if she theologized the social and historical circumstances, in the mode opposite to naturalizing them, she would risk the same failure: that particularity (or plurality) is erased by confinement to one kind of factuality, whereas as conceptions allow interpretative access to any kind of fact. The work she produces will omit so many particulars from the complex reality it is to account for that it makes no sense of the object of study. To study a bit of the past is to enter the gap, 
starting to try to fill it; and in the gap the philosophical issues of our larger commitments are the soil, air, and sky of theoretical inquiry, whether we are thinking as logicians, scientists, hermeneuticists, or historians, even though the direct object of our research outside of the gap is more concrete.

As commonly as naturalizing and more commonly than theologizing, she will treat human historical events as social facts by using methods from anthropology, economics, linguistics, geography and demography, critical theory, sociology, psychology and other quarters in as sharp and as insightful way as the available facts allow her to do. The socio-economic approach is perhaps the most common; I shall say more about this below. These approaches, too, rely on the historian's higherorder conceptual and moral commitments.

While this thesis is not primarily a study of the ontology of history, nor does it include direct exposition of my own larger commitments, I do say that by following the line of thought described at the beginning of this section of the chapter one will see a shape outlining the constructive possibility of intellectual history. It neither naturalizes nor theologizes, not so much because either is wrong but because its job is a different one. Its job is legitimate and valid but subject to the same liabilities to unifying at the expense of plurality and of conceptualizing at the expense of morality. People trap themselves in ideas, Mary McCarthy once said; and Hannah Arendt made the same observation as her most forgiving way of describing why smart philosophers 
became Nazis. Historians need ontology because they need a moral philosophy; but, like all moral agents, they must find a way to compromise with the force of conceptual principles. Approaching human history as social history seems to avoid these difficulties and has been immensely productive of truth. But any such approach finally refers to higher-order commitments in both ontology and in ethics.

D. The objection from untranslatability.

Contemporary philosophical objection to express accommodation of moral issues in conceptual and universalizable forms in historiography is widespread. It is strong even in the field of the history of philosophy. In the year of this writing, an historian of philosophy wrote the following in the most eminent recent collection of papers on theoretical issues in the history of philosophy:

Above all, I oppose Ideengeschichte-as if ideas had a coherent history on their own. Ideas are formed or created by human beings when they are needed, just as tools are invented or produced when needed. Also, once found and then forgotten in the storage of the history of ideas, they can be rediscovered after long periods if people are looking for them when grappling with new problems - as we remember a tool that might be helpful to solve a problem when it had rested unused in the garage for years....

Thus, although we have a long tradition of philosophical texts, dealing with problems, and a big tool box of rules and concepts to solve them, acquired over the last 2,500 years, new philosophies originated because of new problems that had come up or because the old solutions were no longer sufficient. That is why there cannot be a historia perennis in any strict way. ${ }^{43}$

\footnotetext{
${ }^{43}$ Ursula Goldenbaum, "Understanding the Argument Through the Then-Current Public Debates, or My Detective Method of the History of Philosophy," in Philosophy and its History: Aims and Methods in the Study of Early Modern Philosophy, edited by Mogens
} 
Her substantive argument is that we cannot link up ideas that were invented in different contexts because they are meaningful solely within the linguistic and cultural sphere in which they were used. ${ }^{44}$

Martin L. Davies lately pursues this idea, along with other arguments, to a very far point: that every effort we make to translate thoughts or events from the historical past increases their untranslatability. ${ }^{45}$ Each theory trumps its predecessor by dominating the discourse and thereby successfully adding to the coercive voice of the historian, the authoritarian discipline of history, and the incarcerative presence of the past that politicians, historians, and policemen of all kinds use as the "'megamachine' of the management system" in modern societies. ${ }^{46}$ This, he claims, is the sole and inevitable actual product of historical discourse, remorselessly reproducing

Lærke, et al. (Oxford: Oxford University Press, 2013), 72-73. The use of tools, taken in even the widest sense, hardly exhausts human creative capacity. Prof. Goldenbaum's words do not even come close to describing what "looking for" and "remembering" a simple physical tool is actually like.

${ }^{44}$ Goldenbaum's ideas follow the well-known ideas first argued by Quentin Skinner in 1969 to the present, and her exclamation echoes a number of statements by Henri Lefebvre from the 1920s onward.

${ }^{45}$ Davies uses not only Wittgensteinian ideas but also Freudian ideas, concepts from media theory and sociology, and a strong view of reification (in debt to Adorno, though understated) to make a wide-ranging (repetitive and ranting) case against history in his two books, Historics. Why History Dominates Contemporary Society (London and New York: Routledge, 2006) and Imprisoned by History. Aspects of Historicized Life (London and New York: Routledge, 2010). His recent paper, "The Redundancy of History in a Historicized World," in Rethinking History, vol. 15, no. 3 (September 2011), 335-353, concisely argues his core claim at quite sufficient length for the reader who wearies of redundant harangues. ${ }^{46}$ Davies, Historics, 132ff., 146ff., and esp. 152ff.; see also his other lines of approach at $82 \mathrm{ff}$ and 122ff. 
"mortiferous historicism."

The domain of thought is not rightly separated from the other domains of human activity. Davies separates them, making thought an epiphenomenon on historical time, a venomous parasite. But awareness of the recursive continuity of consciousness, by means of historiography or any other means, is not, as Azviel Tucker shows, separate from or an advance upon thought or upon history. ${ }^{47}$ Nor is it less substantial than the contents of historic time. The memory of something and a reflection upon that something are not the same in so far as the latter grows from the former by recursion— that is, through a period of mental reflection—but they are otherwise sufficiently the same as parts of human mental activity. One mental act and the perdurance of that act are not acts of basically different kinds. One who claims that reflection is separate from other human activity, in order either to compliment or to disempower it, is making an ontological distinction where there is none, which is taking words for things. To say that thought is an activity with multivalent relations to all other activities, which themselves have the same kinds of relation to thought, is to say that it is part of the world we experience, just as physical labor is part of our experience as well as something by which we experience the world. No boundary is clear, all is virtually infinitely complicated no matter whence

\footnotetext{
${ }^{47}$ Azeviel Tucker, Our Knowledge, 4 et passim. Tucker naturalizes thought, which is the opposite direction from my own, that of "idealizing" (though that is not the right word) reality; but his argument, based on the history of historiography, is still valid.
} 
one starts analysis; and each thing yet has distinction from other things, which we subject to our testing of intelligibility according to the means we have in hand best to accomplish this test.

The ultimate antagonism of thought and reality in Davies' philosophy leads him to say, correctly, that much of the use to which the linguistic turn has been put re-enforces reification; or, in other terms, it enhances rather than diminishes the effect of recursive thought to rigidify ratio at the expense of the autonomous agency of persons, not to mention that of historians in particular. Although a good deal of critical theory pitches itself against the autonomy of individual personhood, it nonetheless regards its own theoretical movement as a liberating step, even within high-order determinism. In general critical theory (including deconstruction) and the inscription of practices morally responsive to issues of gender, class, and society in writing history has the ethical aim of persuading us toward compassion toward others, showing their human worth more fully than historiography had used to show it. This aim makes them basically different from inquiries that conceive of their objects as fully bounded by language. It points to a sharp distinction between the linguistic turn and the other "turns" that enrich our understanding of meaning in historical time, such as anthropological, gender, class, and other perspectives. The argument from untranslatability empowers that which it hopes to disempower.

Untranslatability, opacity, extreme particularization, and total localization are 
not by any means the only possible outcomes of context-sensitive reading. Against the claim that there are no universal conceptions of value, one puts the entire history of human communication, from person to person and thence to groups and eras- - the whole vast amount of communication people do successfully make in the past and in the present. A history of communications would work on models of translatability as well as of shortcomings in our mutual understanding. The argument, whether in weak or strong versions, that meaninglessness is the controlling result of linguistic or social analysis, fails to recognize this. Since communication is actual, one has no reason in toto to hold that conceptions are not communicable.

E. The objection from the material turn.

The closer, and most recent, argument against intellectual history lies in the material turn (also called "the turn to things") rather than in the linguistic turn. ${ }^{48}$ The material turn, comprising material culture studies with recent theoretical developments, directs our attention to the omnipresent and fine-grained networking of persons, groups, natural forces, and objects. It is the flowering of the confluence of art history and cultural history, fed by economic, social, and critical-theoretical scholarship, in the last half-century or more. Inquiry into the material text and its

\footnotetext{
${ }^{48}$ G. B. Madison's The Hermeneutics of Postmodernity. Figures and Themes (Bloomington: Indiana University Pres, 1988) was an early klaxon in this movement from the perspective of post-modernist literary and cultural theory. The
} 
history of transmission moved with these studies and now throughout them, so that the old history of the book has become a big, active discipline and a widespread historiographic method since it buoyed out of a century's foundation-laying.

An argument from the philosophical principles supporting material culture studies on the part of some, or many, of the scholars practicing it, runs something like this. First, objects made by people, and natural objects appropriated by people, represent the full or virtually the full range of human endeavor. The physical products of our endeavors, taken as the human world emergent from matter rather than as the human world reduced to matter, are the media through which we make and know ourselves. Therefore the investigation into culture must critically examine mediation as the substance of all representation. A second step transforms mediation, shedding the category of representation. Artifactual objects and events and our narratives of them do not merely re-present human life as culture and ideas or as persons and groups of persons. Rather, they act upon us, as well as we upon them, in the sense that diffusion of awareness of them alters our further production. We invent culture and society by means of them. Another way to put this is that current material culture theory says that it is far from adequate to hold that production reflects culture and that we must see that production constitutes culture. It invents culture. Especially in its modes of reproduction, circulation, and diffusion, production makes societies into what they are. For some thinkers, they even make all 
individual persons into what they are.

These two claims - the first about representation and the second about constitution-outline both the principles of material culture studies and its historical development. There is a third step that emerges from a philosophical movement of the last three decades generically called object-oriented ontology. Its best-known form is Speculative Realism. Its principle is a basically new ontology, neither idealist nor realist nor phenomonological nor pragmatist, though echoing all of these. In this view, every type of human activity and every kind of object all are active, constituting agents in the real world, which is a network they comprise as equally inventive actors. This is a brief exposition of Bruno Latour's "actor-network theory," which an international group of philosophers have substantially enriched. ${ }^{49}$ To historians it offers striking and rich new ways to account for human history. It also supports the re-composition of human life into the long story of worldwide human

\footnotetext{
${ }^{49}$ The paradigm of object-oriented ontology as an historiographic practice is, in my view, Manuel de Landa's War in the Age of Intelligent Machines (New York: Zone Books, 1991). Some of the recent philosophical works in this field include Ian Bogost, Alien Phenomenology, or, What it's like to be a thing (Minneapolis: University of Minnesota Press, 2012); Levi Bryant, The Democracy of Objects (Ann Arbor : Open Humanities Press, 2011); Levi Bryant, Nick Srnicek and Graham Harman, eds., The Speculative Turn: Continental Materialism and Realism (Melbourne: re.press, 2011); Graham Harman, Guerilla Metaphysics. Phenomenology and the Carpentry of Things (Chicago: Open Court, 2005); J. Ladyman, et al., Everything Must Go (New York, Oxford University Press, 2007); and Quentin Meillisoux, trans. Ray Brassier, After Finitude. An Essay on the Necessity of Contingency (London: Continuum, 2008). Do note that in 2013 and 2014 more monographs investigating these conceptions appeared than ever before, and this certainly will continue in the coming years.
} 
presence (world history), of life as a whole, of Earth, and even of the cosmos. ${ }^{50}$ This is sometimes called "deep history" and comes in a deeply pessimistic version and in a mildly hopeful, or at least virtuously exhortatory, version..$^{51}$

For my present purposes, I will focus examination of this view on the thoughts of Gilbert Simondon (1924-1979). ${ }^{52}$ This thesis cannot do Simondon justice, but I choose him because his work is a foundation of object-oriented ontology and yet I find a thread in it that leads in a different direction—-through moral personhood towards meaning in historical time, which I propose to be the business of historians. Working prior to Latour, at the earliest post-war start of object-oriented ontology, he tried to give technology a universal, or philosophical, meaning, rather than a meaning bounded by cybernetics, information theory, biology, or any other science.

In Simondon's view, no bit of information exists except as a fictional abstract from the world. To treat it otherwise is to treat as a robot, but no robots in the strict

\footnotetext{
${ }^{50}$ Michael McKeon, "Mediation as Primal World: The Arts, the Sciences, and the Origins of the Aesthetic." In Siskin and Warner, eds., 384-412.

${ }^{51}$ For the rejectionist view see Harold Fromm, "How We Became So Beautiful and Bright: Deep History and Evolutionary Anthropology," in The Hudson Review, vol. 65, no. 1 (Spring, 2012): 19-42. For a more exhortatory view see Dipesh Chakrabarty, " The Climate of History: Four Theses," in Critical Inquiry, vol. 35, no. 2 (Winter 2009): 197-222.

${ }^{52}$ Gilbert Simondon's Du mode d'existence des objets techniques. Edition augmentée (Paris: Aubier, 1989) was first circulated as a dissertation in 1959. A partial English translation by Ninian Mellamphy, On the Mode of Existence of Technical Objects, has been published online by the University of Western Ontario, 1980. For a strongly written brief exposition by Simondon of his position, see his "The Genesis of the Individual," translated by Marc Cohen and Sanford Kwinter, in Incorporations, edited by Jonathan Crary and Sanford Kwinter (New York: Zone, 1992), 296-319.
} 
sense of the word exists because every real thing functions in the context of the world. Abstraction is, like robots, a myth. ${ }^{53}$ The recording and reproduction of information increases our awareness of the real world background (milieu).

However marginal it may always be in terms of our attention, the background is the harbour for dynamisms, and it is what gives existence to the system of forms. Forms interact not with forms but with their background, which is the system of all forms or, better still, the common reservoir of the tendencies of all forms even before they had separate existence or constituted an explicit system. The participational relationship connecting forms to their background is a relationship which straddles the present and brings the future to bear upon the present, that which brings the virtual to bear upon the actual. This is so because the base is a system of virtualities, of potentials, and of moving forces, whereas forms are a system of the actual. Invention is a taking into account of the system of actuality by a system of virtualities; it is the creation of a new system from these two. ${ }^{54}$

Simondon rejects dialectic as the motor of history in favor of gestalt, in which figure has a manner of change peculiar to it, undetermined by ground. Nothing so symmetrical and tight as causality, of which dialectic is an account, is adequate to explain human culture, because information does not act upon a cultural object as "un bloc fermé." ${ }^{55}$ Knowledge dynamically and plurally branches off from its stable background as a figure mutates apart from its ground. We try stably to control the information we gather, but if stable control were the determinant it would be "the death of all further change" (la transformation ulterieure). The reason human affairs

\footnotetext{
${ }^{53}$ Simondon, On the Mode, 7-8.

${ }^{54}$ Simondon, On the Mode, 51.

${ }^{55}$ Simondon, Du mode, 145-146.
} 
change is that information "supersaturates" (sursaturater) human operations. ${ }^{56}$ This is a philosophy of history.

It is also a philosophy of ethics. Simondon draws his thought to a focus on this connection of morality to the invention of every future. He calls it "genesis," by which he means a relationship between humanity and the material world brought to light (à la lumière) with every technological innovation. Ethics is the essence of "technicity,"57 the term he uses for the "awareness of technical objects." ${ }^{n 8}$ Objects are not static blocks but are activated by the network of information humans hold. Technicity is an ontological force, and an ontological force is a moral force. ${ }^{59}$

Both are forces rather than substances. Because technics combines the theoretic modes of intellection with ethical practice and because technics is diachronic, then ethical knowledge is diachronic. This pont is highly consequential, because most moral philosophy, especially when philosophers apply the tools of

\footnotetext{
${ }^{56}$ Simondon, Du mode, 163. In Simondon's view, in the digital age this supersaturation has caused a highly networked distribution of knowledge and energy to replace the tradition close relationship of artisanal and industrial work through human power (see Arne De Boever, "Introduction" to Gilbert Simondon: Being and Technology, edited by Arne De Boever, Alex Murray, Jon Roffe, and Ashley Woodward [Edinburgh: Edinburgh University Press, 2012], 5-6).

${ }^{57}$ Simondon, Du mode, $154 \mathrm{ff}$.

${ }^{58}$ Simondon, On the Mode, 13.

${ }^{59}$ Simondon also insists on the moral equality of human persons and the machines they use. This is generally taken to mean that we must conceive of our prosthetics as part of ourselves, but Simondon is quite clear about his advocacy of respect for the equal status of machines. I myself have not yet evaluated this opinion. For more on this and Simondon's notion of personhood see Muriel Combes, Gilbert Simondon and the Philosophy of the Individuation (Cambridge: MIT Press, 2013), 59-66.
} 
meta-ethics to normative ethics, reflects on moral life in an impoverished framework purged of the movements of dilemma and choice in favor of propositions and stasis. ${ }^{60}$

Simondon does not halt before a deep connection between ontology and ethics but instead tries to explain it, and he explicitly addresses ethics. On the other hand Simondon must, like virtually everyone else, point to an explanatory gap somewhere between old-fashioned spirit and conventionally understood matter ("undoubtedly very difficult to clarify.... All we can see is that...") One reason is the difficulty of knowing what it really means to see that information causes a change or motion-a problem so far from being solved that "information" should still rightfully be regarded as an index to a buffet of metaphors or as itself a metaphor. Simondon strives to overcome this by presenting conception as diachronic. It is more than dialectical: it moves emergently from background to foreground and anagogically from choice of action to information.

This view of ideas, moral life, and the relations between the two is nonessentialist and existential. To expand it in the present issue of intellectual history, one has reason to say that it plausibly describes a view of history in which controlling universal conceptions, emerging from the sums of information and experience humankind acquires, are, presumably during the course of responses to moral

\footnotetext{
${ }^{60}$ For an account of Simondon's notion of technicity in processual terms see Aud Sissel Hoel and Iris van der Tuin, "The Ontological Force of Technicity: Reading Cassirer and Simondon Diffractively," in Philosophy \& Technology, vol. 26, no. 2 (June 2013): 187-202,
} 
dilemmas, incessantly resumed into moral life which in turn openly invents conception. Also, this view is neither conventionalist nor relativist; it involves no coincidence of the mind with reality (or Being) as other than itself, nor does it leave social consensus untouched over time by the growth of conception as if it were invulnerable to the epiphytic "history of ideas." Conception alters convention by moral action, though moral action is altered by many factors; and moral action alters production through universal conceptions as well as by other operations. The situation is indeterminate and creative. Genesis includes all human capabilities, each supplementing the other. In this picture conceptions are a necessary step in the diachronesis of cultural and moral life. ${ }^{61}$

Simondon gives us in prospect a view of intellectual history that material culture does not overwhelm to the loss of the ways ideas entail other ideas, and that nonetheless is not fatally detached from material and social life, condescending to it, or ignorant of it. His primary commitment to the history of information technology is part of his final project. The concept of information did not limit him in his project; its technology became technicity, and technicity became the story of communication for him, or was on the verge of becoming this for him or for us. He opened this possibility.

\footnotetext{
${ }^{61}$ Pascal Chabot, The Philosophy of Simondon: Between Technology and Individuation (London: Bloomsbury, 2003), 23-34 and 114, holds that Simondon tried to construct a postEncyclopedist optimism.
} 
Object-oriented ontologists have not yet chosen to follow the possibility, and they have so far devoted very little attention to ethical theory. To date they limit subjectivity to the state of exercising agency and agency to the effect that each and every entity can have on any one or more other entities. They have either already reduced personhood and cannot accept it as something non-natural on the terms of their ontology—or they have yet to discover it. Yet their ontological project does allow for the legitimacy of the history of conceptions and can provide higher-order moral commitments for the historian. This brief discussion of Simondon is a small demonstration of these possibilities, despite what some of its proponents say or think.

This school of thought, nonetheless, is making a tremendously important contribution by seeking a philosophical account that takes us past the battles between realist and idealist ontology. Their achievements of twentieth century phenomenology and sociology had this aim as well and are a foundation of material culture studies. From its stand in the digital post-human, the Speculative Realists sense certain weaknesses in phenomenology and endeavor to deepen the ground. But some things lack. Commonly socio-economic determinism wipes out a robust conception of personal agency. Object-oriented ontology does not change this since it endorses cultural phenomena that drive human agency into the information network, dissolving it there and proclaiming the "democracy of objects" ${ }^{32}$ - that

${ }^{62}$ This is the title of a book by Levi Bryant (see above). 
ontological equality of persons and things which sometimes today seems to be coming true in the "network of things" supported by QR codes and subsequent programs. There are also other contemporary philosophers of history who address the special difficulties that ontological dualism presents to the humanities. ${ }^{63}$ The focus founding work in critical theory of production on the nineteenth century-the work of Walter Benjamin —is followed by many other intellectual historians who work on the same period. One of my purposes in this thesis is to say that the Rococo obsession with objects is also fertile ground for thinking about the development of present and future tendencies, especially because it is contemporary with and, I argue, connected to Berkeley's creation of idealism.

Historians ought to be aware of this picture. In the history of philosophy a deep intuitive and actualized link between the poles of abstract ontology and praxis of moral philosophy always obtains. Simondon suggests for us a possibility of taking conception as broadly expressing both logic and moral life and, by doing so, of remembering moral personhood. This, I think, requires other developments beyond the scope of this thesis. But Simondon's ideas offer one way of establishing intellectual history that compatibly supplements material and social historiography.

${ }^{63}$ For example, Hacking, Historical Ontology. 
F. Reconciling historical context and logical structure in intellectual history.

Reflection on these objections and possibilities sheds light on the three questions I raised earlier in this chapter.

The first question is, are onto-philosophical ideas truly logical constructions, nothing more and nothing less? I suggest that they are not, because they grow through transmission. Transmission, I would argue in terms of issues beyond the scope of this inquiry, is not reducible to materiality. More importantly, moral obligation forbids us from such reduction in light of the suffering that is history; rather, the imperative to address the full conditions of human existence require us to account for the growth of conception as a theoretical argument about moral agency, debating it, changing it, etherealizing or solving it, furthering or retarding it. ${ }^{64}$

The second question is whether thinking people should study the growth of conception strictly in order to develop new ideas or also to gather certain values and benefits from the history itself? If an historical account of an episode in intellectual history is boxed in by accounting for its context, it has limited benefit for the thinker, who might as well take on the ideas on their own. But we can grab hold of the history of conception without limits that are, after all, disciplinary, contingent on the current academy. When we do so, we cease to limit the creativity with which human

\footnotetext{
${ }^{64}$ I have suggested elsewhere that even the great normative ethical theories (deontological ethics, consequentialism, and virtue ethics) as well as the analytical tools of meta-ethics can help historians of all kinds recount events and explain objects and our narratives of them.
} 
beings employ their memories.

The third question is, in what manner do the generalizing, even totalizing conceptions that philosophers write or speak about relate to the cultural production of the time? This springs from our common observation that periods of historical time have moods and style that extend bafflingly far from the discourse of philosophers to one another-that a letter in the Acta Etuditorum seems sometimes to have a close link to a candlestick made by a contemporary artisan, for example, and that mood, fashion, style, or world-view change in ways that combine great amounts of harmony with great amounts of variation. ${ }^{65}$ This is a primary question of universal historiography, rocketed to dominance by Hegel and pulled and picked at in innumerable ways since then. How closely is one art linked to another in its day, one mode of production to another, one kind of cogitation to another?

When one looks at good recent scholarly work in the ontology of history and in the ontology of art, one sees that the objects of study are strikingly similar. ${ }^{66}$ They are both time-bound. Both are extant through forms of repetition and performance. Both are extraordinarily resistant to quantification. Both, most of all, elude successful notions of lawful regularity. Dessicated attempts to prescribe the laws of art litter the history of art. Despite the apparent regularities of economics, projects for finding

\footnotetext{
${ }^{65}$ This issue is one of the most prominent issues in art historical theory, beginning with Reigl through Wölflin and Panofsky to Gombrich

${ }^{66}$ See Christy Mag Uidhur's fascinating editor's “Introduction” to Art and Abstract Objects (Oxford: Oxford University Press, 2012).
} 
positive laws of history have failed. The reason is that the link is not one of domination and submission. History and art need not defer to the mighty power of logical entailment, but they cannot elude philosophical inquiry by proclaiming that its conceptual issues have been dissolved. Philosophers do not often enough acknowledge that logic is power and that power is not compassion. The business end of our thinking and production is the moral imperative. This consideration ought to regulate how far we go when we analogize one art practice to another. It stands above the independences and the dependencies of modes of production on one another. The need to compromise for the sake of this and the value of creativity, which is deeply though freely linked to moral life, is a good guide to historiographic method. Ethics and ontology both need history, and history is in need of them.

The inventors of the first modern attempts after Descartes to describe forms of personal and cultural knowledge differently from scientific knowledge were Berkeley and Vico. In the same decades of the Rococo era the arts seem to flourish together, departing from rationalism and appearing nearly at once in the most diverse crafts and places that European culture offered. They seemed to have no common origin and no identity. Their liability to analogy to one another was continuous with their resistance to analogy. Their common identity both could and could not be found. Both then and now it was obvious yet invisible, legible and sensuous yet ungrasped. The age exemplifies the problems of accounting for the growth of conception in 
domains innocent of theory, exacerbated by the bounty of Rococo production. And the age also saw really two new attempts to change the growth of conception that have had incalculable influence-Berkeley through his invention of idealism and Vico through his invention of modern philosophy of history. It seems possible to grasp something of the Rococo through these philosophers that so far is untold and to grasp something of their ideas through the arts of their time. This consideration will turn this inquiry towards previous efforts to characterize this period through philosophical conception, as well as return to the question of stylistic wholes, in Chapter 4.

G. The most difficult objection.

In The Enlightenment Past Daniel Brewer pointedly summarizes a profound critique of what I call intellectual history made by Roger Chartier and Michel de Certeau, among others. He says of any implication that ideas, conscious or unconscious,

have an intrinsic signification, existing independently of their interpretation.... [that it] may well belong to the covert strategy the historian employs his or her own relation to the past. By covering over traces of how the past is 'consumed', the individual historian can make it seem as if the concept of mentalité, along with other categories generated by historical analysis, were in fact universals.

....Taking the example of intellectual history, l'histoire des idées, Geistesgeschichte, Certeau notes that its object, the idea as that which can be thought in a given time...is not so much a real, historical object as sign of a 
constitutive need on the part of historiography. Intellectual history stands for the impossibility of eliminating the ideologies that inform historiography. ${ }^{67}$

This critique, based in the work of Foucault, strikes fear into the intellectual historian—not principally because of the claim that accounts of intellectual history are ideological, because this is another way of stating that historians work on their higher moral and philosophical as well as political commitments and that therefore "genealogy" is a necessary part of honest endeavor; but rather because of the penetrating psychological insight that intellectual history is projection, even when it is not undermined by any notion of total history or of essence.

This is partially true. Researching, thinking, and writing intellectual history is part of the growth of conception. It is a philosophical endeavor, part poetry, part desire, part belief, part logic, part fact, like all philosophy. On the same grounds all historical accounts, though putatively guided by facts, are inspired by vision. Intellectual historiography and all history writing also are like novels and poems and paintings and buildings and bridges and even Louis XV console tables: they share themes and features in the manner we commonly denote by the word "style" as shorthand for a virtually infinitely complex story of communication, influence, and decision.

In most every human creative endeavor, men and women test out their

\footnotetext{
${ }^{67}$ Daniel Brewer, The Enlightenment Past. Recovering Eighteenth-century French Thought (Cambridge: Cambridge University Press, 2008), 5-7.
} 
inward sense of the shape of reality on materials that circumstance puts into their lives. This is "projection" in its largest sense: the endeavor to animate the world, to understand life, to fix ourselves in a heartless universe, and to find evidence of and for our souls in it. The invention of machines and of computers is part of this, and some of the early story of these inventions is to be found in the Rococo under the concept of continuous creation, of which this thesis is an intellectual history in the period under consideration. The story of machine intelligence even in the Rococo decades is far greater, of course; it has no hard chronological limits before, during, or after the eighteenth century, when it is viewed as part of the basic effort of humans to animate the world. Intellectual endeavor is no better and no worse merely because its materials are "thoughts" and especially because these thoughts are neither more nor less material than anything else. The fact that human personality inspires systems of conceptions and also histories of the growth of conceptions unites intellectual history to production rather than separates it, and it also unites the historian's present to the past she studies.

H. For interdisciplinary intellectual history. In her meticulous study of the workshops of Rococo interiors, Katie Scott makes an argument, by now familiar to the reader, for shoving the history of conception out in favor of the history of production: 
The urge to see and describe order in decoration, and moreover to see it as a natural part of the logic of a style, is, I think, to participate unwittingly in the self-deceptions of the society for which it was deployed. Most significantly, such participation serves to ensure the existence of conflict which was part of the process of decorative production and an essential constituent of its meaning.... it seem[s] important to reintroduce the fine arts to their economic context and to abandon the polite assumption that eighteenth-century decoration was the work by night of insubstantial 'fairies.... ${ }^{.68}$

She describes her project as objecting to the illusion "that co-operation resulted from the naturally synchronized task-orientation of the artisanal and artistic trades involved." ${ }^{169}$ A society's notion of its unity is an illusion, she claims. The historical truth is a group of conflicts contesting the future, rather than simply being herded down a barricaded corridor. Conceptions do none of her shepherding. To her they are a preposterous ether that is falsely supposed by historians who study stylistic development or the growth of conception to co-ordinate mysteriously the work of craftsmen, designers, and consumers. Her argument that style was not magic but rather was a matter of communication among human persons of matters based at least in part on their power relationships is correct for a project that untangles exactly why patrons, seeking the prestige and wealth and pleasures of independence in their Parisian homes during the Regency from the uniformity of the Versailles panopticon, and artisans, making decisions as to material and techniques in order to lift the pressures on their profits, produced the Rococo decor.

${ }^{68}$ Katie Scott, The Rococo Interior. Decoration and Social Spaces in Early EighteenthCentury Paris (New Haven and London: Yale University Press, 1995), 6-7.

${ }^{69} \mathrm{Scott}$, Rococo Interior, 61. 
I have shown why there need be no theoretical battle between accounts of the growth of conception and accounts of the production of culture-intellectual history and material culture studies - because the whole range of human endeavor has a common basis. I suggested a so-called "weak" notion of style that avoids the use of conception as a baton for domination. I have argued in several ways that the history of science and technology, as well as socio-economic history, should invite intellectual history rather than repel it. This point supports arguments against excessive periodization, and it also fares well in the project of world history. Furthermore, I have suggested the capability of conceptions to "summarize" endeavors that work on different materials. Conceptions are like bridges from one kind of production and thinking to another. ${ }^{70}$ This leads to a strong concept and practice of interdiscplinarity. The strongest reason of all remains.

Are not people interdisciplinary? If academic disciplines can be interdisciplinary, is this not in the end true because people act and create as agents whose moral personhood is a more powerful principle of choice than anything else - so powerful that it lies behind the sense of the values of disciplinary work? It is

\footnotetext{
${ }^{70}$ Reinhard Koselleck, in Futures Past. On the Semantics of Historical Time, translated by Kenneth Tribe (Cambridge: MIT Press, 1985), 21-39 and 73-91, advocates a version of the "bridges" notion that follows the linguistic turn with some modifications. Koselleck argues that the general experience underlying the history of ideas began to be unlocked by new historiography after about 1760 that tied temporality to natural life for the first time ("historicity") (32-33). Upon this basis, increasingly over time, historians of ideas have the capacity to describe the basic structures bridging all human creativity, whether of objects or of texts, through intellectual history that crosses all disciplines (85-93).
} 
not philosophers alone who think about meaning, knowledge, existence, and moral value. Everyone does, though with differing kinds of clarity, commitment, and awareness and through differing media. In other words, there is no good reason not to accord Katie Scott's Rococo artisans the same dignity of conscientiousness that we accord to Berkeley and to Vico. There is every good reason to do think that the philosophers and artisans are both aware of moral dilemmas and both therefore have sufficient quanta of personhood. However academically unintellectual they might be, all people are intellectuals. William James once said that every person in his audience had a view of the world particular to herself that accounted for the world to her and that she used to probe the world.

Meantime, each and every historian is limited by her circumstances, but likewise each and every historian ought to take honesty as the master virtue; in this regard, historians of every type are equal to one another and to all other persons. Taking people as interdisciplinary thinkers helps to grow our recognition of the moral equality of all persons. Intellectual history at its best works towards this end.

But first it turns us toward the Rococo style itself, brilliantly lovely and brilliantly problematic. 
Chapter 3: Rococo Style

One of the aims of this thesis is to explain just a little bit of the raveling together of creative activities into the invention and communication of conceptions. In Chapter 2 I gave an account of the method of interdisciplinary intellectual history that I use to study Rococo style in this thesis and described some of the particular interest that the story of Rococo has for theorizing the history of ideas. When the subject matter of intellectual history is addressed to material culture-or, to put it another way, when the study of the history of conception meets the study of the history of production, the issue that specially arises is that of style. In this thesis by "style" I mean a line or lines of conception driving through culture powerfully enough to inspire or to support a vast, wide creative production of high ingenuity, skill, vigor, and intelligence. Henceforward in this thesis I refer to my subject as Rococo style. After examining the problematic of style, this chapter then portrays the aesthetic qualities of Rococo style. I shall claim below that a group of affects related to contemporary philosophical conceptions make Rococo style a meaningful and veridical notion. The present chapter describes the characteristic visual and plastic features of the style, in order to lay the ground work for further interrogation of relevant contemporary philosophical conceptions. 
The question of whether productions differing as to medium, place of fabrication, or even date may correctly be associated with one another through the notion of style is a sub-set of the basic question of the validity of intellectual history. Stylistic movements in art and design exist, and groups of people use stylistically linked designs of things as "badges," ${ }^{, 11}$ but do we not risk deception when we use style or similar notions to summarize an age? Is an account of stylistic conceptual unity useful information? Or is style more truly a socio-economic phenomenon? If it is correctly regarded as being, at least in aspect, conceptual, how is the diachronic development of conception and style to be understood?

This last question is especially relevant in looking at the Rococo because the task of distinguishing it in a consequential way from the Baroque and the Enlightenment has proven to be difficult. It has been part of most historical discourse on Rococo effects in art, literature, and culture. The Rococo lasted longer than a period and was too short to be an age. It was not an era because it did not dominate. Rococo was less temporary than an impulse and steadier than a trait that comes and goes. Chronology seems to oblige us to squeeze it into place after Baroque and before Enlightenment, yet this both misrepresents the cultural change and mistakenly limits the period of Rococo. As a view of the world the Rococo has something of the

\footnotetext{
71"Badges" is Gombrich's word, in his conclusions as to the issue of style in Sense, 215-216. Gombrich's book, largely devoted to seeking a correct understanding of the concept of style, sets his subject within the Rococo problematic (20-31).
} 
Baroque and something of the Enlightenment, but it also can and ought to be distinguished from both of these world-views.

There are two chief arguments advanced against the notion of stylistic wholes. $^{72}$

The first is that decorative motifs have no reference to questions requiring conceptual scrutiny, such as order and disorder, theories and practices of vision, or moral and other symbolism, but are to be accounted for in a separate domain of aesthetics. ${ }^{73}$ This is to argue, in effect, that style is not a valid term for connecting by similarity two or more intellectual practices, artistic practices, or even ornamental motifs. I call this the "aesthetic" argument against the interdisciplinary intellectual history approach to style.

The second is that accounts of the socio-economic domain adequately explain the psychic and conceptual operations in choice of decor, with the understanding that art is a socio-economic construction. In Chapter $2 \mathrm{I}$ addressed this domain of explanation in theoretical terms. I call this the "socio-economic" argument against the interdisciplinary intellectual history approach to style.

Historians studying Rococo arts who accept the aesthetic argument, disliking both the reductive readings of style and also overly large notions of style and

${ }^{72}$ Cf. Bernard C. Heyl, "Meanings of Baroque," in The Journal of Aesthetics and Art Criticism, vol. 19, no. 1 (Spring, 1961), 275-28, for a survey of the art historical issues of style designation as applied to the pre-Rococo Baroque.

${ }^{73}$ As Gombrich puts it in Sense, 301-302, style is a "freely created world." 
historians, deflate the Rococo by identifying it with its favorite ornaments—such as the rocaille, the shell, or the C-curve-taken as simply superficial things, or sometimes by phrases, like le genre pittoresque as a way of evaporating the problem of the Rococo as much as possible. Each of these designations by themselves has little actual meaning, although they all perhaps succeed in avoiding confrontation with conceptual issues. Excellent factual accounts and observations accompany some studies in this vein. But without an idea of style —not too Hegelian, not too fugitive; neither an engine of absolute reason nor a difference engine—we impoverish our understanding of the Rococo. Description of Rococo style strictly in terms of single aesthetic affects, represented by single ornamental motifs, does this. If we say that the Rococo was not more than an array of ornamental motifs or even a group of artistic practices, we would abandon inquiry into the kind of higher-order conceptions that we otherwise find indispensable to understanding the Baroque or the Enlightenment, even when these conceptions are in synchronic conflict. The minimizing approach takes a part for the whole, sometimes because its proponents hold that such "wholes" did not exist.

Sometimes the strategy for deflating the Rococo takes the form of saying that Rococo was a fashion, or "mere fashion," this being a more transient thing and therefore lower grade of activity than art or philosophy. This way of putting the matter opaquely trades on an unspecified notion of the way in which diverse forms of 
expression and communication constitute a culture. The notion of fashion obliges us to think about how to account for the relations among productions of artifacts that is neither to deterministic nor too weak. To call Rococo a fashion would be to use the best word and the worst word at the same time.

We are now in a position to consider the "aesthetic" critique of styles as wholes in the context of art historical analysis of Rococo style. Here this critique finds Rococo decor to be too superficial to reflect moral or intellectual conceptions and elides further inquiry by limiting Rococo to one ornamental theme narrowly conceived or by attacking its supposed superficiality. Historians largely confined their investigation of the ideas behind Rococo material production to the critique of Rococo arts in France, which led to the neo-Classical ascendence after about 1745-1755. Diderot led this critique accompanied by artists themselves, such as Charles-Nicholas Cochin (1715-1790), and by other men of letters, such as Étienne La Font de Saint-Yenne (1688-1771), commonly called critique from "sensibility.",74

By the beginning of the critique from sensibility the Rococo had quickly dispersed among centers of power in several nations. To varying extents until about

\footnotetext{
${ }^{74}$ The proximate source of the phrase is Stephen Gaukroger's The Collapse of Mechanism and the Rise of Sensibility. Science and the Shaping of Modernity, 1680-1760 (Oxford: Clarendon Press, 2010), but "sensbility" has long been used to name large parts of the postRococo European mentality. In that context it must be understood to contain several lines of thought that do not seem to have been comfortable together, such as natural morality, empirical awareness, a code of behavior finely tuned towards both strong emotion and harmony, and both restrained neo-classicist aesthetics along with the incipience of overtly emotional romantic aesthetics. Chapter 9 of this thesis treats Diderot's critique in detail.
} 
1790 the patrons of the arts continued to request Rococo inspiration and inflections in the objects they bought. Craftsmen not only continued to produce works in this style but also, at scattered dates in scattered places, exceeded the accomplishments of others during the height of French Rococo. Some of the most exquisite and expensive interiors ever made were "post-Rococo" and not French, but Dutch, German, and Spanish. Rococo architecture moved through the years at different paces, for example, in Sicily, Savoy, England, and the New World. Rococo style did not cease. It submerged, and it surfaced not only throughout the dominance of neo-Classicism but also in the Romantic era and much, much later.

The critique from sensibility does indeed recognize styles in art as wholes, but it is mis-appropriated for reductive arguments against the notion of Rococo style. By not using intellectual history to investigate the Rococo on its own terms, on its inside, so to speak, they assume that the character Diderot and others made for the Rococo was veridical and universal rather than a caricature. Since Rococo spread widely and energetically, something in it was not blocked by the French critique from sensibility. To take the contemporary French point of view as the limit of inquiry is to stay within the puzzle rather than to head toward the wider inquiry when the narrower does not succeed.

A different approach from the aesthetic argument about style is to look at the formal qualities of Rococo works of art, such as shape, illumination, ornament, and 
location. That inquiry is fractured by the many media that interested Rococo artists, who did not fail to express their differing personalities in these many fields of plastic creation. Intuition of a unity among all these objects pushes art historians from differences to conceptual commonalities. ${ }^{75}$ Some altogether give up the job, ${ }^{76}$ but most satisfy the question by limiting Rococo style to Rococo decorative motifs, which then neatly fill up the universal category and then seal the subject off from other areas of contemporary culture deemed more consequential and worthy. ${ }^{77}$ The part will not do for the whole, not least because taking it for the whole limits understanding how big and how interesting the whole might be. As Chapter 1 shows, Rococo style reveals deep currents of conception in response to just a little pressure. In sum, the geographic and diachronic diversity of Rococo style makes it impossible to regard it as merely the effect of a peculiar form of intuition, to be called "aesthetic," and suggests instead by its very plurality that some wide-ranging thinking accompanied this taste.

The second deflationary argument against the study of style is what I call the socio-economic analysis. Nothing I say here is meant to question the value of socioeconomic history. I am, instead, arguing against the use of such historical analysis as

\footnotetext{
${ }^{75}$ The best exposition of Rococo maximalism is William Park, The Idea of Rococo (Newark: University of Delaware Press, 1992).

${ }^{76}$ For example, Rémy G. Saisselin, The Enlightenment against the Baroque. Economics and Aesthetics in the Eighteenth Century (Berkeley: University of California Press, 1992).

${ }^{77}$ See note 80 , below.
} 
a superior fundamental account of Rococo style. Inquiry into the material and commercial modes of production tells the stories of creativity as commanded by production (among other causes) and of its influence through reproduction. The most important study for reviving interest in the Rococo among art historians, FiskeKimball's The Creation of The Rococo, ${ }^{78}$ took this approach. That book also steadily claims the French taste as the veridical Rococo, arguing against exogenous influences at every turn. The most particularized, style-deflating form of this inquiry is Scott's The Rococo Interior s, continuing Fiske-Kimball's view of incomparability of French Rococo. As I discussed in Chapter 2, she stakes the claim for production over conception. In her view style is a conception without internal consistency and an account of the reason or manner of the artists and consumers "following" the conception is false. Scott turns instead to building sites and workshops as places in which the historian will see actual social conflicts.

Rococo style was certainly a struggle. It was not an effortless efflorescence of decor, and it negotiated a revolution to come. Every moment in history does this; everywhere dreams invent new culture. And Rococo style was eminently not a matter of rigidly coherent manifestos. Yet Rococo style was also the site of intellectual as well as economic conflicts: the conflict between the constraints of

\footnotetext{
${ }^{78}$ New York: Norton, 1964.
} 
logically entailing conception and the freedom of artistic production. ${ }^{79}$ The skill of the artisans expressed, cunningly or unconsciously, the path between these two ways of thinking that contemporary philosophers also sought, using the current issue of infinitude and the sublime as their topical material. Its visual rhetoric was abundant with un-reason, which every motif and curve served to perform. The large theater of Rococo performance took symbolism polyvalently: everything that one might pack into a particular symbol it packed in without making a show of the conceptual work and instead confining the show to the appearance of the finished artifact. In the hands of Rococo artisans correspondences between appearances led to a profound consideration of the nature of rational unity, especially through stylistic uniformity. To acknowledge its assertiveness against causal restraint and its hardy perdurance amidst intensely rationalizing styles is part of the project the historian undertakes in trying to account for Rococo style. This, then, is a strong reason to avoid the socioeconomic critique of style, that by axiom it suppresses remarkable factual characteristics of Rococo style, such as its flexibility and durability, before actually

\footnotetext{
${ }^{79}$ One of the first historians to begin Rococo revisionism was the great Diderot scholar Herbert Dieckmann. Rococo, he said, was not a unifying concept in contemporary experience, since it was coined in the nineteenth century (as is well known), and served to identify some of the dissatisfaction with the "Age of Reason" that developed after the French Revolution. Furthermore, he argues that it was as much psychological, indicating a "capacity to be pleased with one's self," as it was formal, indicating "dissatisfaction with the internal contradiction of reason" discovered by philosophy. "Reflections on the Use of Rococo as a Period Concept," in Peter Demetz, Thomas Greene, and Lowry Nelson, Jr., ed.s, The Disciplines of Criticism. Essays in Literary Theory, Interpretation, and History (New Haven: Yale University Press, 1968), 419-436.
} 
taking them into account. In sum, the actual content of Rococo production cannot be historically accounted for without including higher-order conceptualizations.

If style in material production as intellectual wholes be granted, and if a nonreductive inquiry into style be stipulated, then we come to problems specific to the peculiar situation of Rococo style. This problematic area in characterizing the Rococo arises from parts of these two critiques. The aesthetic critique has a weak notion of the Rococo. Kimball and Scott are committed to a strong notion of Rococo style narrowly conceived as production. Both picture a "small' Rococo that readily breaks apart when inserted into a big picture of the history of Occidental art and culture between the Renaissance and the French and Industrial Revolutions. In particular, the Kimball and Scott ideas of particularized study of production, whether or not it pitches headquarters in France, or even if one regards the whole Rococo scene as centrally and truly defined by French practice, allows the historian to shape Rococo style out of the chosen facts of commercial demand and creative response. Trying to hold the deflated view of Rococo style in this way reveals precisely the strong meaning of Rococo in light of which deflation is impossible or erroneous.

The reason is due to the larger issues in writing the history of early modern Occidental culture that I referred to at the beginning of this chapter. Because the Kimball and Scott approaches rely on a solely French topography of production and on the Parisian rejection of Rococo style, which then is taken retrospectively to 
formulate the French Rococo, especially for art and social historians of the Enlightenment and the French Revolution, this approach is so overly local that any nearby larger historical imaginarium can overwhelm the notion of Rococo style. In the context of the history of Occidental culture the neighbor is very big. It is the Baroque, which is used to defeat conceptualization of the Rococo. Baroque and Rococo Architecture and Decoration by Anthony Blunt and his colleagues ${ }^{80}$ is notable for mentioning the word "Rococo," either as noun or adjective, as infrequently as possible. Blunt brings it up just once and not in a way to do it justice: he attributes an outbreak of Rococo style in Rome to the hot Sicilian blood of Filippo Juvarra (1678-1736), who worked in Rome for five or six years from 1704 when his career led him north, finally to Turin, where he created lavish Rococo churches and palaces for the Savoy kings of Piedmont from 1714 until the his death. ${ }^{81}$

One of Blunt's co-authors was the architectural historian Christopher Tadgell. Within the domain of production-oriented art history, the most conception-oriented and universalized approach is frequently that of the history of architecture. It deals with large objects—-many of them are palaces and churches—and with legible, complex, and thorough-going conceptual and practical planning for their production.

\footnotetext{
${ }^{80}$ Baroque and Rococo Architecture and Decoration, edited by Anthony Blunt(New York: Harper and Row, 1978). Blunt wrote the lead 100-page section (titled simply "Part I") as if the word "Rococo" were not in the book title.

${ }^{81}$ Blunt in Baroque and Rococo, 59.
} 
In his recent Transformations: Baroque and Rococo in the age of absolutism, ${ }^{82}$ Tadgell thoroughly inspects Rococo architecture through detailed formal accounts. He has a spacious concept of style: not simply Baroque but the Baroque as the home-base art of the absolutist age in church and state. Here conception of style is vast and heavy; but for Rococo the results, though far from meager, are always to see it as late Baroque. It "advents" out of Baroque, and it "retracts" back into Baroque..$^{83}$ It "hangs on" in France, but it is "resolved" in Dresden. ${ }^{84}$ Its detours through "excesses" must end because the heart of them is retraction from the architectural Orders and the theatrical supposition of the atectonic in place of the absolutely architectonic. The absolutist political and aesthetic point of view is that what cannot stand up straight will not last.

It might readily seem that the Rococo minimalists bring a strong reason for their deflating move to the discussion: that the Baroque went very deep and that Rococo did not. Baroque was tall and wide, spinningly kinetic, tragic, pessimistic in the face of a mad vast world full of diseased and occult forces among which we are "basically solitary and agonistic beings." ${ }^{85}$ Rococo gestures, on the other hand, are so contained and graceful that they mime movement, riffling the instants of time,

\footnotetext{
${ }^{82}$ London: Routledge, 2013.

${ }^{83}$ For example, Tadgell, Transformations, 290-294, 480-482

${ }^{84}$ Tadgell, Transformations, 661, 715- 716.

${ }^{85}$ José Antonio Maravall, Culture of the Baroque, translated by Terry Cochran (Minneapolis: University of Minnesota Press, 1986), 149-172.
} 
motions mocking motion. The style seems to have been eloquent, self-possessed, polite, persuasive, and well-mannered.$^{86}$ Both Baroque and Rococo tried to absorb the viewer by theatrical techniques. But why should the latter be in fact nothing more than the former in a late stage, a stage supposed to be less profound and more an indication of weakness than of some kind of strength? Why even hint that Rococo needed purging by firm and super-crystalline classicism?-especially since the moralist can turn on the enameled stillness of Neo-Classicism and say with John Adams that its "elegance chased out virtue"? ${ }^{87}$ When Rococo style questioned identity and when it hinted that society is a travestie, it spoke with clarity of fragility and transitoriness. When it portrayed very small or hidden worlds, it was not recondite but extremely eloquent. When it was light and pretty or when it was erotic, it was not diluting a purer and harder spirituality. When it was luxurious, it implied, at the borders of reality, questions as to what exists, what we know, and how we know it. It can have done so, unless our point of view is so angry, resentful, or contrary, even with good moral reasons, that we cannot credit it. In addition, the notion of continuous creation as read in Berkeley and Vico will show that Rococo

\footnotetext{
${ }^{86}$ This side of Rococo style was never better appreciated in print than by Sacheverell Sitwell in his Baroque and Rococo (New York: G. P. Putnam's Sons, 1967). This book, written when Rococo was wholly out of favor, is a tour of Rococo in southern Italy, where complete Rococo towns had been forgotten by art historians.

${ }^{87}$ Quoted in The Wrightsman Galleries for French Decorative Arts. The Metropolitan Museum of Art, edited by Daniëlle Kisluk-Grosheide and Jeffrey Munger (New Haven: Yale University Press, 2010), 3.
} 
style rejected the major metaphysical concepts fundamental to the Baroque view.

Kierkegaard said that if only Hegel had said after publishing his books that " it was all a joke,' he would have been a great man." Absolutism in the age of absolutism was not as absolute as it pretended to be, the pretension itself being the exposure of anxiety and deficiency. As a mode of thought, according to which meaning in historical time is explicable only by unifying it with the central conceptions of the period, in any period though perhaps most of all in an age of absolutism, it ends by imposing "style" in place of diachronesis. Rococo was the anti-absolutist style, a style that subverted periodization. It expressed, as the creative production of every age has, the tension between determining conditions and both private and social agency. The solution to the problem of understanding this expression of tension and agency in the Rococo comes from grasping some conceptual unity of Rococo ornament, rather than separating out the motifs that Rococo producers bundled together. Abundance of decorative motifs performs this tension at every curl, curve, and corner, springing out and holding back at some spot in vision both too near and too far.

Ornament is a statement of a spot to be held in both restraint and freedom. The most maximally superficial decorative motif can offer the strongest statement because it rests on the epidermis, because it is there where nothing quite supports it and it floats seemingly almost quite free, most exposed. The thickest Rococo 
decoration, such as that in the other German churches, looks ready to peel off the structure and flutter into mid-air. ${ }^{88}$ The maximal vulnerability of Rococo effects enables profound interpretation, even while it attempts to escape inquiry by its tricks of the eye or distractions of sensuality. Rococo style relentlessly moves the center frame, renewing at every turn of our gaze, which it tried to master, from wholes to parts and back, from anarchy to rigidity within style, from the mechanical to the moral and back, from correspondances on the level of neo-Platonic harmonies to the virtually infinite complexity of human personality.

The puzzle of style is the native tongue of the Rococo; and its chief topic of conversation, that which cannot stand up. Objects made in Rococo style present different and even contradictory kinds of artistic and discursive connection. Like all objects of historical inquiry and of artistic interest, they do not reify inevitable laws of logical entailment. They present creativity in conscious opposition to logical entailment. Rococo objects do this with studied insouciance, and they do it to a high degree. The study of the Rococo also combines a sensitivity to human variation that

\footnotetext{
${ }^{88}$ In his study of the engravings of Johann Esaias Nilson (1721-1788) Karsten Harries regards the so-called "excess" of ornament in Rococo imagery, e.g., the picture overflowing the frame, as a passage from aesthetic to beholding to longing for personal love (The Broken Frame. Three Lectures, [Washington: Catholic University of America Press, 1989]). He also makes the interesting remark that the ornamental frames within Nilsson's engravings are both separate from the picture and generative of the picture. In his The Bavarian Rococo Church. Between Faith and Aestheticism (New Haven and London: Yale University Press, 1983), he regards the flying festooning of Rococo churches as subtle indications of the instability and final decay of matter, mediating the viewer's awareness of the creative substrate it thereby reveals.
} 
historians, art historians, and artists require, having the character of an anomalous breed squished between two standard breeds, sometimes compared to Mannerism, amidst great pulses of rationalistic thought. It also seems anodyne because after classicism engulfed Rococo style its inner question did not re-appear in art until Surrealism, ${ }^{89}$ although some of its outward forms were repeated. ${ }^{90}$ Where this kind of creativity is at work, the chief concerns are communication rather than proof and moral imperatives rather than logical consistency.

In order to look to philosophical interpretations of the Rococo in the following chapter, I shall first describe Rococo style in painting, arts, and architecture through its chief ornamental motifs, interpreted as visual rhetoric, and formed into conceptions. $^{91}$

${ }^{89}$ One can see the Rococo spirit in André Breton's Manifeste du surréalisme (1924).

${ }^{90}$ Cf. Deborah Fausch, “Rococo Modernism: The Elegance of Style," Perspecta, vol. 32 ("Resurfacing Modernism"), (2001): 8-17. See also references to Vico and surrealism cited below in Chapter 6.

${ }^{91}$ I developed the following discussion, occupying the balance of this chapter, from material in a number of major catalogues of Rococo objects. Each of them has a discussion of nearly every theme developed below as well as many, many beautifully reproduced images. The best of my illustrated sources (including some cited above), covering principal locations and artists of particular interest to me, are: Reinier Baarsen, et al., Rococo in Nederland (Amsterdam: Rijksmuseum Nederlands, 2001); Blunt, et al., eds., Baroque and Rococo; Charissa Bremer-David, ed., Paris: Life and Luxury in the Eighteenth Century (Los Angeles: Getty, 2011); Emmanuelle Brugerolles, ed., Boucher, Watteau and the Origin of the Rococo. An exhibition of $18^{\text {th }}$ century drawings from the collection of the École Nationale Supérieure des Beaux-Arts (Paris: École Nationale Supérieure des Beaux-Arts., 2005); Peter Fuhring, Juste Aurèle Meissonnier. Un génie du rococo 1695-1750. Vol. 1 (Turin and London: Umberto Allemandi, 1999); Henry-Russell Hitchcock, "Peter II Thumb and German Rococo Architecture," in Essays in the History of Architecture Presented to Rudolf Wittkower, edited by Douglas Fraser, Howard Hibbard, and Milton J. Lewine (London: Phaidon, 1969), 170-188; Hyde, Making Up the Rococo.; Kisluk-Grosheide and Munger. The Wrightsman 
The most famous motif of the style is rocaille. ${ }^{92}$ The Rococo artist places images of rocks - painted, engraved, chased, or carved — in such a way as to create spaces of which the interior complexity is for the most part intimated and only partially exposed. Rocaille imagery is like a heap of clues and hints arranged in variations on the idea of concavity. However, these largely refer to themselves rather than to mysteries paired with symbols or truths well-hidden in allegory. The puzzle

Galleries; Wolfram Koepfe, Extravagant Inventions. The Princely Furniture of the Roentgens (New York: Metropolitan Museum of Art, 2012); Peter O. Krückmann, Paradies des Rokoko. Das Bayreuth der Margräfin Wilhelmine. (Vol. 2: Peter O. Krückmann, ed. Galli Bibinea und der Musenhof der Marguerite von Bayreuth.) (Munich: Prestel, 1998); Marianne Roland Michel, La Joüe et L'art Rocaille (Paris: Athena, 1982); Carolyn Sargentson, Merchants and Luxury Markets. The Marchands Merciers of Eighteenth-Century Paris (London and Malibu: Victoria and Albert Museum and the J. Paul Getty Museum, 1996); Marianne Schuster, Johann Esaias Nilson. Ein Kupferstecher des Süddeutschen Rokoko 1721-1788 (Munich: Neuer Fildser, 1936); Scott, The Rococo Interior; Michael Snodin, Rococo Art and Design in Hogarth's England (London: The Victoria and Albert Museum, 1984); Tadgell,

Transformations; and Pierre Verlet, La Maison di XVIII.e siècle en France. Société Docration Mobilier (Paris: Baschet, 1966).

For the older literature on the Rococo see Vittorio Santoli, "Dichiarazione del tema del Convegno," in (Accademia Nazionale), Maniersimo, Barocco, Rococò: Concetti e Termini. Convegno Internazionale.... Relazione e Discussioni (Rome: Accademia Nazionale dei Lincei, 1962), 11-23.

Of the internet image databases from the holdings of various museums, by far the friendliest and most useful is (Metropolitan Museum of Art), The Wrightsman Galleries for French Decorative Arts, online at: http://www.metmuseum.org/en/collections/new-installations/the-wrightsman-galleries-for-f rench-decorative-arts.

For the present purposes I will use the superb examples in the Wrightsman (ed. Kisluk-Grosheide and Munger) and Cooper-Hewitt (ed. Coffin, et al.) exhibit catalogues and the to give further illustrations of techniques and objects by references because they are comprehensive, expertly written, perfectly illustrated, and commonly accessible in American research libraries. These will be cited as "Wrightsman" by catalogue entry number and "Cooper-Hewitt" by page or figure number.

${ }^{92}$ Most books on the Rococo have some discussion of rocaille, but the best of all is Hermann Bauer's fascinating Rocaille. Zur Herkunft und zum Wesen eines Ornament-Motivs (Berlin: de Gruyter, 1962). 
is, in this sense, the viewer's gaze- - her life, not a life beyond or below. As grotto, it often suggests the safe sanctify of the Carthusian hermit's cell and portends the melancholy bower of the Romantics. ${ }^{93}$

Rocaille is some other thing as well. Some art historians say that it was an imagined spongy substance that came, perhaps, from the center of the earth. Blunt actually defines it in his glossary of technical terms as "an amorphous, rock-like material. ${ }^{\text {"94 }}$ A chthonic matter, it was capable of metamorphosis into any shape an artist chose provided it reflect its difference from other matter, its freedom from ordinary form, its meta-structural limitlessness, its grotesque in opposition to charm plus its charm in opposition to the grotesque, and its combination of ancient endurance and complete mutability at the hands of unpredictable natural forces like that of volcanoes—it was pictured as being produced out of volcanoes ${ }^{95}$ —or water. As materia prima it sits precariously but impressively in place to express deep forces and their contradictions to one another and to us. In a drawing of rocaille organic matter by François Boucher (1703-1770), shown as figure 5, water and plants and stones all seem to be phenomena of the same substrate stuff. ${ }^{96}$ Concavity represents the extension of the substrate. The growth of foliage is no more an unfolding of this

\footnotetext{
${ }^{93}$ This is also called the "auricular" motif.

${ }^{94}$ Blunt et al., eds., Baroque and Rococo, 341.

${ }^{95}$ Bauer, Rocaille, 3.

${ }^{96}$ For an etching by Claude-Auguste Duflos of Boucher's drawing see Cooper-Hewitt , 52 fig. 17.
} 
stuff than is the flow of water or the shape of stone or, for that matter, the human alteration of stone placed among the natural objects in the composition.

The raffle-leaf is a drawn motif of a dividing bit of growing vegetation that, having initially branched at rough right-angles, is unfolding more and smaller inner growth harmonious in form with the whole but freely filling the area in and around the central venous structure in the drawing. It was a long-established theme for drawing exercises. ${ }^{97}$ Rococo vegetation generally represents organic nature through a group of motifs that imply an urgesprung, as rocaille does but less directly because they are formed by nature through the principle of generation, which shares only the largest notion of creativity with the rocky source-stuff. The raffle-leaf is handy for any kind of frame because it is capable of making cartouches of any shape. Raffleleaves decorate the tables in figures 3 and $9,{ }^{98}$ and their shape is adapted into the shapes of the large stucco cartouches high on the walls of many Rococo buildings, such as the Asamkirch in Munich (figure 1) and the Apollotempel (figure 12) in Bayreuth.

Rococo artists used a virtually unlimited range of other organic motifs. The most famous of these is the shell (coquille), partly because of its antiquity as the

\footnotetext{
${ }^{97}$ Nina A. Mallory, Roman Rococo Architecture from Clement XI to Benedict XIV (17001758) (New York and London: Garland, 1977), 3-14, discusses the evolution of the design from leaf to bracket to $\mathrm{C}$-curve.

${ }^{98}$ For other examples of raffle-style table ornaments see Wrightsman no. 25 and CooperHewitt pp. 40 fig. 1, 45 fig. 5, 49 fig. 13, and 59 fig. 25.
} 
emblem of the pilgrim. ${ }^{99}$ The first Rococo appropriation of the shell was a kind of shock in contemporary art. It stood apart from noble and elegant shells. Although graceful, it started to twist, split, and ramify; it ingested other things such as coats of arms and candelabra; it popped up on surfaces that should be smooth, on mouldings where the eye was not to have rested, on top of things it should have been covered up by; and it took the place of lucid representations of structure where structural support was needed, such as on a sconce. ${ }^{100}$ Also, its form suggested the rock grotto, which was already overpopulating decor from the rational point of view. But perhaps most of all it seemed to cause all the ocean to flood into homes and temples, drowning or replacing familiar beloved shrubs surrounding our settlements, wrecking our ships. It heralded the unleashed bathysphere, which was more unknown then than now.

The palm-tree and other exotic species were enrolled in Rococo decor. No longer did the acanthus leaf crown and guard the sacred. The notion of invasion goes much further even than the kingdoms of flora and fauna. The invading hosts included Chinese, Japanese, and Indian people, perched in improbable places doing either absurd or unreasonably admirable things. In Jean-Baptiste Pillement's (17281808) Market Scene in an Imaginary Oriental Port (figure 11) the houses and other structures are rickety. At first they seem to be like the trees and palms among which

\footnotetext{
${ }^{99}$ See Wrightsman no. 15 for a pair of scallop-shell dishes. Paul Valéry's famous essay "Man and Sea-Shells" (in Paul Valéry An Anthology, edited by James R. Lawler [Princeton: Princeton University Press, 1977], 119-157) begins with a discussion of the Rococo motif. ${ }^{100}$ For sconces see Wrightsman no.s 58 and 63.
} 
they stand, structures organically firm in the same way; but they are also under siege from nature, in a tolerable homeostasis but subject to invasive weakening. The shapes of the building are in fact very different from those of the trees and much less stable. Screens and wall papers by Pillement and others show Oriental figures perched on shaky curving sticks, branches, or ropes, balanced like tumblers. Some French artisans learned to remove enameled and lacquered veneers and translate them like relics in full strange colors into salon baubles and space-fillers. ${ }^{101}$ Another, less concrete invader was at hand: the feminine erotic—a matter I shall return to in Chapter 10.

One other motif connects these, literally. It is the support structure found in virtually every example of Rococo style. In fact, it is something the presence or absence of which commonly authorizes attribution of the Rococo label. This is the "C-curve," sometimes called the "S-curve" when one C tops another, also known by Hogarth's name for it, "the Line of Beauty." This is the basic building-block of visual organization in Rococo style, so pervasive that it configures both physical structures called for by the subject and the representation of every other type of idea, turning all of the former into specimens of the latter. It configures Rococo design, endowing it with its own teeter-totter instability. Yet it is given to the viewer as stable, though the rationalists in the audience rapidly objected, not being content with the delusory

${ }^{101}$ For the amazing veneer techniques, see Wrightsman cat. no.s 12 and 17. 
rest where theory required an edifying illustration of solid rest. From stable to collapsing, from jittery and nervous and fragile to standing within larger groups of scaffolding, the C-curve louchely grins back at those inclined to be skeptical of it. One side of the viewer's mind asks, why must images veridically express forces when they are merely illusions, merely works of vertù? The other side says that truth shall not be denied and that art's influence must be for truth. Each C-curve is a little miseen-abîme of this aesthetic and intellectual problem.

I am going to mention one more motif that has been almost completely overlooked, as far as I can find. This is lattice-work. It was used to fill areas bounded by curvaceous borders as contrast, usually kept in check because the sinuous edge breaks the regular knots according to its figural course. The logic of lattice is in itself completely disregarded by the decorative program. Irregular curvilinear, polygonal, and mixed cartouches enclose grid-like lattices, cut off from their geometric extensions and from neighboring lattice patches. Lattice-work serves both symmetry and asymmetry, and sometimes even the joins of its elements are all not painted or stuccoed in relief, submerged in basket-weave or just not there at all. Its contrariness is circumscribed, and yet it is not repression or incarceration pure and simple. Nor does it add solidity. It seems to serve to emphasize the artificiality of the Rococo form, by filling in the picture when creative imagination has made free with nature. The illustrations to this thesis include three examples of lattice: in the wall behind 
the Louis XV console discussed in Chapter 1 (figure 3), on a flamboyant German settee (figure 2), and between the domical ribs and solar centerpiece of the Apollotempel (figure 12). The corset structure of the lattice is an interesting problem, to which I return in Chapter 10.

Artisans in the Rococo style applied light, gold, and color to many of these surfaces, as illustrations from the interiors of a sacred and pseudo-sacred buildings show (figures 1, 12, and 13). The technology to make sufficiently strong large expanses of glass and mirror was invented around 1690-1710 in France. ${ }^{102}$ Where tapestries had covered walls for warmth and effect, mirrors were placed to expand space and deepen vision with the suggestion of infinity. Wood wall coverings were no longer paneled in a simple way but filled with intricate congruent and contrasting systems of higher and lower and inner and outer frames. ${ }^{103}$ Not wood alone was given new life. From small towns in Italy men with generations of knowledge in the craft of stuccoing moved for work to Piedmont, Austria, Bavaria and Württemberg, Prussia, the Low Countries, and France. ${ }^{104}$ These stuccadors, entering into Rococo feeling and supported by wealth-engorged demand, made intricate images picturing motifs of every sort in surprising, impossible network structures that unfold to the

${ }^{102}$ Scott, Rococo, 31. A great example if the (English) Rococo mirror is in Cooper-Hewitt 102 fig. 44.

${ }^{103}$ Wrightsman 3-22 surveys the place of wall paneling in Rococo interior decor. See Wrightsman no.s 1-9.

${ }^{104}$ Tadgell, Baroque and Rococo, 348ff. 
tracking eye. Prodigious gilding picked up the light, reflecting it again. In the German and Austrian churches the decor with gold is perhaps unrivaled throughout the world for complexity and strength. Gold mounts held up corners of consoles and held cracked Chinese porcelain together, recalling the lattice (figure 6). Enamelists added extensive panels not only in France but also in Spain. The color-palette was light, especially in France, but thick and extended to rich oranges elsewhere in Europe. White was not neglected either, abundantly used to great effect everywhere, often as part of extended variations on regional armorial hues. All colors, even white and black, were illuminated by the glow.

In France, the Rococo interiors of new or renovated older city houses generally were "boxed" inside of conforming classicized vernacular exteriors. ${ }^{105}$ In Germany Rococo building were churches and palaces often in the countryside, and so the exterior expressed what was somewhat repressed even in the 1730s in France. The building plans, in England as well, show a tendency to organize the interior without restriction as to the exterior. ${ }^{106}$ The inside did not reflect the outside but rather shifted away, having been so fully filled with images and ideas as to have become active, even motile. One's view of brackets, piers, buttresses, vaults, pendatives, ribs, columns, and pilaster either inside or outside Rococo structures did

\footnotetext{
${ }^{105}$ See Michel Gallet, “Quelques Étapes du Rococo dans L’Architecture Parisienne” Gazette des Beaux-Arts (March, 1966): 145-168.

${ }^{106}$ Snodin, ed., Rococo Art and Design, 192ff.
} 
not lucidly show weights and their supports. The Rococo churches of Bavaria and Austria are famous for this affect, erected to show defiance of gravity on a majestic scale. In the Weiskirch built by the genius Dominikus Zimmerman (1685-1766) (figure 13) heavy corbels support empty air, while the entire upper level seems to float unsupported; at the enter four solomonic columns hold nothing at all.

Throughout Rococo architecture all over Europe spectacular columns departed their Orders, like work dogs freed to be home companions. String courses were left to the Renaissance, and imposts were for the humble.

These and other techniques brought the motifs I describe and others into every part of three-dimensional structure, from caskets to porte-cochères. They aggressively invaded the surface, sometimes all the more outlandish for not quite reaching the center of a panel to complete the conquest by intertwining but rather leaving a negative space, even in brilliant white, governed by the whims of the decor corseting it. The decor aggressed into depth, the third dimension, overgrowing it until decor pulled depth to the surface, to itself. Thus depth became an index of proximity rather than of distance, a self-examination according to the hermeneutics of presence. Three-dimensionality became a rhetoric trope for two-dimensional intimacy. From this came one of the most important impressions that Rococo style made: just as the weight of structure, such as a dome or vault, seemed separate from what supported it and the support elements had puzzling rather than blatant 
horizontal connections each to the one next to it and down the fillade or the nave, so also ornament seemed to peel away from the surface that was notionally the purpose of the ornament. The figures, bold or delicate, natural or fantastic, lifted off the elements that had been supposed to invent the interior space or the exterior volume. Rococo style took hold of the spaces of habitation, pleasure, government, and worship and displaced them, or rather, dis-oriented those who looked at and moved within and around them, albeit by means of pleasure and emotion, intelligently and skillfully elaborated.

This auriferous, air-borne world, full with familiar amazement, comfortable pleasure, and glowing creative presence, was mobile, almost portable. It was on the move through the international market for engravings. Throughout the hand-press period, booksellers and print-sellers alike sold single-leaf prints. About the middle of the sixteenth-century, Roman print publishers began to produce suites of engravings of Rome that they sold as portfolios. Printers in Antwerp turned this idea into a rich trade in suites of engravings on natural and religious subjects, including emblem books. Illustration in atlases and travel accounts, scientific and medical works, and even works of fiction or poetry greatly thickened throughout the seventeenth century. However, the Rococo artists—notably Meissonnier, Jacques Lajouë (1687-1761), and François de Cuvillies (1695-1768), but also many anonymous— and their publishers picked up on a field of illustration that was almost abandoned: the 
pattern book. Numerous lace-pattern books were produced up to around 1600, and illustrations of all kinds—-for example, of Ovid's Metamorphoses—were a cheap and internationally available source of subjects for painters and almost every kind of craftsman up to the beginning of the Baroque period. This practice greatly declined until suddenly it became Rococo style, propagating the fashion through the trade in prints for both collectors and artists. ${ }^{107}$

The mobility of Rococo style was part of its fecundity. Mirrors expanded it deep within interiors, while the presses of Paris and Venice circulated it to every corner of Occidental culture within the decades of the 1730s and 1740s. Rococo style had a tendency to miniaturize things, as a portfolio of prints essentializes and opens from the inward to the gaze from the outside a suite of rooms, an extended visual meditation on the design of vases, or the unlimited interior of the imagination itself tapered down into a suite of a hundred cartouches, each of which freely and pointedly presents whatever one can think of telling the world in words and pictures within a small frame.

This too can be a subversion of conventional weight and dimension. It was allied to the intensification of interiors, the life of which was famously enhanced

\footnotetext{
${ }^{107}$ The role of the print publisher is treated in nearly every major book about the Rococo. Those particularly interested in this should see Peter Fuhring, "The Print Privilege in Eighteenth-Century France I," The Print Quarterly, vol. 2, no. 3 (1985): 174-193; Fuhring, "The Print Privilege in Eighteenth-Century France II," The Print Quarterly, vol. 3, no. 1 (1986): 19-33; and Fuhring's illuminating essay on Huquier, "Boucher and the Ornament Designers," in Brougerolles, ed., Boucher, 346-321.
} 
among the bourgeoisie in Regency France on a pattern that extended through other classes by mass production of culture until what seemed to be a zenith—or a nadir-in the later nineteenth century but that was exceeded by our own times in magnitudes unimaginable to the critics of commodification at the turn of the twentieth century. And it had a further role in the creative imagination. Rococo style allowed sight of the more fine-grained representation of detail based on closer inspection of nascent pattern—the smallest leaves and buds promising the mature in their form. In part this came from the inventions of microscopy and other enhancements of optics, and in part it was a step in conception toward the notions of deep structure that nourished scientific activity in the next century.

In Rococo style depths were not in their accustomed positions. Everything looked haptic, so that the subject and the object made a tactile and courteous presence — sometimes ceremonially and sometimes intimately so—behind which groaning ballasts of mass, labor, and the far rushing world were not to be noticed. Structural and decorative elements moved from their appointed stances. They took on the manner of gestures, as if inanimate things that signified stability were changing, bending and scrunching and spinning as if the images were animated visions. ${ }^{108}$

One more element that stands for the others as well as on its own account:

\footnotetext{
${ }^{108} \mathrm{~A}$ close look at even so fatuous an object as Louis XV chairs and sofas shows this strange sense of depth, q. v. Wrightsman no.s 14, 16, 18, 20-21, 31, and 34.
} 
atectonicity. In architecture, as the privative of architectonic, it first means not having a roof and by extension means the appearance on not having strength (Greek tonos, stretching) and completeness (Greek tecton, builder) and appearing instead to reach rootless out into space. Atectonicity opposes the architectural Orders, hierarchy, and the logical subordination of an idea to its roots. It bridges ruptures by fusing together elements, leaving, in turn, new ruptures. ${ }^{109}$ The Rococo effect is something more, however. When things reach out into space to us, or seem to do so, the line between their outwardness and our inwardness blurs. Whereas there had been things in space out there, now space was placed inside us or at the very least space no longer had the depth it used to have. Distance was shorter-it was less like distance and more like mind. The oddity of so much of Rococo depiction enhanced this flatness: what the wallpaper showed could not really be a Chinese acrobat under a parasol flying on a string suspended from a leaf unless its condition of existence was in the viewer's mind and not circumscribed by the world of downwards gravitation. So the Rococo effect lies between flattened space and ateconicity but comprehends them both. I will use the words "rococo effect" to describe the atectonic conjunction

\footnotetext{
${ }^{109}$ Jean Weisgerber, Le Rococo Beaux-Arts et litterature (Paris: Presses universitaires de France, 2001), 16. Weisgerber 11-12 strongly emphasizes the central position of atectonic effect in Rococo style. Jean Sgard,"Style Rococo et style Régence," in (Centre auxois d'études et de recherches sur le XVIIIe siècle), La Régence (Paris: Armand Colin, 1970), 11-20, takes the opposite view, that Rococo is an "aesthetic of correspondences." This could be a fruitful approach without necessarily disregarding atectonicity. She also says with some reason that Rococo is "the most unified of the grand styles" (14).
} 
of the motifs and techniques I have described in this chapter. It is something like what we call by the name intentionality.

The gilt-mounted Chinese vase (figure 6) illustrates the balance of cohering and dissolving forces to which freedom from or denial of causation directs our attention as our eyes busily scan an object or an image in order to keep it from troubling sense of the settled arrangements in mundanity. ${ }^{110}$ This restless ocular fluttering is called papillotage. Many like it were produced in Rococo France: vases of no particular antiquity, though sometimes by chance of great age or rarity, valued for color and form were framed by a pedestal gilt-bronze curvilinear mounts with raffle-leaf or rocaille decor. In this case, the pedestal and mount not only focus our eyes but also appear to keep the vase, dangerously though attractively riven by cracks, in one piece. Something else happen as well when looking at this piece. The juncture of internal and external forces, like atmospheres in which the whole is suspended, is rendered dynamic, stable for the blink of an eye. The large handles are not part of the vase at all and not necessary to its support. They signal mobility and whisper to us a long history of ownership, survival, travel, and trade across the seas. The vase is winged, able to move again on its own. But how can it animate itself? It not only has no motor, it really is just about to fall apart, caught in the nick of time by industrious hands. The base is superfluous—it is luxury, too-because the vase itself ${ }^{110}$ For other gilt mounts see Wrightsman cat. no.s 17, 19, 62, 64, and 68; and Cooper-Hewitt p. 85 fig. 18. 
has a base. The ordinary job of the base, to bear a load, has disappeared as if by a magic trick.

Over the two centuries succeeding the Rococo decades, a great body of philosophy, psychology, and sociology was to be devoted to naming this effect and accounting for our construction of the intentional world. The project is nowhere near its end merely because humanistic subjectivity perpetually runs into the intractable difficulties it hoped to solve. As to Rococo style, I propose that it was, at least in part, a solution of this puzzle for its own times. The growth of conception in the last half of the seventeenth century gave this problem the form in which Berkeley and Vico received it and tried to solve it. The Rococo effect was an aesthetic interrogation of atectonicity that reflected the similar conceptions developed as responses in the work of Berkeley and Vico. 
Chapter 4: Rococo Variations

In the first chapter of this thesis I introduced Rococo style by brief references to the sublime as an issue in the philosophy of art, to the infinite as an ontological problem, and to illusion (anamorphosis) as a philosophical issue concerning expression and communication. All three of these philosophical problems are existential and moral as well as aesthetic, metaphysical, and epistemological. Having now spoken to my method and to my notion of Rococo style, I return in this chapter to these problems to begin my account of Rococo artistic conceptions as reflections of contemporary philosophical ideas by reviewing previous efforts to connect philosophy and the Rococo. A survey of other Rococo studies from the point of view of the history of ideas tells us what is understood and how little is understood about the boundary-crossing nature of Rococo style, and it establishes the interpretation of Baroque and Enlightenment culture next to which the place of the Rococo has to be carved out. ${ }^{111}$ Rococo style, flourishing at varying dates in different locations, sought

\footnotetext{
${ }^{111}$ Some of the most recent directions in Enlightenmnt theory that are relevant to this thesis are in Clifford Siskin and William Warner, eds., This is Enlightenment (Chicago: University of Chicago Press, 2010): Michael McKeon,"Mediation as Primal World: The Arts, the Sciences, and the Origins of the Aesthetic," 384-412, which applies acor-network theory to the Enlightenment; and Clifford Siskin, "Mediated Enlightenment: The System of the World," 164-172, which bleeds "Enlightenment" onto "Romanticism" much as Baroque is
} 
freedom from dominant forms of order in both the Baroque and Enlightenment eras.

Both of these forms of order sustained their own inner contradictions and

instabilities, on which the Rococo played. By not standing still Rococo style showed

a conception of the unity of style without over-determinaton.

Art historians recognize the Rococo as a style intensely productive in a certain

period (though not strictly confined by date), but intellectual historians rarely

acknowledge or address it. The majority of art historians, for their part, regard

Rococo as a late Baroque, sometimes nicknamed Barocco diminuendo, Barocesco, ${ }^{112} \mathrm{a}$

"subjectivized" Baroque, ${ }^{113}$ "diluted" or "hedonistic" Baroque,${ }^{114}$ or "humanized"

often bled into the Rococo.

${ }^{112}$ A good survey of some of these terms will be found in Walter Binni, "Il Rococò letterario," in (Accademia Nazionale), Manierismo, 218-237. A very competent and thorough account of the history of the term "Rococo" is Rémy Saisselin's "The Rococo Muddle," in Studies on Voltaire and the Eighteenth Century. Volume 47 (Geneva: Institut et musée Voltaire, 1966), 236-238, n.s 2 and 3. But see also the very different approach of Nicholas Newman,"In the Name of Rococo," in RES: Anthropology and Aesthetics , no. 40 (Autumn, 2001): 129- 34.

Noting the remarkable attention paid by art historians to the history of the word rococo-no other style name comes close-and the varying meanings of the word, he points out the anxieties these circumstances disclose. He then applies Peircean semiotics to it. His conclusion is that the word's instability of reference both mirrors and adds to the aesthetic effects relating to instability that Rococo art makes.

${ }^{113}$ Pevsner, Nikolaus, "The Genesis of the Picturesque," in Studies in Art, Architecture and Design. Volume One: From Mannerism to Romanticism (London: Thames and Hudson, 1968, 50ff.

${ }^{114}$ Patrick Brady, "Rococo Style in the Plastic Arts and Literature: Theory, Method, Application," in Literature and the Other Arts.... , edited by Zoran Konstantinovič, Steven P. Scher, and Ulrich Weisstein, (Innsbruck: Institut für Sprachwissenschaft der Universität Innsbruck, 1981), 90. 
rather than "heroic," 115 having "lost its nerve,"116 or hyperbolic and even degenerando. Others, however, assimilate Rococo to the utopian classicism of the Enlightenment, using such clobbering names as Rokokoklassizismus or "classicistico-rococo" and “arcadico-rococo." 117

This is the tendency of historians of ideas, as well, who, because much of Enlightenment literature was published during the vogue of Rococo style, supervene the former onto the latter. Rococo style being regarded as a matter of small objects, they do not so much as mention it, despite the occasional nod to the jumbo-sized Rococo objects, palaces and churches. There are exceptions: one American scholar considers it the "essential" style of the century, thus stretching the word to cover everything else. ${ }^{118}$ And just a few, notably Hermann Bauer's Rocaille in 1962 and Philippe Minguet's Esthétique du rococo. in $1966,{ }^{119}$ see deeper philosophical

\footnotetext{
${ }^{115}$ Fausch, "Rococo Modernism,"14-15.

${ }^{116}$ Patrick Brady, "Rococo Style in European Theater," in Eighteenth-century French theatre: aspects and contexts : studies presented to E. J. H. Greene, edited by Magdy Gabriel Badir and David J. Langdon, (Alberta: University of Alberta, 1986), 57.

${ }^{117}$ Patrick Brady, “The Present State of Studies on the Rococo," in Comparative Literature, vol. 2, no. 1 (Winter, 1975), 23. A good example of the depreciation of Rococo is JeanJacques Glotton, “L’architecture de la Régence," in (Centre auxois), La Régence, 44-57, who regards it as the "chant du cygne" of the grand Baroque style.

${ }^{118}$ Park, The Idea of Rococo, 13. Park and Brady, "Present State," both have good accounts in English of the different approaches to the Rococo in the older literature. They lacks the material studies approach of the last couple decades and also a strong philosophical basis. Most of the exhibition and museum catalogues and recent monographic studies I have mentioned also describe the historiography in short introductory sections.

${ }^{119}$ Paris: J. Vrin. Minguet's book is the most thorough and penetrating conceptualization of the Rococo yet published, seconded by Bauer and more recently by Marian Hobson's work.
} 
conceptions at work in Rococo production. Bauer and Minguet have penetrated this subject more deeply and more originally than any one else, although there is much they did not consider. ${ }^{120}$ Apart from these few exceptions, either Baroque theory or Enlightenment theory swamps the historians of ideas, who have committed themselves to the spectacular growth of both fields. Baroque theory leans to conceptions of the self, exposing the forerunners and the earliest types of phenomenology, but the philosophers I link to the Rococo begin to develop this line of thought in ways that different strains largely replaced in the history of philosophy. Enlightenment theory in its two principal forms, the critical-theoretical and the progressive-scientific, also gives a little light on the Rococo. Both have missed a more full appreciation of the conceptual development that Rococo style represents.

The actual position of the Rococo is more nuanced in relation to both Baroque and Enlightenment culture than approaches through theories of the one or the other allow. The "battle" of the ancients and the moderns, which attracts much of the attention historians pay to high culture from last quarter of the seventeenth century to the first quarter of the next, poorly fits the crazy freedom of the Rococo. Rococo admits many things that theory pulls apart, and it largely side-stepped theory until

\footnotetext{
${ }^{120}$ Jean Deprun, "Une oeuvre philosophique de la Régence: La Lettre de Thrasybule à Leucippe," in (Centre auxois), La Régence, 153-164, associates some social and political philosophy with the Rococo, as does Pierre Francastel, “L'esthétique des lumières," in Utopie et Institutions au XVIIIe Siècle. Le Pragmtisme des Lumières, edited by Pierre Francastel (Paris: Mouton, 1963), 330-352.
} 
the immense gravity of neo-Classicism hypostatized natural morality. The sublime rode in upon empiricism. To see the peculiar shape of Rococo style is good reason for the method of this study: to parachute down into the middle of it by looking at the two philosophers whose long-influential ideas seem to lie hidden by undiscovered links to the conceptual developments reflected in Rococo style.

For if, as I have said, intellectual history traces the growth of conception by perspicuous thought, two points follow. First, this growth does not have a rigidly forward direction. Conception picks up notions and ideas from various fields of endeavor in different parts of many societies in a temporal order not congruent to logical order. Even a genetic account requires the historian to move backwards and forwards in time to find many small parts of large events firing in advance and retreat and in both fruitful and useless directions to which the calendars of years and decades do not correspond except by extremely wilful imposition of such magic tricks as metaphors and stories of progress. Human reason seeks unity, even when unity exceeds evidence, even when conspiracy theory is the last resort. Every location and all personnel of every event do fit the order of time if one has in hand a sufficiently inflexible view of causality. ${ }^{121}$ But strict causality can be made likely only by factual events and not by reference to the "laws" that express causality. In this sense the historian defeats the absolute idealist and the absolute materialist— Kierkegaard

\footnotetext{
${ }^{121}$ Koselleck, Futures, 38, 79, 88, emphasizes the combination of diachronic and synchronic that history of concepts makes possible.
} 
would have had this veto on Hegel, besides the arguments he did have, had he been an historian. No one should mistake the history of ideas for a history of essences; in fact, the difficulties and capabilities peculiar to intellectual history come from its being a history of existences of the non-natural domain.

The second consequence is the actual pattern of intellectual history. This is one of variations on themes. Perspicuous thought works on large and basic patterns of responses to fundamental questions (as well as by other techniques), such as what exists, how we know anything, what is the right thing to do, and how do we understand experience. Its synchronic course is not clear progress toward answers nor does it clearly progress from one stage of inquiry to another. Most often in Occidental history several kinds of responses run together, some carrying on only after long intermissions. We use both recent and distant past as maieutic material. Intellectual history is not left formless merely because its course is not rigid entailment from one person or situation to the next. Its shape comes from perennial questions. These are its "universals." The notion itself of variations on a theme is in fact one of its chief objects of inquiry, if not the chiefest. The historical processes of the growth of conception is one of many soaring and counter-flowing changes.

The Rococo effect presents a particularly wide field of variations of ideas, since it unconstrains plastic variation. Rococo objects are things the design of which appears unstable but are in fact stable; they are images of such puzzling things, either 
actually built, proposed to be built, or fantasy projects; and they are objects most of the signs of which do not refer to the object itself. The signs have uncertain relation to the referent. They are often inapposite when judged as parts of the whole, and they can even be non-veridical in connection to their natural or conventional origins. The difference, however, is leavened by unexpected links between elements—links that are not causal but atectonic. They rely sometimes on family resemblances or kinship, drawing from Renaissance and Baroque forms of classification; sometimes, on abstract similarities, picking up contemporary rationalism as if in parody. But mostly the bonds that a Rococo object are built out of are more secret than so-called "esoteric" secrets.

Rococo style stands apart from what Michel Foucault calls the modern episteme, because in the pre-modern episteme, in Foucault's terms, the referents outnumber the signs. ${ }^{122}$ I put it this way: that in the seventeenth century knowledge outstripped the human capacity to understand it, hence nature began to slip our grasp even more than hitherto. The gap in which to find unitary soul or universal spirit darkened, having fissiparously widened and deepened. The old ways of finding justice and the good in our cognition were being defeated in the increasingly dominant mode of thought. Occidental early modern thought advanced into difficulties that hitherto had not dominated it, while at the same time it produced

${ }^{122}$ Michel Foucault, The Order of Things. An Archaeology of the Human Sciences. (New York: Vintage, 1994), 58, 94, 117, 136, et passim. 
solutions to many other problems of knowledge. The Rococo was a solution that did not conquer. In the work of David Hume (1711-1776) the skeptical critique unitary soul and universal spirit was about to become part the problematic of modernity.

The Baroque style had faced the proximate beginnings of this same difficulty — the rapid expansion of knowledge — and responded by increasing production of signs. It did this, among other ways, by inventing machinery for knowledge based on ars combinatoria and by more than occasional hints of the occult or obscurantist, such the engravings of allegorical grottos and gnostic mountains in alchemical works such as Heinrich Khunrath's Amphitheatrum of $1609 .{ }^{123}$ By the early eighteenth century, the possibilities for the occult option narrowed and changed. In Rococo style we see them in the garden fantasies built for Princess Wilhelmine in Bayreuth in $1753^{124}$ or the gothic and romantic notes some scholars see in the Rococo. This way of reproducing other-worldliness within some framework of Enlightenment clarity was a compromise Rococo style reached. As to Baroque knowledge machinery, the idea was unattractive to the Rococo mentality, as we shall see in both Berkeley and Vico. The network concept is however very attractive to the mentality of our own times. In construing the classical and modern epistemes, Foucault focused on the change in representation from resemblance to analysis. He does mention Berkeley and

\footnotetext{
${ }^{123}$ The suggestion that the famous engravings illustrating Khunrath are a proto-rocaille cames from Krückmann, Paradies des Rokoko, vol. 1.

${ }^{124}$ Described at length and beautifully illustrated in Krückmann, Paradies des Rokoko.
} 
Malebranche as "variables" through whose thought the old system of signs and representations becomes random after it has ceased to be divinatory and before it becomes positive, analytic, and logical. This idea is a small, not inaccurate glimpse into Rococo conceptions.

Foucault's history of ideas never mentions the Rococo. He moves from PortRoyal logic straight on to Cuvier, Lamarck, and Bopp. ${ }^{125}$ He means this to be part of the course Occidental thought ran from souls and signs to merely ourselves, as he puts it; ${ }^{126}$ and it is the part in which we, re-making reason, ${ }^{127}$ "invented the subject" - the early eighteenth century, ${ }^{128}$ which he calls "the Enlightenment" ${ }^{129}$-yet in his many cuttings and divergences of history he seems not to have caught the force of Rococo variations, running forward and backward and over themselves in France and central Europe during the crucial decades of 1710 to 1750 . But this schema of discourses does help to picture the decades-long "occasion" in which Rococo style moved, capturing in objects a sense of abundance variety. By then, as Foucault explained, referents far outnumbered the old system of signs, requiring the stern and purifying re-arrangement empiricism imposed on rationalism by building omnipresent, unstoppable taxonomies.

\footnotetext{
${ }^{125}$ Foucault, Order of Things, 54-57.

${ }^{126}$ Foucault, "The Prose of Actaeon," in Foucault, Religion and Culture, 81-82 (75-84).

${ }^{127}$ Foucault, "Pastoral Power and Political Reason," in in Foucault, Religion and Culture, 136 (135-153).

${ }^{128}$ Foucault and Foy, "Who are you," in Foucault, "Pastoral," 92-93.

${ }^{129}$ Foucault, "Pastoral."
} 
Foucault's ideas owe something to Walter Benjamin (1892-1940), who began the modern discussion of allegory in his famously troublesome Habilitationschrift on German Baroque tragedy in $1926 .{ }^{130}$ He described the arc of representation from the symbol, which has need solely pf its other half as its referent, through the enigmatic emblem to allegory, the indexicality of which is infinite. ${ }^{131}$ In its fear of infinity reason does not tolerate ambiguity and therefore, in Benjamin's view, had to separate conceptions from all other ideas, progressively purifying signs of every form of expression except its own. ${ }^{132}$ This move, however, is due not only to the impatience of reason but also to an effect produced by allegory itself. In its ambition it brings everything into play, allegory exposed everything, cutting moral feeling off from "its hidden, and, if one might say so, wooded interior." ${ }^{133}$ In other words, the multiplication of allegorical meanings tended to disenchant nature, just as severely as the accumulation empirical facts are thought to do. Now flooded with light, moral meaning becomes merely "visual meaning." For Benjamin this means that everything that should move us to moral action is turned into the historical spectacle of our lives as "petrified, primordial landscape," by which he means far-away vastness of codified meaning. These are much like vast data banks of facts often seem to us to be oppressive and rigid, except that allegories are full of immovable false moral

\footnotetext{
${ }^{130}$ The Origins of German Tragic Drama, translated by John Osborne (London: N.B., 1977).

${ }^{131}$ Benjamin, Origins, 160-161.

${ }^{132}$ Benjamin,Origins 162-163.

${ }^{133}$ Benjamin,Origins, 165; cf. the "overcoming of muteness" on 227.
} 
structures deposited by the successive miseries of human history. Therefore they are so "untimely, sorrowful, unsuccessful" as to make us feel powerless in the face of power. ${ }^{134}$ This is the source of his view of the Baroque as proto-totalitarian, taking its gigantism and absolutism at face value, "the triumph of the hieratic,"135 shooting its roots down into the "elements which make it up," which in turn resist the falsification they are doomed to, so that the hieratic system is "constantly convulsed by rebellion." ${ }^{136}$ Taxonomy, as Foucault understood, was not enough to calm this. As W. H. Auden said, "Our apparatchiks will continue making / the usual squalid mess called History." ${ }^{137}$

Setting aside further development of theories of allegory for the present purposes, Benjamin's tragic view of the Baroque gives another piece of the Rococo problematic. ${ }^{138}$ José Maravall's masterful expression of the Baroque milieu likewise describes an era centered on tragedy. Exhausted by war, moving troublesomely in an ever-larger plaza, or hotel, where everything goes upside down, more than full of himself, the Baroque person was "basically a solitary and agonistic being" more

\footnotetext{
${ }^{134}$ Benjamin, Origins, 166-167.

${ }^{135}$ Benjamin, Origins, 169.

${ }^{136}$ Benjamin, Origins, 207.

137“Moon Landing” (1969), lines 37-38.

${ }^{138}$ Sigrud Wiegel, Walter Benjamin Images, the Creaturely, and the Holy, translated by Chadwick Truscott Smith (Stanford: Stanford University Press, 2013), 184-194, hows that Benjamin would have regarded the intensity of detail in the Rococo as a sign of its place in a late, funerary stage of tragedy rather than as something joyous.
} 
oppressed by her choices than soothed by titanic devices of comfort and persuasion. ${ }^{139}$ "In the most critical stage of its alienation from nature, in the seventeenth century," writes intellectual historian Gordon Teskey, allegory was sought as a comfort and an explanation but turned out to be confusion and subversion; it is a struggle as basic as that of Venus and Mars; it always "approach[es] chaos" and violence. ${ }^{140}$ With what could an age of reason follow the Baroque but something "even more radical"? ${ }^{141}$ The Rococo was a pause in this movement, linked to a glimmer of conceptual hope, but a pause so lambent that it is easily overlooked.

Theodor Adorno (1903-1969), inheriting some of his ideas from Benjamin, extended the tragic view into the Enlightenment. ${ }^{142}$ In Max Horkheimer's (1895-1973) and his Dialectic of Enlightenment, reason is like fire rushing past water insufficient to stop it. The hissing this emits is terror. "Men pay for the increase of their power with alienation from that over which they exercise their power." ${ }^{143}$ Entailment by logic is "fatal necessity" - the same that overcomes heroes in myths. ${ }^{144}$ Adorno elevated suspicion of language by a precise and constant application of dialectics to all verbal conception.

\footnotetext{
${ }^{139}$ Maravall, Culture of the Baroque, 161.

${ }^{140}$ Maravall, Culture of the Baroque, 69 57-58.

${ }^{141}$ Maravall, Culture of the Baroque, 171.

${ }^{142}$ Translated by John Cumming (New York: Continuum, 1988).

${ }^{143}$ Adorno, Dialectic, 9.

${ }^{144}$ Adorno, Dialectic, 11, 13.
} 
The concept, which some would see as the sign-unit for whatever is comprised under it, has from the beginning been instead the product of dialectical thinking, in which everything is always that which is, only because it becomes that which it is not. ${ }^{145}$

Foucault, too, tended to restrict imagination to the world just as it is, straying only a little bit. ${ }^{146}$ Both might owe their elision of the Rococo to this tendency. Adorno especially must have judged the Rococo to be an unaffordable luxury. Truth for him lies in dialectical analysis, the enemy of which is terror, there being little middle ground save for that which Adorno allowed out of his own good taste in the arts. Inaccurate dialectic produces terror; sloppy work, easy thinking; any obliviousness of our own tyrannical desires with respect to nature, much less man, is deadly. Benjamin saw the Baroque as terror responding to the infinity of referents, and Adorno saw the Enlightenment as terror in response to the sublime universe construed as signs that diminish the ability of humankind to shape its destiny. Adorno paid the price for his narrowness: the Enlightenment was far more complicated than he allowed, and his account has come to seem ever more restricted to one among many enlightenments. ${ }^{147}$ But something did go wrong in the use of

\footnotetext{
${ }^{145}$ Adorno, Dialectic, 15.

${ }^{146}$ Foucault, "The Prose of Actaeon."

${ }^{147}$ Jeffrey D. Burson, "Reflections on the Pluralization of Enlightenment and the Notion of Theological Enlightenment as Process," in French History, vol. 26, no. 4 (2012), 525-537, includes a good recent survey of this subject. Burson proposes a model for thinking about the Enlightenment that, he hopes, is neither totalizing nor "balkanized." It relies on theology and secularization to provide a scale of grey shades for describing lines of thought in the period. Whatever the merits or demerits of this, it can be strongly interdisciplinary.
} 
reason over the next centuries, and something is to be feared, despite Kant's and all good peoples' best efforts, unless we detach the actual Enlightenment from the subsequent history that safeguards it on a bright white cloud. Naturally, no one wants to fail at this. Adorno's dialectical interpretation of the Enlightenment does not stand alone in refusal. It has been accompanied, as well as opposed, by the plural Enlightenment that historians have uncovered and described from many approaches. Many of them—post-structuralist, feminist, theological, and others, specialists in all the arts and letters of the era—share Adorno's (and, of course, Foucault's) desire to reverse our destruction of the world. Jürgen Habermas pointed out that the root of Adorno's position was assertoric. Adorno, he says, fails to convince us "that there is no way out." ${ }^{\text {148 }}$ Perhaps we refuse to be convinced. No one knows how all this will turn out.

A portion of inspiration for discovery of the many Enlightenments is due to Foucault because his theory afforded differentiation, and yet a portion is also due to Adorno. Reductive though Adorno's fear was, one great reason we study history the way we now do is because we again and again forcefully learned about the problem of our self-destructiveness in the last century. A great part of recent historiography on the Occidental eighteenth century grew out of tension between the terror the

\footnotetext{
${ }^{148}$ Jürgen Habermas, The Philosophical Discourse of Modernity. Twelve Lectures, translated by Frederick Lawrence (Cambridge: MIT Press, 1995),128. The argument begins on 112. The italics are Habermas's.
} 
previous and current centuries cultivate and Habermas's prompts to find a way to keep hold of reason, discourse, and progress. From here, as a product of Baroque infinitude and Enlightenment sublimity, one can catch sight of a "Rococo Enlightenment," to join the other contemporary Enlightenments. Rococo style fills the same prime decades, even as it waned in the later half of the century. Perhaps it over-fills the Enlightenment, now more like a warehouse than a suitcase or steamertrunk in size, not as a "counter-Enlightenment" a half-century early but as another, neglected path toward progress.

Despite the origin they share in the moral experience of modernity, from the French and Industrial Revolutions through Auschwitz and beyond—and with all peoples around the world as well—what I shall call the progressive-scientific view of the chief Enlightenment thinkers widely diverges from the dialectical. The expansion of knowledge and capabilities that Occidental peoples made in the nineteenth and following centuries pulls eighteenth-century culture at the heart of Europe toward itself. The continuing ontological development of network and digital discourses is today beginning to pull this consensus apart, but the success of the scientific method, with concessions to physicalism (as opposed to bare materialism) and, in some cases at least, a generous and humble spirit, continue to cast the key light on the progressive-scientific view of the Enlightenment.

This view requires rejecting the influence of non-empiricist philosophy in the 
Rococo period, in order to leave sentiment as safe company for scientific empiricism. One of its principal and most learned historians as of this writing is Stephen Gaukroger in the most recently published volume of his history of science since the Scholastic period. What I have so far described, following Benjamin and Foucault, as the infinite excess of meaning over communication, Gaukroger calls that sensibility with which the French Enlightenment thinkers replaced rationality confused by infinitude. In Gaukroger's words, "all subject areas with cognitive aspirations," finding metaphysics "a dead end" in the pursuit of greater knowledge and expression, brought in "sensibility" as a principle of judgment among the "many possible forms of understanding of the world."149 Gaukroger's subject is the period in which the leading edge of European thought turn from mechanism to sensibility. In his view, sensibility was a way to take on a moral perspective in the face of the fractionating world that infinitesimals both as abstract concepts and mechanics — "cognitive practices and cultural productions"—-was presenting. ${ }^{150}$ Diderot and Étienne-Bonnot de Condillac (1715-1780) become the philosophers of sensibility. Gaukroger also mentions Berkeley and Vico, although not in connection with one another, as thinkers who tried to explain the reasons for the rise of sensibility — especially and importantly, the problem of "non-propositional" thought. ${ }^{151}$

\footnotetext{
${ }^{149}$ Gaukroger, The Collapse of Mechanism and the Rise of Sensibility, 2-4.

${ }^{150}$ Gaukroger, Collapse, 5, 139, 411.

${ }^{151}$ Gaukroger, Collapse, 4.
} 
Gaukroger's view of the Rococo, if he were to state it directly, is that of Diderot. Diderot rejected mechanism and the Rococo for similar reasons: they too harshly subdued nature, plus he had other objections specific to Rococo style that Gaukroger, who sees all legitimate cognitive practice as scientific, does not write about. Now mechanistic natural philosophy and Rococo style seem to be very different points of view, and indeed they are, as this thesis establishes. But if one holds that nature itself, when humans gently conform themselves to its wisdom, will yield a natural morality, having in itself the solution to the gap between physical nature and our subjective values and passions, one would then regard the unimaginative mechanical philosophy and the inflamed imagination of Rococo flaunting of naturalness as very much like one another. Gaukroger's account requires one to see the Neo-Classicism that followed Rococo style as the fulfillment of sensibility's rejection of rationalism. Mario Praz certainly showed that the NeoClassical is hotter and friskier than naive reactions finds it to be, ${ }^{152}$ but it is doubtless colder than Rococo. Both Rococo and Neo-Classicism suggest that "the unification of mechanics" was more of a problem to their contemporaries than sensibility could solve.

Gaukroger believes (like most people) that Berkeley's theory of soulful operations in the world is wrong, leading him to mis-appraise the role of the

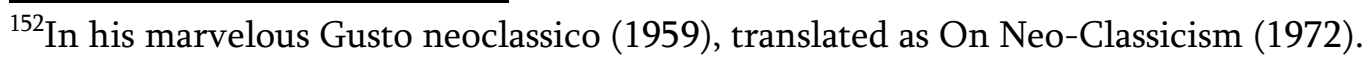


occasionalism in the period. He is starkly determined in his rejection of Vico's central ideas. ${ }^{153}$ Having rejected earlier theories of matter as the foundation of natural philosophy, the age of sensibility had to rest on something beside reaction. Gaukroger names this as the re-thinking of Lockean sensationalisam into sensibility. Once again, the way that Rococo style bedazzled the age counts for nothing in the historical account, just as Gaukroger specifically deflates the parts of contemporary philosophy that became as powerful as naturalism in the two centuries since Kant. In its conceptually inchoate though throughly realized production, Rococo style suggests complexities in the Enlightenment that the progressive-scientific view overlooks.

Diderot's moralist aesthetic, classifying Rococo style as late Baroque, took the petite manière ${ }^{154}$ fueled by infinite fantasy as caprice, enervating, even buffoonish, certainly feminized; luxe (the superfluous) usurping faste (the necessary); ${ }^{155}$ amateur rather than sophisticated, boring rather than sweet; unreasoned like financial gambles

\footnotetext{
${ }^{153}$ Gaukroger, Collapse, 426; and at greater length in his paper "Vico and the Maker's Knowledge Principle," in History of Philosophy Quarterly, vol. 3, no. 1 (January, 1986): 29-44.

${ }^{154}$ This phrase as a description of Rococo style suggests that a comparison of the dismissive or minimizing approach to it with the same pattern as applied to smaller traditions running before or along side of grander or more extensively respected traditions is worthwhile. In Aesopic Conversations: popular tradition, cultural dialogue, and the invention of Greek prose (Princeton: Princeton University Press, 2011), Leslie Kurke shows that the "little tradition" critique of the Athenian philosophers associated with Aesop was overcome and since suppressed by the Socratic critique of contemporary philosophers and the conception of philosophy that Plato developed.

${ }^{155}$ This is the theme of Saisselin's The Enlightenment against the Baroque. See also his earlier work, Taste in Eighteenth Century France. Critical Reflections on the Origin of Aesthetics or An Apology for Amateurs (Syracuse: Syracuse University Press, 1965).
} 
and as unreasoning as a disease. One of the responsibilities of intellectual history is to show that conceptions do not grow by clean stops and starts. They do not grow and then come to a period like a sentence by Edward Gibbon. This requirement makes the moral obligation of recounting history tricky because it is necessary to remember and tell he moral claims of the other side. In this case the other side is non-verbal, as Rococo had no theorists. In thinking about Rococo style one must consider not only the moral life of the patrons, to which scholarly consideration of it has generally been confined, and not that of the artisans solely as proletarians or of the dealers solely as bourgeois, but of the style itself. ${ }^{156}$ If style can be said to exist, if we can grant to anything the capacity to unify a group of years or productions, this thing is the moral rather than the formal qualities. The moral claims of Rococo style were not confined to elevating luxe over faste.

Our understanding of Regency luxe has grown less exclusive to the ruling classes. A carnival was going on in its day-including steps in the liberation of the body through dance, right in the streets of Paris—a great range of experience and inspiration that the moralist either ignored or rejected. ${ }^{157}$ Watteau's harlequins, once a triviality, are now understood in a wider social and cultural context. One of the

\footnotetext{
${ }^{156}$ Sargentson, Merchants and Luxury Markets, studies the socio-economics of the guilds. Paris: Life and Luxury, Bremer-David, ed., takes an approach that manages to cover important concepts, such as time, among most of the participants in Rococo style. ${ }^{157}$ See Thomas E. Crow, Painters and Public Life in Eighteenth-Century Paris (New Haven: Yale University Press, 1985), 45ff.
} 
critics' targets was the sensuality of Rococo, which is not only erotic but a part of a kind of sensuousness in Occidental culture that the growth of philosophical conception around 1710-1720 presaged.

Our tendency to connect the critique of Rococo from the 1750s and 1760s to our own appropriation of elements of neo-Classical architecture as the visual ideal of democracy ${ }^{158}$ leaves us likely to accept Diderot and La Font de Saint-Yenne's presentation of what was in fact a "false impression...of a broad anti-Rococo consensus." ${ }^{159}$ Recent material culture studies also tend to assume or affirm this on the basis of the distinction between Rococo as bourgeois interior decor and class tensions that embarrassed the patrons of Rococo-a split, as Mikhail Bakhtin put it, "between private eros and public sobriety."160 This does not describe Rocco outside Paris. But even beyond this consideration, we are far too sober for the Rococo if we do not love illusion, accepting it as one of the ways in which the aesthetic exposes reality and reconciles us to it. We would likewise be too sober for Neo-Classicism if we could not accept its illusions. Throughout the Enlightenment period we see many forms of contrast, successive and simultaneous, rather than consensus. The contrast between rationalist fixity and empiricist fluidity expresses disagreements within one dominant way to organize knowledge, the authoritative use of propositional

\footnotetext{
${ }^{158}$ Saisselin, Enlightenment, 5.

${ }^{159}$ Crow, Painters, 10.

${ }^{160}$ In Rabelais and His World, translated by Helen Iswolsky (Bloomington: Indiana University Press, 1984), 115-119.
} 
discourse. Beneath that are wider splits and bridges within rationality and within sensuality that, rising in part from utopian hope and present fear, claim the largest possible plasticity with which to mock progress determined by logic or facts, to pick and choose at will between opposites, to comprehend anything to which the imagination ranges, limited though it is by each person's circumstances and those of her era, and to fight off life's own humiliating and sublime fearfulness. NeoClassicism, Baroque rationalism, and Enlightenment empiricism, and perhaps all adventures in conception and production, mix alternate rationalities and alternate sensualities over the decades in ways comprised by moral conflicts in which all sides—not only the most verbally eloquent or tartly rational or publicly loudest side-make high-order claims on moral obligation.

That Rococo style is especially shameless in its sly but sharp forward edge might be one of the reason its critics then and now, with the best intentions, have desired to blunt it. The moral complexity of the Rococo effect and the related philosophical issues of embodiment make quick disposal of what we might call the naturalistic sub-division of the progressive-scientific interpretation of Rococo style. This view explicitly recognizes the Rococo and gives it a good, socially useful job (rather than the job of a parasite) as the "sugarcoating on the harsh pill of empiricism"161 According to this view, the Rococo was the full representative of

\footnotetext{
${ }^{161}$ Patrick Brady, "A Sweet Disorder: Atomistic Empiricism and the Rococo Order of Vision," in Studies in Eighteenth Century Culture, vol. 7 (1978): 451.
} 
empiricism, sweetening true and fundamental sensible cognition. Like a whale swallowing herring, the style swept in the infinite variation of minute details in nature and of the processes of organic growth and then returned them in the form of art-objects. According to this view, the Rococo effect present a puzzle in order to delight us with the surprise reveal that the puzzle is unreal, there being no contradiction and nature being solid and complete in its real plenitude. ${ }^{162}$ Like nature itself, supposedly, it is seamless symbiotic, anti-hierarchical, and distributed with democratic ease and liberty. In the end Classicism ${ }^{163}$ came as a better worker in this job, cleaning up the excesses of the superannuated style.

Like Diderot and like Gaukroger, this view sees the Rococo as "a total loss of nerve." ${ }^{164}$ Benjamin and Adorno, though calling it late Baroque or early Enlightenment, also see the Rococo as very nervous indeed. Diderot and Gaukroger are correct in pointing out that Rococo style was a transformation of perception but

${ }^{162}$ Brady, "Sweet," 456: "The rocaille, in fact, while it is compensatory in shape (that is, as an autonomous whole), is essentially metonymic in function (that is, as part of a greater whole): while it appears to float about and settle at random, it actually comes to rest in places where it serves to conceal the structural organization of the architecture, as if to deny the latter's necessarily studied rationality. The distinction, the hierarchy between wall and ceiling is thus denied. And of the two ways of viewing the rocaille, we have seen that the perspective central to the rococo mode of vision is that which subordinates the part to the whole-a perspective which consequently valorizes the metonymic rather than the compensatory role of the rocaille."

${ }^{163}$ Brady, "Present State," 24: "The role of the rococo in Germany is similar to that of preciosité in France: by its purifying influence, it made possible the transition from baroque to classicism (LR, pp. 34-37). This fact gives an added insight into the intimacy and significance of the relationship between preciosite and French rococo, and also, perhaps, into the presence of considerable classical strains in the postrococo period (i.e., after 1760)."

${ }^{164}$ Brady, cited above in n. 5 . 
wrong to see it in the end as the tidier, "purer" result of scientific observation and advanced morality based on sensory knowledge rather than as a deeper change in the nature of subjectivity and the dynamic ontology of the world. Benjamin and Adorno are right to see the profound themes and struggles of Occidental humankind thrashed out in phase after phase from Descartes to the French Revolution. And they are right to reveal the true great moral dilemmas here that are disguised, though mutated, wrapped up and also unwrapped, in an historical dialectic. The nervous flux of Rococo epistemology fashioned a specific dynamic response to infinite plenitude and the real mess of a heartless universe, only occasionally subjugated by the classicizing impulse, during the distracting and fleeting years in which it went from "an accidental inflection" 165 to a personality type and the again underground whilst other illusions of objectivity and perfectability commandeered the philosophy of knowledge.

A conceptual appreciation of Rococo style requires more ambition than the imitation of microscopy can satisfy. Rococo was vast-scaled, though also concerned with the minute. Its concepts had the resources to produce spectacles of all kinds, from opera, theater, and dance to the striking, dramatic appearance of gold mount holding together a Chinese vase cracked with a thousand veins. This quality is too often called charm. Bauer much more aptly calls it a "meta-style." 166 I shall not yet ${ }^{165}$ Gallet, "Quelques Étapes," 146 "une inflexion accidentelle."

${ }^{166}$ Bauer, Rocaille, 41-77 
go quite far, out of fear that the attractive prefix "meta" over-simplifies matters, , subtracting layers by its popularity rather than adding layers as the word is meant to do. The art historian Michael Levey calls it an "anti-style."167

But even within the limits constraining analogies among the arts, the Rococo artist's abundance of newly observed natural detail, suggesting the infinitesimally small and the unimaginably large, reflected in the observation of human and social detail, perhaps never previously so nuanced and diverse, is a sufficiently powerful concept to trigger changes in notions of enclosure, uncurling, and distribution in space - thus of space itself, its virtuality and its reality and also of the structures within space. The plastic arts of the Rococo were one part of this fundamental development in Occidental thought, drawing from it and contributing to its forward movement. Rococo objects present themselves at a balance-point between the past and the future of conceptions of space — and of time, as I shall explain in the following chapters- that is particularly confusing to us and yet, as Minguet says, "never more perfect."168 By challenging stability, coherence, and consequence, atectonicity fuses ornament with fundament in such a way as to reveal structures different from those established by precedent conceptual convention. This is part of the reason by which Rococo can simultaneously be chthonic and trivial. Mere concavity comes to stand for all reality.

\footnotetext{
${ }^{167}$ Levey, From Rococo, 16.

${ }^{168}$ Minguet, Esthétique, 156.
} 
The large conceptual reach of Rococo style was a moment for a certain kind of freedom. As Levey puts it, Rococo style was

"deliberately removed from the task of recording natural appearances.... [and from] being historically true or didactically moral. That did not last long. ${ }^{169}$

The great lights of the Enlightenment resisted the Rococo without recognizing the freedom that their critique rejects. They did so in order to develop and protect the story of enlightenment they were at that moment creating. It is interesting to note that historians who dismiss intellectual history, such as David Brewer, and historians who make the strongest theoretical defenses of it, such as Reinhard Koselleck, both regard the Enlightenment as creating a new "historicity" by a network of selfexplanations that centralizes itself. To do this, it was necessary to reject Rococo, the immediately precedent movement of conception, by lumping it in with the old, rejected Baroque. ${ }^{170}$ In so far as Rococo style was seen by contemporaries to join contradictory things, "to upset formal harmony and to undermine balanced proportions," in the words of art historian Marian Hobson, ${ }^{171}$ it seemed to threaten the progress from superstition to science and from prejudice to morality that Diderot, Condillac, and others strove to realize. In truth the span of concepts behind Rococo

\footnotetext{
${ }^{169}$ Levey, From Rococo, 19, 16.

${ }^{170}$ Dan Edelstein, The Enlightenment. A Genealogy (Chicago: University of Chicago Press, 2010), 16-18.

${ }^{171}$ Marian Hobson, "Philosophy and Rococo Style (2002)," in Marian Hobson, Diderot and Rousseau: Networks of Enlightenment, edited and translated by Kate E. Tunstall and Caroline Warman, (Oxford: Voltaire Foundation, 2011), 204. (Most of this essay is a reading of Diderot.) She develops the same view of the Rococo at greater length in The Object of Art.
} 
effects was part Enlightenment — part free, sensuous, sensible, optimistic —as well as part Baroque — kinetic, theatrical, assimilative, pessimistic —and yet it stands apart from both these phases of the history of ideas.

The gap over which the atectonic moves, frequently represented in Rococo objects by the inside of concavity, becomes a space in which newer connections between our inward consciousness and outward reality obtain. These connections are strange at first, but we seek them and then they grow into our philosophy, arts, and culture because they meet previously unmet needs and provide a way of looking at the world to replace one that over time people find they must reject because it is false or limited, cutting off structures we seek or need, repressing what now appears novel and unfamiliar but nonetheless gains strength as decades and centuries pass.

Rationalism limited our impress on reality in some ways while falsely exaggerating it in others. ${ }^{172}$ It elided some aspects of personal or human life, repressing some hopes or needs that resurfaced around 1710 through the creativity of a style in the supposedly less noble projects of interior decoration and the plastic arts.

Atectonics, onto which rocaille shapes open, was one part of the long development of animated relations in place of fixed substances in Occidental ontology and culture. A great part of the difficulty in setting Rococo inside of, or late in, or over against Baroque lies in the extent to which one regards Baroque as

\footnotetext{
${ }^{172}$ This observation owes a great deal to Gaston Bachelard, The Poetics of Space, translated by Maria Jolas (Boston: Beacon Press, 1994), 17ff. and 67-8.
} 
ontologically relational rather than substantial. It is of course not purely the one or the other. The trouble is that Rococo is even less purely one or the other, if I may put it that way, or rather that one, the relational, begins hesitantly to emerge in Rococo objects, dimly to our eyes, and then rather quickly became fugitive. ${ }^{173}$ Rococo style reflects a path not much taken in philosophy, though it had great influence in other parts of Occidental culture. It is now re-appearing, though not honored, in the troubled mutation called object-oriented ontology.

The Baroque, as Gilles Deleuze (1925-1995) has shown, was relational, but the relations were directed toward an apex. Deleuze tries to perfect the balance, characterizing the limitless microscopy of Baroque vision as entirely leveling, riskily opened to every bit however low and heavy and yet indissolubly connected to the weightless, incorporeal, infinitely macroscopic top of the ontological pyramid. ${ }^{174} \mathrm{G}$. W. F. Leibniz's (1646-1716) ontology expresses maximum receptivity—that is, is

\footnotetext{
${ }^{173}$ It contributed to Hegelian historicism but was a contrary spirit within it as well as with respect to those adversaries of Absolute Idealism, whether Marxist, analytic, or humanist, that finally, it appears, squashed it.

${ }^{174}$ Gilles Deleuze, The Fold. Leibniz and the Baroque, translated by Tom Conley (Minneapolis and London: University of Minnesota Press, 1993), 29, 35, 87. Deleuze gives a rather lucid exposition of his view on Leibniz and the Baroque in a lecture on "Leibniz," online in Les Cours \& Conférences de Gilles Deleuze, at http://www.le-terrier.net/deleuze/07leibniz15-04-80.htm.

Deleuze in his philosophy of history seeks to maximize particularity. He therefore thinks of history more as the dismantling of subjectivity than as its progress, as Hegel thought it to be. This follows the accounts of Simon Lumsden, "Deleuze and Hegel on the Limits of Self-Determined Subjectivity," in Karen Houle and Jim Vernon, eds., Hegel and Deleuze. Together Again for the First Time, (Evanston: Northwestern University Press, 2013), 133151); Nathan Widder, "Negation, Disjunction, and a New Theory of Forces: Deleuze's Critique of Hegel," in Houle and Vernon, eds., 18-38.
} 
internal variation among things and organisms, compatible with the maximum divine guidance - that is, fully true reality. Deleuze describes the effect of Leibniz's claim that divine wisdom creates all those variations:

Classical reason toppled under the forces of divergences, the incompossibilities, discords, dissonances. But the Baroque represents the ultimate attempt to reconstitute classical reason by divine divergences into as many worlds as possible, and by making from incompossibilities as many possible borders between worlds.... ${ }^{175}$

[In Leibniz] The task of perception entails pulverizing the world, but is also one of spiritualizing its dust. ${ }^{176}$

In this way spirit can exist in the gaps between the dust, the infinity of "borders" (or variations") being adequate to the infinity of God. The infinitely great creates, requires, and inhabits the infinitesimally small, just because divine substance is essentially different from material substance. ${ }^{177}$ Leibniz, as Justin H. E. Smith beautifully explains, wanted to get into the inside of bodies for as much as he atomized them he desired also to find the empty spot at which he could plant the banner of discovery, with explanation, of the soul. ${ }^{178}$ The apex was not topographically, or even conceptually, orthogonal to the dust; rather, it created the dust (or monads in their variations) just so as to be present in the relation of creator to created but entirely separated as substance.

\footnotetext{
${ }^{175}$ Deleuze, The Fold, 82.

${ }^{176}$ Deleuze, The Fold, 87.

${ }^{177}$ Gilles Deleuze, Difference \& Repetition, translated by Paul Patton (New York: Columbia University Press, 1994), 45.

${ }^{178}$ Justin E. H. Smith, Divine Machines. Leibniz and the Sciences of Life (Princeton and Oxford: Princeton University Press, 2011).
} 
This is the picture of Leibniz's Baroque that Deleuze gives us. To anyone who has read Leibniz' Monadology or his Theodicy, there can hardly be a more complete expression of a harmonic architectonic of universal conceptions than these works of Leibniz. ${ }^{179}$ Deleuze makes full use of the infinite, agreeing with Benjamin that any object "overflows its frame" into the networks linking all things. ${ }^{180}$ Benjamin, however, did not accept the prophylactic against the terrorizing sublime that Deleuze says Leibniz offered. But if the Baroque saw disharmony and terror and defended against it, and the Enlightenment deployed the moral sentiment of natural reason to redress the weakness of the Baroque defense by hierarchical metaphysics, how did the Baroque change around 1690 to 1710 so as to expose its weakness? By what turns in the history of conception was such a result made possible from such an instigation, in the Deleuzian view?

Deleuze therefore has to give us the "neo-Baroque," which he mentions only once and without any context. ${ }^{181}$

The reconstitution could only be temporary. With the neo-Baroque, with its unfurling of divergent theories in the same world, comes the irruption of incompossibilities on the same stage, where Sextus will rape and not rape Lucretia, where Caesar crosses and does not cross the Rubicon, where Fang kills, is killed, and neither kills nor is killed. In turn harmony goes through a crisis that leads to a broadened chromatic scale or of unresolved accords,

\footnotetext{
${ }^{179}$ Deleuze, The Fold, 33. Deleuze does ask whether Leibniz is so dominant as to create the idea of the Baroque within us regardless of whether anything else Baroque ever existed ${ }^{180}$ Deleuze, The Fold, 125.

${ }^{181}$ Deleuze, The Fold, 82; but cf. 137.
} 
accords not brought back to a tonality. ${ }^{182}$

Indeed: no perfect harmony ever could stand, and it never did exist. Deleuze's theory of the Baroque provides us with an additional notion with which to make some philosophical sense of the Rococo. Earlier in this chapter I described the change in relation of signifier and referent according to Foucault and then pointed out that Benjamin developed this idea in respect to allegory as a oppressive force inspiring resistance, which, Adorno argued, cannot come from reason itself. Realization of the utility and significance (not only the terror) of abundant empirical observation when added to the sense of finitude created a beautiful but frightening sublime to which we are attached like a person holding a pole with a strong electric current running through it. Deleuze adds one last piece: that the architectonic Leibniz created, which has become a sacred mandorla around the Baroque, failed.

Deleuze's "neo-Baroque" dissolved the Baroque. One of the most highly regarded art historical readings of the Rococo says the same thing but in simpler terms, that a period of great, rigid, hierarchic grandeur "was a bound to cause a swing of the pendulum." 183 But there was more positive contact and there were more constructive ideas in Rococo style than simply resigned disappointed to the imperfection of Baroque or orgiastic monkey-business out of relief or anger or opportunity. Atectonic replaced architectonic. This is not just privative conception

${ }^{182}$ Deleuze, The Fold, 82.

${ }^{183}$ Deleuze, The Fold, 13, 58. 
but the start of a search for deeper structure.

In the four following chapters I will explore these philosophical issues in

Berkeley and then in Vico, apply them as ontology to Rococo style, and return to the special theme of continuous creation. 


\section{Chapter 5: Berkeley's Creation}

In this chapter I will take a section of the third Dialogue of George Berkeley's Three Dialogues Between Hylas and Philonous of 1713 as my primary text for studying aspects of contemporary philosophical conception related to Rococo style. ${ }^{184}$ This section, about ten percent of the third Dialogue, comprises 14 exchanges between the interlocutors, in all of which each party makes one speech. Philonous, because as the author's voice he speaks the correct view of the matter, has the longer speeches. But not all of Hylas's lines are short or formulaic, nor is Philonous an easy partner. Hylas's criticisms drive the section, as they do the whole work. At the point at which this inquiry enters the dialogue, Hylas presents his final objection, all others having been satisfied, directly before the summing up and peroration of the dialogue and the work. Hylas wants to know how the conception that the world and all things in it are ideas in our minds is to be reconciled with the description of the Creation of the world in Genesis. Within his early major works this is Berkeley's highest-order

\footnotetext{
${ }^{184}$ Citation from Berkeley's Treatise are given as "Treatise" by the author's own paragraph numbers, standard in all accurate editions. Citations from his Dialogues, which is three texts without internal markers, and other works are given as "Dialogue" (or the name of the work) by volume and page number from the Luce edition of his Works, thus cited below. The context or the note establishes which of three dialogues is referred to or quoted.
} 
response to the Baroque problem of existential annihilation by infinitude. ${ }^{185}$

The link between the various philosophical issues Berkeley takes up and his ideas about the nature of fundamental reality is unusually clear. Great philosophers often address narrow issues in light of great questions, seeking consistency and truth, but their concept analysis often is very long and the books equally so. Berkeley's early books are short. His thought in them is always about fundamental reality right from the start. This is particularly true of his views on causation, which are, as I see it, immediately concerned with the first cause, divine Creation of the world. Because his conceptions are counter-intuitive revisions of such basic notions as cause, knowledge, and reality, some readers are tempted to regard them as mere terminological disputes. ${ }^{186}$ In their recent handbook survey of the current state of analytic philosophical work on causation, L. A. Paul and Ned Hall say that ...it is philosophically naïve [sic] to think...that argument over fundamental reality must render any disagreement about the nature of causation purely terminological. ${ }^{187}$

Sometimes people who write about Berkeley say that he "re-defines" ideas or reality

\footnotetext{
${ }^{185}$ The reading of Berkeley's idealism from this text on the Creation is not a comprehensive reading of Berkeley's philosophy, although it is based on the interpretation of Berkeley that I believe to be valid. For the purposes of this inquiry there is not space to address all the conceptual and topical constituents of his thought, especially as it changed over time.

${ }^{186}$ For the reception of Berkeley's intensely counter-intuitive claims in his own day see Harry M. Bracken, The Early Reception of Berkeley's Immaterialism 1710-1733 (The Hague: Nijhoff, 1963).

${ }^{187}$ L. A. Paul and Ned Hall, Causation. A User's Guide (Oxford: Oxford University Press, 2013), 13. Their discussion on 10-13 explains the issue of this constraint on debate about causes.
} 
or other basic concepts. Instead, in what follows I say that Berkeley "re-constitutes" basic concepts.

Berkeley published the Dialogues in 1713 as an expansive defense of his Treatise Concerning the Principles of Human Knowledge, published in 1710. The Treatise is short, its principal conception appears on the first page, and its lead exposition is a matter of 33 paragraphs. The 122 following paragraphs extend and defend the thesis, filling out what the title-page calls Part I of a "treatise." No Part II appeared, so historians treat the Dialogues in close relation to the Treatise. The burden of the treatise is to account for all beings as spirits, rather than as matter or as anything else to any degree. Accounts of the metaphysical coup by which Berkeley sets his project in motion center on his anti-materialism and his affirmative idealism, but Berkeley is as much at pains to refer ideas to spirits as he is to do away with matter. ${ }^{188}$ The nature of matter is to be unknown partly because the notion is empty,

\footnotetext{
${ }^{188}$ Reliable standard complete accounts, debating the standard philosophy of mind and epistemological issues, include Jonathan Dancy's excellent Berkeley: An Introduction (Oxford: Blackwell, 1987); G. A. Johnston, The Development of Berkeley's Philosophy (New York: Russell \& Russell, 1965); A. A. Luce, Dialectic of Immaterialism: An Account of the Making of Berkeley's Principles (London: Hodder and Stoughton, 1963); George Pappas, Berkeley's Thought (Ithaca: Cornell University Press, 2000); and George Pitcher, George. Berkeley (London: Routledge \& Kegan Paul, 1971). In the last couple decades numerous collections of papers (but no new general account) have been published, some of which will be referred to below. The most recent is Berkeley's Lasting Legacy: 300 Years Later, edited by Timo Airaksinen and Bertil Belfrage (Newcastle Upon Tyne: Cambridge Scholars Publishing, 2011). In addition to these, see Reexamining Berkeley's Philosophy, edited by Stephen H. Daniel (Toronto: University of Toronto Press, 2007). Of particular interest for the Dialogues is Daniel Flage, "Berkeley’s Epistemic Ontology: The Three Dialogues," in New Interpretations of Berkeley's Thought, edited by Stephen Daniels,(Amherst, NY: Humanity Books, 2008), 45-76.
} 
as Berkeley wants to prove it to be, and partly because even if matter existed it would not be capable of intellection. ${ }^{189}$ If there is to be any knowledge in the world spirits must comprise the world. The same is true of will: matter cannot will, what can will we call spirit. The deadness of matter is quite complete, so that if matter were what existed nothing at all could exist. Matter itself is nothing. ${ }^{190}$

Berkeley's understanding of the concept of "idea" is this: an idea is that which is necessary and sufficient for human knowledge. ${ }^{191}$ Whatever that is, an idea is. Ideas are no more than this, and nothing more exists than this. ${ }^{192}$ Such a purely privative re-constitution of the common notion is all Berkeley requires us to set his rejection of matter apart from John Locke's (1632-1704) notion of ideas and substances and even from Descartes' dualism. ${ }^{193}$ But anti-materialism becomes idealism by means of a constructive consequence Berkeley draws from the minimal constraint afforded by his line of thought. ${ }^{194}$

\footnotetext{
${ }^{189}$ Treatise, 25, 72.

${ }^{190}$ Treatise, 73-74.

${ }^{191}$ On ideas as mind-dependent objects of signs see Kenneth E. Winkler, "Berkeley and the Doctrine of Signs," The Cambridge Companion to Berkeley, edited by Kenneth E. Winkler (Cambridge: Cambridge University Press, 2005),152.

${ }^{192}$ A. C. Grayling, "Berkeley's Argument for Immaterialism," in Cambridge, edited by Winkler, 177.

${ }^{193}$ Berkeley's response to Descartes is anchored in his theory of vision, which I do not here examine, q. v. Margaret Atherton, "How to Write the History of Vision: Understanding the Relationship between Berkeley and Descartes," in The Discursive Construction of Sight in the History of Philosophy, edited by David Michael Levin (Cambridge: MIT Press, 1997), 139166.

${ }^{194}$ John E. Yolton, Realism and Appearances. An Essay in Ontology (Cambridge: Cambridge University Press, 2000), 96, supports this view by showing that for Berkeley true existence of
} 
I say it is granted on all hands...that it is possible we might be affected with all the ideas we have now, though there were no bodies existing without resembling them. ${ }^{195}$

("Without" here mean something like "outside of our own minds" rather than "lacking resemblance.") Each piece of knowledge exists inextricable in the context of all the rest of our knowledge, which is fully and adequately conceived as a system of connections standing alone inwards to ourselves. Sensory impressions are still sensory, but sensation exists solely as our knowledge, which is ideal. Berkeley also expands the "knowledge" he wishes to account for in the beginning of the paragraph into being "affected." This change suggests the plurality of kinds of human knowing. The sufficiency of sensations and intuitions to account for the world cannot be due, in Berkeley's view, to external matter.

The chief feature of our ideas is not their origin in matter but the story of their intelligibility to the inventor, holder, or recipient of them. The result largely evacuates intelligibility of the traditional sort—for centuries understood to be the information delivered to us by reality through the species intelligibilis (the form, shape, or portion of a material thing that enters us a truthful sensory impression). The connections among ideas blocks the way of relating them to the external world. It is their history that is in the way, both as a check to rationalism and as a door to objects is our notions of the existence of objects. In his view, whereas Descartes based knowledge on "the presence of mind" in the world, Locke and Berkeley began the move towards regarding the mind as the essential "epistemic presence" for us (xi-xii).

${ }^{195}$ Treatise, 18. 
indefinitely many new ways to understand human presence in the world. ${ }^{196}$ We can see something like the concept that the history of objects and the world containing them is the history of our understandings of them. This is Berkeley's meaning in these texts with respect to ideas and objects, that objects are knowable only as the story of our ideas of them because they are otherwise uncreated and non-existent. There is no valid account of reality except as the compilation of the contents of minds, to wit, "ideas."

It is as impossible to imagine knowledge apart from ideas as it is to conceive eternity apart from a creation, though we cannot conceive a beginning, or an end to time whereas we must conceive of knowledge in company with memory. ${ }^{197}$ In the third Dialogue Berkeley develops this notion as "congeries" of ideas, ${ }^{198}$ and it becomes an identity structure between eternal, or archetypal, knowledge and temporal, or ectypal, knowledge. ${ }^{199}$

The "mind-dependence" of all things is not for Berkeley a merely categorical

\footnotetext{
${ }^{196}$ This suggests that some notion of history like this underlies or can replace what common is called "mediation."

${ }^{197}$ John D. Wild, George Berkeley (Cambridge: Harvard University Press, 1936), 31, citing Berkeley's early private notebook published as Philosophical Commentaries, generally called the Commonplace book, edited by A. A. Luce (London and New York: T. Nelson and Sons, 1944), C.752: "Knowledge, or certainty, or perceptions of agreement of ideas—as to identity \& diversity, \& real existence, vanisheth; of relation becometh merely nominal; of coexistence, remaineth."

${ }^{198}$ The Works of George Berkeley Bishop of Cloyne, edited by A. A. Luce and T. E. Jessop (London and New York: T. Nelson and Sons, 1948-1957), 2.249.

${ }^{199}$ Starting $n$ the first Dialogue inWorks, 2.204 and culminating in th third Dialogue in Works, 2.254-255.
} 
or analytic relationship. He is trying to answer questions about the nature of our existence that science and philosophy of the seventeenth century had raised.

How often must I repeat that I know or am conscious of my own being, and that I myself am not my ideas, but somewhat else, a thinking active principle that perceives, wills, and operates about ideas.... ${ }^{200}$

Having determined that reason gives no certainty to sensation, Berkeley argues that we are not at a position of such certainty about our selves as well as about the world as Descartes thought himself to be on an unbreakable foundation from which he could penetrate all the sciences without any other consideration apart from our unaided selves. The "active thinking principle" adds our history into the world in which we exist. Berkeley holds that the stories of the world that our ideas constitute are sacred, validated by something other than our reason. ${ }^{201}$

The categories of creator spirit and created spirits thus enter into the Treatise from near the very start, in par. 6 . The constant companion of Berkeley's discourse on spirits is his discourse on annihilation of existence. Spirits are always shadowed by their annihilation. Without spirits ideas vanish, and spirits themselves must vanish if ideas give way to matter. The Creation of all things, which is the elimination of nothingness, is itself unintelligible to us without the awareness of nothingness that veridical though very partial copies of the creator's intelligence of

${ }^{200}$ Works, 2.233-234. Philonous' manner is generally impatient.

${ }^{201}$ Margaret Atherton, "Berkeley's Theory of Vision and its Reception," in Cambridge Companion, edited by Winkler, 152-155, emphasizes that for Berkeley human understanding needs our a temporal train of associations to its "innocent eye." 
these matters gives us. The universal Creation is the explanation of reality; all our ideas of substance, matter, mind, and existence must make sense of the Creation and can refer solely to what the Creation was and is, what it brought to pass and how and why God did so.

It therefore ought to be no surprise to us that Berkeley appeals his case to scripture near the end of the Dialogues. ${ }^{202}$ He must of course show that his view accords with scripture, but in this section of the third Dialogue Berkeley does more than tidy up. He invokes "the plain obvious sense of Moses" as his authority. ${ }^{203} \mathrm{He}$ places the Creation at the center of his philosophy because the notion of matter is a chief obstacle to understanding the nature of God and of Creation, and it is ever Berkeley's purpose to explain God to us by making belief reasonable and inevitable. The Creation is the invention or constitution of everything as it actually is. To understand the one is to understand the other. Berkeley connected the history of our understanding with something processual, rather than instant, in the divine Creation. He has established a container for the infinitude of things by identifying the world with humankind, and he has established a prophylactic against annihilation by an "identity structure" between us and the truth, that is, between thought and being. Without a temporal element, Creation might be as unfriendly to us as nature itself:

${ }^{202}$ The section of the second Dialogue concerning the Creation isWorks, 2.250.32-256.10. ${ }^{203}$ Works, 2.256. The same and similar expressions are common here and throughout Berkeley. 
something we have no part in, that happened without us, and is indifferent to us.

Berkeley is also advancing into another territory, very much at the far edge of what he grasps either as a matter of philosophy and faith or as a matter of deep structure revealed by the "the plain obvious" result of observation of the world around us. For this he requires the authority of Moses, the observer of the greatest theophanies in the Occidental tradition; and with this he takes on the stance of the truth-knowing thinker who cannot know truths he is aware of but recognizes as beyond his reach. For all his bulldoggish attitude, both in 1710-1713 and in Siris in 1744, Berkeley sometimes reveals the modesty of someone who goes not quite where he intended yet follows the indicated path. ${ }^{204}$ Few Berkeley scholars have followed him; comment on this section of the third Dialogue is scanty. ${ }^{205}$

${ }^{204}$ Berkeley's North American career seems an instance of this. Headed toward Bermuda full of zeal to establish his college, he ended up in Rhode Island and had the happiest period of his life while abandoning the missionary project. A. A. Luce's The Life of George Berkeley Bishop of Cloyne (London: Thomas Nelson, 1949) remains a solid account of this strange man.

${ }^{205}$ Kenneth P. Winkler discusses in support of the phenomenalist, as opposed to the perception, interpretation of Berkeley in his Berkeley. An Interpretation (Oxford: Clarendon Press, 1989), 220-222. Robert G. Muehlmann in his Berkeley's Ontology (Indianapolis: Hackett, 1992), 253-261, reads the continuous creation discussion strictly in terms of the problem of the intermittency of existence under Berkeley's view (as he sees it) that only perfectly localized particulars exist. On the inconsistency of faith and science inconsist in Berkeley see Daniel Bertini, "Berkeley, Theology and Bible Scholarship," in George Berkeley: Religion and Science in the Age of Enlightenment, edited by Silvia Parigi (Dordrecht: Springer, 2010), 129. For Berkeley as holding an anti-fideist and instrumentalist view of faith see David Berman, George Berkeley: Idealism and the Man (Oxford: Oxford University Press, 1996), who finds this in Berkeley's early notes of 1706-1709; see also his reply to Bertini, "The Distrustful Philosopher: Berkeley Between the Devil and the Deep Blue Sea of Faith," in George Berkeley, Parigi, ed., 148-157. For more on this theological issue see Roomet Jakapi, "Christian Mysteries and Berkeley's Alleged Non-cognitivism," in Reexamining, Daniels, ed., 
In his appeal to Mosaic authority Berkeley seeks safety from change by reading unchangeableness into the Genesis myth of the Creation. In this regard he moves away from the dynamic instabilities of the Baroque toward fideist certitude. This is not simply a tactical move to fortify his epistemology. It had the effect of introducing a new register of unresolved instabilities, which we have seen represented by Rococo atectonic style.

\section{Philonous says:}

When things are said to begin or end their existence, we do not mean this with regard to God, but His creatures. All objects are eternally known by God, or, which is the same thing, have an eternal existence in His mind: but when things, before imperceptible to creatures, are, by a decree of God, perceptible to them, then are they said to begin a relative existence, with respect to created minds. ${ }^{206}$

Here Berkeley frames his basic distinction between human knowledge and divine knowledge in terms of the Creation. The difference is binary and rigid. The Creator is not at all contingent and therefore His "knowledge" is not like ours, needing nothing of either contingency or necessity because it is outside of time and all interval. It is more like pure act than it is like our clunky mundane knowing and then doing. The human is entirely contingent. There is no knowledge except contingent knowledge. All contingent things exist solely through being known.

The Creation happened in time, which was created as were the heavens and

188-198.

${ }^{206}$ Works, 2.251-252. 
the earth, and so was at heart the creation of contingency. Philonous continues:

Upon reading therefore the Mosaic account of the creation, I understand that the several parts of the world became gradually perceivable to finite spirits, endowed with proper faculties; so that, whoever such were present, they were in truth perceived by them. ${ }^{207}$

The Creation created intervals, intervals comprise time, and the passage of time is the essence of contingency. Berkeley's claim is not that what existed for God is unveiled to human knowledge and thereby created, since existence for God is entirely different from existence for us. His claim is that things exist for us and other spirits because spirits are like God in being agents of knowledge. Berkeley's explanation of his immaterialist idealism throughout these two texts leading to this moment also reconstitutes knowledge every bit as much as it re-constitutes "ideas" in the famously startling, lightning-quick bullet-to-the-heart argument of the first few pages of the Treatise.

He stresses the distance between finite and infinite. Again, Philonous, a page later:

May we not understand it to have been entirely in respect of finite spirits; so that things, with regard to us, may properly be said to begin their existence, or be created, when God decreed they should become perceptible to intelligent creatures, in that order and manner which He then established, and we now call the laws of nature? You may call this a RELATIVE, or HYPOTHETICAL EXISTENCE if you please. ${ }^{208}$

This tops off a thread from the beginning of the Treatise straight through to the end

\footnotetext{
${ }^{207}$ Works, 2.252.

${ }^{208}$ Works, 2.253.
} 
of the Dialogues. Berkeley argues that the created world is a world of perfect contingency. Necessity, too, is just an invention of God's to make things good for us, but it matters not a flip to divine omnipotence. God is powerful enough to create pure contingency, so through and through pure that it is nothing but contingency; and God is both able and willing to sustain it. Historians well recognize that Berkeley disposes of the whole mass of primary and secondary qualities, but they have not recognized something still more radical. Berkeley's argument disposes of Leibniz's, and the Baroque's, hierarchy of being. He leaves two levels only of being: the divine and the contingent. The rest is non-being.

One of the working parts of Berkeley's logical structure is his rejection of infinity. ${ }^{209}$ He does not of course reject it as it applies to God, but he rejects it as any part of human knowledge. God is infinite, but humans cannot understand infinity although we conceive it. This rejection appears, somewhat disguised, through his rejection of "abstract ideas," a line of thought heavily controverted by modern scholars though often without recognizing that infinity, the very model of an abstract idea, is his target. ${ }^{210}$ Every abstract idea denotes something infinite, in Berkeley's view. An abstraction makes little sense unless it is an unbounded notion. But all our knowledge, as Berkeley has it, is direct knowledge. No gradient of non-being stands

\footnotetext{
${ }^{209}$ Treatise, 123-132; second Dialogue in Works, 2.211-212; and third Dialogue in Works, 2.228, 231-232, 235-236.

${ }^{210}$ For more on this aspect of abstraction in Berkeley see Winkler, "Berkeley," 140-7.
} 
between us and what we know, God, who knows no interval or division, having created us and it together. Where Leibniz saw the infinitesimal gradients of perception and appetition, Berkeley saw plain contradiction. He challenges Leibniz's notion of infinitesimals, while admitting its utility in calculus, by arguing that God has no need of action at a distance, or explanatory gaps, or any gradualist mechanisms. For Berkeley the evident proof of this is that our ideas-from sight and the senses, in our intentions and our will- comprise specifics. We do not see infinitesimals or infinity.

In what way does knowledge grow to include universals? ${ }^{211}$ In order to account for universals, Berkeley has to conceive of a warrant for knowledge of each an every particular grouped together-not turned into one essence but collected while retaining the character of ideas bound to time and space. What one includes in a universal is wholly up to her, as words are merely "machines" for practical purposes; ${ }^{212}$ but the possibility of including ideas from different times and places remains. Since God's mind is the only warrant for knowledge, being the creator all things known and unknown, the divine first cause leaves no room for any notion of

${ }^{211}$ Samuel Rickless, “The Relation Between Anti-Abstractionism and Idealism in Berkeley's Metaphysics," in The British Journal for the History of Philosophy, vol. 20, no. 4, (2012), 723-740, recognizes Berkeleyan universals have constructive content derived from his antimaterialism but does not apply the full force of the notion of creation in idealism to Berkeley's associationism. The paper is nonetheless a valuable account of how the truth slips in between standard analytic critiques by Pappas, Winkler, and others.

${ }^{212}$ Treatise, 65. 
secondary causes. The logical result of this line of thought is that what is true of the Creation is true of ongoing human knowledge. Berkeley does not quite get to this point, but he comes close.

He has Philonous put himself onto the scene of the Creation. This is just a heuristic for Berkeley, but this weird counterfactual trembles on the edge of a different domain. Philonous says that:

Why, I imagine that if I had been present at the creation, I should have seen things produced into being - that is become perceptible - in the order prescribed by the sacred historian. ${ }^{213}$

The world we have has to be as it is - this is where any such attribute as necessity lies, in the divine command — and we must know it as God would have us know it. But, as Berkeley frequently says, "there is no absolute existence."214 Everything is part of the relative existence that is the created order. When Berkeley re-constituted causality in the Treatise, he gave reason to hold that God is not only the first cause but the only cause. Everything else we conventionally hold to be causal, since none of it is due to the "stupid thoughtless somewhat"15 we call matter," is God's "secret mechanism,"216 put out to guide and re-assure us, His creatures. If God needs no more than His will, and no other instrument, to create the universe, then the universe, permanently

\footnotetext{
${ }^{213}$ Works, 2.251-252.

${ }^{214}$ E.g., Works, 2.253 and 256; and Treatise, 24 and 133.

${ }^{215}$ Treatise, 76.

${ }^{216}$ Second Dialogue in Works, 2.210.
} 
supplied with divine volition, cannot depend on anything else. ${ }^{217}$ Perfect

contingency cannot be more perfect or less imperfect, and it includes the story of human knowledge. This is Berkeley's answer to the Baroque dilemmas of infinitude and creation.

The conception that this lead to is that of continuous creation. ${ }^{218}$ Its place in philosophy and theology prior to the Baroque era is beyond the scope of this thesis. Robert Boyle mentions it in a note. ${ }^{219}$ Leibniz suggested it as a complement to the plan of pre-established harmony. As both he and Nicholas Malebranche (1638-1715) recognized in their correspondence with one another, if every event belongs to beings all of whom exist within the dynamic of all events, if this is the place of each within the universe, the very being of each, then God must conserve the harmony by intervening at every infinitesimal instance of the intersection of the every being with every other from every point of view—in all circumstances, all places, all times, every way.

Two explanations of this omnipotent intervention are possible. ${ }^{220}$ The first is

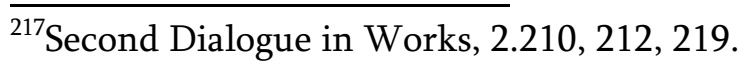

${ }^{218}$ P. A. Byrne, "Berkeley, Scientific Realism and Creation," in Religious Studies, vol. 20, no. 3 (September, 1984), 453-464, describes some of the approaches to continuous creation immediately preceding Berkeley. His interest in Berkeley's conception concerns Berkeley's need to reconcile natural science with religion. On all fronts this concept deserves a real historical account.

${ }^{219}$ David Bates, “Super-Epistemology," in The Super-Enlightenment: Daring to Know Too Much, edited by Dan Edelstein (Oxford: Voltaire Foundation, 2010), 59.

${ }^{220}$ Marc Bobro, "Leibniz on Causation," in The Stanford Encyclopedia of Philosophy (online at: http://plato.stanford.edu/archives/sum2013/entries/leibniz-causation/), works out the 
concurrentism. This view requires that we explain the maintenance (or conservation) of the identities of entities by the proposition all beings endure through time, "endurance" meaning continuous existence as wholes through every instant. Given this, concurrentism holds that each being continuously acts as an emanation from God's continuous action, concurrent with the whole being of every existent. The second is occasionalism, adopted by Malebranche. Under this view, beings perdure as collections of successive events having intervals between them, perdurance being continuous existence through events that are discrete. God acts to hold together what is broken up at every occasion. Berkeley knew this issue well, denying that he was an occasionalist and never mentioning concurrentism as a distinct notion. Why?

For Berkeley, concurrentism is correct in holding that God exists and acts in perfect enduring unity but incorrect in holding that, as a result, entities enter into existence as faint copies of divine unity, a notion Leibniz describes as emanation. ${ }^{221}$

On the other hand, Berkeley's view is that occasionalism rightly holds God to be the only cause but errs in claiming that God newly creates the universe at the infinity of distinct instants, which Leibniz calls fulgurations. ${ }^{222}$ Berkeley's line of thinking in

conceptual and historical analysis of the two answers available to Leibniz. I follow Bobro's account but have added the concepts of perdurance and endurance and other matters in order to follow the issue of continuous creation in the contexts of Berkeley and Vico. See also Jeffrey K. McDonough, "Leibniz: Creation and Conservation and Concurrence," in The Leibniz Review, vol. 17 (2007), 31-60.

${ }^{221}$ Bobro, "Leibniz," sec. 2, citing Leibniz's Discourse on Metaphysics, sec.14 and other texts.

${ }^{222}$ Bobro, "Leibniz," sec. 6, citing Leibniz's Theodicy, sec.s 27 and 31 and other texts. 
facts does away with all the different kinds of causality Leibniz had to maintain in order to keep his universe operating, which are very many indeed and stand in uncertain relation to one another. ${ }^{223}$ Berkeley's position differs by the addition of one ingredient. For him God does not continuously intervene to sustain creation but rather He continuously adds to creation by creating more through the cognation of spirits.

Readings of his early notebooks and draft of the Treatise also shows the conceptual pre-conditions for this line of thought, to which he came even closer in his 1734 revision of the Treatise and the Dialogues. ${ }^{224}$ Berkeley did not fully work out how to make sense of this. He is not clear, for example, as to what kinds of identity that we commonly attribute to objects are from God and what kinds are from us. ${ }^{225}$ He would be hard pressed to specify or evaluate the contribution that human creativity makes to conserving and adding to the world.

In a letter to his philosophical friend Lady Percival written three months before the publication of the Treatise, Berkeley states that "there being nothing new

${ }^{223}$ An amazing "Hierarchical Map of Leibniz's Causes" is appended to Bobro's article, at http://plato.stanford.edu/entries/leibniz-causation/map.html. This chart is truly a mirror of the Baroque as ontology or cosmology.

${ }^{224}$ Talia May Bettcher, Berkeley's Philosophy of Spirit. Consciousness, Ontology and the Elusive Subject, (London: Continuum, 2007), 26ff.; see also her "Berkeley on SelfConsciousness," in New Interpretations, Daniels, ed., 179-202.

${ }^{225}$ See Daniel Flage, "Berkeley, Individuation, and Physical Objects," in Individuation and Identity in Early Modern Philosophy, edited by Kenneth F. Barber and John J. E. Garcia (Albany, NY: Statue University, 1994), 135-149. 
to God," all the events of the universal Creation appear to be successively solely and strictly in the cognition of "finite spirits." ${ }^{\text {226 }}$ Humans are such spirits. During the phases of the original Creation prior to the creation of human persons, other kinds of finite spirits, having already been created, were the percipients for whose cognition divine acts become existent. ${ }^{227}$ The principle connecting God's permanent knowledge to our novel knowledge, like two sides of the same coin, is one of aspect, which I use in the grammatical sense of the word. From God's point of view time does not exist nor does novelty. The human point of view is opposite. Novelty comes with temporality, as does continuity. In this fashion Berkeley would do away with any difficulties that continuous creation brings, holding that all such puzzles are due to aspect.

Directly after his discussion of the Mosaic account of Creation in the third Dialogue, our author advances a peculiar device to explain the continuity of things from our aspect: the divine ideas are the archetypes of our ideas, and our ideas are the ectypes of divine ideas. ${ }^{228}$ Though much has been made of this little plan, it seems an ad hoc, even stillborn notion used to enhance the reader's impression of the singularity of divine cause and the illusory inefficacy of secondary cause. Its contribution is a repetition of what Berkeley elsewhere holds to be the only

\footnotetext{
${ }^{226}$ Letter to Percival, 6 September, 1710, in Works, 8.37-38.

${ }^{227}$ Works, 2.253-254.

${ }^{228}$ Works, 2.254-255.
} 
legitimate kind of universal. What appear to us to be laws and universal ideas are simply regularities that God uses as the gift of certainty to our minds. ${ }^{229}$ Abstraction does them violence. ${ }^{230}$ The sole warranted kind universal is the particular universal, in which we associate ideas on the basis of our being affected by their similarity. Such classes are entirely motile and might have anything to do with God's arrangement of things only in so far as He inspires them in our blind rambling through the world.

My purpose is not to defend Berkeley's philosophy but rather to examine it in the context of the history of ideas. The normative philosophical reading of Berkeley is analytical. ${ }^{231}$ It carefully considers logical, ontological, and epistemological issues that rapidly swarm out of Berkeley's work raises upon the least inquiry or reflection. A.C. Grayling, in a paper that ably examines the range of issues the analytic approach considers, describes three levels of explanation necessary to satisfy these difficulties. Properly aligned, these levels make Berkeley's basic ontology resilient. ${ }^{232}$ Were it not so devilishly defensible philosophers would long ago have forgotten it, but as things are analysis of concepts covers only a portion of the perennial issues to which Berkeley addressed his philosophy.

\footnotetext{
${ }^{229}$ Treatise, 31-32.

${ }^{230}$ Treatise, $97-100$.

${ }^{231}$ Q.v., Stephen H. Daniel, “How Berkeley's Works are Interpreted,” in George Berkeley, ed. Parigi, 3-14.

${ }^{232}$ Grayling, "Berkeley's Argument," in Cambridge, ed. Winkler, 170-175ff., a section titled "The machinery of Berkeley's argument."
} 
I have not described the analytic issues but read Berkeley, instead, in the light of one of the perennial issues. The analytic defense does not do this for the good reasons philosophers have for focusing their inquiries, but the prevailing academic philosophers also unwisely resist the historical framework. The one monographic attempt to study the wider genealogy of these ideas, linking them to such themes as the book of the world, gnosticism, utopias, and hermeticism, was quickly rejected in favor of the "familiar" Berkeley, the font of so many interesting ideas. ${ }^{233}$ This Berkeley might be "familiar" now, but Berkeley himself would not have recognized it. Reference to Leibniz is scarce in the Berkeley literature, which favors Locke, even over Malebranche.

The Berkeley of 1710 to 1713 did not require levels of explanation. For him one notion, one explanation, one cause did away with the rest. Even more importantly, Berkeley was bothered by existential questions as to what the meaning of existence is, and why something exists or was created out of nothing, and what answers there might be to the terror that annihilation reasonably inspires in us at every occasion and every moment. This is the reason that he justifies the Mosaic account of Creation by the conception of continuous Creation just before the

${ }^{233}$ Costica Bradatan, The Other Bishop Berkeley. An Exercise in Reenchantment (New York: Fordham University Press, 2006). This work, dismissed by the gate-keepers of Berkely studies in a Berkeley Newsletter review, usually does not appear in the bibliographies of major analytical works about Berkeley, and yet it is academically sound though not, whatever its limitations. 
peroration of his two greatest works. Divine Creation is the final form of ontology for Berkeley, in whose lifetime it had been thought up and debated.

Berkeley represents a movement of thought and feeling that, like the Rococo, is not clearly Baroque or Enlightenment, and is neither traditionally metaphysically or newly positivist. It is a slow and subtle stream, submerging and re-emerging over centuries before and after Berkeley's day. It has been unhappily mangled by confusing it with something called the Counter-Enlightenment, if such a thing ever existed. ${ }^{234}$ For now let us call Berkeley's way of "changing things into ideas," instead of ideas into things, a movement of conception that historians of ideas often have missed. For example, David Brewer, speaking on behalf of the entire Enlightenment:

What I wish to read in the eighteenth-century shift fro idealism to materialism is a move from a more disembodied and dematerialized understanding of thought to one that always seeks to locate the latter's contextual determination. ${ }^{235}$

It is hardly the case that idealism went under in 1789. It only just began, at least in modern thought, in the work of Berkeley. Some of the potential of idealist conceptions did not become clear or were gradually forgotten during most of the entire subsequent periods of Occidental thought. It is novel to recognize that, paradoxically, Berkeley's idealism led to greater "contextual determination" rather than less; and that his faltered addition of history to subjectivity, through the notion

\footnotetext{
${ }^{234}$ On the Counter-Enlightenment see the beginning paragraphs of Chapter 6 .

${ }^{235}$ Brewer, The Enlightenment Past, 51.
} 
of continuous creation, was a powerful, fundamental step in theory. Yet this is the case I have made.

Near the end the Baroque era, the idealist line of thought subverted the desolating infinitudes that supported the Baroque sense of order and meaning. Leibniz described this harmony in defensible conceptual claims more powerfully, and more beautifully, than any other thinker of the time. At the same time, Leibniz's vast system included the seeds of a monistic idealist ontology for philosophy after and against Descartes. Conflict among monads resisted elimination by definition, so that proclamation of harmony failed to dismiss the facts of discord. Consciousness of plurality grew into consciousness of infinity, multiplying infinitely the invasions of discord into every continuity. Sun Kings could not control emergencies, and experience brought an overwhelming number of exceptions to theodicies fortified by the latest natural philosophy. The grandest, most heavenly artificial mechanisms cast a skeptical light on all mechanism, as self-doubt makes the hand that thought to have created causes in its invented mechanisms doubt causality all together.

At some moments of the period around 1700 this doubt appeared as skepticism, at other time it appeared as annihilation. A correct concept of God's universal Creation was, to many, the best response to both. Berkeley expressed the fundamental fears behind skeptical doubt in a most restrained way, arguing indirectly that Leibniz's complex causal orders repressed rather than resolved these fears. He 
had conviction in the philosophical method sufficient to motivate his using it to explain faith, of which another result was to narrow the purchase of philosophy in ways sympathetic to the claims of the new natural and social scientists. They too needed to set aside Leibniz's universe-sized pyramid of hierarchically harmonious Baroque metaphysics, as well as the perfect circle and the perfect mirror dreamed of in past and present hopes.

One way to distinguish and to class things is by their differing powers of causality. If one cause solely operates everything, all secondary causes being playthings by comparison, however regular and warrantable, all thing are ontologically equal in this respect. Berkeley, again, does not go this far, but his work shows that this notion, one of the chief products (labeled the "democracy of objects") from the idealism-inspired new "object-oriented ontology, has its remote origin in Berkeley. Berkeley did not recognize the exception to this egalitarian system that humankind claims, with the notional and ideational parts of our cognition, as a problem. His not explicitly or fully accounting for human personhood is very closely related to his not explicitly inquiring into the shape of history his main ideas formed. In regard to both personhood and history, he had uncovered the nothingness under Baroque abundant accumulation. Having sure understanding of the Creation of all things was the most obvious path between nothingness and infinitude, just suited to finite and intense overcognizers, busy both building and destroying. Berkeley 
maintained the sacrality of everything by means of the concept of continuous creation, and he advanced human activity into the sphere that causality had threatened to rule and indeed seems still to rule. The constructive content with which he could have filled in a picture of the distinctly human lay in identifying our cognitive activity with our creative activity. He did not do so, but he seems to me to have come close to it. Berkeley did not move what we now call history into Mosaic sacred time, remaining inside a domain he helped to breach.

The account I have given of Berkeley's ontology points to the growth of conceptions in the period of Rococo style, as distinct innovations separate from both the Baroque and the Enlightenment but intimately related to both movements. The dishabilitation of causality allows unique psychic freedom in creating relations among things, even thought quantifiable and probabilistic causality must be maintained for practical purposes. Our consciousness, rather than the rules of perspective, is the real limit of spatial depth, leaving a flatter but wider field of imaginative vision. Depth becomes ideal: the awareness of structures deeper, or other than, mechanical causality as determinative of human experience begins from here to spread into cognitive projects and into discourse and will also come slowly to unite with some scientific inquiry in the nineteenth century. The appeal of atectonicity and the interest in it grew from these conceptions.

Berkeley's systematic thinking returned toward the end of his life—in the Siris 
of 1744 - to the cosmos of secret sympathies and signs as the deep structure of human knowledge and production. ${ }^{236}$ This move did not advance conceptual understanding of creative activity as the core of human personhood. Just how are humans god-like in their thinking and doing? If God is all, is our creativity nothing? If our creativity is something, is God less than all? At the same time that the young Berkeley was finding his way to these questions, surpassing his own skepticism by a revolutionary line of thought but stumped as to the next question, a rather older scholar at the other end of Europe was more ready to take the next step.

\footnotetext{
${ }^{236}$ Siris has received unprecedented attention in the last decade. Matthew Holtzman's "Berkeley's Two Panaceas," in the Intellectual History Review (vol. 21, no.4, 2011), 473-495, puts Siris in context with the earlier works and gives a complete account of recent studies of the book.
} 
Chapter 6: Vico's Imagination

An ontology that replaced causality with perfect contingency in a cosmos directed by an active God offered two contradictory results for philosophical anthropology. On the one hand, humans are as inert as matter, like putty or puppets whom God activates and of whose affairs He is the doer. Humans would have had very little to think about in Berkeley's created cosmos were they not also spirits, beings in whom all ideas exist and without whom ideas, and therefore the world, do not exist. Ideas would remain the sole reality, God alone possessing them. But Berkeley tried to mediate God and humankind. That the mediating conception between heaven and earth is unfinished is the common state of Occidental philosophy, but that an active principle of human knowing and doing should fail to survive the unfinished metaphysics is a much more rare outcome. Berkeley considered humanity and reality to be in the closest possible epistemological connection, so this outcome is contrary to the aim of his ontology. His conception of humanity lacked realization of the force of time, or history, in the being of humans. Nevertheless, this vision of a perfectly contingent world in which human knowing and doing may shape what causality must do to our own utility, pleasure, and moral needs was a philosophical expression of Rococo effects in the arts. 
The second of the two conceptions that comprise the Rococo effect is one of the notions of history developed at the beginning of the eighteenth century. As in the case of the strain of thought about causality the previous chapter described, this notion of time was one among others that Occidental people were thinking out in this period. This notion, like that of causality, was neither characteristically Baroque nor Enlightenment, although it shared something with both. It was neither basically empiricist nor basically rationalist. Scientific ideas did not decisively entail it, though they were influential.

Nor did this notion deeply stand against the Enlightenment or any Enlightenments. The work this chapter considers, by the philosopher of history, language, and law Giambattista Vico, has sometimes been assigned to the "CounterEnlightenment." ${ }^{237}$ This term purports to name a describe a group of dissenters from Enlightenment optimism, progressivism, materialism, atheism, republicanism, and elitism, and from its physics, biology, sociology, and natural philosophy. Enough of a burden to be against several or all of these things; more than enough if one thinks of the very many versions of each of these; yet more when one recalls that the thinkers

\footnotetext{
${ }^{237} \mathrm{~A}$ recent discussion on the weblog Persistent Enlightenment has incisively discussed the question of the Counter-Enlightenment, beginning with this post: http://persistentenlightenment.wordpress.com/2013/10/14/counter-enlightenment1/. In The Legacy of Vico in Modern Cultural History From Jules Michelet to Isaiah Berlin (Cambridge: Cambridge University Press, 2012), 195-255, Joseph Mali discusses Isaiah Berlin's invention of the term and its relation to Vico in Berlin's work. Mali considers Vico to be "a man of the late Baroque" (155-157).
} 
of these thoughts were novelists, scientists, painters and everything else in addition to the philosophers; defeating enough to recall that they were English and Italians and Russians and Swedes and Americans, as well as French; poor as well as rich, protected as well as oppressed—all these considerations must disturb the proposed CounterEnlightenment just because they fragment the Enlightenment. Yet the "Counter" group likewise includes thinkers of deeply diverse natures, such as the blind rage of Joseph de Maistre, the humility and humor of Georg Hamann, and the pluriform genius of Giambattista Vico.

Vico's thoughts changed in fundamental ways from the period of his first philosophical work in 1710—not to mention his earlier published work, the seven commissioned academic orations of 1699-1707— to the first edition of his Nuova Scienza in 1725 and even in the third edition of 1744 at the end of his life. The initial positions he took in De Antiquissima Italorum Sapientia in 1710 seeded the Nuova Scienza, but reading them through the Nuova Scienza is not wise, though common enough. From 1710 to 1725 he advanced his thinking in the manner of a new form shedding the shell of its seed's husk. To understand the kernel the inquirer is best advised to examine it on its own ground. Although Vico's later major work superseded the earlier and although the three editions of the Nuova Scienza are the source of his great influence from about a century after his death ever growing 
through the present day, ${ }^{238}$ inquiry into the De Antiquissma is well worth while. In it one observes ideas noticeably set amid the late Cartesianism of Vico's youth. Also, one sees a line of thinking that, neither rationalist nor empiricist, appears in Rococo style and that, what is more, growing at an edge of the mainstream, represents some paths for the growth of conception that were not then taken but appears from time to time in Occidental culture. A part of studying an early work of a writer or thinker is to step aside or even to challenge a unified line of historical progress. ${ }^{239}$

${ }^{238}$ The current period of interest in Vico was proclaimed in Giambattista Vico: An International Symposium, edited by Giorgio Tagliacozze and Hayden V. White (Baltimore: Johns Hopkins University Press, 1969), a huge collection of contributions. Quite a few other collections of papers have followed. For a long survey of just one part of the literature unfamiliar to most Anglophone readers see Giuseppe Ricuperati, "A Long Journey. The Italian Historiography on the Enlightenment and Its Political Significance (1890-1990)," in Historiographie et Usage des Lumière, edited by Giuseppe Ricuperati, 232-260 (Berlin: Arno Spitz, 2002). Ricuperati concentrates mostly on the politics of the Italian Vico scholars in the 1970s.

${ }^{239}$ In what follows I rely on both of the two newer editions with translations: On the Most Ancient Wisdom of the Italians Unearthed from the Origins of the Latin Language Including the Disputation with the Giornale de' Litterati d'Italia, edited and translated by L. M. Palmer (Ithaca: Cornell University Press, 1988); and On the Most Ancient Wisdom of the Italians: drawn out from the origins of the Latin language, edited by Robert Milner and translated by Jason Taylor (New Haven: Yale University Press, 2010). The Palmer edition includes Italian and English texts of the two unsigned contemporary Italian critical reviews of the work and Vico's responsa, which are very helpful in understanding the work. The Milner and Taylor edition has a better Italian text and a somewhat better translation, although I strongly feel that both translations, badly fall short of Vico's style and meaning. They use English words that conform with standard modern disciplinary usage rather than words that give the reader Vico's range of connotation and historical reference.

My citations from this work, given as "De Antiq." use Vico's liber and chapter numbers followed by the page number from the first edition in parentheses where relevant, thus: De Antiq., VIII.3.127.

For the whole context of Vico's publication of this book, see Harold Samuel Stone, Vico's Cultural History: The Production and Transmission of Ideas in Naples 1685-1750 (Leiden: Brill, 1997), 184-195. On the authorship of the reviews see Barbara Ann Naddeo, Vico and Naples: The Urban Origins of Modern Social Theory (Ithaca: Cornell University 
The particular form of this problem that Vico's De Antiquissima presents are paradoxes in its line of thought, which appear as self-contradiction or as inconsistency. The truer view of them is that his thought was already cracking open its framework. Vico's use of words was imaginative. His work was at one time considered a wild, useless jumble. Different and contrary strains appear throughout the three Nuova Scienza editions corrected by Vico. Within his own counsels Vico's philosophical temperament must have been many-colored and ever-changing, rapid rather than slow as the decades of interval seem to us to be. The text of De Antiquissima seems to fragment as it moves from long earlier blocks to short shards toward the end.

Vico works through two problematics in this book. The one this chapter first concerns is his move toward understanding that all analytic ideas, such as those comprising mathematics, are historically conditioned. He starts by arguing that they, the model of human cogitation, reveal truth. He ends by stating that both God and fortuna, co-operating in "the conservation of the universe," governs thought. ${ }^{240}$ The second problematic concerns language. In 1710 Vico thought about language

Press, 2011), 90, n. 155. A neglected part of Vico's life in Naples is explored by John Robertson, "Political economy and the 'feudal system' in Enlightenment Naples: outline of a problem," in Peripheries of the Enlightenment, edited by Richard Butterwick, Simon Davies, and Gabriel Sànchez Espinosa (Oxford: Voltaire Foundation, 2010), 65-86. Vico’s autobiography is rather a different subject for investigation than Vico's actual life, q. v. Donald Phillip Verene, The New Art of Autobiography: An Essay of the Life of Giambattista Vico Written by Himself (Oxford: Clarendon Press, 1991).

${ }^{240}$ De Antiq., VIII.3.127. 
according to traditional classical philology. In 1725 Vico thought about language: as

an historical agent in cognition, as human creativity, as the matrix of myth, and as the constitution of culture. This enormous development of philology lies deep within his early work. The old orientation toward language was the shell he discarded during fifteen years labor. Although De Antiquissima addresses a field narrower than culture, tacked down by the metaphysics of punctum and conatus, this text shows part of the deep structure of Vico's later achievement. ${ }^{241}$ It also shows deep movements of conception that led elsewhere, into other values and expressions productive in the neglected territory between Baroque and Enlightenment.

Vico's first words state the most famous and controversial idea in the book. ${ }^{242}$

${ }^{241}$ For Vico's contributions to the philosophy of language, see David L. Marshall, Vico and the
Transformation of Rhetoric in Early Modern Europe (Cambridge: Cambridge University
Press, 2010); and Jürgen. Trabant, Vico's New Science of Ancient Signs: A Study of
Sematology, translated by Sean Ward (New York: Routledge, 2004.).
${ }^{242}$ Vico discusses the verum/factum principle in the "First Response" ("Riposta Prima") in On
the Most Ancient Wisdom, ed. and trans. L. M. Palmer, 122).
The debate over the verum/factum principle began early in Vico studies and arises in
the debate as to whether Vico's ontology is realist or idealist. Of course in one way it is each
and in another way it is neither. My line of argument here is that it is grounded more in
idealism similar to Berkeley's than in "scientific" realism or strong naturalism. In addition,
the argument of this thesis is that by using arts of the period to illuminate the work of
Berkeley and Vico we come to a richer and more nuanced understanding of the work of these
philosophers, of early modern idealism, and of the revolution in eighteenth century
philosophy of history, just as we often learn more about the arts of a period when we
illuminate them by contemporary philosophy.
Sandra Rudnick Luft, "Embodying the Eye of Humanism: Giambattista Vico and the
Eye of Ingenium," in The Discursive Construction of Sight in the History of Philosophy,
David Michael Levin, ed. (Cambridge: MIT Press, 1997), 167-196, vigorously argues that
Vico's concern was not ontological at all but rather was wholly epistemological. So far as I
know she is alone in taking this contrarian position.
The most accurate and insightful writing on the verum/factum principle includes: the 
For the Romans verum and factum reflect [reciprocantur] one another or, as the technical vocabulary of Schools has it, they both completely change into one another [covertuntur]. ${ }^{243}$

Vico adopts this proposition as his own. His usage of "verum" throughout refers to true knowledge of the world rather than to truth or the real world itself. Factum, then, also refers to knowledge but from the point of view of any agent who creates an object of knowledge. That agent can have most truthful knowledge of any selfcreated object of her knowledge. The relation between truthful knowledge and the creation of objects of knowledge is intimate, almost inexpressible. Vico's Latin words denote a binary identity structure, but this structure is kinetic rather than dialectic. It moves solely in one direction: creation comes first, then knowledge; no perfectly knowing something without having created it. This particular kind of knowledge is one among other kinds of knowledge, but it is the one that yields complete truth and is therefore the one in which Vico is chiefly interested.

This claim takes Vico to the following conclusion:

first chapters of Nicola Badaloni, Introduzione a Vico (Bari: Laterzi, 1995), generally considered the best comprehensive account of Vico's philosophy; Nikhil Bhattacharya, "Knowledge 'Per Causas': Vico's Theory of Natural Science," inVico: Past and Present Giorgio Tagliacozze, ed., (Atlantic Highlands, NJ: Humanities Press, 1981), 182-197; John Milbank, Religious Dimension, 77-113; James T. Morrison, "Vico's Principle of Verum is Factum and the Problem of Historicism," in the Journal of the History of Ideas, vol. 39, no. 4 (October-December, 1978): 579-595; David R. Lachterman, "Mathematics and Nominalism in Vico's Liber metaphysicus," in Otto and Viechtbauer, eds. (see next item), 47-86; Stephan Otto, and Helmut Viechtbauer, eds., Sachkommentat zu Giambattista Vicos Liber metaphysicus (Munich: Fink, 1985); Tom Rockmore, "A Note on Vico and Antifoundationalism," in New Vico Studies, vol. 7 (1989), 18- 27; and Nathan Rotenstreich, "Between Participation and Constitution," in Otto and Viechtbauer, eds., 87-98.

${ }^{243}$ De Antiq., I, 14, following the proem. My translation. 
...thus the human mind can think about things, but it cannot understand them; and this is why it is a participant [particeps] in reason, but is not the constitutor [compos] of reason. ${ }^{244}$

The human way of understanding reality is like seeing a flat image (imago plana) such as a line drawing (monogramma...pictura). ${ }^{245}$ At the beginning of the chapter Vico began to define the possibility of truthful knowledge, and yet here he finds that human knowledge falls dramatically short of the completely truthful. Divine truth, which he calls plasma, is multi-dimensional, capacious of everything in reality. It is the exactissimum reale verbum, eternally existent. ${ }^{246}$ In one sense the opening here straight to the heart of the Nuova Scienza is very wide: if there is anything that humans make, humans can have such knowledge of these things that their knowledge alters the way they make them. But in another way there is no opening, for God created the universe and innumerable worlds, leaving nothing for humans cognition except outlines—charcoal or lead or crayon, thick or thin, color or black—which, in any case, are very much like shadow of true light. He is in the same difficulty we left Berkeley in, having arrived at it by a different route.

Vico then slowly blurs the gap between our epistemic status and God's in the next chapters. ${ }^{247}$ Humans do create mathematics, the operations of this science taking

\footnotetext{
${ }^{244}$ De Antiq., I.15. My translation.

${ }^{245}$ De Antiq., I.16.

${ }^{246}$ De Antiq., I.18.

${ }^{247}$ De Antiq., I.1.22-23.
} 
place in our inner world or universe. ${ }^{248}$ Our method of creation is division: hacking things up to put them together in different ways, enabled by notional infinitesimality.

But he goes no further, for as to the external world all our other practices, from mechanics to ethics, are less and less certain. Since it is the best we have, mathematics is the model for our thought. ${ }^{249}$ Its objects are the products of our thinking, they are our creations. We best think by beginning with what we create because we know it best. The objects of mathematics are not the objects of nature, but we nonetheless use them to understand nature. Our understanding of nature is at its root our endogenous creation. Vico therefore regards them as uncaused causes, creating out of nothing as God did. In this way our mathematical ratiocination ought to be considered proof by causes, which conventionally it is not, because the immutable forms of which it treats are the ultimate causes of things. ${ }^{250}$ Relying on metaphor, he goes to pains to justify the powers that our mathematical forms pick up from divine power by being in one respect in the same class of things, and it is a near thing. ${ }^{251}$ But it enables Vico to call them essences and to regard them as forces. ${ }^{252}$ His recognition of the human creation of mathematics will shortly have a dramatic consequence.

\footnotetext{
${ }^{248}$ De Antiq., 1.23 ("universum intra se complecteretur").

249"First Response," in On the Most Ancient Wisdom, ed. and trans. L. M. Palmer, 128.

${ }^{250}$ Bhattacharya, “Knowledge," in Tagliacozze, ed., 190, says that creation by the truths of logic and mathematics is ongoing.

${ }^{251}$ De Antiq., III.51.

${ }^{252}$ De Antiq., III.3.49, IV.53.
} 
Entering into the body of his fourth chapter, Vico takes up the principal concept with which he liberates his notion of verum/factum. ${ }^{253}$ This is his notion of movement (momentum, movendum, or motus). When an agent creates a thing, the object of its creative force is in a state different from that in which it was before or during creation. Creation's products are "real," which means that they are sensuously perceived and received as ideas, or this would not be creation; in philosophical terms the objects of creative force are extended. Extension is inherently other than what is impeded from extension. Therefore the effort of existent things to pass impediments to their existence finished when their creator caused them to be. What happens to them thereafter is movement and the causes and effects attached to each movement, that is, of other acts of creation. ${ }^{254}$ Groups of creative acts are known as histories, or history.

Another way to put this is to think of time as continuous motion rather than as a series of points (puncta), each of which employs an internal spring (conatus) to advance to the next point. Vico argues that to hold that the punctum is a body at rest and to hold that while at rest it communicates motion to another body is a contradiction. Extension is continuous, not communicated, motion. Insisting on consistency in applying the notion of extension, Vico shifts discourse from the

\footnotetext{
${ }^{253}$ De Antiq., IV.1 includes a long argument against the Zenonian paradoxes of motion and change.

${ }^{254}$ De Antiq., IV.2.74-78.
} 
infinite divisibility of realia into points and toward a more pure notion of continuity or momentum. He detaches the infinitude of points from an infinitely divisible reality because such reality is without sufficient reason for existent objects. It could not be extended, only thought. What is more, as in Berkeley, the mechanism of divisability must fail if anything is to happen or to move, and the impediment to stasis by divisability posited as conatus, explaining nothing, does not suffice to move a point. ${ }^{255}$ Only reality in motion, or motion itself, suffices to do so. One cannot explain motion by rest; rather one must dig into understanding motion on its own terms, for "Natura est motus" ("Nature is movement"). ${ }^{256}$

It is little noted that Vico's point, characterized as quasi-vitalism or, more correctly, as true diachronesis, links mechanistic philosophy with combinatorial arts and rejects them both. They both require secret forces, much like the occult sympathies of the Renaissance. He applies this to Kircher as well as to Leibniz, ${ }^{257}$ and it is reasonable to think that he was also thinking of Giovanni della Porta (1535-1615), an immense personage in Neapolitan science, as well as of other Baroque esotericists.

What does our perfect intelligence of mathematical forms have to do with the ceaseless motion of physical nature, given that we are incapable of God's really

\footnotetext{
255“Second Response," in On the Most Ancient Wisdom, ed. and trans. L. M. Palmer, 171-172. ${ }^{256}$ De Antiq., IV.2.77.

${ }^{257}$ Refs
} 
truthful knowledge? Although Vico is very positive in his claims, he was to spend the rest of his life thinking about this issue with increasing perspicacity. ${ }^{258}$ Towards the end of De Antiquissima he starts to find a thread that will lead him further out of the Baroque maze. By way of answer he says that the senses lead (condit) perceptions into memory (memoria), within which remembering (reminiscentia) moves them forward (promit) into the faculty of imagination (facultas imaginitiva). Both remembering and imagination are parts of memory—for the moment. Vico still seeks an active but accurate and obedient faculty for human creativity. This faculty must be independent of God, since it is faulty and pertinent to us, and nonetheless must be also capable of controlling or at least influencing physical nature. It must be a power pertaining to human nature, the capability of which he is still struggling to pinpoint.

On the very next page he finds it. He calls it ingenium. There are two types of ingenium, both described by metaphor: the acute type, which more quickly joins (unit) at acute angles; and the obtuse type, which more slowly does the same joining but at obtuse angles. Vico's surface notions are geometrical, for ingenium is used by engineers and anyone employing mathematics. ${ }^{259}$ But the necessity that drives Vico to this notion in this chapter is more demanding than he so far had recognized or admitted. Unire, to unite, is a word of vast implication in philosophy, far vaster than ${ }^{258}$ Cf. Paolo Fabiani, La filosofia dell'immaginazione in Vico e Malebranche (Firenze: Firenze University Press, 2002), 43-54, describing Vico's argument against the "univocity" of empirical claims.

${ }^{259}$ De Antiq., VII.3.106. 
the traditional concepts of geometry, for to unify is to create anew, or to synthesize. The aim of understanding human creativity, which after all is the reason to look for the deepest, earliest source of wisdom, as Vico purports to do in this book, escapes the conceptions he then had at his disposal. He has to connect the human ownership of mathematics to the divinely-inspired human creation, which is larger than mathematical reason comprehends. He must subordinate mathematics and logic to a different human faculty that they depend on—a faculty by which human create mathematics and logic and is therefore precedent to them both in time and in power.

To explain ingenium is to pull something out of mere memory. For if ingenium is an intellectual faculty working on the perfect model of mathematics and if it successfully adds to knowledge as time progresses, it follows that the human agent, unless she is merely mechanical, is inventing mathematics—-that the mathematics we have and use is a product of progressive historical processes. Amid the tangle of his words and ideas Vico becomes very clear for a moment about the conditions in which our intelligence actually operates.

Really, if you plugged the geometric method into actually doing things in life, "you would do nothing more than take on the job of driving yourself into insanity by reason" and thus you would lead yourself right through the messy [anfractus] course of human life just as if desire, foolhardiness, chance and circumstance did not reign in human affairs. ${ }^{260}$

${ }^{260}$ De Antiq., VII.5.110. The quotation is from Terence, Eunuchus 62-63. 
Soon he adds that events perturb language like a catapult, ${ }^{261}$ and then for pages and pages lays out an historicizing theory of ingenium. Aristotle is useless, and so is Descartes, for syllogisms are locutions several times removed from reality; and the method of them gets in the way of ingenium, which does not merely react to information with words but industriously makes events as well as things. ${ }^{262}$ Its "eye" is imagination. ${ }^{263}$

Vico has decided that although mathematical thinking claims logical precedence over other thought it is not prior in time. It is our most effective tool, but it speaks only of itself and tells us nothing of how we came to know this tool, of how we have used and not used it, and of how we use various kinds of thought in combination with it or without it, against nature and with nature, to destroy and to build. This is story of the origin in time, rather than in logic, of knowledge and, even more importantly, of the communication of knowledge. ${ }^{264}$ By the time of the first Nuova Scienza, Vico declares that "Subservient to the divine architect, the artificer of

${ }^{261}$ De Antiq., VII.5.111-112.

$262114 \mathrm{ff}$

$263121-2$

${ }^{264}$ Gaukroger, "Vico" makes the normative empirical case against Vico's claim that the maker's knowledge of the object she made is different from natural knowledge of that object or of the world. For Gaukroger only one kind of knowledge is "necessary." Another line of recent critique is Maurizio Ferraris, Documentality: Why it is Necessary to Leave Traces, translated by Richard Davies (New York: Fordham University Press, 2013), 131, claiming that the whole idea of social or historical knowledge is defeated by its inherent uncertainty. That we can have certitude about human affairs is "an idea denied by the fact of controversy among historians and by the general lack of transparency in the social world." 
the world of nations is human will."265

The story of how and why Vico's struggle in De Antiquissima led him to organize a philosophy of history around the common sense of humankind and the laws of nations and of how this philosophy developed in the three editions of his great work is beyond the scope of this thesis. There is, however, one further conception relevant to Rococo style in his later work. In the first edition he holds that the developmental order of conceptions expresses the immutability and universality of the natural law as human collectives discovered it in the conflicts of good conscience with deeds. ${ }^{266}$ He stresses the universality as revealed in the concept of law and therefore in its history. By the third edition, nearly two decades later, he describes the diachronic accumulation of truthful thought, or wisdom, as the result of a process he calls universali fantastici ("imaginative universals"). ${ }^{267}$ These are our accumulating, rectifying, improving, growing, wise, cognitive conceptions. Imagination is now a real force, of which memory and ingenium are no more than parts, that is adequate to represent the full and best use of our faculties. ${ }^{268}$

Under Leibnizian Baroque harmony the divine plan administered itself to each

\footnotetext{
${ }^{265}$ De Antiq., II.3.47.

${ }^{266}$ E. g., De Antiq., II.5.55.

${ }^{267}$ The New Science of Giambattista Vico, edited and translated by Thomas Goddard Bergin and Max Harold Fisch (Ithaca and London: Cornell University Press, 1988), sec. 934-935.

${ }^{268}$ Leon Pompa, “Imagination in Vico," in Tagliacozze, ed., 162-170, however, disagrees, reading Vico as giving a minimal role to imagination, or at least more minimal than many scholars see, because Vico does not hold imagination to be a form or ground of knowledge.
} 
individual, none of which communicated it to any of the others and each of which executed the plan by means of the inner spring called conatus, which in turn used apperception to advance its energy through its internal parts. Each added to the others made the whole, and each class of monads piled on top of the next weakest class all the way up to the top, above which God, having ordained the whole history of all these individuals, had no need of additive action. The principle of the hierarchy was anagogical; the matter subject to anagogy was mined by infinitesimal division and therefore was infinite. The ars combinatoria was a kind of interface with this infinity, by which the power of infinity was transformed into secret networks of sympathies that a human mind might explicate and manipulate. Nonetheless, infinitude was in truth not controllable. It outran all volvelles, all typography, all mechanism. Humans next make yet more clever and more complicated machines to catch up and catch hold.

In the seventh chapter of De Antiquissima Vico most emphasizes his critical analysis of dividing and joining. Seeking a wider understanding of unire, he thinks it must be less like merely abutting things and more like synthesis, renewal, or creation. Clear and distinct ideas do not suffice absent the context of everything the agent does to form or attain them. Universali fantastici are part of Vico's solution to the insufficiency of logical division and the fruitlessness of ars combinatoria. Vico tended to regard division as attrition and decay. In De Uno Universi Iuris et Principe Uno of 
1720, he opposes the simplicity, flexibility, and goodness in the created order to the vitia of division, pulling apart, and corruption. ${ }^{269}$ When the vicious forces pull individual things apart, ingenium uses the divine qualities to conserve the collectives of things. Later, in 1725 , it is collectives, which he calls nations, that mediate the providential plan through universali fantastici. The plan is perfect and as a predetermining order does not change nor is its coverage other than universal. But all the immutability is of the infinite God, with whom humans seek to unite themselves. ${ }^{270}$ The human relation to God through conscience leads to people cooperating with one another in corporate cognition and invention.

Like Leibniz and the Baroque synthesis generally, Vico held that the universe is conserved and that God does the conserving. Like Hobbes, Leibniz, Spinoza, and others, Vico held that the mathematical (or geometric) method produced the most God-like knowledge or, at the least, the most useful results. But he made a crucial change of aspect. For Leibniz and the others God's knowledge and will actively constrained human knowledge and will. Truth, as it were, mugged human deeds. For Vico truth, being God's and not ours, is not a boundary that stops our search for knowledge. The nature of human temporal doing is to follow the conserving power of providence. This is a creative power pertaining to ${ }^{269}$ De uno, VII. The section numbers in De Uno are standard in all accurate editions. The edition I consulted is vol. 1 of part 2 of the Opere edited by Fausto Nicolini (Bari: Laterza, 1968). Part 2 is in 3 volumes comprising all Vico's writings on legal theory.

${ }^{270}$ De uno, XI. 
human action in time.

Towards the beginning of this discussion I quoted some of the words Vico used to try to express his conception of human knowledge. In one section of De Antiquissima, he used the two verbs reciprocare and convertire, used in the reflexive voice, in to express relations of strong similitude that fall just short of identity. He uses the two nouns particeps and compos to describe a position of participating in but not controlling a faculty or process. The verbs come from the technical lexicon of Scholastic philosophy and name the action linking verum and factum. While scholars endlessly shift the semantic ranges of verum and factum in order to understand Vico's use of the principle, they ignore the verbs. Vico's two nouns add a dimension to the concept, particularizing it from a different angle. Without trying to reconcile the verum/factum principle with all of Vico's thought, leaving it as a term relative to the successive stages of his philosophical development, we are now in a position to see that, whatever sociological, ontologically realistic, or materialist and atheist turn his thinking eventually took, the principle of 1710 expresses a pool of conceptions that was larger than it alone supported. ${ }^{271}$ Vico imported it from the schools in his first step to understanding.

\footnotetext{
${ }^{271}$ Lachterman, "Mathematics," in Sachtkommentar, edited by Otto and Viechtbauer, does a good job of situating Vico's early ontology in the rest of his work. He would argue that Vico holds mathematics in greater regard than I have allowed. See also his Ethics of Geometry: a genealogy of modernity (New York: Routledge, 1989). James Goetsch, Vico's Axioms: The Geometry of the Human World (New Haven: Yale University Press, 1995) approaches Vico's "geometry" by way of his rhetorical and philological theory.
} 
The verum/factum principle leads to two novel conceptions: first, that humankind's self-understanding has an unfolding, unceasing developmental history; and that from within this history it drives our intellectual, artistic, and social creativity. This conception limns a portion of the movement of ideas during the first quarter of the eighteenth century that ought to be understood on its own. As Vico's first great step, it represents rejection of the infinitely deep and distant cosmos of the Baroque, although Vico shared a good deal of the Baroque sense of tragedy. It also represents caution as to Enlightenment naturalism along with faith in progress.

It also requires some sense of the import of human self-understanding beyond all local moments. The content of this transcendence was wide open to everything from theism to positivism, as it almost always has been throughout Occidental history. The options have different specifications that the lexicon of philosophy is competent to supply along with proper full differentiations even among the nearest variations. In the early eighteenth century these options included vitalism. Vico, though he did endeavor in the first Nuova Scienza to view human intelligence in a global conspectus, ${ }^{272}$ was not a vitalist, though perhaps not far from one. The most prominent vitalist, Georg Ernst Stahl (1660-1734), invented the word "synergy," which is a notion Vico does seem to come close to as he tries to invent a new synthesis among concepts in tension with one another.

${ }^{272}$ Cf. Vico, The First New Science, II.1, 4, 5. Division by book and chapter is standard in all accurate additions. 
Esotericism was another form this impulse took, especially later in the eighteenth century. ${ }^{273}$ Vico would have rejected it just as he rejected conatus, but to the modern naturalistic mentality any kind of cognition other than what we call scientific is as bad as outright occultism. ${ }^{274}$ This reaction helps mark the distance between the conceptual field around the verum/factum principle and what we call the mainstream of the Enlightenment. It is not retrograde, either: the discourses in the later history of ideas that it suggests are much more like phenomenology, or structuralism, or some kinds of Marxism than it is like absolute idealism, romanticism, or perfectionism of most kinds. ${ }^{275}$

Yet it is not entirely distinct from all these things. They became what they were through the circumstances of the growth of conception amidst human deeds in the centuries since the time of Vico. To see this principle, that of a non-rationalistic creative, dynamic order in human agency, whether it is artistic, scientific, social, or moral, on its own, apart from polemic and from the winning tides, apart even from Vico, is to try to grasp in its full particularity the conceptual side of the singular moment of artistic production I call Rococo style.

By defending divine creation and divine providence Vico maintained his

\footnotetext{
${ }^{273}$ See Peter Reill's interesting paper "The Hermetic Imagination in the High and Late Enlightenment," in The Super-Enlightenment, edited by Edelstein, 37-52.

${ }^{274}$ This would be Gaukroger's view.

${ }^{275}$ Rotenstreich, "Between Participation and Constitution," in Sachkommentar, edited by Otto and Viechtbauer, compares Vico's philosophy of history with Kant's.
} 
orthodoxy for many of his contemporaries and for some of his modern readers. In reading his shiny rhetoric and following his relentless inquisition of the classical tradition, making it his very own, it is impossible not to sense originality that stops at nothing. Consequently he appeals to the modern mind, from the renovation of historiography by Michelet and his successors in accounting for the French revolutionary upheaval of the whole old order of Europe to the novels of James Joyce. ${ }^{276} \mathrm{He}$ appeals to the post-modernist mind as well, for us in the first instance through the work of the philosopher of history Hayden White but also in work from many hands in the last two decades. They appreciate his antifoundationalism.

In the place of Cartesian foundation he put the principle that human invention makes all the truths that humans can best know. Composing the truth is a God-like faculty. His notion of human knowledge expands within a God-created world, although he invested human minds with a purpose and scope so greatly grown that they could go far on without much of God right at hand. The hint of the Godlike being too great a provocation, other philosophers have closely analyzed and defeated the verum/factum principle. The conception that we have a special knowledge of what we make is both profoundly dear to modernity and, in a sense, to peoples at all times and profoundly alien to a scientistic age.

Yet the study of history, if it is anything at all, is a means of understanding

${ }^{276}$ See Mali, Legacy; and the same author's Mythistory: The Making of Modern Historiography (Chicago: University of Chicago Press, 2003). 
that specific relation humans have to their objects and events that we call meaning. The narratives of deeds and inventions report meaning from historical time, and it is in time that they create their meaning. This is the most universal interpretation of Vico's principle. Thus, too, its ambiguity, inadequacy, the unresolved issues around it that are suspect to analysis. Vico himself was suspicious and critical: the Nuova Scienza both abandons it and develops it. It might appear mere psychology or ardent feeling to us, and yet that is not how one ought to try to understand history. In this way the conception stubbornly defends itself. At the least it tells the truth that there is something to be understood in human thought that ought not to be reduced.

For Vico in 1710 the conception that human life is a matter of making a world for humans, guided by God, struggling to build safe homes, enfolded in itself yet animated, and due to virtually boundless imagination was not the thought of others. It was not the Baroque deadly infinite gushing from the infinitesimal depths of causation. It was not the world of reason the vanquisher of myth nor the world of reason in fear of nature. It was a conception somewhere apart from these worldviews but also somewhere in the middle of them. Some part of the Occidental mind in these times was taking a tough look at laws, natural or positive; at its own hunger for animation and circulation of ideas, things, feelings, money; and at the issue of moral constraint. We are poets at heart just as we are scientists at heart, inventors as well as cognizers, deeply unconscious in our motives as well as pinpoint planners, and 
language-speakers as well as concept-reasoners.

While maintaining divine creation and power, Vico massively invested human knowing and doing in the social and material world, which is full of our ideas of things in motion and made actual. Our myths do not encumber it, in Vico's view, the opposite of that of Benjamin. Instead they are the start of our liberating ourselves from them, from misconception, and from the ideal origins of our thinking, such as mathematics. Mathematical rationality is for Vico like the myth of Zeus. Vico notes the particular way we use myths and maths—-to overcome themselves, like strong staffs we swing on over obstacles and dangerous drops or like strings we swing along as if relying on the clouds in heaven to hold the other end while we move from one place to the next and better place in our mundane adventure. We are therefore, in Vico's view, strong upon the earth, sustained by God in our continuously and freely creating a world both richly material and rather fantastical. In Vico's ontology the passage of time - the substrate of history—replaced intrinsic causality. Temporal causality could be regular and lawful, but regularity and law were not of its essence. History is more battles raging than clocks ticking; and order fades by each of its selfaffirming products, ebbing at the moment it is full. For all its splendor, Rococo style rides on a deep structure incorporating awareness that the liberty it uses is passing, always passing; and that perhaps the utilitarian approach to knowing and doing is the least useful of all approaches. 
Chapter 7: Rococo Ontology

The project of this chapter is to construct some of the general claims about the nature of existence that are to be discerned in the milieu of Rococo production by looking at the ontologies of Berkeley and Vico as I have described them in the two preceding chapters, in connection with one another. Conceptions help us to understand production, and production to help understand conceptions: this is an interdisciplinary intellectual history. Ideas of the most immaterialist sort and objects of the most sensual sort help to explain the passage of culture from Baroque to Enlightenment from around 1690 to around 1750.

Before hunting the ideas, I suggest the reader bear an artifact in mind. It is the undated image of an "ornament" conceived and drawn by Meissonier (figure 8). He could have made this design at almost any time in his adult life, but it probably dates from the period after he became a master goldsmith in 1724 and after appointment as designer for the king's bedchamber and cabinet in 1726.

The drawing depicts something that could be used in the decoration-called enjoliment ${ }^{277}$ —of almost anything: beds, sconces, wallpaper, snuffboxes, consoles,

${ }^{277}$ This concept covers the whole place and work of decor in French society. For its social and material sides, see Hyde, Making Up, 86ff., who describes enjoliment as a practice of vanity and worldliness; and Sargentson, Merchants, 12ff., 23ff., and throughout, who gives a marvelously detailed account of the artisanal work that went into organizing production, the 
sofas, desks, etc., by means of most crafts, such as woodcarving and porcelain manufacture in addition to metal work. Every medium, one supposes, can present this shape. Curves and concavities comprise the form. These suggest raffle-leaves and flames, but they leave the viewer in no doubt as to the man-made nature of the motif and therefore of any object it adorns. One may say that the "material" is rocaille: that is, that it is an invented image derived from a certain set of concepts, is not fully determinate as to whether it is organic or inorganic, gives the appearance of internal driving force but is vague as to the nature of this force, and is fully realized in the viewer's mind as capable of being made of many sorts of matter. Although it has movement and depth, it appears unsupported and uncaused. It is active but not selfexplanatory. Its position in space on the sheet and as installed on any manufactured object is atectonic. Would it stand up or topple over? The lines on the sheet imply both outcomes. The thing could be organic or mechanical or inorganic; the truth is concealed. More generally, it is a picture of contradiction and combination. The lobes and the swirls of the design are congruent and nested, but they also barely touch. The elements might either fly apart or merge into one vortex. What kind of being is this? What view of reality, from the cosmos to what one can hold in one's hand, does this express?

This image and many like it that have the Rococo effect are among other

designing, and the assembling of wares. 
things visual explorations of issues of human knowing and doing then current in philosophy, such as the deep structure of reality, movement and change, the nature of organic life, human knowing and making, and the relations of humans with nature and with God. Berkeley's immaterial idealist conceptions of divine creation and Vico's diachronic understanding of human creativity, both resulting in radical critiques of causality and construction of the world as pure contingency, express the production of signs adequate to the abundance of reality tamed by a measure of free human self-indulgence. In Chapter 8 we shall see how these elements of the notion of continuous creation became part of a way of animating reality called Rococo style.

Bishop Berkeley and Giambattista Vico each published his first major work in 1710 and his last in 1744. Both men pursued lines of thought eccentric to the mental orbits of the day. Their heterodoxies had important points in common, though they lived in different cultural milieus within Europe. ${ }^{278}$ The courses of their intellectual growth seem very different. Berkeley began with an upending critique of contemporary thought and ended by reversion to a kind of Renaissance gnosticism in the Siris. Vico began as a renewer of philology and ended as a revolutionary relentlessly focused on re-interpreting antiquity and re-founding philology. Of course each pursued his own continuous lines of thought: both, with roots in the whole history of philosophy, rolled out bodies of thought that in truth were so potent

${ }^{278}$ Berkeley, as mentioned above, lived for four years in Rhode Island and lived in London for several periods. Vico never left Naples. 
that they startlingly confound our notions of reaction and revolution. They forcefully moved between what seem to us to be opposite poles. This is one of the reasons on account of which much of modern thought regards their concepts as confused and archaic, though other moderns find prophetic powers in their work. In the end the reason they are not more often associated with one another is that it is easier to find their disagreements or their agreements with us than to discern the complicated ways in which they were in agreement, though from different philosophical standpoints, with some part of their own times.

One value of such discovery is that it calls into question the modernity of any period that reflects on the past through intellectual history. When we see conceptions in one or more of the times in which they arise and in one or more of the ways in which they do so-from among many moments and many ways for each idea—we see them in more basic condition than that in which we have to think of them knowing what we know and having experienced what we experience. An historically embedded conception is, oddly, often more rawly logical than the roughly "same" conception taken in the context built out of our many beliefs, reasons, desires, and motives. We cannot of course remove our minds from our times, but we can deepen the angles of conceptual understanding to some degree through original context, just as logic pure of context also does to some degree. But to confine "original context" to language or to social conditions, and especially to make one of 
these the critical ontological factor, results in missing some of the most profound understanding that intellectual history affords us. I refer to the moral life of persons and societies, to the dilemmas they face and to their choices, all regarded as the experience of moral forces and moral deliberation. Moral deliberation extends from the most abstract ways of thought to final choice of action. To find meaning in historical time is largely a matter of bringing to life the moral dilemmas compelling a line of conceptual growth in one of its contexts precedent to our own state of mind.

Berkeley stands at the start of modern idealism, which produced the fundamental conceptual structure of all cultural theory. Vico stands at the start of modern historiographic thought; Vico and Montesquieu together are arguably the founders of the social sciences. The two great driving lines of thought Berkeley and Vico launched in 1710 meet and separate in complex ways over the subsequent three centuries. But the only attempt I know of to bring the two into one philosophical conspectus is the claim on them made by Ernest Glaiserfeld (1917-2010), one of the most important social constructivist researchers, as the joint fore-runners of constructivist theory. ${ }^{279}$ The principle of his "radical constructivism" is, in his words, Radical constructivism, thus, is radical because it breaks with convention and develops a theory of knowledge in which knowledge does not reflect an

${ }^{279}$ Glaserfeld's best exposition of his history is in "An Introduction to Radical Constructivism," in The Invented Reality: How Do We Know What We Believe We Know?...., edited by Paul Watzlawick, translated by the author (New York: Norton, 1984), 17-40. For some of his other writing see Key Works in Radical Constructivism, edited by Marie Larochelle (Rotterdam: Sense, 2007). 
"objective" ontological reality, but exclusively an ordering and organization of a world constituted by our experience. The radical constructivist has relinquished "metaphysical realism" once and for all, and finds himself in full agreement with Piaget, who says: "Intelligence organizes the world by organizing itself." 280

In his role as predecessor Vico was not to be an ontological realist. Rather, Vico's contribution was to constitute knowledge as human production, specifically as "awareness of the operations that result in our experiential world."281 Glaserfeld's claim on Berkeley is rather more lightly made because Berkeley mentions divine providence with more conviction than Vico seems to Glaserfeld to do. Berkeley held that even though our knowledge represents no reality separate from our selves it nonetheless is stable by virtue of its internal construction as given and then guaranteed by God. To Glaserfeld's attempt to make an origin-story for constructivism it was indispensable for Berkeley to have argued that a knowing being is as much a being as a known being. It is no limitation in social constructivism that we are always and ever subjective cognizers because being is nothing other than subjectively cognizing constructive mental acts.

Starting with Jean Piaget (1896-1980) and Paul Valéry (1871-1945), constructivism was a beneficiary of one of the ways in which idealism and the human sciences twisted together from the very late nineteenth century into the full rearing of modernism. Phenomenology was another. But both Berkeley's and Vico's

\footnotetext{
${ }^{280}$ Glaserfeld, “An Introduction," 5.

${ }^{281}$ Glaserfeld, “An Introduction,” 8.
} 
philosophies, like phenomenology or constructivism, drive a road between, around, or over ontological realism. To the extent to which any compromise with the pure materialism of the scientific method, or even with scientific method constituted with emergent physicalism, must be defeated by strict understanding of scientific method, both Berkeley and Vico are poor candidates for any theory claiming to be scientific, as constructivism does. ${ }^{282}$ Even long after the rejection of crude positivism, the only way to save them for science (thus construed) is to hold that Vico was actually a realist. In this case it is hardly possible to associate his ideas closely with Berkeley's.

Yet a link lies between Berkeley and Vico that reveals one neglected side to

\footnotetext{
${ }^{282}$ Two more recent attempts to develop Glaserfeld's notion are Rebecca Collins, "An Ontological Constructionist Interpretation of Vico's Philosophy of History," in New Vico Studies, vol. 22 (2004): 33-47; and Thomas Erling Peterson, “Constructivist Pedagogy and Symbolism: Vico, Cassirer, Piaget, Bateson," in Educational Philosophy and Theory, vol. 44, no. 8 (2012): 878- 891. Collins discusses verum/factum along with an interesting study of storia/istoria in Vico, but in the end her argument for a constructivist reading of Vico is that such reading suits constructivism. Peterson gives a larger than usual account of the twentieth-century context of constructivism, and the article is particularly noteworthy for discussing Gregory Bateson (1904-1980), one of the most under-appreciated thinkers of the last century. But it is not a close reading of Vico. Both papers discuss the Nuova Scienza but do not discuss De Aniquissima. This is a particularly unfortunate gap in Collins' paper. Michael R. Matthews, "Constructivism and Science Education: Some Epistemological Problems," in the Journal of Science Education and Technology, vol. 2, no. 1 (1993): 359370; and W. A. Suchting, "Constructivism Deconstructed," Science and Education, vol. 1 (1992): 223-254, are sharp critiques of the historical claims of Glaserfeld's constructivism. Another thoughtful approach to constructivism is Carla Bagnoli,"Constructivism in Metaethics," in the Stanford Encyclopedia of Philosophy, online at: http://plato.stanford.edu/entries/constructivism-metaethics/.

Bertil Belfrage, attempts to read Berkeley as a radical constructivist in "Berkeley's Way Towards Constructivism,” in Berkeley's Lasting Legacy: 300 Years Later, edited by Timo Airaksinen and Bertil Belfrage (Newcastle Upon Tyne: Cambridge Scholars Publishing, 2011), 3-14.
} 
their times—a link that is part Baroque and part rejection of the Baroque, part Enlightenment and refusal of it, and is also a complication inside some of the founding inheritances of modernity. This is a link between ridiculously counterintuitive concepts—-that human ideas is the only stuff that exists and that humans make rather than find the only truth there is—and artistic production that was almost absurdly carnal and prolific. This art looks like ordinary flesh, but it suggests an extraordinary idea of reality. Both this body of production, the Rococo, and the conceptions I propose to associate with it dug deeply into matter itself. Both executed inquiries into the nature of reality that were original to their age. Neither would have existed without the deeper interrogation the other expresses. The appearance of a body of philosophical thought and a body of decorative style together, was a phase of Occidental culture at white heat, skimming from off a vast past its quick clutch of basic interrogations of the human presence in the world, tied up into bundles of abstract and concrete discourses that rapidly germinate in the centuries to follow while simultaneously retreating before the polemic it has provoked upon itself.

During the preceding eras Occidental knowledge of nature and of mind grew into invasions of the interiors of organisms, language, thinking, and number. Tough and durable machinery, such as the printing press, working with durable materials, such as ink and paper, sharpened critical thought, which in turn created more 
intricate machinery for inquiry and, eventually, for storing the results of inquiry. In conceptional discourse this development took infinitude as one of its chief themes, starting from the endless multitudes that infinitesimality yielded and moving to sheer quantity of beings, events, and things and, finally, of our narratives of objects and events. Hierarchy, followed by taxonomy, was employed to tame infinity. Its pomp disappointed, displaying tragedy from within. Therein old suspicions of the material world and of the reach of the human mind that were ingredients in Plato's initiation of Occidental philosophy again taunted the anxieties of those subjected to the increased magnitude of systematic observation.

Berkeley's critique of causality was in part a product of this anxiety and had three reactive effects. First, it undermined the machinery that invasive sensory inquiry unveiled, which was lawful causality. He argued that if we accept the standard account of causality we must hold that causes too were infinitesimally divisible and therefore could not stabilized. As a further consequence, his analysis determined that causes ware indistinguishable from effects. If every thing and every kind of thing is ontologically equal, no thing governs others. No thing or kind of thing could actually give the stability we experience and expect. Berkeley's ultimate claim is that the reality of infinitude was not stable, though we talk as if it were, and therefore it cannot exist. If we know that reality is stable, as plain obvious experience shows us, then something other than causality stabilizes it. The second effect of his 
line of thought was to conceptualize what must be the case if the void left by this destruction of causality is to be filled. Berkeley turned a ghostly outline into a spiritual shape. The secret was out, made plain by the insufficiency of cause to be sufficient reason. There must be God because things plainly exist. The third and most important effect was to put human persons back firmly into union with reality. Infinity was our friend again. This step was Berkeley's most difficult, requiring the rest of his life to try to work out. In 1710 it delivered a new form of an ancient idea, that the springs of motion in this world are hidden from our best efforts, by adding the full field of our inner lives to the means of inquiry. ${ }^{283}$ The pattern could now be atectonic, capable of crazy connections between subjects and appearances. Berkeley did not hold a pluralist ontology, but his argument that the one kind of real being infinitely transcended pure contingency helped to free imagination from older and lesser bounds.

Though God has already created everything, for Berkeley human persons create things new to themselves. Once accustomed to newer things, we know them through habit rather than through our discovery of them or their being unveiled to us. We call them properties, qualities, or modes just because we are familiar enough with them that after they first seem to be part of an external material world we then use nominal categories to discuss or explore them. ${ }^{284}$ In all this the capacity of human

\footnotetext{
${ }^{283}$ I refer here to Berkeley's New Theory of Vision (1709), his first published work.

${ }^{284}$ Berkeley, Treatise, 49.
} 
persons as conscious spirits mimics divine creation ex nihilio. In the passage of the third Dialogue I discussed in Chapter 5 Berkeley attempts to soften the dynamism of this link between God and humans by introducing non-human spirits, or persons, that also are creative perceiving consciousnesses but are not part of the human story strictly speaking. ${ }^{285}$

The relation of human creative capacity to that of God was at the heart of contemporary attacks on Berkeley both in France and England. One line of critique was to link Berkeley to Malebranche's occasionalism. This makes Berkeley's thought seem so other-worldly as to have no hold in this contingent world save by constant divine miracles. The other line of critique linked Berkeley to Locke and later to Hume. The inevitable outcome of his thought is made out to be atheism. To the one he was a reactionary mystifier in opposition to the new science, and to the other he was as bad as the skeptics. The tension lay in the middle, where neither Baroque metaphysics nor Enlightenment materialism reached, where nature's vastness defeats our comprehension, and where power required our utmost practical endeavor to control. The region in which the creative enterprise of Rococo style flourished was the conception of a creative capacity the power of which is due to our own consciousness having been formed on something other than the model of physical nature alone—on the model of God in Berkeley's view and by ingenium in Vico's.

${ }^{285}$ Berkeley, Works, 2.253-254. 
The contemporary nerve that Vico's De Antiquissima struck was close to causality but rather different as well. He was topically concerned with civil law. Just as he admitted the perfection of mathematical thought but denied its competence in much of human affairs, so also he desired to reveal the actual and the proper priority of human making over rationalist conceptions of truth. Eventually he struck at the heart of the idea of law in myth; but in 1710, before digging into law's history itself, his project was to link our creativity—our ingenious capabilities—-to something other than timeless reason. In his view "true providence," as Karl Löwith points out, deceives and reveals according to our capacity to understand, our ingenium. Giving us a rough road is just what it means for providence to operate in history. ${ }^{286}$ So although Vico's interest in theodicy was rather different from Berkeley's, it still was a disturber of familiar assurances by re-framing causality in terms of our knowledge of it.

Knowable causes, in Vico's view, do not operate as properties of objects or events. Properties, qualities, and the like are, like propositions, static, hence unchanging, mere words, and hence not causative. We cannot know points (puncta) to act upon themselves because to say they do adds nothing to our idea of their existence. It merely transfers the mystery from "cause" to "conatus." Vico does say that mathematics is a knowledge of causes, but precisely this claim is the damnation

${ }^{286}$ Karl Löwith, Meaning in History (Chicago: University of Chicago Press, 1967), 128. 
of conventional causality. Even if some basic structure of the world is mathematical, mathematical inquiry requires actions by human agents. It is thus the structure of the world at one level only, and that, Vico finally decides, is not the deepest level. Doing mathematics requires human invention and development of mathematical ideas. It also requires words and deeds and other objects of human manufacture. This is the reason that law, and logic as well, are not efficient causes. All lawfulness depends not on its own ideal inner structure but on human deeds. This consideration is proof that verum is factum, and it also adds to the proof that verum/factum is a correct principle.

Ingenium is a moving force related at the deepest level to human knowledge of everything, including causality. It pushes momentum from punctum to punctum. As a comprehensive power it brings everything into the human and the human into everything, but comprehensiveness is not its most important aspect for Vico. Its character as ontologically fundamental is due to its bringing everything human into the sphere of human ingenious activity. Just as mathematics led Vico to the deeper structure of human deeds, so jurisprudence led him to the deeper structure of myth. Beneath all his inquiries, at the stage at which they stood in 1710 as well as at later stages, is what one might call an inquiry into facere (making or doing) as a philosophical anthropology. All forms of facere are time-bound, even mathematics, which is not a thing as eternal as it is taken to be and is, rather, a product of historical development, like all human productions, the pace of which is that of ingenium as 
this core human faculty commits to memory and recalls from memory. By these activities it fashions useful conceptions from what are in themselves unmoved, isolated perceptions, barely inscribed, and verbalized with increasing productivity as ingenium gathers its stock of truths from the activities we perform. Human history is a history of conceptions inscribed into mental and material production. Vico holds that if this were not the case we could not truthfully account for the world and that we could not even develop a proper conception of truth.

Later Vico tried to specify the power of imagination. One of his answers was good faith, or conscience, as its motive. To us today the forceful omnipresent human mark suggests the panoptic, dominative regime of power. In 1710 the matter stood differently. Vico's search for the motive force within human activity suggests claims of a kind previously made by Thomas Hobbes (1588-1679), that law depends on certain virtuous action rather than on supra-mundane coercive force. In his later work Vico historicized this approach by his reading of the figure of Jove. Here in his metaphysics he responds to the danger natural force presents to human life by trying to fill in the hollow space, that place at which the human mark, if it is to sustain our conviction in it, must be structurally active according to our relations with it-our communication of the truths and deeds we register to one another and our societies. This notion must have begun to alter his understanding of divine providence, which language, as wisdom, still protects. 
Recall that Vico locates ingenium as participant (particeps) in reason but not (compos) framer or master of it. Both Berkeley and Vico mix passivity and activity in a similar way, which itself is distinctive in the philosophical context of the time. For Berkeley perceptual ideas are passive but God is active, while the human person's notions actively and continuously create knowledge as the deep structure of the world according to the order of God and as God does in his atemporal but unceasing existence. For Vico ideals objects—-the objects of mathematical reasoning-are passive and God is passive in so far as He created what is perfect, but human persons create the deep structure itself of the world according to that part of God's unceasing activities that govern the continuous world. Humans do not master reason, God alone does; yet He also created that reality in which faculties other than hegemonic reason that He gave us are the creators, the inventors, the constitutors, and not merely participants. ${ }^{287}$ If there were no such domain, nature would overwhelm humanity. If we will not recognize such a domain, we shall not understand the patterns of action and inscription that all of us are always making. We should then not be active truth-makers but only passive participants.

Berkeley rejected Descartes's cogito principle as a barrier between persons and their own history in God's continuous creation. For him the channel from each human spirit to God was made cleared, not obscured, by her every cognitive act,

${ }^{287}$ De Antiq., VI 
which re-inscribed or unveiled truth if she understood the identity structure of humans and the world in each act. The goodness of God, like His creation, continues. Vico's rejection of the cogito both defended humankind from that responsibility for evil to which the divine creator alone is adequate but also marked out the vital domain that God in his wisdom makes particularly human. ${ }^{288}$ Vico transformed memory and phantasia into the active creative imagination. ${ }^{289}$ What we now call his discovery of social realities was in its early metaphysical form the plan of providence to give human persons a sociable adventure and a collective struggle. For both thinkers human creativity is not mimesis either of nature or of the acts of other persons. All aspects of the external world, including its appearance of overwhelming power, are to be wholly and really understood as material given to men and women in the plan of divine creation. At least in the period under consideration, neither philosopher addressed the fear that the sociable project of human communication in the world could not be kept from deformation as repressive social control.

Defending human existential and social projects against developments that seemed to threaten it, their ontologies furthered the moral purpose of defeating scepticism as to knowledge and faith.

These passages from the loci examined in Chapters 5 and 6 demonstrate the near variations in Berkeley's and Vico's conceptions of firm ground for human being.

\footnotetext{
${ }^{288}$ Verene, New Art, 108-109.

${ }^{289}$ Trabant, Vico’s New Science, 110.
} 
Philonous, the voice of Berkeley, contends to Hylas that:

...God knew all things from eternity.... Consequently, they always had a being in the Divine intellect.... ${ }^{290}$

This implies that human production, thought, and action are grounded in God. ${ }^{291}$

Defending his the first principle of his metaphysics, Vico says in the first Riposta:

Thus, with the faculty of knowledge derived from that proven principle which I call ingenium [ingegno], a man can put together things of different kinds, which seem to have no relation to one another in the view of someone lacking ingenium. Human ingenium rises and crests [onde] in the world of the arts, just as nature is the ingenium of God. ${ }^{292}$

Both men rely on God to defeat scepticism. Berkeley has God always in possession from the beginning, so that our knowledge and activity come in the course of time to be equal to the truths we come to understand. Human creative activity is part of an identity-structure that comprehends our knowledge and divine being. Human creation of knowledge is a human activity parallel to divine creative activity but not identical to it. We cannot understand infinity, Vico, says, but we "can go about gathering it." ${ }^{293}$ We come to understand what God has planned and provided for, but we do so by making knowledge and deeds. For both philosophers not only is God the guarantor but also the world must be construed by humans according to a kind of knowledge special to them and inspired by God. This knowledge is not natural

\footnotetext{
${ }^{290}$ Works, 2.253.

${ }^{291}$ I leave aside the historical progress of the question of freedom of the will.

292“First Response," in On the Most Ancient Wisdom, ed. and trans. L. M. Palmer, 127.

293“First Response," in On the Most Ancient Wisdom, ed. and trans. L. M. Palmer, 122.
} 
knowledge. Its contents are closer to the deep structure of God's plan of the world than is natural knowledge.

If the constructivist notion of knowledge is "functional adaptation" within realist ontology, Berkeley and Vico can hardly be its predecessors. They held idealist ontologies, which make a different thing out of "functionalism" than realist ontology does. Idealism in this period provoked—as realism also did but in a different way—profound new claims about meaning, language, the material world, artifactuality, law, documents, and conscience. Berkeley's and Vico's idealism, though offered as compromises with realism, suggest both hollowness inside natural force and also danger from it, and they then move to considering human intentional knowing and making as constituted in such a way as either to replace or to overpower the evacuated yet terrifying forces of nature. The conflicts within this position are no accident, and it tried to hold them off to no avail, so that Occidental thought was obliged to move more directly to ward off the terrors of sublime natural moral and physical force. But just for a bit idealism claimed a kind of freedom and adequacy for our ingenuity and perspicacity.

The kind of paradox we see in Rococo style results from the situation of an idealist ontology that describes human presence in a cosmos it does not trust. It trusts human agency and doubts mechanical agency. This does not mean it refuses to use mechanism or refuses drawing effects out of causes. It means, rather, that human 
agents might look upon "practicality" a little differently than realist ontologies suggest they do. It means approaching knowing and doing with a different inflection. One sees the complicated result in the eighteenth-century automaton. In an age of mechanistic thought, these were machines that questioned mechanism by seeming to be machines and at the same time clearly, except in the eyes of the duped, utterly incapable of functioning without direct human operation. Artifacts with the Rococo effect are like these automata: they look like the causal engines of our ordinary world and yet they look different from these; they are impossible, ridiculous, fantastic, alive but not really, alive on account of the hands that made them and not on account of any principle inside of matter.

The Meissonier ornament was one of hundreds of thousands of decorative elements that comprise exploring the tactile, visual, and conceptual nature of a continuously created and creative cosmos, which is full of contradictions, impossibilities, human ideas, human efforts, and human failures. This image, and innumerable others that we have from the hands of Meissonier, La Jouë, Gilles-Marie Oppenord (1672-1742), Cuvillies, and the other Rococo artists, is as much a reflective inquiry into the nature of ornamentation itself as it results from the specific production of enjoliment. As such it expresses an idealist view of the whole broad issue of the movement of conception through matter. 
Chapter 8: Continuous Creation

The story of the conceptualization of temporal process as neither alienating God from man nor man from God is closely related to the very long history in Occidental culture of thought about animating dead matter-and in the domain of critical thought to our familiar theme of the relations of conception and production. The story of Pygmalion describes this ancient problem, and it is perhaps worth noting this story was one of the most common plots for Rococo ballet. Animation of matter was also an interest among those who make and watched automata equally as it was of scientists and amateurs who probed matter to find the spring of life from Descartes through the eighteenth century and after. Doctor Faustus and Victor Frankenstein are the fictional types of all such inquirers.

After the hierarchy down which vital and spiritual principles emanate has been negated in the thinking, both conceptual and productive, that this thesis has examined, another principle now entered the discourse from around 1710. Physical nature was for the moment a little less to be feared. It had been probed, and its laws were being revealed. The human subject could be accorded a clearer and freer agency in such a world. Although the looser clothing in which Rococo effects represented matter seemed to let out the tension, to our eyes the tension is visible in the frantic 
shapes. Anxiety remained, and fear was making ready. The concept of the sublime denoted moral as well as physical powers in material nature that did not need omnipotence and omniscient divinity and could not be denied just by denying such divinity. The discovery by Occidental thought of the creative power of finite temporal process at a moment when it seemed that human ingenuity, provided with God's help, was an active and rather innocent creative agency began to seek the springs of life in the growth of life rather than in one sole pre-installed packet. In the Treatise, Berkeley confesses that the notion of time baffles him:

For my own part, whenever I attempt to frame a simple idea of time, abstracted from the succession of ideas in my mind, which flows uniformly and is participated by all beings, I am lost and embrangled in inextricable difficulties. I have no notion of it at all, only I hear others say it is infinitely divisible, and speak of it in such a manner as leads me to entertain odd thoughts of my existence; since that doctrine lays one under an absolute necessity of thinking, either that he passes away innumerable ages without a thought, or else that he is annihilated every moment of his life, both which seem equally absurd. Time therefore being nothing, abstracted from the sucession [sic] of ideas in our minds, it follows that the duration of any finite spirit must be estimated by the number of ideas or actions succeeding each other in that same spirit or mind. Hence, it is a plain consequence that the soul always thinks; and in truth whoever shall go about to divide in his thoughts, or abstract the existence of a spirit from its cogitation, will, I believe, find it no easy task. ${ }^{294}$

Two decades later he suffered the same perplexity. In the last of his "philosophical letters" to the American philosopher Samuel Johnson (1696-1772), Berkeley says that the "succession of ideas I take to constitute time, and not to be only the sensible

\footnotetext{
${ }^{294}$ Treatise, 98.
} 
measure thereof...."295 If time is a way of measuring, it must be a measure of something. Duration must be that something. For Berkeley duration does not exist because it does not exist in God: "There is in him no change, variation, or succession." ${ }^{296}$ Of this Berkeley is sure, that time truly is nothing, and this is why disputing about it goes nowhere. It "embrangles" him. If he cannot make anything out of its passing in our consciousness it must be because he thinks we are sufficiently like God that we too can perceive and conceive apart from interval, with everything present always and at once, though He also confines us to interval. Yet our merely human capacity breaks apart the uninterrupted unity known to God. Somewhere between God's physical and regular arrangement of the world within which we exist and our semi-divine ability to control time, perhaps we might use interval to create things, rather like God does, in capricious stories at speeds of change that we commonly know mostly in illusions or delusions.

It is rather difficult to fill out this option in detail. ${ }^{297}$ Berkeley does not see his way around the theological issues of time that perplexed him since he started to philosophize, and his American friend agrees. A point, he says, cannot be both

${ }^{295}$ The fourth "Letter" from of 24 March1730, in Works, 2.293.

${ }^{296}$ Loc. cit.

${ }^{297}$ Johnson actually gave Berkeley a way to develop this. In the third "Letter," from Johnson to Berkeley on 5 February 1730, Johnson says that the actual infinity of God means that created entities exists not merely at one point in time or in space but necessarily in alicubis: somewhere, anywhere, on many occasions (Works, 2.288). In his reply Berkeley does not recognize this as helpful and digs himself into embranglement. 
stationary and moving or stable yet changeable. The notion of the new "looks to me like a contradiction." ${ }^{298}$ I suggest that the historical resolution of Berkeley's problem was in the invention of animation - a very long growth starting in the bizarreries and capriccios of Rococo style, of which Berkeley's and Vico's metaphysics are the conceptions, and leading to the moving photography of Eadward Muybridge, Louis Lumière, Georges Méliès, Thomas Edison, and others at the end of the nineteenth century.

The problem was not solely Berkeley's. Three centuries before the first motion picture philosophical minds were engaged in a phase of the perennial issues of change that centered on the concept of continuity. Infinite data and infinite imagery were in their conceptual sights. Infinitesimal divisibility removed constraints that sustained continuous action. It left no ends toward which motion surged or to which it must answer. This was also a moral problem because it disempowered theodicy, leaving providence so isolated and overmatched it seemed little more than destiny or oppressive determination. ${ }^{299}$ Leibniz invented the calculus to answer a moral

\footnotetext{
${ }^{298}$ Works, 2.286-288.

${ }^{299}$ In The Society of the Spectacle, translated by Donald Nicholson-Smith (New York: Zone, 1994), 102-105, Guy Debord writes what amounts to a brief theory of the Occidental early modern. Once the wealth Europe accumulated from the Crusades was diffused into a prolonged increase of commerce and productivity, he holds, mythic religious conceptions of time were replaced by "irreversible time"-the concept of history as a mundane movement forward of diversification and expansion of human activity. This includes "the infinite accumulation of knowledge" and the ever-expanding production of spectacles from the Renaissance onwards. The bourgeois of the Baroque and the Enlightenment, whose basis was endless forward-driven commerce, took all time and therefore all history away from any
} 
problem as well as a mathematical one. Infinitude would defeat, he feared, God's

choice of the finite world He actually created. Nothing less than the best could even possibly exist, unless God is not omnipotent or unless God chose to create infinite worlds rather than to have created this present world by choosing it out of infinite possibilities.

It is not hard to understand the anxiety Leibniz must have felt when he confronted these options. In a letter of 1713 he states that if other worlds remain possible then this world would not be necessary; and if not necessary, then not created supremely good; and if not created supremely good, then God's election of the supremely good would be thwarted by necessities He could not overcome. If another world might be utopia, what good is God's wisdom? ${ }^{300}$ Leibniz's logic drove but one answer to this: that God's timeless, ceaseless creativity is entirely exercised on this

spiritual conception (such as mythic or cyclical time) and made it into universal history, encompassing the entire exploitable planet. "The triumph of universal time was also its metamorphosis into the time of things" that, through the specialists tied to it, made society superfluous. This takes Debord to the eve of the French Revolution. The transit from Baroque to the eighteenth century means the loss of spiritual or psychic foundations for community, which are replaced by capital and things. Under this theory, Rococo would represent the tipping-point of this transition, when knowledge shatters everything but private indulgence in and enjoyment of objects displaying consumption in the richest ways. That this continues in increasingly twisted firms through our own day is the core thesis of Debord's famous book.

${ }^{300}$ This letter has not yet been published in the Akademie Sämtliche Schriften und Briefe. It is part of a correspondence published as "La correspondence de Leibniz avec Goldbach," edited by A. P. Juschkewitsch and Ju. Ch. Kopelewits, in Studia Leibnitiana, vol. 20, no. 2 (1988): 175-189. (OCLC and JSTOR catalogue this article under the editors' names, but I have entered it in my bibliography as a primary source Leibniz.) Leibniz attributes a notion of continuous creation to one J. Hansch, of whom nothing else of any consequence is so far known. 
world alone. What he has created, he continuously creates. Berkeley put the same problem another way in the passage quoted above: if God does not omnipotently and omnibenevolently control all creation, then life has no meaning in any way that makes sense to Berkeley.

Berkeley was more like an existentialist than a rationalist. He was concerned not only about the gap in the existence of things from point to point in time but also about the gap in existence from one percipient spirit to another, i.e., from me to you, within collectives, and among communities of persons. He does write a good deal about the gap in existence from point to point in space, but historians have far less often noticed his communitarian concerns. In part this is due to the technical terms in which philosophers examine this issue, but in good measure it is also due to Berkeley's avoidance of overt attention to this point except in terms of the community of believing Christians. The community of humankind is trans-temporal, and so the communitarian issue is deeply "embrangled" with embrangling time. Towards this matter, located outside of his pastoral attitude, Berkeley showed anxious avoidance in his early work. Like time, "number is nothing fixed or settled.... It is entirely the creature of the mind...."301 yet numbers are subject to general laws. God guides our judgment in arranging things so that they are not just "any how and at random produced." 302 Our existence requires this order, reason being a mere tool of

\footnotetext{
${ }^{301}$ Treatise 12.

${ }^{302}$ Treatise 64.
} 
existence. Existence requires maintenance in continuity with other persons, else the isolation of the famous unheard falling tree in the forest or, as Berkeley (knowing nothing about desert ecology) puts it, the life of each person would be like the unknown life of a plant in the desert.

As he says in the passage on the Mosaic account of creation, God makes the world "gradually perciptible [sic]" to the spirits whose minds He so constituted as to receive this something out of time but disguised as time. This is very much like continuous creation. Human agents are both freely creative like God but wholly and entirely guided by God through the general laws of nature. So continuous creation does not defeat the perennial antinomy of freedom and necessity because the all-ornothing character of binary logic fails when time, unveiled by God, so deeply conditions us that it binds us to creaturely circumstance. For Berkeley time is so illogical that the only way to understand it is just to accept it as divine providence. This move makes time more "real" than it is as a human notion. Berkeley felt he conquered puzzles of spatial location by this move, but as to temporal location he admits an absurd into the system of the real world. This is less tidy than Leibniz's solution but far truer to human experience, and in this sense-a sense Berkeley craves throughout his work-it is more commonsensical. The community of humankind is created continuous and is nearly mysterious to us. Our minds do not admit understanding of it by abstract ideas but by concrete ones. Our daily, ordinary 
activity confutes the rationalist explanation of the world.

The medieval homo creator now took a fateful turn. ${ }^{303}$ Scientific knowledge has never ceased to improve the rational understanding the system of the world, in which it both abandons the rationalist principle as molded by Leibniz to a certain extreme pattern when replacing it with a different biological science and also amplifies through the invention of digital information and the deeper understanding of networks consequent to this invention. Despite its growth, empirical science as part of the rest of society has lived with the discontent, nevermore a secret though often dismissed by the recurrent strains of positivism, that feels absurdity in personhood and injustice in the collective. The real effects of these forces become blatant after the passing of theodicy and began to call for a kind of action that just passes over the conflicts of reason. Dissent against reason again and again takes the form of practice as well as of discourse. One here begins to see that an artistic expression of this situation by homo creator might mock or take apart the rationalist world view. In this respect Rococo style was a conceptual art, with a real though unverbalized critical program based on the contradiction between continuous creation without which it was thought we cannot know the world nor act nor produce and the rationalist programs that seems to work well in serving the material needs of humankind.

$\overline{{ }^{303} \text { Milbank, Religious Dimension, } 14 \mathrm{ff} .}$ 
Whereas for Berkeley time is an opaque practice separating man from God-a kind of toy, like causation itself, that God provides us in order to fill our limited capacity for edification and our less limited spiritual and material needs-for Vico in 1710 time is a happier theater of multiplicity in which we might approach divine infinity in ways suited to our limits. That we cannot grasp essences is no troublesome limitation for him. The puncta, which are unparticularized metaphysical material, supply all the needs of connection between being and becoming that the metaphysics of participation requires since Plato. ${ }^{304}$ Vico needs no other class of things by which materia prima is made into specific existents, such as the species intelligibilis of scholastic philosophy, because he regards human actors as the creative agents. He wipes away the "third man," or infinite multiplication of intermediate entities, in favor of the divine powers that humankind has. The infinity of God is less impossible or impossible in a different manner than it traditionally was, for it is not an infinite multiplication but rather a wholeness that connects us as well as separates us. ${ }^{305}$ Once again we observe that infinitude is being tamed. Untamed, it is formless, merely unending addition or division; tamed, it is generative, plastic, always in process and under construction. Vico holds that God give us access to this "metaphysical material. ${ }^{306}$

\footnotetext{
${ }^{304}$ Rotenstreich, “Between,” 97-98, emphasizes Vico's neo-Platonism.

${ }^{305}$ Rotenstreich, "Between," 91.

${ }^{306}$ Milbank, Religious Dimension, $188 \mathrm{ff}$.
} 
Our means of access is not mathematics because mathematics deals with the complete, that is, the essential. It also has, in Vico's view, the unenviable task of working upon an infinite quantity of perfected objects of analysis. The surprising truth is, Vico, says, that true outcomes of mathematical operations come by chance. ${ }^{307}$ This science is inadequate to its huge object, as we ourselves are, so human mathematicians happen upon any good result (opera) by chance from the whole pool of available truths. So much, once again, for the ars combinatoria. Truth isn't discovered: it is made. As Gilbert Simondon says, there is no such thing as a robot. However deep the mechanism, humans are doing the making and the learning. Vico's 1710 explanation of human working on materia metaphysica is rough. He needed new conceptions about language, which is essential to all understanding; about society, because it is that accumulate the pieces that become universali fantastici; and, perhaps most of all, about myth, coming to understand it as the true form of the understanding itself, bridging the gaps from person to person, community to community, and age to age. Eventually he concluded that myth reveals more than it disguises, because truth comes not in what we analyze but in what we synthesizein all that we ourselves make, necessarily impressing the inevitable and enduring stamp of mythic form upon them.

While Berkeley paused upon seeing that time must be a part of providence,

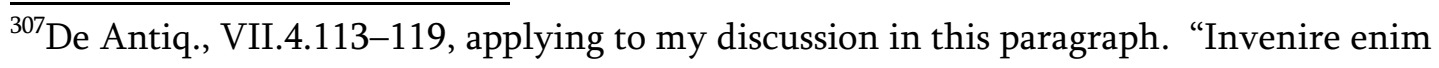
fortunae est' ("Discover comes out of chance") (119). 
Vico moves homo creator a few steps further by holding that time is the theater wherein humans participate in the creation of objects and events. Vico twins divine and human actions. In the preliminary metaphysics of 1710 , everything that is comes to be by some making. God's intervention is a the principal member of a class of actions that includes human intervention, although the divine and the human are of course different. This in my view is what Vico says in the early passage I have often referred to: the divine is master, or compos, of the reasons for the world; the human is a participant, or particeps, in the reasons for the world. The distinctive activity of ingenium is that it continuously mediates what God continually creates, thereby also humanly continually creating. Berkeley initiated philosophical focus on the history of our knowing through our ideas and notions, since there is no existence part from them, and barely saw that ideas and notions are not static but processual or historic. Vico grasped that if object and events either must be mediated as objects of analysis or as the contents of our narratives then even the objects of analysis are more truly understood as narratives. Later he took these narratives as linguistic and mythic, but in 1710 he took them more primordially as free human invention and creation.

This step enabled Vico to understand the collective as something beside the undetermined action of divine providence or the straightjacket of logical entailment. It vitally depends on communication among humans. The universali fantastici are parts the commons required for communication among people. But they never are 
abstracted from sensibility or replace particulars. ${ }^{308}$ Vico' view is that ingenium guides sensibility within the commons. The communication it makes is not only spatial, that is, joining parts together, including machinic production; it also is temporal. The universali fantastici help create our awareness of the sensory flow of momentum. They are not concepts, even when they constitute myth, for myth itself in Vico is not rude, unrealized conceptualization. Myth does not rest on logic nor is it resolved or dissolved by logic. Universali fantastici produce histories, or stories mythic or otherwise of objects and events, inventing and constituting them within the discourse they bring into being. When our understanding grows, our stories grow more full of sensory detail, rather than more structured by abstraction. They become more fully self-contained worlds that we have created. This, Vico is saying, is the truth about human knowledge, that it is not a nominalist or skeptical technology that disenchants and dis-moralizes the world but is in truth a group of moving histories about human morals, passions, and thoughts. Some forms of knowledge, such as the Aristotelian, misunderstand the story. They are part of the story, they are but one of the stories, and they do not comprise the whole truth nor subvert the truths of all the other stories.

In the world-views of Berkeley and Vico, the continuity of created reality is not mechanical. Providential continuity is a disputed territory within this view, an ${ }^{308}$ David W. Black, Vico and Moral Perception (New York: Peter Lang, 1997), 44ff., puts this very well. 
index of the force of the religious belief of the one man or the other. For both men mechanism exists and science learns correctly to operate it, but the picture of reality they hold is not mechanistic. The continuity is animated through and through first ideally by God and then temporally by us. It itself is the deepest structure of our existence. Vico expresses this very well when he re-shapes the meaning of genus, as we saw in Chapter 6. He describes the mind's wandering between simple forms and complex ones in search of something from each kind that history, the fully tallied tale of sensuous and intellectual memory, keeps and use on the model of precedents in jurisprudence. ${ }^{309}$ Human ingenium works upon continuity in order to gain understanding, and this makes history. Berkeley found that a psychological anthropology was a more complete explainer of vision than physics, and Vico put this kind of insight into an a more comprehensive metaphysics. Although Kant probably did not read Vico, this conception grew, along with other material, into his conception of autonomous human judgment, inclusive of but not untrammeled by the material world— the key to his philosophical anthropology.

All that God made is good, in the Christian view. From this Vico reasoned that human persons, as participants in divine reason or mind, can make the good by making the true. Humans make the true by operating upon materia metaphysica, which, though it exists in our mind (as genera), we shape into the world. Unformed,

${ }^{309}$ De Antiq., IV.3.43-44. 
infinitely deep, wholly comprehensive, abiding and ever-ready, this "matter" is the raw material for our imagination. We invent from it, and it constitutes our creations.

To say we "operate" or "guide" this generative thing, this immensely potent and important thing, is to use small words for the largest reality, short of God, that Vico knows.

Right here, where so many indefinite and ambiguous words are called upon, we attend to the metaphysical crux between versions of human knowledge that remains the most pervasive issue in theorizing humankind. It rives all human reflection, but the conjunction of two of its sites is the object of this thesis: art and historiography. ${ }^{310}$ Metaphysics, a philosophical study of truth, is one way to address it, and ethics is another. But the third of course is by the beautiful or, as we now say, by art and aesthetics - the three-fold basis of Occidental philosophy in the broadest sense of the word. Where the true and the good are under discussion, the beautiful is nor far behind. In this way the conception of continuous creation, in both stronger and weaker connections to divinity in the ontology I have been describing and which reflects much of the span of philosophical theology in the first half of the eighteenth century, addresses production as well as conception. Upon the conception that the intervention of God into a contingent world is a mediation from the perspective of human intelligence, then our knowledge also is mediation, and our creative activity

${ }^{310}$ Recent aesthetics and metaphysics are inching towards this notion. See the various papers in Uidhur, Art and Abstract Objects. 
mediates matter as well as words, all taken as "media." Production as well as conception has a history mediating our ingenious reflection upon the moving continuity in which we exist. Here in the Rococo is the proximate beginning of this ever-increasingly interconnected and pervasive configuration of self-reflexive conception.

In the world of Leibniz the infinitely complex cosmic structure, although internally fully relational, was static with respect to our understanding. For us grasping the architectonic of the cosmos is an intellectual operation and not a sensory or, broadly speaking, an epistemological one. Berkeley breaks this by knocking out the wall between perception and existence. For him, the vastness of spiritual reality and sensory reality were co-extensive. Nothing in the created world was too great for us to comprehend. It does not overwhelm us, nor need we fear it so much as to try to master it. For Vico the analogy between divine and human creativity is stronger and more explicit than it is in Berkeley at any point. Vico overrides mechanical causality with generative creation, fortified in mankind directly from its source in God. Vico did not regard the human mind as mastering reason because, in part, it need not. It as not so greatly in need of reason as to depend on it. It has other faculties that seem quite strong enough since they are the powers by which human agents have created society, institutions, all knowledge, and all history. With such accomplishments, for all their defects, humanity need not fully fear nature. It has a divinely endowed 
strength with which to match natural forces. Vico's metaphysics lays the basis for what he believed was a correctly balanced appreciation of the forces in the domain of human life. By his move of granting causal status to mathematical law, he actually evacuates causality, relegating it to the lesser domain of machinic perfection and establishing ingenium in the resulting atectonicity. Without ingenium we would be at the mercy of nature. This in fact was the philosophical outlook that grew from the naturalizing of human cognition later in the century and, in the next, in response to the discovery of previously unknown deep structures in physical forces, chemical elements, organisms, and, ultimately, in the psyche. ${ }^{311}$

For a few decades, differing from one national culture to another during different spans within the century, Rococo style animated the a-causal cosmos, having snatched it from infinite mechanism and hiding it from the forces of nature under a vast plumage. I now draw the reader's attention to another group of productions and conceptions within Rococo style: the new mechanisms and ideas with which Rococo theatrical production animated its fictive worlds.

The invention of machinery to change scenes in a theater made for a highly consequential development from the special visual effects that medieval paraliturgical spectacle used. Improving on techniques employed since antiquity, these machines materialized the Christian interest in transition through celestial hierarchy to the

${ }^{311}$ The refers not only to Freud but to Kierkegaard, Schopenhauer, and Nietzsche as well. 
earth and even to hell. ${ }^{312}$ Scene-changing technology slowly developed after Mannerism from the earliest Baroque stage productions and civic and private spectacles. When the Jacobean court in London and its successors, from around 1603 until about 1675 , began to stage masques, which required rapidly mutating allegorical displays far more complicated to effect than the static scenery of Renaissance productions, Inigo Jones (1573-1652) enclosed the outdoor-scene open stage of the Middle Ages and Renaissance with a housing within which working parts were hidden. ${ }^{313}$ The back scene now could be pulled apart in the middle and retired to the wings. The wings, multiplied from the back to the front to create depth, ran on tracks along which sets were pulled in increasingly flexible patterns. Formerly the curtain and the trap beneath the stage had been the only areas in which to hide machinery in order to make the action appear mysterious. Now the stage was both transparent and occult. This was the key to enchantment. Many more images crowded attention, and mechanisms made them fly and flap and flip within seconds. This allowed for more expressive interludes, more deeply reflective of the principal action, than hitherto, stimulating music and dance.

In France in 1641 the proscenium arch was introduced to the same effect,

\footnotetext{
${ }^{312}$ Hubert Damisch, A Theory of /cloud/. Toward a History of Painting, translated by Janet Lloyd (Stanford: Stanford University Press, 2002) covers much more than theatrical effects in the later Middle Ages and the Renaissance, but it is an excellent work of intellectual history with which to investigate this area.

${ }^{313} \mathrm{My}$ account follows that of Richard Southern, Changeable Scenery. Its Origin and Development in the British Theatre (London: Faber and Faber, 1951), 32-108.
} 
enabling décor simultanée. But while theatrical production in France and on the Continent flourished, its grandeur was pinioned by the program of depicting the heavens, that is, infinitude. In Italy and later in Paris, after 1645, Giacomo Torelli (1608-1678), along with the commedia dell'arte re-founded as the Comèdie Italienne, expanded the cloud-reveals, wire-guided birds, and thunder boxes of Florentine opera of the 1630s, into the immense staging of imported ballets. Louis XIV, from 1660 onwards, funded gigantic sets for his majestic entertainments that used these mechanisms. ${ }^{314}$ In Vienna and Prague, in central and southern Germany, in Jesuit theaters and the civic theaters, and throughout Italy, huge backdrops, made by tremendous amounts of labor, took the viewer deep into the many stages of the cosmic, or national, architectonic, but the scene was classically stately and domineering. ${ }^{315}$

Speaking generally, both English and Continental theater were bound by perspective to static or stiffly kinetic representations, even though their size and complexity increased. Renaissance and later perspective was congruent to allegory: both organized parts of reality linked by internal networks into finite containers

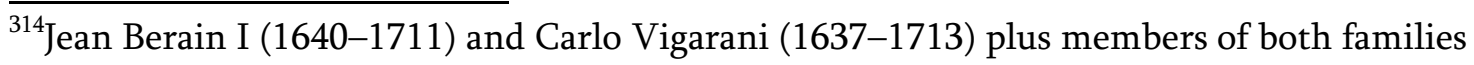
were Louis XIV's chief theatrical designers.

${ }^{315}$ Oscar G. Brockett, Margaret Mitchell, and Linda Hardberger, Making the Scene: a history of stage design and technology in Europe and the United States (San Antonio, TX: Tobin Theatre Arts Fund, 2010), 111-130. See also T. E. Lawrenson, The French Stage and Playhouse in the XVIIth Century: a study in the advent of the Italian order (New York: AMS Press, 1986), 201-253. 
while simultaneously maintaining the presence of infinity. Perspective mediated the references to what lies beyond that which is presented and the subject's point of view. As Lyle Massey has shown, the tension between the subject's perspectival control and the power of the larger cosmos-between the immobilized, disembodied viewer and the indefinitely changeable universe, created reality itself around our small Cartesian inquiring minds—rendered the medium of perspective ambiguous and inadequate. ${ }^{316}$ Around 1700, a new development launched a change in spectacle that concurred with the flourishing of Rococo style.

This change was the invention of the scena per angolo, invented in 1703 by Ferdinando Galli Bibiena (1675-1743), according to his own claim, and published in 1711. ${ }^{317}$ The Galli Bibiena family, Ferdinando and his brother, Francesco, his two children, his grandson Giuseppe (1669-1757)—the most prolific of them all—and even his great-grandson, who worked until 1787, designed innumerable productions wherever the Rococo flourished in great cities at all points of the compass in Europe. Giuseppe was the architect of more theaters than anyone before or probably since. For the lonely Princess Wilhelmine (1709-1758) in Bayreuth Giuseppe and Carlo Galli Bibiena (1656-1749) built magnificent halls, stages, and sets. These and other drawings and engravings by family members, depicting not only effects but the details of the machinery and construction, remain marvels of intelligence,

\footnotetext{
${ }^{316}$ Massey, Picturing Space, 19 et passim.

${ }^{317}$ Brockett, Making the Scene, 131-156.
} 
theatricality, and sight. The Galliari, even more prolific and inventive than the Galli Bibiena, and the Quaglios were other self-training families of Rococo spectacle specialists working everywhere in Europe from the beginning to the end of the eighteenth century. ${ }^{318}$

At first Ferdinando called the new tricks of vision "occult lines." This phrase points to the metaphysics of what were so truly visual that they were nothing if not seen. The causes of these visions were the hidden machines and the disposition of masses on the stage according to the new principle of production. The history of this intriguing machinery, deserving of an historian's full attention, and closely connected to the amazing development of optics in the seventeenth century, is beyond the scope of this thesis. It is the chief non-machinic element, Ferdinando's invention that is part of the Rococo effect. Its principle was to replace tectonic relationships with the self-sustaining and self-containing force of the imagination. Instead of aligning the wings in descent from the monopunctual perspective running from the monarch in the royal box to the celestial image deep at rear center stage, the creator imagined sight lines from many points in the hall. Ferdinando and his successors then angled the wings to face these the different angles from various directions in the hall. Formerly anchored to the guide tracks along which scenery slid into the absolute correct view, the flat wing walls moved perspectives and were moved by perspectives.

\footnotetext{
${ }^{318}$ Loc. cit.
} 
Now wings could be curved as well as flat. Furthermore, they could be scaled to be larger when closer to human beings, setting the imaginary into the experience of the ordinary viewer as something that might very well exist by good rights despite its unconventionality or outrageousness, rather than correct and conceivable solely from the seats of God and king.

When these designs were built as structures on the stage, rather than presented as images, they displayed their stage-effect impossibility while their temporary and fantastic conceivability also impressed the viewers by means of the arts of the engineer. Since the scenes were atectonic from the start nothing inhibited ornamenting them, and so they were encrusted with equally atectonic castellation, stucco masses, illogical supports, matter swirled into jewels, flames, oceans, columnar domes, domical columns, and vanishing volutes. These things, even as ridiculous effects, proclaimed their own reality and implied a conception of reality not based on mechanical causality. The imagination sustained by human persons in their inwards and outwards capacities continues a created world to the inception of which it has unique access.

The color drawing attributed to Ferdinando or to a draughtsman in his shop (figure 7) can represent with equal plausibility a stage set or the ceiling of a domestic room such as a salon or bedroom. I have not addressed the Rococo domestic interior in this thesis for reasons of space and scope, but the nearness of stage sets to real 
bedrooms and salons in Rococo buildings is an interesting way to look a bit at both. It might be hard to understand that curved ceiling lines were one of the most upsetting and unorthodox ideas of Rococo designers. If a ceiling does not rest, or appear to rest, on its bearing walls, it will not look supported or fully harmonious with the structural space it is in. Curving the edges of the ceiling masks the tectonics. And if this did not shock enough, decor invaded the irrational curving space, masking the mask with shells and other rocaille in stucco or with painting that represented fantasies themselves full of unlikely events in puzzling perspective.

Replacing tapestries that held in heat with wainscot and then re-presenting the wainscot with inner and outer panels articulated by rocaille motifs was an offense to the sense of honesty and probity that was held to be desirable as old-fashioned and fundamental virtue. The critics of Rococo regarded Neo-Classicism, which seems decorative to us, as sober and functional and virtuous precisely because it replaced Rococo effects with clear material and moral geometry.

The corners of the curved ceilings of Rococo Paris were even more capital offenders than the edges because they violated boundaries. They echo the angles wings of the Rococo stage machinery. In the drawing, the corners can be draperies or other dividers that pull apart to reveal the scene set within. They show arches intersecting at atectonic angles and in multiple perspectives. Tectonic boundaries, like fixed staged dividers, were hierarchic because they ordered the ranks of the other 
elements within the whole. Rococo style preserved multiplicity but capped it if from infinite power and control. Its effect was that of freedom rather than that of control. Creation was not controlled but continuous.

Against Locke Berkeley held that our senses do not show a rationalist cosmos and will not produced true knowledge without our having the non-sensory intelligence of which sensations are a phenomenon just like the objects which they appear to present and upon which our senses operate. Since the stability of the world lies deeper than sensation, our capacity to know and depict the world is free from an obligation to mime causality. To the extent that we construct the world we have the power to alter its structure and even the capacity to reveal the deeper, foreign, bizarre structures on which our construction depends. One may model Rococo aesthetic representation on the imaginative freedom in what we know of these theatrical productions. ${ }^{319}$ It is a possibility conceivable in the contemporary ontology that now we understand solely as supporting knowledge of lawful causal structure. But it had the capacity to take thought in another direction, sometimes followed in Occidental

\footnotetext{
${ }^{319}$ One of the capital images of the Rococo, Watteau's Harlequin, testifies to the depth of connection between the inner core of the Rococo and performance. One benefit of considering the Rococo in terms of the kind of philosophy under discussion here is that the intellectual history might encompass both the experience of the theater and the visuality that the style produced. For Watteau and the theater, see Josephine Touma, "From the Playhouse to the Page: Visual Sources for Watteau's Theatrical Universe," in Studies in Eighteenth Century Culture, vol. 40 (2011), 83-101. In my view this possibility is enhanced by the previously unattributed painting "The Italian Comedians," c. 1720, acquired by the Getty Museum in 2012 after the curator concluded that it is the work of Watteau-whether or not it is a Watteau.
} 
culture, that Rococo style expressed in its gorgeous physicality and spectacular illusionism.

Like Baroque artists, the craftsmen of the Rococo created kinetic illusions. The two periods of dynamic illusions differ, but strict division or description of pure forms likely will not survive the complexity of the facts. One rough way to describe the difference between the Baroque and Rococo kinds of kinesis is that the former was largely spatial and the latter more or less truly temporal. Another way to describe them is to say that Baroque kinesis was dynamic but that Rococo kinesis was animated, the difference being that the dynamic is the realization of potentiality and that the animated relies on no former unrealized state. Michel Foucault distinguished the intellective formation of classes or universals on the basis of similarity from the their formation on the basis of difference, the former being Renaissance and classical, or pre-modern, and the latter being the leading indicator of thought from early modernism to structuralism. Rococo style and the metaphysics associated with it by the argument of this thesis requires an opposite development. Under the present view, the Baroque operated upon differences as unfolded in infinite spatial division within hierarchy and the Rococo operated on similarity found in the intimate connection of animated successive parts. This position makes an exception to Foucault's schema but is not a rejection of it except as a totalizing concept. Like many scholars Foucault overlooked the subtle verges that the Rococo imagination 
wrangled from other trends in Occidental thought. Rococo style expresses a path that much of Occidental culture did not take. One might say that it was not well expressed again until the Surrealists. ${ }^{320}$ But it was practiced in the intervening centuries. It had its effect as one part, among others and side by side with the scientific knowledge that grew out of a different ontology, in the metamorphosis of vision and of thought leading to, and furthered by, the invention of cinema.

Rococo objects frequently have a hallucinatory quality. Shapes seem to melt. The position of ornaments twists more greatly in objects made by around 1740 than the same ornament in the same kind of object, of very similar pattern, made in 1715 or 1725. Meissonier's famous silver tureen (figure 10), of which several exemplars exist, is a good example. At a superficial glance it look like a composition of floral elements, including fruits and leaves, not unlike a drawing of a cute animal's house in a children's book or kitschy pottery. It was part of a set filling a table or sideboard set against or within walls likewise invaded with torqued motifs such as Meissonier's own and equally famous sconces (girandoles). Closer consideration shows that the object is not naturalistically observed but is more like a capriccio: structural elements are placed together atectonically. The leaves that should support the base peel away, as do the elements of the lid. The C-curves on the bowl are, strangely, both congruent and mirrored. They in fact are the key to the design far more than the ${ }^{320}$ See Charles A. Cramer and Kim T. Grant, "La démarche poétique from Vico to Surrealism." New Vico Studies, vol. 22 (2004), 63-84. 
showier larger parts are. They represent the way the leaves curl directions opposite to one another and indifferent to the architectonic of the object. The C-curves simply ignore the bowl; neither they nor the foliage have much to do with the bowl if one thinks of the bowl as a stationary round pot. It is a pot but not a stationary one, in so far as decor can make it otherwise. Meissonier uses the technique seen in his drawing of an ornament (figure 8): decor applied at the outermost superficies suggests internal force, de-familiarizes the object, and turns it into a hallucination of movement sufficiently continuous as to conserve the form but asymetrically changing at related but differing rates in different parts.

Another effect of these two works by Meissonier that is extremely common in Rococo style is flattening of depth. That Berkeley in 1709, in the heart of the Rococo years, proposed as a proven truth that there is no depth vision and that what we take for it must, like action at a distance, exist in a reality present and proximate to the spirits in whom everything that exists as ideas, is no coincidence with Rococo effects in the same period. Strong Rococo depth is shallow by the rules of classical perspective; by these rules great Rococo paintings and other inscribed images are as flat as film or act like a skin beaten to translucency. But the use of Rococo effects creates intense unexpected atectonic depth: the crown that flies from a molding straight into the beholder's eyes, the fantasy palace on a stage that swallows the stage curtain and the hall whole, the little figures on a screen that tumble against gravity 
around one another, the curving ceiling or wall that floats away from all bearing mass, and the maze of arches or staircases that appear not to conform to mundane logic.

In media archaeology, the sub-discipline devoted to studying pre-cinema, the genealogy of animated movement frequently includes versions of the ars combinatoria, such as the work of Giovanni della Porta and Athansius Kircher (16021680) or early thinking devices such as volvelles. ${ }^{321}$ Yet the use by of revolving scenery by some Rococo theatrical architects, such as Jean-Nicholas Servandoni (1695-1766), ${ }^{322}$ while it descends from the earlier pre-history of the panorama, brings in the differing point of view of the animated atectonic of Rococo style. The entire style diffused its effect through different kinds of images until it just faintly touched the radically new domain of moving imagery. The position of Rococo production, properly understood not only with respect to stylistic periods but also within the long-term morphosis of images up to the era of panorama and finally the era of the image in full motion, adds a set of continuities and divergences to our picture of the eighteenth century, to the history of conception, and to the history of visual

\footnotetext{
${ }^{321}$ This is the direction taken, rather poorly, by Siegfried Zielinsky, Deep Time of the Media. Toward an Archaeology of Hearing and Seeing by Technical Means, translated by Gloria Custance. Cambridge: MIT Press, 2006), 57-100. This work is greatly prized by media archaeology scholars, and it has many worthwhile ideas, but in my view it does not grasp the histories of ideas with sufficient command, though scholarly command is expressly not Zielinsky's goal.

${ }^{322}$ Brockett, Making the Scene, 147-148.
} 
communication. ${ }^{323}$

Two of the most thoughtful media historians ask the question "How does one avoid reducing all other media to a footnote to the history of the moving image?"324 They and their colleagues form media archaeology around disparate technologies and deeply historicized contexts in order to avoid this, using "variantology" to refuse "theoretically oriented explanations" and "overarching explanations," despite "the risk of atomism."325

The Church of St. John Nepomuk built from 1733 to 1746 by the genius Asam brothers (hence called the "Asamkirch") (figure 1) is a brilliant creation interesting

${ }^{323}$ The two chief histories of pre-cinema entirely omit Rococo style and effect. They are Erkka Huhtamo's fascinating Illusions in Motion. Media Archaeology of the Moving Panorama and Related Spectacles Cambridge: MIT Press, 2013); and Laurent Mannoni's foundational work, The Great Art of Light and Shadow. Archaelogy of the Cinema, translated and edited by Richard Crangle (Exeter, UK: University of Exeter Press, 2000). For some media archaeology with much less fuss and fumbling see Bernard Comment, The Panorama. (London: Reaktion, 1994).

An obscure paper by Marcel Brion, "Baroque et Esthétique du Mouvement," in Études cinématographiques, vol. 1, no.s 1-2 (Spring-Winter, 1960), 13-31, better covers the territory that the more recent scholars attempt and is alone in covering what they miss. Brion gives a thorough account of these stylistic effects that pre-figure the moving image. Yet while the specific artists, works, and techniques he describes are from the Rococo decades, he always calls them "Baroque." As far as I can tell, Minguet, Ésthetique, 79 n. 65, is the historian of Rococo who cites Brion.

${ }^{324}$ Erkki Huhtamo and Jussi Parikka, Introduction to Media Archaeology. Approaches, Application, and Implications, edited by Erkki Huhtamo and Jussi Parikka (Berkeley: University of California Press, 2011), 13.

${ }^{325}$ On the theory of media archaeology see also Erkki Huhtamo, "Dismantling the Fairy Engine: Media Archaelogy as Topos Study," in Media Archaeology, edited by Huhtami and Parikka, 27-47; Eric Kluitenberg, "On the Archaeology of Imaginary Media," in Media Archaeology, edited by Huhtami and Parikka, 48-69; Wolfgang Ernst, "Media Archaeology: Method and Machine versus History and Narrative of Media," in Media Archaeology, edited by Huhtami and Parikka, 239-255. 
for many reasons, but one minimum point it makes for us is that strong central conceptualization does not lack from the development of Occidental understanding of the structure of the world-at least as far as the Rococo was concerned but in truth, of course, much further. Everything in the church ripples, twists, broadens, and is illuminated directly in the viewer's presence at the spot where she stands. The creation of the moving image was nothing without conceptual development.

Production, however deeply embedded in circumstance, is never truthfully atomized. This interior expresses the concept of continuous creation: that the world is a stuff not alienated into matter but continuously fully intimate with God and to humankind, which can fashion every bit of it into the kinetic expression of free creative force. 
Chapter 9: Diderot's Decision

Even if our power of analogy cannot rightly find in the conceptions comprising Rococo style a category under which to collect the vast productive intellectual ferment of the period from about 1690 until the middle of the eighteenth century, as a way of unifying or adding a fresh specific angle to understanding the Enlightenment, this style was so broadly appealing that it appeared to stretch the creative genius of peoples throughout Europe for five or six decades. Cabinet-makers, goldsmiths, architects and stuccadors, painters and craftsmen quickly carved out new shapes for old things, with innumerable local variations, not unlike the unprecedented successes of historians, philosophers, scientists, and explorers in discovering and recording the world. ${ }^{326}$ Very quickly after about 1745 the panEuropean style changed, although Rococo style did not disappear. Waves of critique helped to change it. Even an edict against this style of decor in Catholic churches stoppered it in Bavaria. This strong flux indicates powerful thoughts and feelings beneath its surface. Something was strongly desired and then was strong rejected. What fears or anxieties did the desire and its apparent fulfillment provoke? I turn now to the critique itself as another source of conceptions by which to understand

${ }^{326}$ Arno Schönberger and Halldor Soehner, The Rococo Age. Art and civilization of the $18^{\text {th }}$ century, translated by Daphne Woodward (New York: McGraw-Hill, 1963), 14-52, create a picture of the fertility of "the Enlightened Mind" and then, 53-108, describe Rococo arts—including music, theater, and private life - as a mirror of the whole culture. 
the individual and social processes of production in this period.

As the art historian Michael Levey put it, "There was no one to champion the rococo; it had only patrons or enemies....”327 Denis Diderot was the most effective enemy, and his critique has been the most enduing. Throughout his life Diderot was interested in the ontological issues I construe as the conceptual basis of Rococo style. This is no coincidence, although scholarship has yet to apply Diderot's philosophical endeavors to his critique of Rococo style in the Salons. ${ }^{328}$ I shall describe such an application in this chapter for the conceptions thesis discusses, although a thorough investigation of the Salons on this basis is beyond my scope, I shall trace the zigzagging story of Diderot's ontological anxieties in his confrontation with the art of François Boucher (1703-1770) in the Salons from 1763 to 1769, citing some of Diderot's comments on the work of Jean-Honoré Fragonard (1732-1806) and of Giovanni Niccolò Servandoni (1695-1766) as well.

Diderot loathed Boucher's paintings. He recognized Boucher's skill, even his genius, and appreciatively described the works; but at heart the man's art bothered him into programmatic critique. In 1763 Diderot's tone was starkly oppositional,

${ }^{327}$ Levey, From Rococo, 111.

${ }^{328}$ Citations below given as "Salons" are from Diderot's Salons, edited by Jean Seznec and Jean Adhémar in 4 volumes (Oxford: Clarendon Press, 1957-1967).

It is not clear to what extent Diderot's views on Rococo matched those of the lesser lights who wrote about the Salons. The best description of the popularization of Salon criticism is Bernadette Fort, "Voice of the Public: The Carnivalization of Salon Art in Prerevolutionary Pamphlets," in Eighteenth-Century Studies, vol. 22, no. 3, (Spring, 1989): 368-394. 
though his style performs its customary generous dance. But his view of the matter was more nuanced than he knew or admitted it to be. In his Lettre sur les aveugles à l'usage de ceux qui voient in $1749^{329}$ he had tried to refute immaterialist idealism but could not untangle himself from it, and so the implications of this untrumped challenge continued to provoke him. ${ }^{330}$ In 1765 he complicated his argument about Rococo style, connecting the ontological problem to gender issues. He is harsh to Boucher, but he was conflicted about the issues at stake. By 1769 his recourse is to withdraw-just to be done with the man and with the style. He gives up fighting, though his opinion of Boucher has not changed in the least. The general direction of the Salons in 1769 and after shows that he ceased to explore the issues through philosophical discourse, and, discovering other solutions, moved on to the line of work that produced the Encyclopédie.

Berkeley's deft, sharp argument for immaterialism shocked the young Diderot, as it did many others. Diderot struggled with it for reasons similar to those that impelled Kant to undertake his heroic reconstruction of rational knowledge in response to Hume's evisceration of cause, hence of self, and hence of moral judgment.

\footnotetext{
${ }^{329}$ Lettre sur les aveugles, edited by Robert Niklaus (Geneva: Droz, 1951).

${ }^{330}$ Diderot's fascinated repulsion from idealism is described in the lively account by Jean Deprun, "Diderot devant l'idéalisme," in Revue internationale de philosophie, vol. 38, no.s 148-149 (1984): 67-78. In France the claim of idealist ontology was made as early as 1686 and response to Berkeley first appeared in 1713 (69-70). Diderot was interested by Christian Wolff's (1679-1754) Leibnizian idealism and first responded to the subject in his Cléobule of $1746(71-73)$.
} 
Hume, who read Berkeley, converted this argument that Berkeley thought a fortress against skepticism into the most formidable skepticism hitherto advanced in Occidental philosophy. All these philosophers-Berkeley and Hume, Diderot and Kant—accepted the metaphysical position that ontology determines ethics. The strength and manner of this determination has come to be deeply contested in postKantian ethical philosophy as positivists and naturalists endeavored to dispose of metaphysics, Wittgenstein and his successors attacked it in the grounding of ethics in verbal discourse, pragmatists such as Richard Rorty and Hilary Putnam have done so under the banner of pragmatism, ${ }^{331}$ analytic meta-ethics grows its systems in nontraditional ways out of realist and non-realist grounds, and post-modernist philosophy mostly tends to try to overcome this by an altogether new ontology. The determination of ethics by ontology is in fact the sharpest end of the deepest cleft in Occidental thought, whether the good itself exists or not, set in motion by Plato himself. All this comes out in Diderot's attack on Rococo style. Diderot's fraught rejection of Rococo style is a good indication that the Rococo, though untheorized, had profound implications, as all human production does in many directions.

The empirical enhancement of vision, proximately beginning with Galileo's

\footnotetext{
${ }^{331}$ Putnam makes his argument easy to read in his Ethics Without Ontology, referred to in Chapter 2, above. Theodor Adorno argued against excessive ontological framing of ethics, which he called "ontologism," in "Extorted Reconciliation: On Georg Lukács' Realism in Our Time," in Theodor W. Adorno, Notes to Literature. Volume One, translated by Sherry Weber Nicholsen, 216-240 (New York: Columbia University Press, 1974).
} 
telescopic observations and hypotheses and extended by microscopy and other sciences in the seventeenth century, deepened through the development of optics. This enabled anamorphosis and other tricks of illusion that I mentioned in the previous chapters. Through them problems in art inevitably turned into difficult ontological problems because vision is the chief guarantor of all the senses. What we see and what we do not see correspond to what we intuitively know to exist and what we must strive to know to exist, driven as we are by material and spiritual stressors to advance knowledge. In 1690 John Locke published the problem, posed to him by William Molyneux (1656-1698), as to whether a congenitally blind adult person suddenly acquiring a full faculty of sight could distinguish between a cube and a sphere. "Molyneux's problem" was a crux for the age in the perennial question of the sensory and supersensible sources of knowledge, of the knowability of all reality, and of the nature of the reality in which we exist. Leibniz and Malebranche soon responded to the problem, and also Voltaire, Condillac, and La Mettrie; but it was George Berkeley in his first work, An Essay Toward a New Theory of Vision, of 1709, who most consequentially argued a new solution and most particularly provoked Diderot. In the Essay Berkeley first stated concepts that we have seen in his work of 1710 to 1713: that all human visual observers use their full sensorium plus the contents of their memories to understand what they see, and that none can do this by abstract or geometric calculations alone. This newly enabled observer, he said, 
encompasses her experiences of the world within her person. Only within the person and in persons alone does anything exist.

Diderot saw this as dangerous solipsism. Malebranche's notion that God miraculously intervened to conserve the cosmos at each and every infinitesimal instant, was absurd to the skeptical empiricist mind just as much as Leibniz's preestablished harmony, of which Malebranche meant to be an improvement in point of commonsensical intelligibility. Berkeley's idealism made Malebranche's occasionalism powerful. It meant a non-social reality, without communication among persons, and it suggested to him a preference for an invisible spiritual world over the material and lively social world. Berkeley's immaterialism threatened to cause even touch itself, the home-base of love, knowledge, and manufacture, to be revealed as something ghostly. Diderot is concerned that if Berkeley's view were true then nature should produce not only nothing but blind people but inert and lonely people. The outside world is the occasion, the means, and the substance of our communication with one another. Yet, as David Hagan's perspicacious reading of the Lettre shows, Berkeley's argument stymied Diderot's desire to reject it. ${ }^{332}$ Diderot

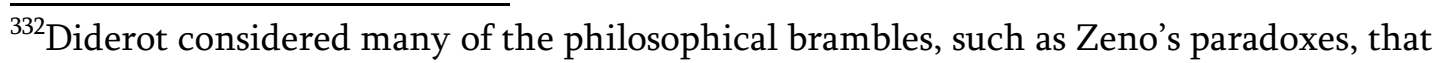
philosophers used to establish ontology. He throws tremendous rhetorical and imaginative force in defense of the power of human communication against what he saw attempts to deflate or disempower it by the solipsists, whom he calls visionnaires in later references (Deprun, 69, et passim). David Hagan's "Threading the Needle: Problems in Reading Denis Diderot's La Lettre sur les aveugles à l'usage de ceux qui voient," in Studies in Eighteenth Century Culture, vol. 40 (2011): 219-245, is devoted to the complexity of Diderot's response to this matter. Not only are there many sides to it, but also Diderot scholars are all over the 
knew that a rationalist construction of knowledge did not suffice to release us from the self-enclosing quality of experience. He acknowledges its impenetrability. On the one hand he says, "I have no idea if what is visible to me is tangible"; 333 on the other hand, he is sure that "...all men see, therefore, one and the same."

His heart was with the social and material world. So whereas he could not solve the philosophical issue, Diderot felt he was on entirely sure ground when he turned to the moral danger of solipsism above all in painting, the highest visual art, in his first attack on Boucher in 1763. When he wrote that Boucher "has everything, except the truth, ${ }^{335}$ he describes the solipsist who has power over the world he creates or imagines and has it all perfectly provisioned and arranged but is disconnected from reality. The imagined world is agreeable in its extravagant absurdity, but it sticks to one ("il vous attache") so that one cannot get away from it. ${ }^{336}$ There is as much warning as humor in Diderot's wit, but he soon drops the condescension and turns out deadly critique.

When you have spent a while contemplating a country scene such as the one we have just outlined [in a typical Boucher painting], you think you have seen everything in it. But you are fooled; you discover there an infinity of precious things! No one understands the art of light and shadow like Boucher. He uses it to turn the heads of two kinds of people, men and women of the world and

place in interpreting it-all, as Hagan shows, taking as Diderot's certain and final position what actually is a layered, intricate series of varying responses.

${ }^{333}$ Diderot, Lettre, 64.

${ }^{334}$ Diderot, Lettre, 65.

${ }^{335}$ Salons 1761, 1.112.1-2.

${ }^{336}$ Salons 1761, $1.112 .13-16$ 
artists. His elegance, his cuteness, his romantic galantry, his flirtatiousness, his taste, his skill, his variety, his spirit, his imaginary carnations, his debauchery, should enchant young rakes, little women, young people, society people, the whole messy lot of all those who are strangers to good taste, to truth, to wise thoughts, to the austere strength of good art! How would they resist flocking to the pompons, nudes, libertinism, and wit of Boucher? ${ }^{337}$

Although Diderot says that the charms of Boucher's work, like that of Ariosto, are trivial, he says also that the imagination that produces the charms is far from harmless. Talent can distract us from recognizing vice. Under immaterialist idealism nature has no more morality than it has causality; there is God alone to make things go in regular order and to see to justice, nature having no endogenous drive to make moral permissions and prohibitions. Boucher has replaced God with his taste, which means his creative skill. As Diderot sees it, if one does not rely on God for justice, one needs nature. He thinks that Boucher does not leave him even nature, which he craved, much less God, who is not at issue. Portrayed as irresistible at the end of the first paragraph of this notice, Boucher's "morceau de peinture" ("morsels of painting") repels Diderot by the end of the second and final paragraph.

In this thesis I have paid a lot of compliments to Rococo style and tried to put in new lights. There are many winning things about the Rococo effect. But it is time to look at it from Diderot's point of view, much of which we today share, at least at first glance. I turn again to Meissonier. Consider his design for a table d'appartement-consoles were so attractive to Rococo artists and their clients that

${ }^{337}$ Salons 1761, 1.112.20-34. My translation. 
they almost always furnish a good representative exemplar-engraved by the man who published, stocked, and sold more Rococo images than any other person, Gabriel Hachure (1695-1772), illustrated as figure $9 .{ }^{338}$ Looking at it strictly from the aesthetic more or less native to us now (and even leaving aside its socio-economic and political contexts) it is, in a word, hideous. First of all, the legs and top form a large, quite useless cartouche. This occupies most of the visual space and is out of place. Then the solid bits are full of holes, senselessly pierced all through, particularly in what is merely a cross-bar at the bottom but also created by garlands hanging from the repeating reverse $\mathrm{C}$-curves of the legs. Rocaille stuff heaves up and down off the cross-bar. The line of the table top edge clumsily mimics the profile of carved stone on a large building, while at the bottom the under-scaled lowest C-curves rest on what must be called very tiny toes. The contrast of the top slab edge down the rollercoaster legs to the footings might induce nausea. On the moral level, even the name table d'appartement is disturbing.

For Diderot decorative surfaces like this table are not only ungainly and absurd, but they also do not convey the deeper and truly inspiring importance of things. Anything that an artist projects at us detached from the more immense nature of which it is a part lacks both charm and gravity. It is not even interesting. He implies that we fool ourselves if we think ourselves charmed by decor that

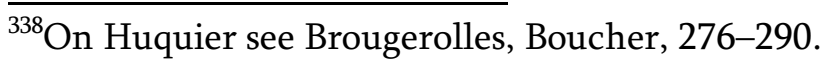


overwhelms its natural context. In his comments on Deshayes, Diderot take the sky as his exemplar. It is not, he says, the blue color or the stars that "transport" us into admiration. It is the immense whole that aesthetically and morally satisfies us. He carefully describes the source of inspiration and aesthetic fulfilment in this way:

Unless I am badly mistaken, it [the source] is the immense space that envelops us, the profound silence that prevails in that space, and other ideas supportive of the connection of astronomy and religion. When I speak of astronomy, I mean the popular astronomy that carries knowledge of the sparkling points of which the bodies are prodigiously scattered at prodigious distances, at which they are the centers of an infinity of worlds hanging over our heads and in which the globe we inhabit would scarcely be visible. There should be no shudder when we imagine a Being that is the creator of that enormous machine, renewing (remplissant) it, seeing us, hearing us, touching us! See, unless I am badly mistaken, the greatest sources of our feelings at the sight of the heavens is half physical and half religious. ${ }^{339}$

What actually deeply motivates us is nature, the workings of which provoke our spiritual and material needs. In reality, he implies, bright stars and subtle blues do not jump out from the sky, nor is the sky an impotent backdrop to their spectacle. What moves us is the whole mass of power that is nature. Nature as the subject of art is the sublime, morality included among its ungovernable forces. ${ }^{340}$ Here is almost the exact language Kant used ${ }^{341}$ combined with a statement of some notion of continuous creation. The idealism he tried tied to shake remained planted in Diderot ${ }^{339}$ Salons 1763, 1.218.22-31. My translation.

${ }^{340}$ On Diderot's notion of the sublime, and the difficulties with it, see Brian Elkner, "Diderot and the Sublime: the Artist as Hero," in Studies in the Eighteenth Century. II. Papers presented at the Second David Nichol Smith Memorial Seminar Canberra 1970, edited by R. F. Brissenden, 143-162 (Toronto: University of Toronto Press, 1973).

${ }^{341}$ See p. 16. 
as he labored to grasp the unsustaining sublime, or felt it demand his grasp.

Rococo style transgresses nature's moral order. The critic ceases to be reserved in his judgments. Boucher, says Diderot in 1765, "step by step" follows "la dépravation des moeurs" ("the degradation of morals"). ${ }^{342}$ He here states what became the accepted normative view of Rococo style. Immediately Diderot brings up prostitutes and the penance they ought to pay but for which Boucher nowhere vouches and never demands. This artist never gives us the whole woman, heartlessly breaking her up into gestures and smiles and pompons he flings across his canvasses. ${ }^{343}$ His sleepy shepherdesses are as silly as they are in operas, except that on the stage they communicate their love by singing and dancing whereas Boucher makes them use pigeons are mercures—-they love through degraded doves rather than with their natural bodies. ${ }^{344}$ Having pulled her out from nature and pushed us into delirious obsession with the parts of her sexual materiality, Boucher gives us un tapage insupportable ("an unbearable noise") ${ }^{345}$ — perhaps literally unsupportable by a nature that would not stand up such a delusory construction of eros.

He finds that Servandoni, who was as wild a Rococo fantasist as any, defaces the Farnese Hercules in the same way, exaggerating each part until the image departs

\footnotetext{
${ }^{342}$ Salons 1765, 2.75.19-20.

${ }^{343}$ Salons 1765, 2.75. 2-8.

${ }^{344}$ Salons $1765,2.80-1$.

${ }^{345}$ Salons 1765, 2.76.11.
} 
from reality. ${ }^{346}$ The "real" Hercules of the "real" myth, strong and massive, was a "sublime" product of nature's power, not a "system" of fetshized exaggerations, ${ }^{347}$ which concludes its degradation by assimilating the heroic man to Antinoüs-the passive partner in homosexual intercourse, no sort of man at all ("n'est d'aucun état"), lazy (oisif), no better or bigger than when he was born despite being given the body of Apollo Belvedere. ${ }^{348}$ Once again Diderot does not rest until he reveals the conflicts within his axiology, for although Antinoüs is the "subaltern," he is not merely a bitch or a fag but is similar to "svelte et léger" ("lean and light") god Mercury. ${ }^{349}$ Every part of his body in Servandoni pictures signifies "instinct." Diderot seems to use this word here not to indicate what is native to us but what we unthinkingly err towards.

Rather than the knowledge associated with material force or skill, such as that of a blacksmith, tailor, or baker, it is "metaphysics." 350

Diderot seems to say that both women and men degraded by the Rococo touch resort to interpretable words (mercures) rather than to natural bodily actions. ${ }^{351}$ This is to replace the sublime with fixating, addictive, inescapable thoughts. After a day looking at Fragonard's hypnotizing tapestries, Diderot finds himself lost in reading

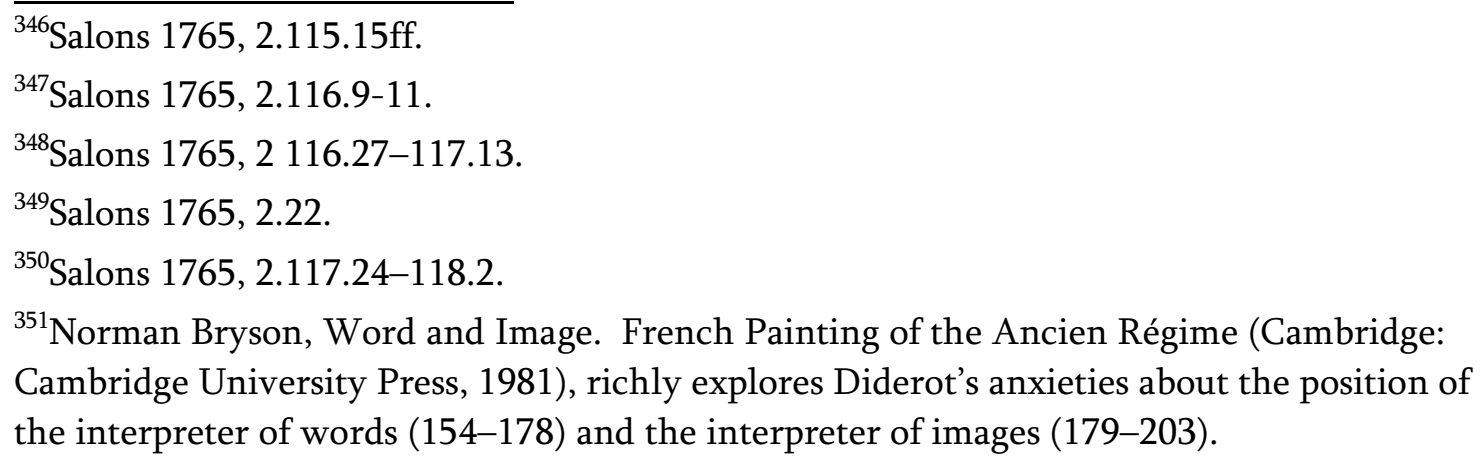


Plato that evening. ${ }^{352}$ He has been trapped in Plato's cave, as is anyone whom Fragonard has victimized by his art. Diderot implies that artists in the Rococo style are the prolific fabricators—in this case literally the weavers—of bright but deeply shadowy illusions. 353 "Grimm," the literary epigone of Diderot's friend and collaborator Friedrich Melchior von Grimm (1723-1807), and he proceed to discuss this in the longest sustained dialogue in the Salon of $1765 .{ }^{354}$ Grimm concludes it by declaring that Fragonard's beautiful dream substitutes "phantoms and spectres" for real persons. The proof of this is that the viewer cannot discern the gender of the figures. Conceptual confusion follows upon material ambiguity. The phantoms therefore signify rather than represent; the work is full of signifiers, which he calls echoes, as full, he implies, as the cave is full of illusions. Echoes are disembodied, reproduced voices. Diderot has put his ambivalence about verbal discourse into Grimm's mouth, leaving his invisible partner to imply that in the end Fragonard, and all Rococo style, has pulled sensuous reality inside out, as it were, exaggerating it so as to subvert its reality and turn it into a bodiless, sexless metaphysics. ${ }^{355}$ Diderot returns to tell us that this kind of art has produced in France "une foule d'artistes médiocres" ("a mess of bad artists"). ${ }^{356}$ Rococo both fixates our gaze on the erotic but

\footnotetext{
${ }^{352}$ Salons 1765, 2.188.21-31.

${ }^{353}$ Salons 1765, 2.188-189.

${ }^{354}$ Salons 1765, 2.190- 98.

${ }^{355}$ Salons 1765, 2.198.13-19.

${ }^{356}$ Salons 1765, 2.200.4.
} 
also dissolves it, rather as Diderot both loves words and is wary of them. This is the way in which Diderot disposes of the femininity of Rococo style. He insists that we love the sublime.

Diderot finds that has given too much credit to Boucher's art and to that of other artists Diderot judges as he judges Boucher's, by conceding the efficacy of the hallucinations it produces. Diderot begins to see in it a theory, like Plato's, that encompasses all art and then condemns it. He has become complicit in this, for the writer about art is a mercure. As if becoming a figure in a Boucher, Diderot fears that he himself is in truth just a messenger pigeon and hence a solitary whose solipsism negates alterity. Systems of signs tie down intelligence. They can make it imbecilic in its constancy, just as if one never had sight or hearing. He has not vanquished idealistic solipsism, but rather the Berkeleyan argument has come around again to confront him with the inadequacy of verbal discourse to the power of the universe and all the things in it. He chose the particular rambling structure and chatty style of the Salons in order to secure his freedom from the finality of words since he could not come to consistent and certain answers in works he had hoped to be systematic, such as the Lettre. His descriptions, like Plato's recursive dialectic, idealize the material reality.

Four years afterward, in the entry on Boucher in the Salon of 1769, Diderot argues himself into giving up the bother of castigating Boucher by cataloguing 
Boucher's many faults. ${ }^{357}$ He then signs off the subject by naturalizing Boucher: the man is passionate even when old, full of vital energy, but he just leaves Diderot cold. ${ }^{358}$ He struggles with him, but he failed to resolve the conflict on its own terms. It is hard to pinpoint the psychic the nature of the anxiety that Boucher's Rococo vision caused Diderot. On the intellectual level, closer to the present purposes, Diderot's renouncing his gaze at Boucher indicates both his resistance to resolution due to the intellectual energy of the idealist claim as represented in these most intensely Rococo paintings and also Diderot's progress as a thinker. He had begun to explore more sophisticated materialist interpretations of the complexity of human affairs. Boucher died in 1770, and Diderot scarcely mentions him again in the Salons. Diderot frequently takes his readers first this way, then that way, and sometimes back around. But he is never so simple as that, either. If painting is immediate experience, it communicate only by reaching the experiences of the viewer. Diderot must give this much to idealism, that the sense of things lies in our sensory experiences, to which a work of art contributes and matches. From this observation two things follow, that one must get words out of the way and that the work of art must not be opaque to our common experience if it is to be beautiful. It must reify the harmony of our sensuous life. It prompts harmony rather the atectonic. The images in a work of art must fall back into a deeper coherence the

\footnotetext{
${ }^{357}$ Salons $1769,4.68 .11 \mathrm{ff}$.

${ }^{358}$ Salons 1769, 4.68-36-69.3.
} 
artist shares with his viewers. As an art critic Diderot decided he ought not add to the problem by his words but rather use his words to draw out the material richness of the painting.

The sublime is Diderot's answer to his ontological concerns. He could not settle them by conceptual or empirical analysis of sensory knowledge. In art he found, in place of a solution, more evidence of the power of illusion to trick us. More specifically he noticed a kind of gaze called papillotage, mentioned in Chapter 3, in which the eye rapidly flits from one representation to others within the painting or other work of art being viewed. ${ }^{359}$ Papillotage is a form of saccadic movement, the unconsciously rapid jumps of visual attention co-ordinated in both eyes; it is a basis of pattern recognition. Rococo style thematizes papillotage and then hyper-charges it, so as to argue for regarding our concepts of regularity in the world as formed by our minds rather than by nature. Diderot found that Rococo art gave representation a fearful power, just as idealism gave the subject a fearful power. Diderot felt it: Boucher made him so nervous that his prose, like Boucher's brush, picked out garlands and stars and feathers and all the hectic multitude of the world imagined without order. And so he stopped co-operating in the breaking up the surface of the

\footnotetext{
${ }^{359}$ Papillotage is a basic concept in Marian Hobson's discussion of Rocco in her The Object of Art, 43ff. David Fried's influential, Absorption and Theatricality. Painting and Beholder in the Age of Diderot (Berkeley: University of California Press, 1980) views the reaction against Rococo as a return from the centripetal effect of Rococo visuality to absorption in the fiction of the viewer's actually seeing the scene representing in paining.
} 
painted canvas and in its proposing a breakup of the stable but very deeply moral universe. The sublime, being the victorious power of nature to regulate the movements of forces, is to be found in the work of craftsmen and in the natural moral grace of things, best expressed in the view of those opposed to the Rococo in the stable ands unanimity forms of neo-Classical style. 
Chapter 10: Rocaille and Lattice

The brothers Edmond de Goncourt (1822-1896) and Jules de Goncourt (1830-1870) described the regime of sentiment that supplanted Rococo style in this way:

When centuries grow old, they become sentimental; their corruption melts. It was a strange moment of the aging eighteenth century, as if the heart of a rake had declined into its second childhood. Humanity, charity, these words seemed suddenly to have the quality of a revelation. Unhappiness became interesting, destitution touching.... There was an idyll in the breeze, a Utopia in the gale. Society caressed an image of virtue which it adorned like a doll. ${ }^{360}$

The idyll was lived for the most part solely by those who could pay for this kind of dream, and certainly for many of them life was not insulated from darkness. For all the supposed falseness of Rococo, the sentimental, moralizing yet progressive neoClassical art and culture that followed was not less illusory. By squelching down the aberrant tendencies that Rococo held in tension, comprising both harmony and opposition, with the normative scientific outlook of the day, Diderot and its other successors might have made their new outlook even more superficial, repressive, and limited in some ways. ${ }^{361}$ This is the way it seems to many people today who look at

\footnotetext{
${ }^{360}$ French XVII Century Painters, translated by Robin Ironside (London: Phaidon, 1948), 244-245.

${ }^{361}$ Roger Laufer, Style Rococo, Style des "Lumieres" (Paris: Librairie José Corti, 1963), 12, 29f., 34, says that the Rococo put conflicts and binaries "at its convenience" for creative
} 
Diderot's love of the paintings of Jean-Baptiste Greuze (1725-1805), Diderot's favorite and exemplary painter, and find great difficulty in seeing the sense of the order that Diderot's aesthetic philosophy aspires to find in the world.

Whether Diderot and his company found the deeper structure that Rococo philosophers and artists were seeking I cannot say. Perhaps the object of both parties endeavors are more similar than we customarily think them to be. But the order of sublime nature that Diderot envisaged was a new deep structure that followed upon Rococo atectonic structure-which was perhaps more question than answer- just as the creative finitude of Rococo followed upon the infinite Baroque cosmic structure. The Gourmonts' view is that what Rococo had at its best slipped away over time. ${ }^{362}$ Perhaps so; but in the movement from the freedom of the question in Rococo to the highly determined answer of Diderot, in which nature imposed both material and moral rules over homo creator, something was lost as well.

Charles-Louis de Secondat de Montesquieu (1689-1755) was educated in the Baroque world-view but was formed as man by the tastes and manners of the Regency, in which Rococo was born. However, his last known work, published posthumously in 1757, expressed more or less fully the newer aesthetic and worldview that Diderot instituted. It was Du Goût, the article on taste that Diderot

tension.

${ }^{362}$ This is also Levey's view in From Rococo. 
commissioned him to write and published in the Encyclopédie. ${ }^{363}$ In his remarkable study of Montesquieu's style and thought, Laurent Versini shows that the completed absorbed the ornate drama of the Baroque aesthetic. ${ }^{364}$ Above all the dynamism of the inverse co-ordinates of the graph, first used by Descartes as "X" and "Y" axes, became a window into the self-adjusting contest of natural and human forces that determines the comprises and harmonies social groups achieve or fail to achieve in trying to form societies in the environment of Earth.

By the time he came to write Du Goût in 1753 and 1754 Montesquieu's view of these operations emphasized the order they imposed. This order imposes itself gently, if that is what "naturally means"; it conforms us to it, but it is unavoidable. In one of his notebook musings on aesthetics, Montesquieu says that architectural orders cannot be changed, or increased or diminished, because they are not arbitrary but taken by us from nature. ${ }^{365}$ Beauty in general comes from our agency and yet it is formed by nature. It is diverse, surprising, and changeable, but first of all it is orderly. Montesquieu is quite interested in the pleasures of surprise, but his interest provoked him to closely track the progression of surprise. In doing this, in his chapter XIV,

\footnotetext{
${ }^{363}$ Essai sur le goût, edited by Charles-Jacques Beyer (Geneva: Droz, 1967). Boyer's introduction is very informative.

${ }^{364}$ Baroque Montesquieu (Geneva: Droz, 2004). On Montesquieu's education and early influences see Montesquieu: les annees de formation (1689 - 1720); actes du colloque de Grenoble (26- 27 septembre 1996), Catherine Volpilhac-Auger, ed. (Naples: Liguori, 1999).

${ }^{365}$ Pensée 882, cited by Boyer in Essai, 37. This entry was probably written about 1732-1733 (q. v., Volpilhac-Auger's online edition from the manuscript at http://www.unicaen.fr/services/puc/sources/Montesquieu/.
} 
when noting the atectonic effect of the lightness of the dome of St. Peter's by

Michelangelo, which sits lightly despite its great mass, he attributes the appearance to the position of the viewer. When the viewer is aware of this, she then has no fear that physical nature can become unruly (démêler), for the atectonic effect is merely apparent and itself comes from natural regularities. Therefore one remains safe within nature, because the art of illusion is a human trick requiring real facts. It is a sort of wit rather than an enigma that provokes questioning. One knows, he says, that the illusion is something "absolutely different from that which the soul knows itself to be."366

This is a critique of the Rococo without naming it, but the result is peculiar. Montesquieu says that because the situation is safe one cannot tear one's self away from the pleasure of surprise. Surprise, and perhaps all spectacle, then captures the spectator, who is safe under enchantment because nature restrains its powers of change. We are drawn to nature's restraint. This implies also that we are relieved from what we have reason to fear, like a hostage who befriends her kidnapper.

The pleasure towards which Montesquieu directs his aesthetics is not so much that of the creation of beauty as it is that of the spectator's grasp of the object under a "general idea." The general idea, closely connected with affirming our existence in place of le néant (nothingness), is pleasure-giving nature. Montesquieu asks us to be

\footnotetext{
${ }^{366}$ Montesquieu, Essai, 91-92.
} 
indifferent to the source of the objects of taste, which is either the soul or nature.

Natural taste and acquired taste are the same, for beauty comes from the natural order. $^{367}$

The distance between Rococo style and Montesquieu runs through their gently contrasting notions of freedom, nature, and creativity. For the Rococo the object flourishes because of its place is in the minds and personalities whence it freely came. For Montesquieu the object is part of a natural world (even if it is an artifact) to which persons must and do adjust themselves. The change from the former to the latter view is subtle but sure: the awareness of freedom has gone or at least is different, nature masters person and persons do not master nature, rules are explicit rather than awaiting our deliberation and attention. Strong contrast turns into softer contrast. Erotic play is more quiet, the precious is rather chastened--more sentimental, less stimulating, magic has become wit. The transparent is now somewhat duller. All that fluttered and surprised and distracted is now known to be a regular, if beneficent, progression.

Put Montesquieu's instructions for enjoying the dome of St. Peter's-from the correct spot, of course-next to the finest Rococo dome, so far as we can see it in the

\footnotetext{
${ }^{367}$ Montesquieu, Essai, 63 (chapter II). For a further development of the place of order in Montesquieu's aesthetics, see André Chatrak, "Le plaisir de l'ordre: pour une nouvelle lecture de l'Essai sur le goût de Montesquieu," in Du goût à l'esthétique: Montesquieu, edited by Jean Erhard and Catherine Volpilhac-Auger (Bordeaux: Presses universitaires de Bordeaux, 2007), 177-190.
} 
third-generation image illustrated here as figure 12: the Temple of the Sun in the Bayreuth "paradise" of Frederick the Great's sister, Princess Wilhelmine. The weight of the dome on the bearing walls is denied right up close rather than from a perspectivally proper point. And not only the weight is denied: the distinction itself between dome and wall is denied. The dome's edges sit back beyond view, not meeting the wall as a separate mass. The rounding wall closes in toward its center just as the domes does. The plinths atop the columns are the only weight the columns support. The columns otherwise stand free, unattached to the dark wall. They do nothing but look pretty, introducing the unitary structure above them. The curving wall also seems set so forward that it is not the wall of the dome: it is the skirt of the dome, which itself seems to continue to the ground out of our sight.

The dark wall is itself atectonic, as if the columns-if they do anything at all—pull it away from the bearing wall beneath the drum edges. All the visual effects of the wall emphasize its distance from the bearing wall: its dark colors, the intriguing pattern of these colors-a very rich, almost unearthly dark grey running vertically with the columns and horizontally with the pediment, enclosing openings in stunning purple marble intricately webbed with light from windows and from gold —and the columns themselves. A line drawn from the top of this curtain wall is actually half-way from the circumference to the center of the dome, about where the deep over-long oval dormers crowded within the lattice and rib decor demand 
attention. The presentation suggests ths matter, in all its richness and depth, is merely a superficies, something real by virtue of a reality that it actually hides away from us. This wall meets the primitive definition of atectonic because it has no roof-just a free wall in need of the dome supported by something other than itself, something perhaps not built by humans, for protection from the nature; and it stretches to the most dramatic extension of atectonicity: it stands away, almost flying off, subverting our expectations of lawful causality.

Yet more complex movements of the decor intertwine everything. These will be found in the rocaille and coquille elements within the window arches and tucked into the pediment. Gilding ties the whole image together, but that is only part of the story. In the cartouche visible between two columns there is an irregular, fragmented gilt mass, something like a continent and islands on a map. Look then from this to the cartouches atop the vertical rib-like filets that mediate crowns on the filet-panel and the swirling life-force of the sun itself. These cartouches in the top register, brilliantly lit by gold, differ each from the other. A lattice fills each, summing up, as it were, the immense grid that stretches from unseen depths up to the bright environ of the sun. Careful examination of the relations between gilt and white space, the upwards lines, and the alternations of pattern is very rewarding to the observer; but the irregular lattice-filled shapes placed between the termini of the domical grids is the most revealing part for the present purposes. 
I mentioned the lattice-work motif in Chapter 3. We see it again as blatantly as possible in figure 2, a settee made in Germany c. $1753-1764 .{ }^{368}$ The skirt of the settee has the same quasi-animated feeling of the console and table discussed above, with its twisting legs and the opposite edges of the seat cantilevered well beyond the kind of graceful proportion Diderot liked. In all my researches I have found no discussion at all of the lattice motif. Whereas rocaille received required standardized attention, and the shell as well, and mirrors or palms-fronds or chinoiseries get due attention, the lattice, though occasionally described is never really observed. Nonetheless it is a prominent element in most Rococo, including bookbindings, where it is closely and suggestively intertwined with rocaille as it is here in both the Apollotempel and the overgrown settee. In nearly every case the rectangular pattern is cut off by an S- or C-curve. Does it restrain it or does it reveal it? One sees the fierceness with which rocaille clips the grid in the Bauer settee, where playfulness and prettiness mildly mask the intensity of Rococo fire-power. Perhaps lattice signifies the deeper structure that inquirers of this period sought, whether they thought it to be sublunary or esoteric, which appears when rocaille is peeled back. Or perhaps it is the heavy-hand of geometry pushing its way out of a too lighthanded restraint. There is something volcanic about both the magma-like rocaille clipping, frustrating, even insulting the implacable force of geometry. I leave the

\footnotetext{
${ }^{368}$ One of two known matching chairs is shown in Cooper-Hewitt, 146, fig. 11.
} 
question of lattice here as a suggestion that I hope an art historian or historian of ideas will one day take up.

Montesquieu's rule for enjoying beauty raises a second question for consideration out of the results of my inquiry. Monopunctual and pluripunctual perspective do battle while influencing Occidental philosophy and arts. In Chapter 1 I said that Rococo style was an attempt to the power of human creativity and the forces of nature: the one being what we feel to be the morally compelling agency of persons and the other being the overwhelmingly powerful tendencies of unenchanted life to go wrong and certainly to pass away. I hope that the reader sees now how brittle and brave the Rococo mediation was. I suggest that it has not yet ceased to bear fruit. Through two centuries of conceptual and artifactual activity we are arriving at barely precedented ways of understanding and using sight and the rest of our cognitive ability as well. ${ }^{369}$

This thesis has paid less attention than deserved to a third area that one might explore based on the thoughts presented here. Another energy might also be behind the blaze of Rococo effects. It is an energy that Montesquieu was keenly aware of: sex and, more specifically, the power of the feminine. Without doubt contempt for femininity drove much of the disdain for Rococo, because men did not think that

\footnotetext{
${ }^{369}$ For a thought-provoking account of possible future outcomes of the growth of conception in the last three centuries since Berkeley see Lisa Cartwright and Brian Goldfarb. "Radiography, Cinematography and the Decline of the Lens" in Incorporations, Crary and Kwinter, eds., 190-201.
} 
Rococo style was butch enough and, alarmed, they hated it. Equally surely at those moments in which style related to Rococo again commanded attention, such as the period of art nouveau, an appreciation of femininity was at work, sometimes as a critique of masculine-identified social organization or of heteronormativity. The art historian Mary Sherriff suggests that rocaille was not the only source of the "gestation" of Rococo. She proposes a monster whose terror was that of femininity: the Gorgon Medusa. She tells a fascinating story of the works in which Medusa rose with her S-curved serpents in France to "break the formal proprieties...and assumptions of academic painting under Louis XIV" and ushered in le goût moderne — the Rococo—as its enemy and successor during the Regency and Louis XV's reign. ${ }^{370}$ Understanding the agency of femininity in the growth of conception in the West, from Ruth through Diotima to Anscombe and Weil, is one of the most important challenges that philosophy faces.

It is not, however, taken singly, more important than the challenges of warfare and ecological catastrophe that all humankind faces. In repeating the principal conclusions of this inquiry I wish to emphasize that the worth of intellectual history, of inquiring in this special way into the relations of conception

370، The King, the Trickster, and the Gorgon: Jean-Marc Nattier and the Illusions of Rococo Art," in Studies in Eighteenth Century Culture, vol. 40 (2011), 1-26. In connection with this see Lynn Friedl's description of the fear of monsters that fops and hermaphrodites aroused, in her"'Passing Women': a study of gender boundaries in the eighteenth century," in Sexual Underworlds, Rousseau and Porter, eds., 234-260. 
and production, directly and fully lies in the help it gives us to understand the large consequences of what and how we think. Rococo style explored and forwarded concepts that concerned how we are to find a way to understand ourselves.

1. The principal affects of Rococo style deny natural causality and instead suggest a different deep structure of reality. It presents an atectonic world, that is, a world in which the true relations of weights and the supports that bear weight must be understood in ways that contrast with the theories of natural philosophy. Atectonicity links the Rococo arts to one another.

2. Berkeley held that material causality was apparent and not real. The real world is ideal and is perfectly contingent on divine providence, natural laws having no other basis. His attack on causality links his idealist ontology to the Rococo arts by way of atectonic effects.

3. Vico held all truth is made by human persons through diachronic processes of discovery under providential guidance. He rejected the view that the divine creation occurred with a cosmology that holds celestial harmony to be the type of earthly mechanics in favor of the view that the deep complexity of reality is continuously produced by non-material forces. His view of creation links his metaphysics to Rococo style through the atectonic effect and the critique of mechanical causality. Furthermore, Rococo production requires a notion of human creativity that has strong analogical similarities to Vico's conceptions. 
4. This thesis links Berkeley, whose early idealist ontology became more esoteric than philosophical, with Vico, whose early work I hold to argue for an idealist ontology.

5. The Rococo concept of rocaille as a basic, omnipresent, and infinitely plastic stuff that humans as makers use to create their world is an expression of the idealist notion, common to Berkeley and Vico, that ideas comprise reality.

6. Atectonicity is one form of the perennial desire to animate material nature through human effort. This links certain Rococo effects to pre-cinematic visuality in the early modern period.

7. Rococo objects frequently display the contradictions of apparent but unreal stability with non-material stability by subtle, showy plays on visual impressions of stability. This effect juxtaposes the Rococo against both the hierarchical stability of the Baroque world view and the conviction that physical nature provides stable and implacable laws of both materiality and morality.

8. The way in which Rococo production and idealist philosophical conceptions are linked is one of exemplary sites in early modernity of the discovery of the deep structure of human personhood through diachronic inquiry. For historians and philosophers of history the episode show that intellectual history is capable of illuminating what other historiographic practices do not examine.

Neither logic abstracted from conception nor materiality abstracted from 
production avoids reduction. They both leave the perennial mysteries of expression, reception, and understanding among humankind, a group of persons desperately outmatched by the cosmos in which it lives and in perpetual struggle between the goods that communication can yield in all matters and its self-destructive capacity to choke on its own successes. What the communication of information actually is depends on what we come to understand about what roles analogy, metaphor, allegory, paradox, and enigma play in understanding the meaning of conception and production in historical time. This in the end is a question not of the agency people have, nor of their subjectivity, but of something that always slips the grasp of rational inquiry but that returns in each and every experience of moral obligation: human personhood. 


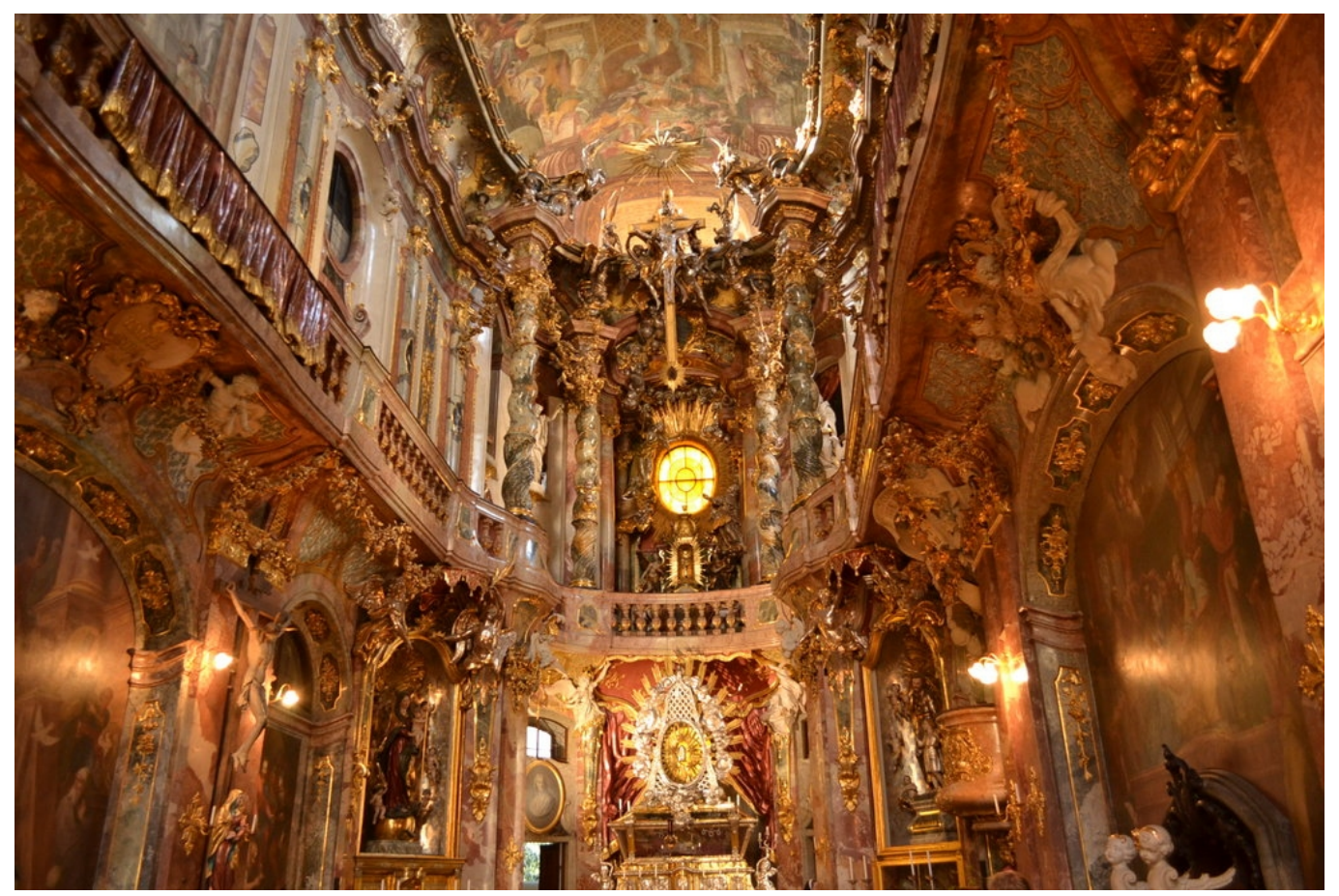

Figure 1

Church of St. John Nepomuk, called the Asamkirche. Egid Quirin Asam and Cosmas Damian Asam, architects. Munich, 1733-1746. 


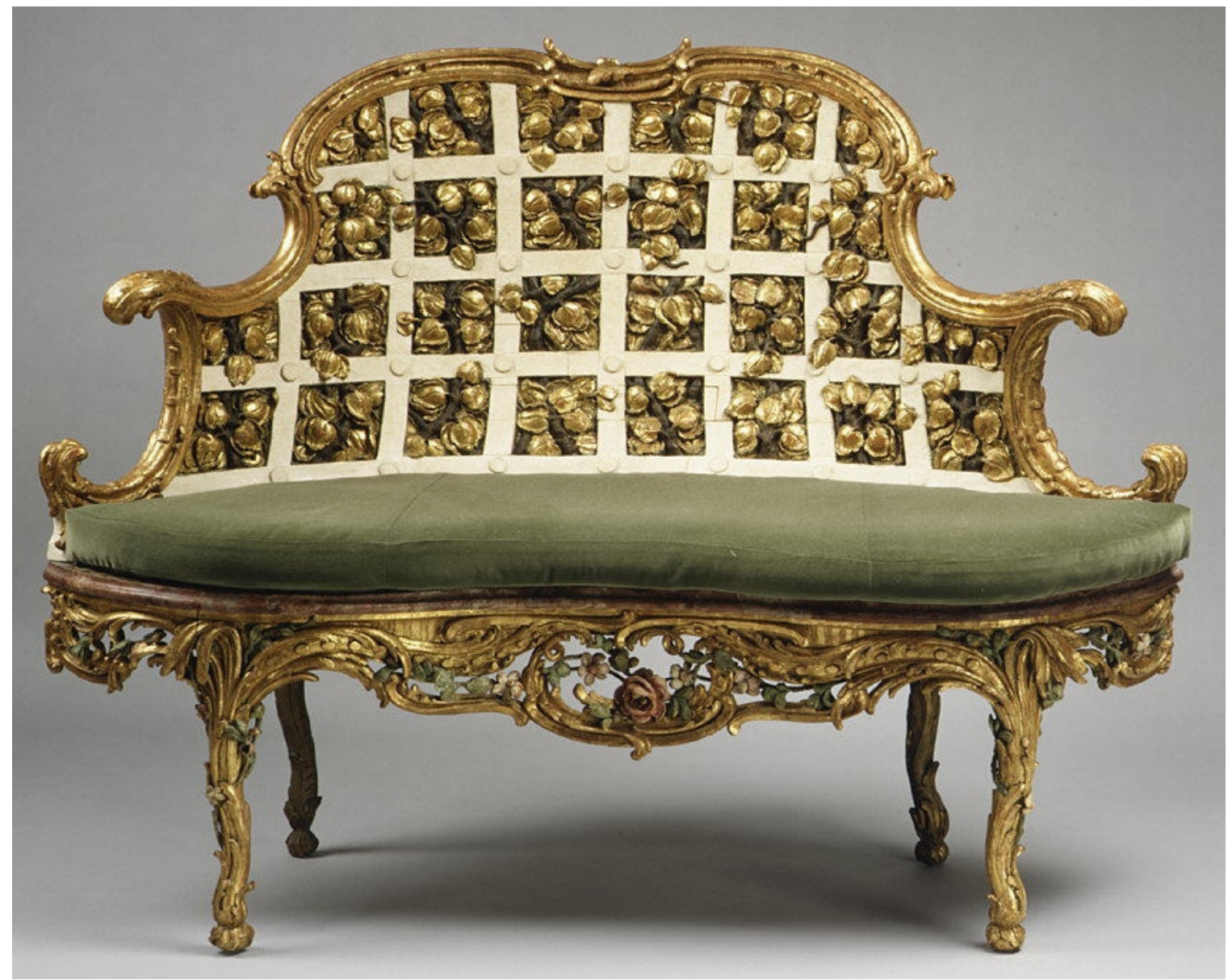

Figure 2

Settee (part of a set). Carved, painted, and gilded limewood. Attributed to Johann Michael Bauer. Bamberg, c. 1753-1764.

Metropolitan Museum of Art, New York. 1974.356.121a. 


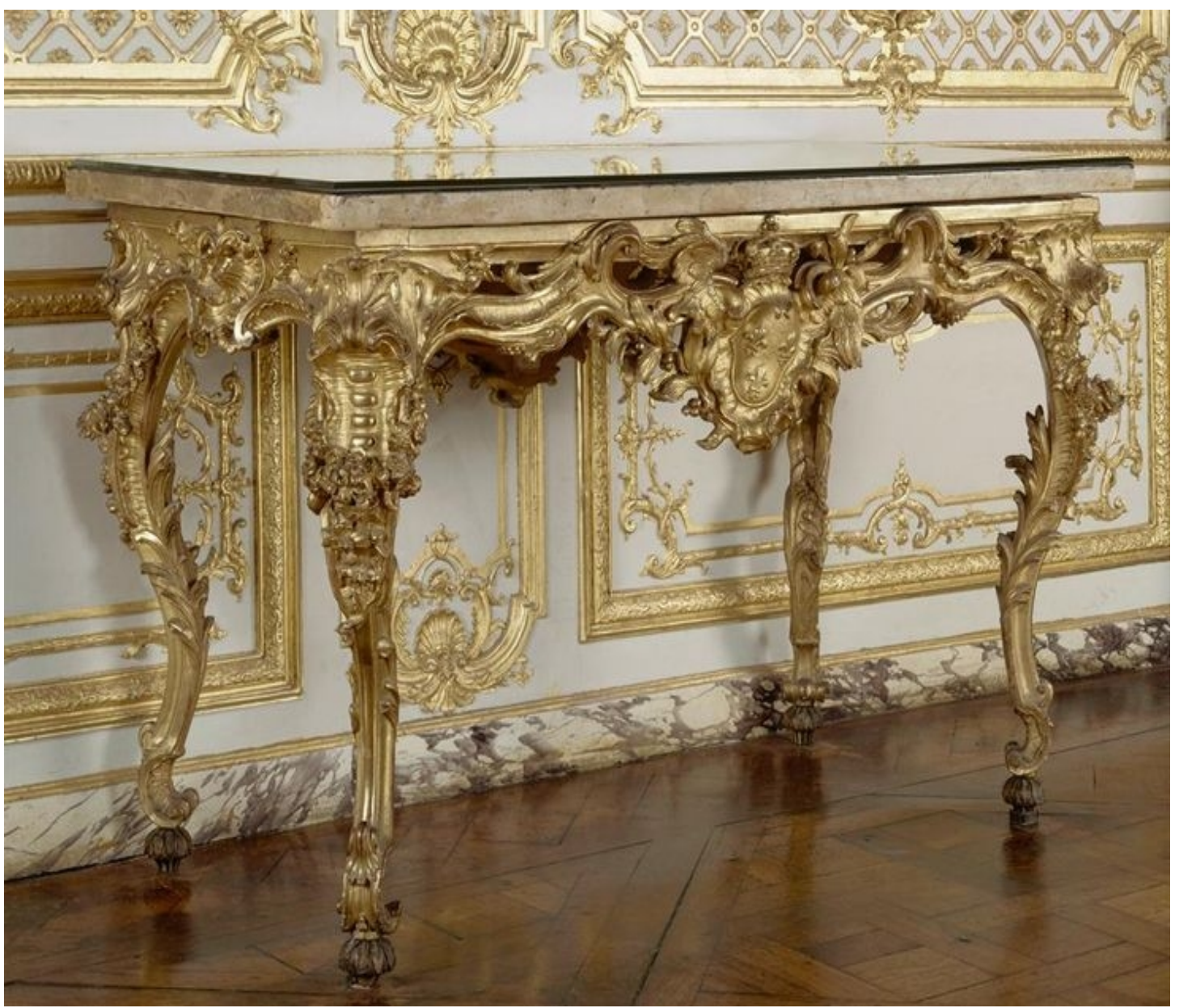

Figure 3

Console (hunting) table of Louis XV. Wood, gilded. Andrieux de Benson and Roumier François Bardou. Versailles, 1736.

Musée national des châteaux de Versailles et de Trianon. Vmb1034-1. 


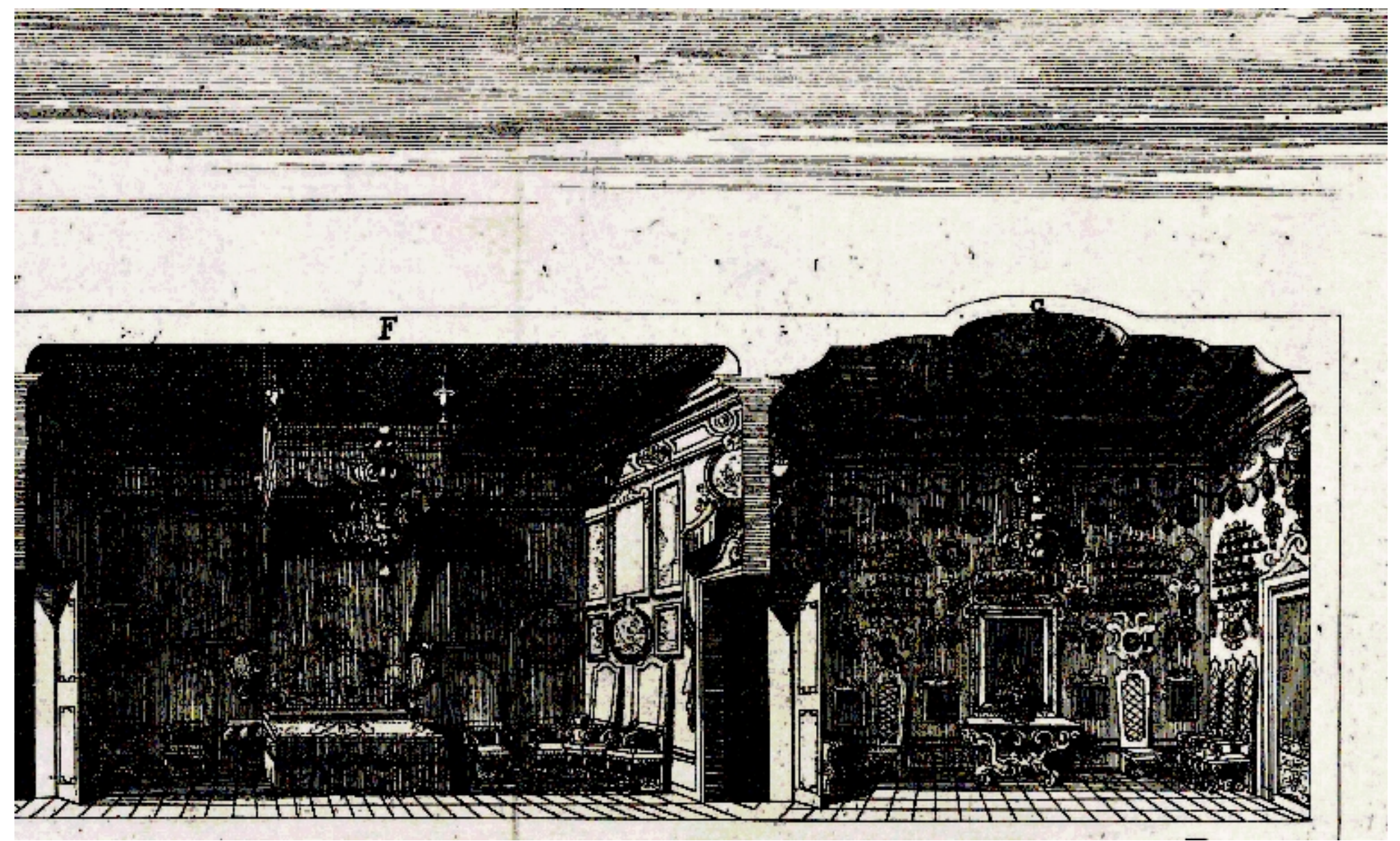

Figure 4

"Parade Apartment." Detail of fig. 4 showing the master bedroom (F) and inner cabinet $(\mathrm{G})$, in the Engraving by Filippo Succi after a drawing by Angelo Bolzano, architect unknown. Palazzo Cervelli, Ferrara, 1736. In Jacopo Agnelli, Descrizione delle grandiose solennità celebrate alla sublime presenza di Sua Eccellenza il sig. conte Lodovico Kevenhiller ... il di' 12. febbrajo 1736 dall' illustrissimo signor Fortunato de' Cervelli ... per le augustissime nozze di S. A. R. Francesco Steffano, duca di Lorena, e della serenissima arciduchessa Maria Teresa d'Austria: rime composte, e consacrate al nome immortale degl'invittissimi sposi. Ferrara, Domenico Bolzoni Giglio, 1736.

Getty Research Institute, Los Angeles. 1385-308. 


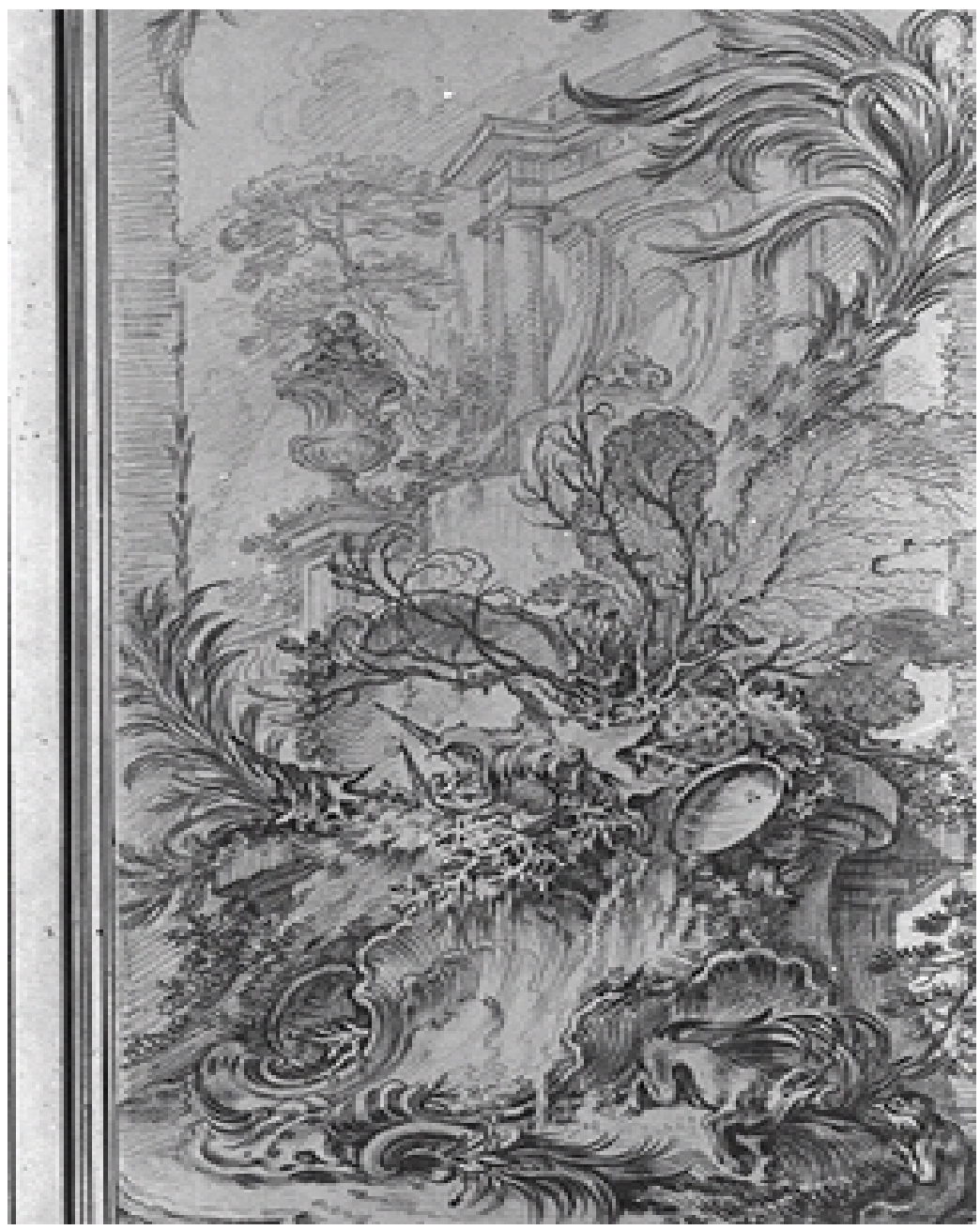

Figure 5

[Rocaille avec plantes exotiques et deux singes]. Ink drawing. Francois Boucher. Paris, c. 1750.

École nationale supérieur des beaux-arts, Paris. O.403. 


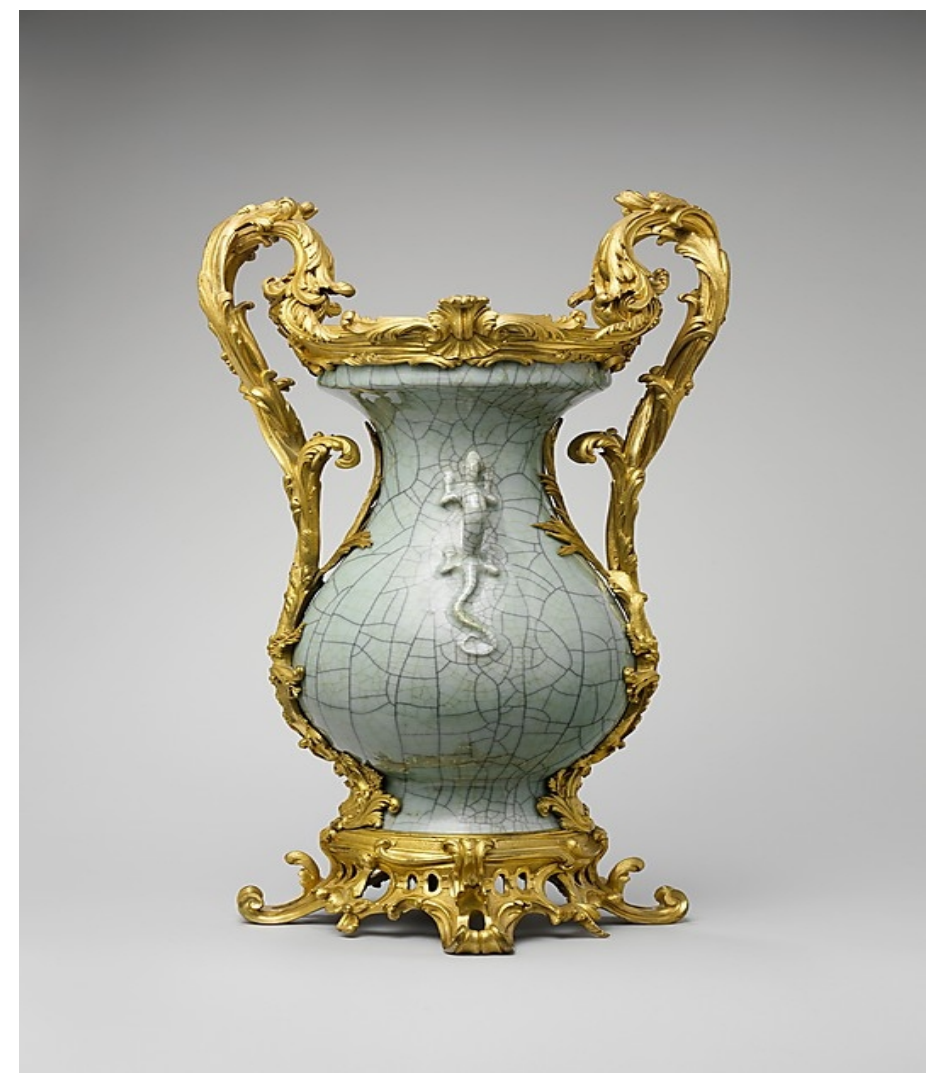

Figure 6

Mounted vase. Chinese hard-paste porcelain vase with French gilt-bronze mounts. Artists unknown. Paris, c. 1750.

Metropolitan Museum of Art, New York. 1971.206.22. 


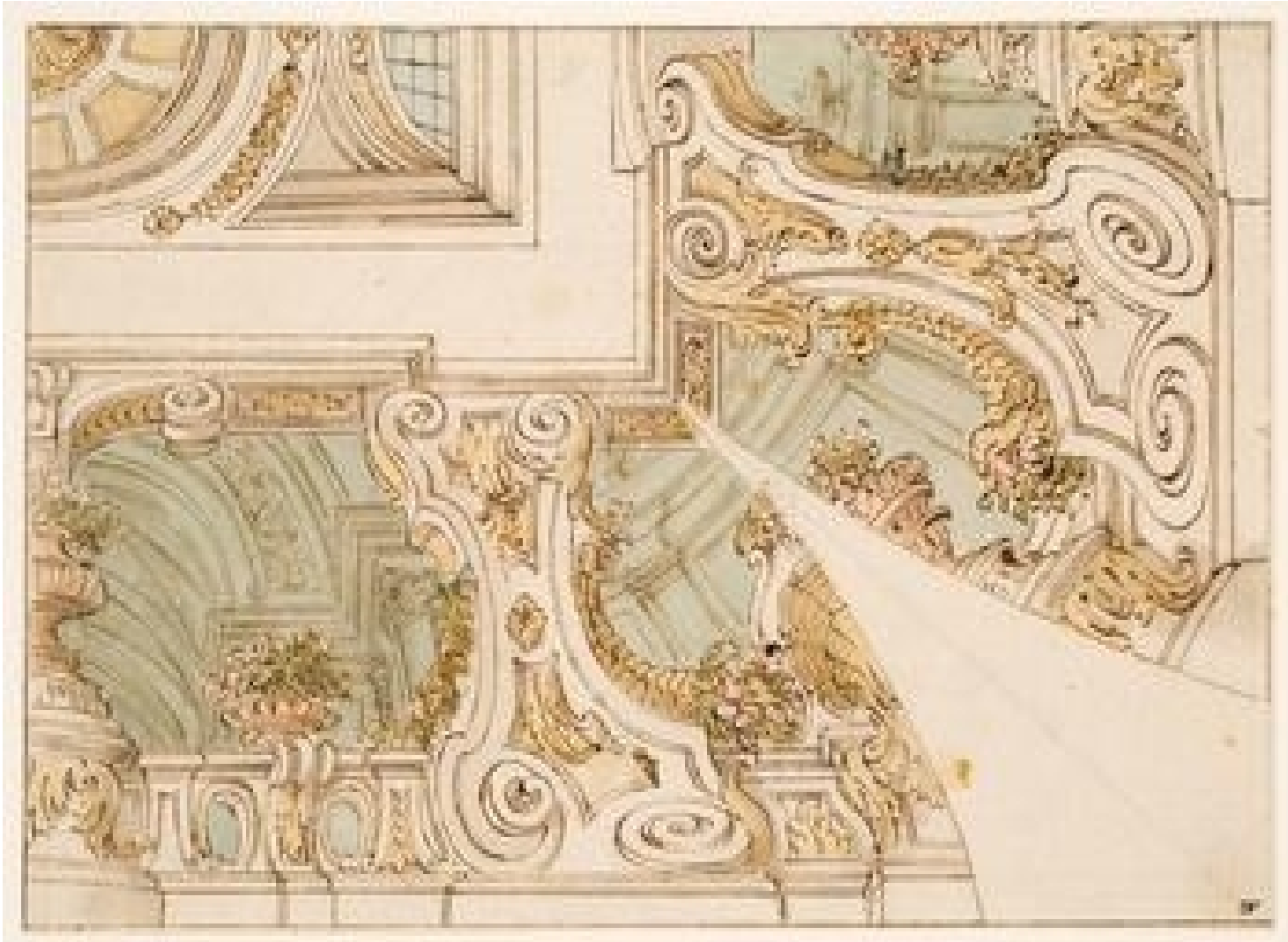

Figure 7

Design for the decoration of a ceiling. Pen and brown ink and coloured wash over graphite. Attributed to Ferdinando Galli Bibiena or atelier draughtsman. Late 17 th-early 18 th century.

Canadian Centre for Architecture, Montréal. DR1960:0025. 


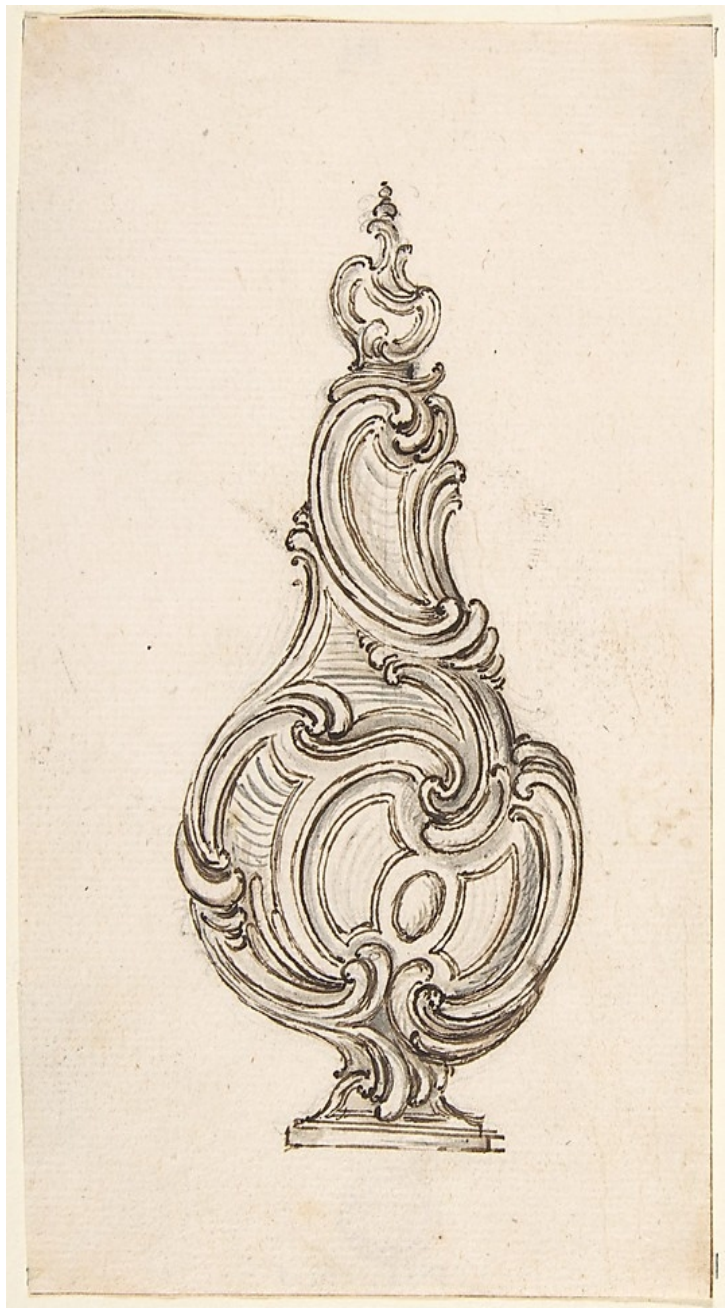

Figure 8

Ornament design. Pen and brown ink, brush and gray wash over graphite underdrawing. Jules-Aurèle Meissonier. Paris, c. 1730-1750.

Metropolitan Museum of Art, New York. 1986.1032.1. 


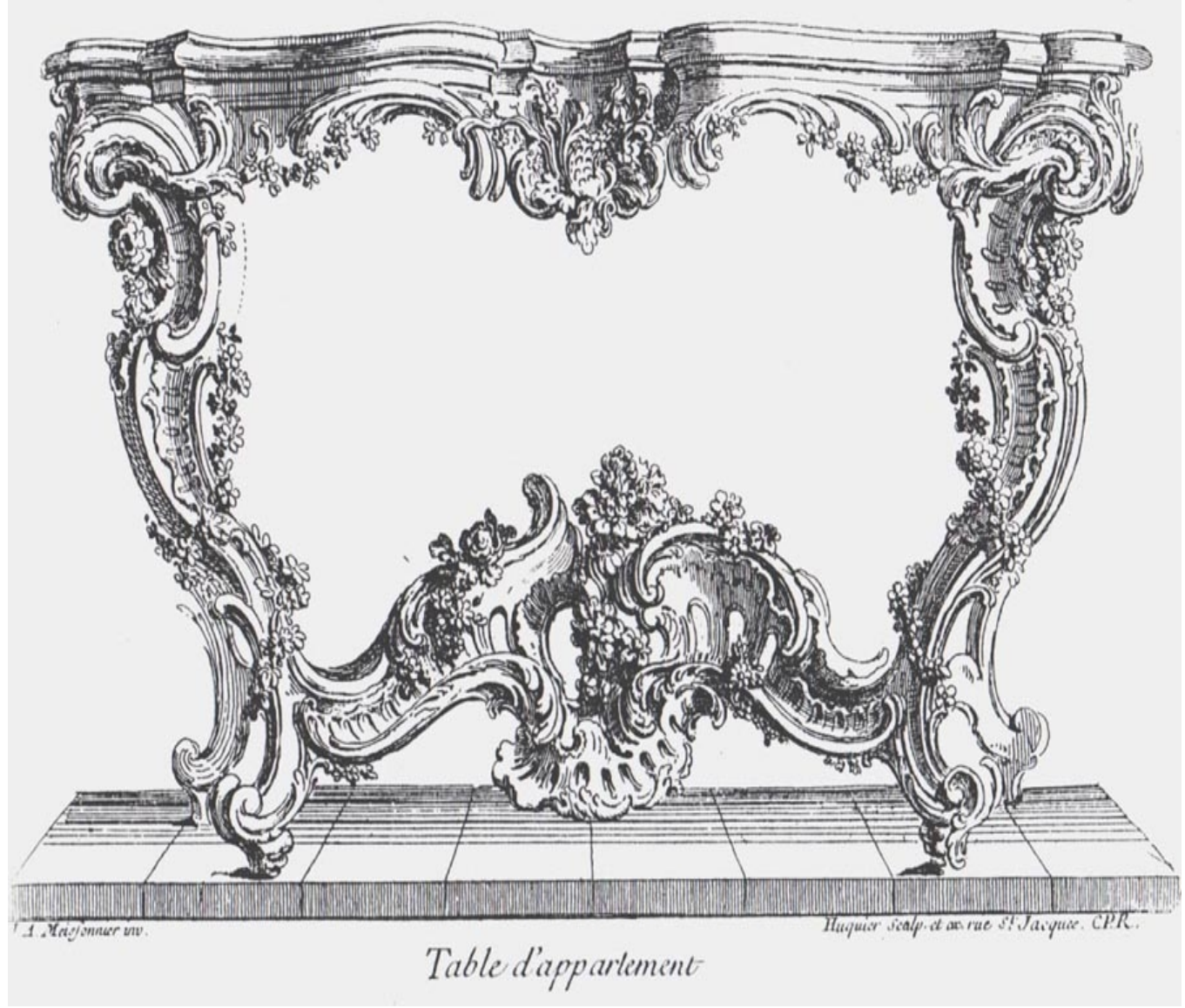

Figure 9

Design for table d'appartement. Engaving. Jules-Aurèle Meissoner, Livres d'ornements en trente pieces and Ornements de la carte chronologique. Paris, c. 1730. 


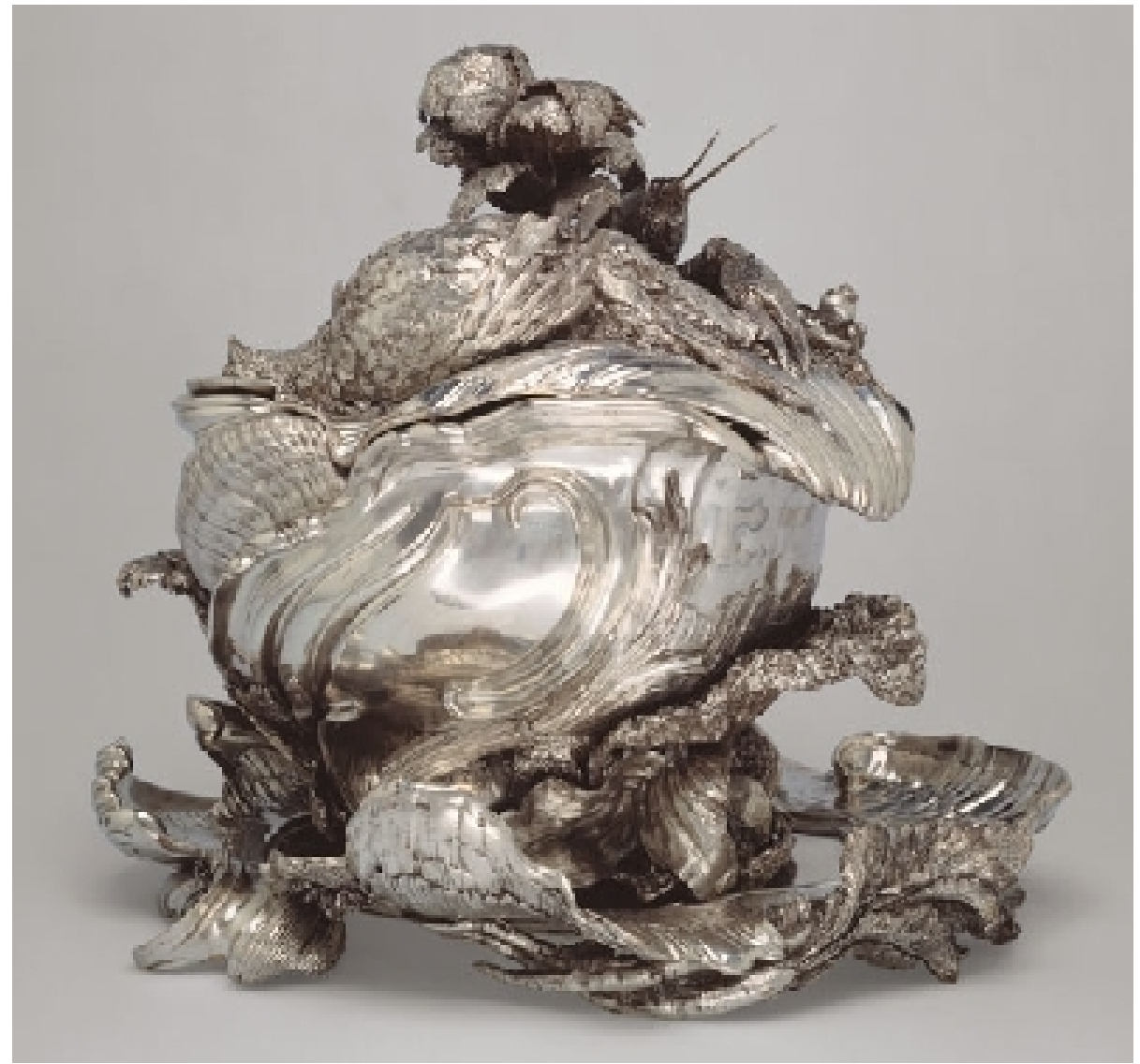

Figure 10

Tureen, stand and cover. Silver. Designed by Juste-Aurèle Meissonnier, executed by Pierre-François Bonnestrenne and Henry Adnet. Paris, 1735-1740.

Cleveland Museum of Art, Cleveland. 1977.182. 


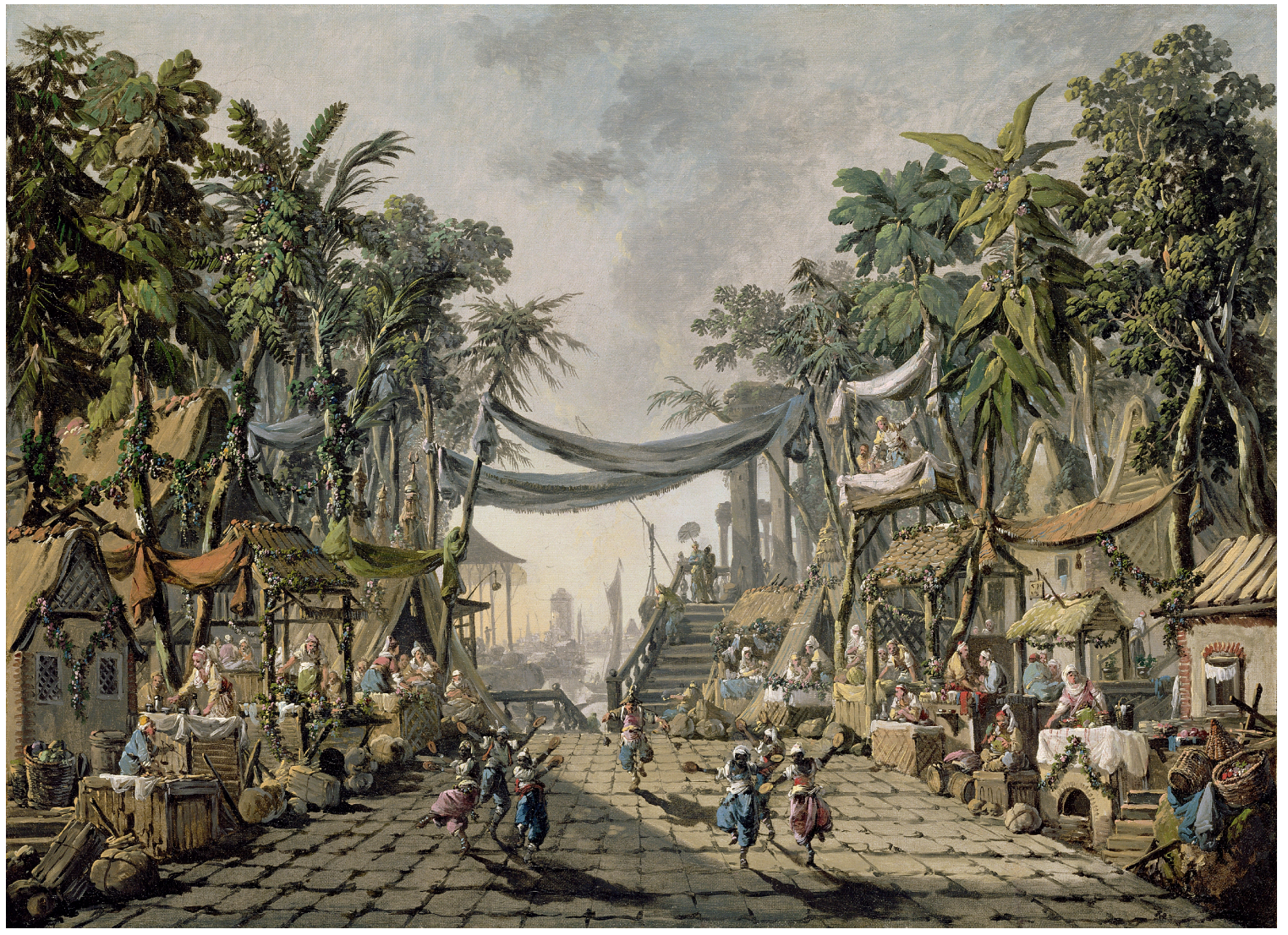

Figure 11

Market Scene in an Imaginary Oriental Port. Oil on canvas. Jean-Baptiste Pillement. France, about 1764.

J. Paul Getty Museum, Los Angeles. 2003.20. 


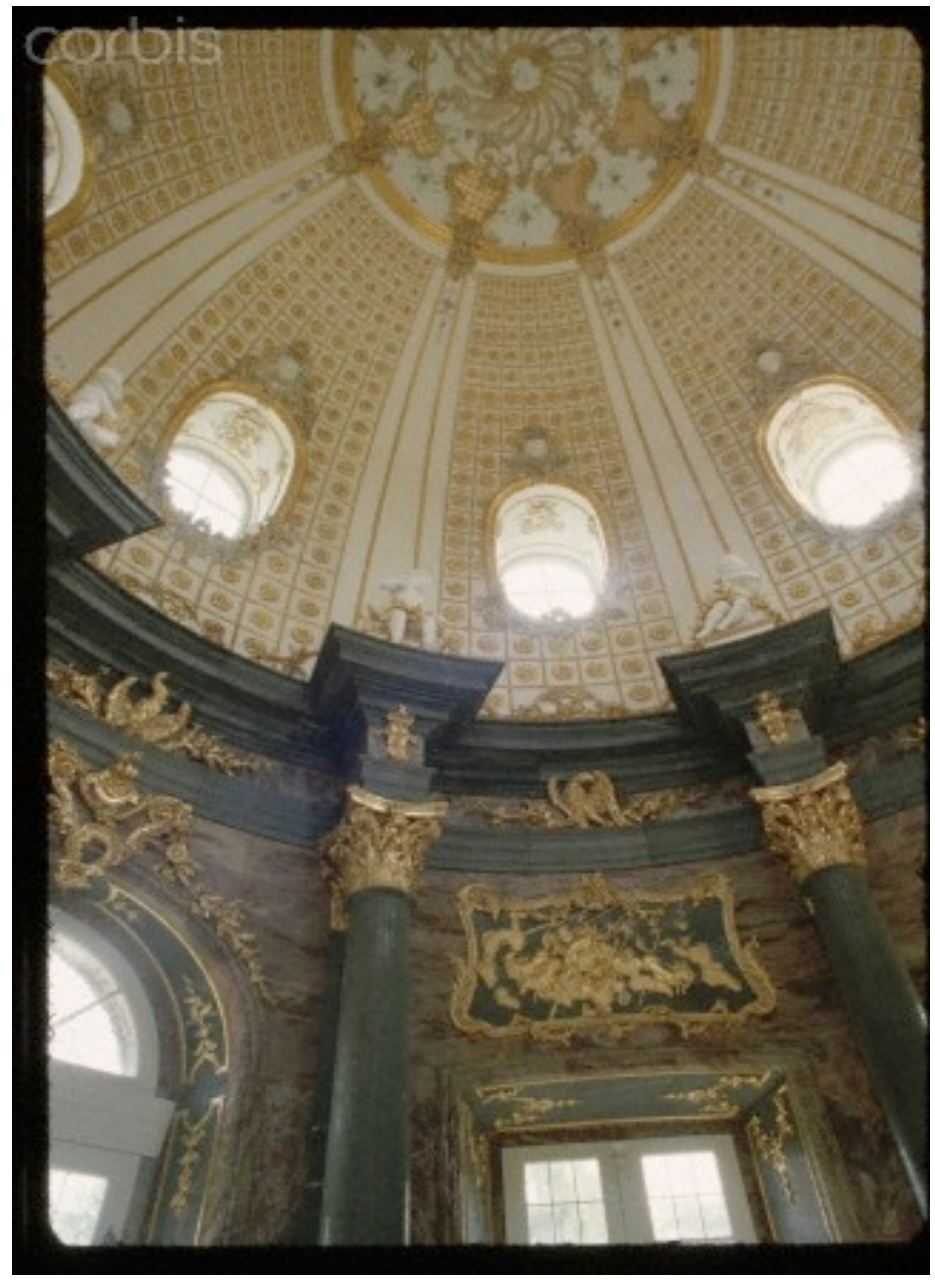

Figure 12

Interior of the dome of the Apollotempel, Hermitage, Neu Schloss, Bayreuth. Joseph St.-Pierre and Carl von Gontard, architects, after designs by Ferdinand Galli Bibiena, 1750.

(Corbis Images) 


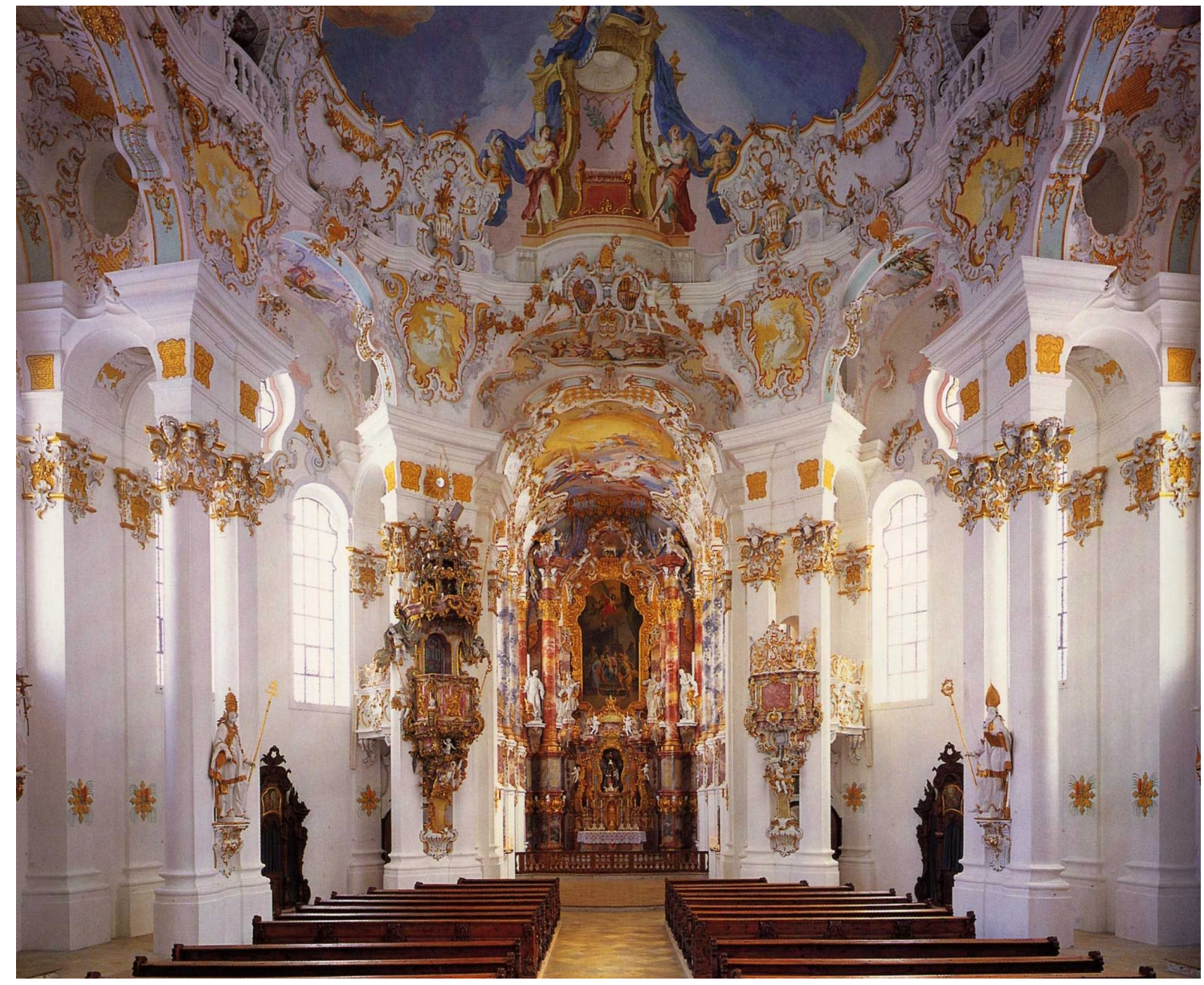

Figure 13

Choir, Weiskirche. Dominikus Zimmerman, architect. Steingaden, Bavaria, 1745. 


\section{Bibliography}

\section{Primary Sources:}

Berkeley, George (Bp. of Cloyne). Philosophical Commentaries, generally called the Commonplace book. Edited by A. A. Luce. London and New York: T. Nelson and Sons, 1944.

-------. The Works of George Berkeley Bishop of Cloyne. Edited by A. A. Luce and T. E. Jessop London and New York: T. Nelson and Sons, 1948-1957.

Diderot, Denis. Lettre sur les aveugles. Edited by Robert Niklaus. Geneva: Droz, 1951.

-------. Salons. Edited by Jean Seznec and Jean Adhémar. Oxford: Clarendon Press, 1957-1967. 4 volumes.

Kant, Immanuel. The Critique of Judgment. Translated by James Creed Meredith. Oxford: Clarendon, 1969.

------. The Critique of Practical Reason. Translated by Lewis White Beck. Indianapolis: Bobbs-Merrill, 1956.

------. Opus Posthumum . Translated by Eckart Förster and Michael Rosen. Cambridge: Cambridge University Press, 1993.

Leibniz, G. W. F. "La correspondance de Leibniz avec Goldbach." Edited by A. P. Juschkewitsch and Ju. Ch. Kopelewits. In Studia Leibnitiana, vol. 20, no. 2 (1988): 175-189.

Montesquieu, Charles Louis Secondat, baron de. Essai sur le goût. Edited by CharlesJacques Beyer. Geneva: Droz, 1967.

Nicholas of Cusa. A Concise Introduction to the Philosophy of Nicholas of Cusa (Trialogus de Possest). Translated by Jasper Hopkins. Minneapolis: University of Minnesota Press, 1978. 
Vico, Giambattista. The Autobiography of Giambattista Vico. Edited and translated by Thomas Goddard Bergin and Max Harold Fisch. Ithaca: Cornell University Press, 1944.

------. De Uno Universi Iuris et Principe Uno. In Il diritto universale, vol. 1 (Opere, part 2). Edited by Fausto Nicolinu. Bari: Laterza, 1968.

-------. The First New Science. Edited and translated by Leon Pompa. Cambridge and New York: Cambridge University Press, 2002.

-------. The New Science of Giambattista Vico. Edited and translated by Thomas Goddard Bergin and Max Harold Fisch. Ithaca and London: Cornell University Press, 1988.

-------. On the Most Ancient Wisdom of the Italians: drawn out from the origins of the Latin language. Edited by Robert Milner. Translated by Jason Taylor. New Haven: Yale University Press, 2010.

------. On the Most Ancient Wisdom of the Italians Unearthed from the Origins of the Latin Language Including the Disputation with the Giornale de' Litterati d'Italia. Edited and translated by L. M. Palmer. Ithaca: Cornell University Press, 1988.

Secondary Sources:

Philosophy and of History and Historiographic Theory

Adorno, Theodor W. "Extorted Reconciliation: On Georg Lukács' Realism in Our Time.” In Theodor W. Adorno, Notes to Literature. Volume One, translated by Sherry Weber Nicholsen, 216-240. New York: Columbia University Press, 1974.

Appadurai, Arjun. "Commodities and Political Value." In The Social Life of Things. Commodities in Cultural Perspective, edited by Arjun Appadurai, 3-64. Cambridge: Cambridge University Press, 1988. 
Bachelard, Gaston. The Poetics of Space. Translated by Maria Jolas. Boston: Beacon Press, 1994.

Bagnoli, Carla. "Constructivism in Metaethics." In the Stanford Encyclopedia of Philosophy, online at: http://plato.stanford.edu/entries/constructivism-metaethics/

Ball, Karen. "Hayden White's Hope, of the Politics of Prefiguration." In Doran, ed., 89-108.

Bataille, Georges. The Accursed Share. An Essay on General Economy. Translated by Robert Hurley. Cambridge: Zone Books, 1988.

Blackwell, C. W. T., ed. Models of the History of Philosophy: From Its Origins in the Renaissance to the 'Historia Philosophica." Dordrecht: Kluwer. 1993

Cartwright, Lisa and Brian Goldfarb. "Radiography, Cinematography and the Decline of the Lens." In Crary and Kwinter, eds., 190-201.

Chabot, Pascal. The Philosophy of Simondon: Between Technology and Individuation. Translated by Alicia Krefetz. London: Bloomsbury, 2003.

Chakrabarty, Dipesh . "The Climate of History: Four Theses." Critical Inquiry, vol. 35, no. 2 (Winter 2009): 197-222.

Combes, Muriel. Gilbert Simondon and the Philosophy of the Individuation. Translated by Thomas LaMarre. Cambridge: MIT Press, 2013.

Crary, Jonathan and Sanford Kwinter, eds. Incorporations. New York: Zone, 1992.

Davies, Martin L. Historics. Why History Dominates Contemporary Society. London and New York: Routledge, 2006.

-------. Imprisoned by History. Aspects of Historicized Life. London and New York: Routledge, 2010.

-------. "The Redundancy of History in a Historicized World." Rethinking History, vol. 15, no. 3, (September 2011): 335-353. 
De Boever, Arne. Introduction to Gilbert Simondon: Being and Technology. Edited by Arne De Boever, Alex Murray, Jon Roffe, and Ashley Woodward. Edinburgh: Edinburgh University Press, 2012.

Debord, Guy. The Society of the Spectacle. Translated by Donald Nicholson-Smith. New York: Zone Books, 1996.

Doran, Robert, ed. Philosophy of History After Hayden White. London: Bloomsbury, 2013.

Ernst, Wolfgang. "Media Archaeology: Method and Machine versus History and Narrative of Media." In Huhtami and Parikka, eds., 239-255.

Ferraris, Maurizio. Documentality: Why it is Necessary to Leave Traces. Translated by Richard Davies. New York: Fordham University Press, 2013.

Foucault, Michel. Religion and Culture. Edited Jeremy R. Carrette. New York: Routledge, 1999.

Fromm, Harold. "How We Became So Beautiful and Bright: Deep History and Evolutionary Anthropology." The Hudson Review, vol. 65, no. 1 (Spring, 2012): 19-42.

Glasersfeld, Ernst von. "An Introduction to Radical Constructivism.” In The Invented Reality: how do we know what we believe we know? Contributions to Constructivism, edited by Paul Watzlawick, translated by the author, 17-40. New York : Norton, 1984.

-------, ed. Marie Larochelle. Key Works in Radical Constructivism. Rotterdam: Sense, 2007.

Goldenbaum, Ursula. "Understanding the Argument Through the Then-Current Public Devates, or My Detective Method of the History of Philosophy." In Lærke et al., eds., 71-90.

Gombrich, Ernst. "Back from Oblivion.” Review of Frances Haskell, Past and Present in Art and Taste: Selected Essays (New Haven: Yale University Press, 1987). New York Review of Books, June 25, 1987. Online at http://www.nybooks.com/articles/archives/1987/jun/25/back-from-oblivion/ 
Habermas, Jürgen. The Philosophical Discourse of Modernity. Twelve Lectures. Translated by Frederick Lawrence. Cambridge: MIT Press, 1995.

Hacking, Ian. Historical Ontology. Cambridge: Harvard University Press, 2002.

Harootunian, Harry. "Uneven Temporalities / Untime Pasts: Hayden White and the Question of Temporal Form.” In Doran, ed., 119-150.

Harvey, David. The Condition of Postmodernity: An Enquiry into the Origins of Cultural Change. Oxford: Blackwell, 1989.

Hoel, Aud Sissel and Iris van der Tuin. "The Ontological Force of Technicity: Reading Cassirer and Simondon Diffractively." Philosophy \& Technology, vol. 26, no. 2 (June 2013): 187-202.

Houle, Karen and Jim Vernon, eds. Hegel and Deleuze. Together Again for the First Time. Evanston: Northwestern University Press, 2013.

Huhtamo, Erkki. "Dismantling the Fairy Engine: Media Archaelogy as Topos Study." In Huhtami and Parikka, eds., 27-47.

------ and Jussi Parikka. Introduction to Media Archaeology. Approaches, Application, and Implications. Berkeley: University of California Press, 2011.

------, eds.. Media Archaeology. Approaches, Application, and Implications. Berkeley: University of California Press, 2011.

Kluitenberg, Eric. "On the Archaeology of Imaginary Media." In Huhtami and Parikka, eds., 48-69.

Koselleck, Reinhart. Futures Past. On the Semantics of Historical Time. Translated by Kenneth Tribe. Cambridge: MIT Press, 1985.

Lærke, Mogens, Justin E.H. Smith, and Eric Schliesser, eds. Philosophy and its History: Aims and Methods in the Study of Early Modern Philosophy . Oxford: Oxford University Press, 2013.

Langer, Suzanne K. Feeling and Form. A Theory of Art. New York: Scribner, 1953. 
Livingston, Paisley. "History of the Ontology of Art." In The Stanford Encyclopedia of Philosophy (2011), online at:

http://plato.stanford.edu/entries/art-ontology-history/

Lumsden, Simon. "Deleuze and Hegel on the Limits of Self-Determined Subjectivity." In Houle and Vernon, eds., 133-151.

Madison, G. B. The Hermeneutics of Postmodernity. Figures and Themes. Bloomington: Indiana University Pres, 1988.

Malusa, Luciano. "The First General Histories of Philosophy in England and the Low Countries.” In Blackwell, ed., 161-370.

------. "Renaissance Antecedents to the Historiography of Philosophy." In Blackwell, ed., 3-65.

Matthews, Michael R. "Constructivism and Science Education: Some Epistemological Problems." Journal of Science Education and Technology, vol. 2, no. 1 (1993): 359-370.

McHenry, Leemon B. "The Ontology of the Past: Whitehead and Santayana." The Journal of Speculative Philosophy, vol. 14 (n.s.), no. 3 (2000): 219-231.

Micheli, Giuseppe. "The History of Philosophy in Germany in the Second Half of the Seventeenth Century." In Blackwell, ed., 371-476.

Paul, L. A. and Ned Hall. Causation. A User's Guide. Oxford: Oxford University Press, 2013.

Rockmore, Tom. "Subjectivity and the Ontology of History." The Monist, vol. 74, no. 2 (April, 1991): 187-206.

Simondon, Gilbert. "The Genesis of the Individual." Translated by Marc Cohen and Sanford Kwinter. In Crary and Kwinter, eds., 296-319.

------. Du mode d'existence des objets techniques. Edition augmentée. Edited by John Hart. Paris: Aubier, 1989. 
------. On the Mode of Existence of Technical Objects. Translated by Ninian Mellamphy. London, ON: University of Western Ontario, 1980. Ebook open access online at: http://www.academia.edu/4184556/Gilbert_Simondon_On_the_Mode_of_Exis tence_of_Technical_Objects.

Smith, Justin E. H. "The History of Philosophy as Past and as Process: Ways of Writing History of Philosophy." In Philosophy and its History...., edited by Mogens Lærke, et al., 30-49.

Sprigge, Timothy. "Whitehead and Santayana." Process Studies, vol. 28, no. 102 (Summer, 1999): 43-55.

Suchting, W. A. "Constructivism Deconstructed." Science and Education, vol. 1 (1992): 223-254.

Tolomio, Ilario. "The 'Historia Philosophica' in the Sixteenth and Seventeenth Centuries.” In Blackwell, ed., 66-160.

Tucker, Azeviel. Our Knowledge of the Past: a philosophy of historiography. Cambridge: Cambridge University Press, 2004.

Valéry, Paul. Paul Valéry An Anthology. Edited by James R. Lawler. Princeton: Princeton University Press, 1977.

Uidhur, Christy Mag. Introduction to Art and Abstract Objects. Edited by Christy Mag Uidhur. Oxford: Oxford University Press, 2012.

Velleman, David. "Narrative Explanation." The Philosophical Review, vol. 112, no. 1 (January, 2003): 1-25.

Widder, Nathan. "Negation, Disjunction, and a New Theory of Forces: Deleuze's Critique of Hegel." In Houle and Vernon, eds., 18-38.

Wiegel, Sigrid. Walter Benjamin Images, the Creaturely, and the Holy. Translated by Chadwick Truscott Smith. Stanford: Stanford University Press, 2013. 
$\underline{\text { Rococo and Rococo-related art history and criticism }}$

(Accademia Nazionale dei Lincei). Manierismo, Barocco, Rococò: Concetti e Termini. Convegno Internazionale.... Relazione e Discussioni. Rome: Accademia Nazionale dei Lincei, 1962.

Adorno, Theodor and Max Horkheimer. Dialectic of Enlightenment. Translated by John Cumming. New York: Continuum, 1988.

Baarsen, Reinier, et al. Rococo in Nederland. Amsterdam: Rijksmuseum Nederlands, 2001.

Bakhtin, Mikhail. Rabelais and His World. Translated by Helen Iswolsky. Bloomington: Indiana University Press, 1984.

Bates, David. "Super-Epistemology.” In Edelstein, ed., 53-74.

Bauer, Hermann. Rocaille. Zur Herkunft und zum Wesen eines Ornament-Motivs. Berlin: de Gruyter, 1962.

Benjamin, Walter. The Origins of German Tragic Drama. Translated by John Osborne. London: NLB, 1977.

Binni, Walter. "Il Rococò letterario." In (Accademia Nazionale), 218-237.

Blunt, Anthony, Alastair Lang, Christopher Tadgell, and Kerry Downes. Baroque and Rococo Architecture and Decoration. New York: Harper \& Row, 1978.

Bobro, Marc. "Leibniz on Causation." In The Stanford Encyclopedia of Philosophy, online at:

http://plato.stanford.edu/archives/sum2013/entries/leibniz-causation/

Brady, Patrick. "A Sweet Disorder: Atomistic Empiricism and the Rococo Order of

Vision." Studies in Eighteenth Century Culture, vol. 7 (1978): 451-462.

------. "The Present State of Studies on the Rococo." Comparative Literature, vol. 27, no. 1 (Winter, 1975): 21-33. 
------. "Rococo Style in European Theater." In Eighteenth-century French theatre: aspects and contexts : studies presented to E. J. H. Greene, edited by Magdy Gabriel Badir and David J Langdon, eds., 53-73. Alberta: University of Alberta, 1986.

------. "Rococo Style in the Plastic Arts and Literature: Theory, Method, Application." In Literature and the Other Arts.... , edited by Zoran Konstantinovič, Steven P. Scher, and Ulrich Weisstein, 87-98. Innsbruck: Institut für Sprachwissenschaft der Universität Innsbruck, 1981.

Bremer-David, Charissa, ed. Paris: Life and Luxury in the Eighteenth Century. Los Angeles: Getty, 2011.

Brewer, Daniel. The Enlightenment Past. Recovering Eighteenth-century French Thought. Cambridge: Cambridge University Press, 2008.

Brion, Marcel. "Baroque et Esthétique du Mouvement." Études cinématographiques, vol. 1, no.s 1-2 (Spring-Winter, 1960): 13-31.

Brockett, Oscar G., Margaret Mitchell, and Linda Hardberger. Making the Scene: a history of stage design and technology in Europe and the United States. San Antonio, TX: Tobin Theatre Arts Fund, 2010.

Brugerolles, Emmanuelle, ed. Boucher, Watteau and the Origin of the Rococo. An exhibition of $18^{\text {th }}$ century drawings from the collection of the École Nationale Supérieure des Beaux-Arts. Paris: École Nationale Supérieure des Beaux-Arts., 2005.

Bryson, Norman. Word and Image. French Painting of the Ancien Régime. Cambridge: Cambridge University Press, 1981.

Buci-Glucksmann, Christine. The Madness of Vision. On Baroque Aesthetics. Translated by Dorothy Z. Baker. Athens: Ohio University Press, 2013. (La folie du voir, 1986.)

Burson, Jeffrey D. "Reflections on the Pluralization of Enlightenment and the Notion of Theological Enlightenment as Process." French History, vol. 26, no. 4 (2012): 525-537. 
Butterwick, Richard, Simon Davies, and Gabriel Sànchez Espinosa, eds. Peripheries of the Enlightenment. Oxford: Voltaire Foundation, 2010.

Castle, Terry. "The Culture of Travesty: sexuality and masquerade in eighteenthcentury England.” In Rousseau and Porter, eds.,156-180.

(Centre auxois d'études et de recherches sur le XVIIIe siècle). La Régence. Paris: Armand Colin, 1970.

Chatrak, André. "Le plair de l'ordre: pour une nouvelle lecture de l'Essai sur le goût de Montesquieu." In Du goût à l'esthétique: Montesquieu, edited by Jean Erhard and Catherin Volpilhac-Auger, 177-190.. Bordeaux: Presses universitaires de Bordeaux, 2007.

Coffin, Sarah, Gail Davidson, Ellen Lupton, and Penelope Hunter-Stiebel. Rococo: The Continuing Curve, 1730-2008. New York: Cooper-Hewitt National Design Museum, 2008.

Coke, David and Alan Borg. Vauxhall Gardens A History. New Haven: Yale University Press, 2011.

Comment, Bernard. The Panorama. London: Reaktion, 1994.

Crow, Thomas E. Painters and Public Life in Eighteenth-Century Paris. New Haven: Yale University Press, 1985.

Damisch, Hubert. A Theory of/cloud/. Toward a History of Painting. Translated by Janet Lloyd. Stanford: Stanford University Press, 2002.

Deleuze, Gilles. Difference \& Repetition. Translated by Paul Patton. New York: Columbia University Press, 1994.

-------. The Fold. Leibniz and the Baroque. Translated by Tom Conley. Minneapolis and London: University of Minnesota Press, 1993.

-----. "Leibniz." In Les Cours \& Conférences de Gilles Deleuze, at http://www.le-terrier.net/deleuze/07leibniz15-04-80.htm

------. Le Pli. Leibniz et le Baroque. Paris: Minuit, 1988. 
Deprun, Jean. "Diderot devant l'idéalisme." Revue internationale de philosophie, vol. 38, no. 148-9 (1984): 67-78.

-------. "Une oeuvre philosophique de la Régence: La Lettre de Thrasybule à Leucippe.” In (Centre auxois), 153-164.

Dieckmann, Herbert. "Reflections on the Use of Rococo as a Period Concept." In The Disciplines of Criticism. Essays in Literary Theory, Interpretation, and History, edited by Peter Demetz, Thomas Greene, and Lowry Nelson, Jr., 419-436. New Haven: Yale University Press, 1968.

Edelstein, Dan. The Enlightenment. A Genealogy. Chicago: University of Chicago Press, 2010.

-------, ed. The Super-Enlightenment: Daring to Know Too Much. Oxford: Voltaire Foundation, 2010.

Eliassen, Knut Ove and Yngve Sandhei Jacobsen. "Where were the Media Before the Media? Mediating the World at the Time of Condillac and Linnaeus." In Siskin and Warner, eds., 64-86.

Elkner, Brian. "Diderot and the Sublime: the Artist as Hero." In Studies in the Eighteenth Century. II. Papers presented at the Second David Nichol Smith Memorial Seminar Canberra 1970, edited by R. F. Brissenden, 143-162. Toronto: University of Toronto Press, 1973.

Engel, Claire-Eliane. "Le Régent collectioneur." In (Centre auxois), 58-65.

Fausch, Deborah. "Rococo Modernism: The Elegance of Style." Perspecta, vol. 32 (“Resurfacing Modernism"), (2001): 8-17.

Kimball, Fiske. The Creation of the Rococo. New York: Norton, 1964.

Fort, Bernadette. "Voice of the Public: The Carnivalization of Salon Art in Prerevolutionary Pamphlets." In Eighteenth-Century Studies, vol. 22, no. 3, (Spring, 1989): 368-394.

Foucault, Michel. The Order of Things. An Archaeology of the Human Sciences. New York: Vintage, 1994. 
Francastel, Pierre. "L'esthétique des lumières." In Utopie et Institutions au XVIIIe Siècle. Le Pragmtisme des Lumières, edited by Pierre Francastel, 330-352. Paris: Mouton, 1963.

Fried, David. Absorption and Theatricality. Painting and Beholder in the Age of Diderot. Berkeley: University of California Press, 1980.

Friedli, Lynne. "'Passing Women': a study of gender boundaries in the eighteenth century." In Rousseau and Porter, eds., 234-260.

Fuhring, Peter. Juste Aurèle Meissonnier. Un génie du rococo 1695-1750. Vol. 1. Turin and London: Umberto Allemandi, 1999.

------. “The Print Privilege in Eighteenth-Century France I.” The Print Quarterly, vol. 2, no. 3 (1985): 174-193.

------. "The Print Privilege in Eighteenth-Century France II.” The Print Quarterly, vol. 3, no. 1 (1986): 19-33.

Gallet, Michel. "Quelques Étapes du Rococo dans L’Architecture Parisienne." Gazette des Beaux-Arts (March, 1966): 145-168.

Gaukroger, Stephen. The Collapse of Mechanism and the Rise of Sensibility. Science and the Shaping of Modernity, 1680-1760. Oxford: Clarendon Press, 2010.

Glotton, Jean-Jacques. "L’architecture de la Régence.” In (Centre auxois), 44-57.

Gombrich, Ernst. The Sense of Order. A Study in the Psychology of Decorative Art. Ithaca: Cornell University Press, 1979.

Goncourt, Edmond and Jules. French XVII Century Painters. Translated by Robin Ironside. London: Phaidon, 1948.

Guyer, Paul. "18th Century German Aesthetics," in The Stanford Encyclopedia of Philosophy, online at: http://plato.stanford.edu/cgi-bin/encyclopedia/archinfo.cgi?entry=aesthetics-1 8th-german 
Hagan, David. "Threading the Needle: Problems in Reading Denis Diderot's La Lettre sur les aveugles à l'usage de ceux qui voient." Studies in Eighteenth Century Culture, vol. 40 (2011): 219-245.

Halsband, Robert. "The Rococo in England: Book Illustrators, Mainly Gravelot and Bentley." The Burlington Magazine, vol. 127, no. 993 (December, 1985): 870-880.

Harries, Karsten. The Bavarian Rococo Church. Between Faith and Aestheticism. New Haven and London: Yale University Press, 1983.

------. The Broken Frame. Three Lectures. Washington: Catholic University of America Press, 1989.

Hazard, Paul. European Thought in the Eighteenth Century from Montesquieu to Lessing. Translated by J. Lewis May. Gloucester, MA: Peter Smith, 1973.

Heyl, Bernard C. "Meanings of Baroque." The Journal of Aesthetics and Art Criticism, vol. 19, no. 1 (Spring, 1961): 275-287.

Hills, Helen, ed. Rethinking the Baroque. Burlington: Ashgate, 2011.

Hitchcock, Henry-Russell. "Peter II Thumb and German Rococo Architecture.” In Essays in the History of Architecture Presented to Rudolf Wittkower, edited by Douglas Fraser, Howard Hibbard, and Milton J. Lewine, 170-188. London: Phaidon, 1969.

Hobson, Marian. The Object of Art. The Theory of Illusion in Eighteenth-Century France. Cambridge: Cambridge University Press, 1982.

-------. "Philosophy and Rococo Style (2002)." In Marian Hobson, Diderot and Rousseau: Networks of Enlightenment, edited and translated by Kate E. Tunstall and Caroline Warman, 203-212 Oxford: Voltaire Foundation, 2011.

Huhtamo, Erkka. Illusions in Motion. Media Archaeology of the Moving Panorama and Related Spectacles. Cambridge: MIT Press, 2013.

Hyde, Melissa. "The 'Makeup' of the Marquise: Boucher's Portrait of Pompadour at Her Toilette.” The Art Bulletin, vol. 82, no. 3 (Sep., 2000): 453-475. 
-------. Making Up the Rococo. François Boucher and His Critics. Los Angeles: Getty Research Institute, 2006.

Kisluk-Grosheide, Daniëlle and Jeffrey Munger. The Wrightsman Galleries for French Decorative Arts. The Metropolitan Museum of Art. New Haven: Yale University Press, 2010.

Koepfe, Wolfram. Extravagant Inventions. The Princely Furniture of the Roentgens. New York: Metropolitan Museum of Art, 2012.

Krückmann, Peter O. Paradies des Rokoko. Das Bayreuth der Margräfin Wilhelmine. (Vol. 2: Peter O. Krückmann, ed. Galli Bibinea und der Musenhof der Marguerite von Bayreuth.) Munich: Prestel, 1998.

Laufer, Roger. Style Rococo, Style des “Lumieres”. Paris: Librairie José Corti, 1963.

Lawrenson. T. E. The French Stage and Playhouse in the XVIIth Century: A Study in the Advent of the Italian Order. New York: AMS Press, 1986.

Levey, Michael. Rococo to Revolution. Major Trends in Eighteenth-Century Painting. London: Thames and Hudson, 1977.

Levin, David Michael, ed. The Discursive Construction of Sight in the History of Philosophy. Cambridge: MIT Press, 1997.

Liebold, Christine. Das Rokoko un ursprünglich mittelaterlichen Kirchen das bayerischen Gebietes - ein von maurinischem Denken geprägter stil. Munich: Stadtarchivs München, 1981.

Loos, Adolf. "Ornament and Crime." In Ornament and Crime: Selected Essays, edited by Adolf Opel, 166-176. Riverside, CA: Ariadne Press, 1998.

Mallory, Nina A. Roman Rococo Architecture from Clement XI to Benedict XIV (1700-1758). New York and London: Garland, 1977. (Reprint of Ph.D. dissertation, Columbia University, 1965.)

Mannoni, Laurent. The Great Art of Light and Shadow. Archaelogy of the Cinema. Translated and edited by Richard Crangle. Exeter, UK: University of Exeter Press, 2000. 
Maravall, José Antonio. Culture of the Baroque. Translated by Terry Cochran. Minneapolis: University of Minnesota Press, 1986.

Massey, Lyle. Picturing Space, Displacing bodies: Anamorphosis in Early Modern Theories of Perspective. University Park, PA.: Pennsylvania State University Press, 2007.

McKeon, Michael. "Mediation as Primal World: The Arts, the Sciences, and the Origins of the Aesthetic." In Siskin and Warner, eds., 384-412.

Merritt, Melissa McBay. "The Moral Source of the Kantian Sublime.” In The Sublime From Antiquity to the Present, edited by Timothy Costelloe, 37-49. Cambridge: Cambridge University Press, 2012.

Metropolitan Museum of Art. The Wrightsman Galleries for French Decorative Arts. Online at: http://www.metmuseum.org/en/collections/new-installations/the-wrightsman -galleries-for-french-decorative-arts

Minguet, Philippe. Esthétique du rococo. Paris: J. Vrin, 1966.

Mitford, Nancy. Frederick the Great. New York: New York Review of Books, 2013.

-------. Madame de Pompadour. New York: New York Review of Books, 2001.

Morizot, Jacques. "18th Century French Aesthetics," in The Stanford Encyclopedia of Philosophy, online at: http://plato.stanford.edu/entries/aesthetics-18th-french/

Mortier, Roland and Hervé Hasquin, eds. Études sur le XVIII siècle: rocaille, rococo. Brussells: Université de Bruxelles, 1991.

Negrin, Llewelyn. "Ornament and the Feminine." Feminist Theory, vol. 7, no. 2 (2006): 219-235.

Newman, Nicholas. "In the Name of Rococo." RES: Anthropology and Aesthetics , no. 40 (Autumn, 2001): 129-134. 
North, Michael, ed. Kunstsammeln und Geschmack in 18. Jahrhundert. Berlin: Arno Spitz, 2002.

Panofsky, Erwin, ed. Irving Lavin. Three Essays on Style. Cambridge: MIT Press, 1995.

Pevsner, Nikolaus. "The Genesis of the Picturesque." In Studies in Art, Architecture and Design. Volume One. From Mannerism to Romanticism, 78-101. London: Thames and Hudson, 1968.

Park, William. The Idea of Rococo. Newark: University of Delaware Press, 1992.

Reill, Peter. "The Hermetic Imagination in the High and Late Enlightenment." In Edelstein, ed., 37-52.

Robinet, André. “Malebranchisme et Régence.” In (Centre auxois), 263-275.

Roland Michel, Marianne. La Joüe et L'art Rocaille. Paris: Athena, 1982.

Rousseau, G. S. and Roy Porter. Sexual Underworlds of the Enlightenment. Chapel Hill: University of North Carolina Press, 1988.

Saisselin, Rémy G. The Enlightenment against the Baroque. Economics and Aesthetics in the Eighteenth Century. Berkeley: University of California Press, 1992.

-------. "The Rococo as a Dream of Happiness." The Journal of Aesthetics and Art Criticism, vol. 19, no. 2 (Winter, 1960): 145-152 .

-----. "The Rococo Muddle." In Studies on Voltaire and the Eighteenth Century. Volume 47, 233- 255. Geneva: Institut et musée Voltaire, 1966.

-------. Taste in Eighteenth Century France. Critical Reflections on the Origin of Aesthetics or An Apology for Amateurs. Syracuse: Syracuse University Press, 1965.

Santoli, Vittorio. “Dichiarazione del tema del Convegno." In (Accademia), 11-23. 
Sargentson, Carolyn. Merchants and Luxury Markets. The Marchands Merciers of Eighteenth-Century Paris. London and Malibu: Victoria and Albert Museum and the J. Paul Getty Museum, 1996.

Schmitter, Amy. " $17^{\text {th }}$ and $18^{\text {th }}$ Century Theories of Emotions." In the Stanford Encyclopedia of Philosophy, online at: http://plato.stanford.edu/entries/emotions-17th18th/

Schönberger, Arno and Halldor Soehner. The Rococo Age. Art and civilization of the $18^{\text {th }}$ century. Translated by Daphne Woodward. New York: McGrawHill, 1963.

Schuster, Marianne. Johann Esaias Nilson. Ein Kupferstecher des Süddeutschen Rokoko 1721-1788. Munich: Neuer Fildser, 1936.

Scott, Katie. The Rococo Interior. Decoration and Social Spaces in Early EighteenthCentury Paris. New Haven and London: Yale University Press, 1995.

Sgard, Jean. "Style Rococo et style Régence." In (Centre auxois), 11-20.

Sheriff, Mary D. "The King, the Trickster, and the Gorgon: Jean-Marc Nattier and the Illusions of Rococo Art." Studies in Eighteenth Century Culture, vol. 40 (2011): 1-26.

Siskin, Clifford. "Mediated Enlightenment: The System of the World." In Siskin and Warner, eds., 164-172.

------- and William Warner, eds. This is Enlightenment. Chicago: University of Chicago Press, 2010.

Sitwell, Sacheverell. Baroque and Rococo. New York: G. P. Putnam’s Sons, 1967.

Smith, Justin E. H. Divine Machines. Leibniz and the Sciences of Life. Princeton and Oxford: Princeton University Press, 2011.

Snodin, Michael, ed. Rococo Art and Design in Hogarth's England. London: The Victoria and Albert Museum, 1984. 
Southern, Richard. Changeable Scenery. Its Origin and Development in the British Theatre. London: Faber and Faber, 1951.

Starobinski, Jean. The Invention of Liberty, 1700-1789. Translated by Bernard C. Swift. Geneva: Skira, 1964.

Tadgell, Christopher. Transformations: Baroque and Rococo in the age of absolutism and the Church Triumphant. London: Routledge, 2013.

Teskey, Gordon. Allegory and Violence. Ithaca: Cornell University Press, 1996.

Touma, Josephine. "From the Playhouse to the Page: Visual Sources for Watteau's Theatrical Universe." Studies in Eighteenth Century Culture, vol. 40 (2011): 83-101.

Verlet, Pierre. La Maison di XVIII.e Siècle en France. Société Docration Mobilier. Paris: Baschet, 1966.

-------. Le Mobilier Royal Française. Meubles de la Couronne Conservés en France. Paris: Plon, 1955.

Versini, Laurent. Baroque Montesquieu. Geneva: Droz, 2004.

Volpilhac-Auger, Catherine, ed. Montesquieu: les annees de formation (1689-1720); actes du colloque de Grenoble (26 -27 septembre 1996). Naples: Liguori, 1999.

Weisgerber, Jean. Le Rococo Beaux-Arts et litterature. Paris: Presses universitaires de France, 2001.

Zielinsky, Siegfried. Deep Time of the Media. Toward an Archaeology of Hearing and Seeing by Technical Means. Translated by Gloria Custance. Cambridge: MIT Press, 2006.

\section{Berkeley}

Atherton, Margaret. "Berkeley's Theory of Vision and its Reception." In Winkler, ed., 94-124. 
------. "How to Write the History of Vision: Understanding the Relationship between Berkeley and Descartes." In Levin, ed., 139-166.

Belfrage, Bertil. "Berkeley's Way Towards Constructivism.” In Berkeley's Lasting Legacy: 300 Years Later. Edited by Timo Airaksinenm and Bertil Belfrage, 3-14. Newcastle Upon Tyne: Cambridge Scholars Publishing, 2011.

Berman, David. "The Distrustful Philosopher: Berkeley Between the Devil and the Deep Blue Sea of Faith.” In Parigi, ed., 148-157.

------. George Berkeley: Idealism and the Man. Oxford: Oxford University Press, 1996.

Bertini, Daniel. “Berkeley, Theology and Bible Scholarship.” In Parigi, ed., 121-140.

Bettcher, Talia May. "Berkeley on Self-Consciousness.” In Daniels, ed., New Interpretations, 179-202.

-------. Berkeley's Philosophy of Spirit. Consciousness, Ontology and the Elusive Subject. London: Continuum, 2007.

Bracken, Harry M. The Early Reception of Berkeley's Immaterialism 1710--1733 . The Hague: Nijhoff, 1963.

Bradatan, Costica. The Other Bishop Berkeley. An Exercise in Reenchantment. New York: Fordham University Press, 2006.

Brown, Michael. "Was there an Irish Enlightenment? The case of the Anglicans." In Butterwick, et al., eds., 29-48.

Byrne, P. A. "Berkeley, Scientific Realism and Creation.” In Religious Studies, vol. 20, no. 3 (September, 1984): 453-464.

Charles, Stephen. "Berkeley and the Lumières: Misconception and Reconstruction." In Daniels, ed., New Interpretations, 283-310.

Dancy, Jonathan. Berkeley: An Introduction. Oxford: Blackwell, 1987. 
Daniel, Stephen H. “How Berkeley’s Works are Interpreted." In Parigi, ed., 3-14. ed. New Interpretations of Berkeley's Thought. Amherst, NY: Humanity Books, 2008.

-------, ed. Reexamining Berkeley's Philosophy. Toronto: University of Toronto Press, 2007.

Flage, Daniel. "Berkeley, Individuation, and Physical Objects." In Individuation and Identity in Early Modern Philosophy, edited by Kenneth F. Barber and John J. E. Garcia, 133-154. Albany, NY: Statue University, 1994.

------. "Berkeley's Epistemic Ontology: The Three Dialogues." In Daniels, ed., New Interpretations, 45-76.

Grayling, A. C. “Berkeley’s Argument for Immaterialism.” In Winkler, ed., 166-189.

Hight, Marc A. "Why My Chair is Not Merely a Congeries: Berkeley and the Single-Idea Thesis." In Daniel, ed., Reexamining, 82-108.

Holtzman, Matthew. "Berkeley's Two Panaceas." Intellectual History Review, vol. 21, no.4 (2011): 473-495.

Jakapi, Roomet. "Christian Mysteries and Berkeley's Alleged Non-cognitivism.” In Daniels, ed., Reexamining, 188-198.

Johnston, G. A. The Development of Berkeley's Philosophy. New York: Russell \& Russell, 1965.

Luce, A. A. Dialectic of Immaterialism: An Account of the Making of Berkeley's Principles. London: Hodder and Stoughton, 1963.

------. The Life of George Berkeley Bishop of Cloyne. London: Thomas Nelson, 1949.

McDonough, Jeffrey K. "Leibniz: Creation and Conservation and Concurrence." The Leibniz Review, vol. 17 (2007): 31-60.

Robert G. Muehlmann. Berkeley’s Ontology. Indianapolis: Hackett, 1992. 
Pappas, George. Berkeley's Thought. Ithaca, N.Y.: Cornell University Press, 2000.

Parigi, Silvia, ed. George Berkeley: Religion and Science in the Age of Enlightenment. Dordrecht: Springer, 2010.

Paul, L. A. and Ned Hall. Causation. A User's Guide. Oxford: Oxford University Press, 2013.

Pitcher, George. Berkeley. London: Routledge \& Kegan Paul, 1971.

Rickless, Samuel. "The Relation Between Anti-Abstractionism and Idealism in Berkeley's Metaphysics." The British Journal for the History of Philosophy, vol. 20, no. 4, (2012): 723-740.

Wild, John D. George Berkeley. Cambridge: Harvard University Press, 1936.

Winkler, Kenneth E. "Berkeley and the Doctrine of Signs." In Cambridge, ed. Winkler, 125-165.

-------. Berkeley. An Interpretation. Oxford: Clarendon Press, 1989.

-------, ed. The Cambridge Companion to Berkeley. Cambridge: Cambridge University Press, 2005.

Yolton, John E. Realism and Appearances. An Essay in Ontology. Cambridge: Cambridge University Press, 2000.

$\underline{\text { Vico }}$

Badaloni, Nicola. Introduzione a Vico. Bari: Laterzi, 1995.

Bhattacharya, Nikhil. "Knowledge 'Per Causas': Vico's Theory of Natural Science.” In Tagliacozzo, ed., 182-197.

Black, David W. Vico and Moral Perception. New York: Peter Lang, 1997.

Cramer, Charles A. and Kim T. Grant. "La démarche poétique from Vico to Surrealism.” New Vico Studies, vol. 22 (2004): 63-84. 
Collins, Rebecca. "An Ontological Constructionist Interpretation of Vico's Philosophy of History." New Vico Studies, vol. 22 (2004): 33-47.

Fabiani, Paolo. La filosofia dell'immaginazione in Vico e Malebranche. Firenze: Firenze University Press, 2002.

Gaukroger, Stephen. "Vico and the Maker's Knowledge Principle." History of Philosophy Quarterly, vol. 3, no. 1 (January, 1986): 29-44.

Goetsch, James. Vico's Axioms: The Geometry of the Human World. New Haven: Yale University Press, 1995.

Lachterman, David R. "Mathematics and Nominalism in Vico's Liber metaphysicus." In Otto and Viechtbauer, eds., 47-86.

Löwith, Karl. Meaning in History. Chicago: University of Chicago Press, 1967.

Luft, Sandra Rudnick. "Embodying the Eye of Humanism: Giambattista Vico and the Eye of Ingenium.” In Levin ed., 167-196.

Mali, Joseph. The Legacy of Vico in Modern Cultural History From Jules Michelet to Isaiah Berlin. Cambridge: Cambridge University Press, 2012.

-------. Mythistory. The Making of Modern Historiographhy. Chicago: University of Chicago Press, 2003.

Marshall, David L. Vico and the Transformation of Rhetoric in Early Modern Europe. Cambridge: Cambridge University Press, 2010.

Milbank, John. The Religious Dimension in the Thought of Giambattista Vico 1688-1744. Part I. The Early Metaphysics. Lewiston, NY: Mellen, 1991.

Miner, Robert C. Vico. Genealogist of Modernity. Notre Dame: University of Notre Dame Press, 2002.

Morera, Esteve. "Vico and Antifoundationalism." In New Vico Studies, vol. 17 (1999): 35-51. 
Morrison, James T. "Vico's Principle of Verum is Factum and the Problem of Historicism." Journal of the History of Ideas, vol. 39, no. 4 (OctoberDecember, 1978): 579-595.

Naddeo, Barbara Ann. Vico and Naples. The Urban Origins of Modern Social Theory. Ithaca: Cornell University Press, 2011.

Naginski, Erika. "Preliminary thoughts on Piranesi and Vico." RES: Anthropology and Aesthetics, no. 53/54 (Spring-Autumn, 2008): 152-167.

Otto, Stephan and Helmut Viechtbauer, eds.. Sachkommentar zu Giambattista Vicos Liber metaphysicus. Munich: Fink, 1985.

Peterson, Thomas Erling. "Constructivist Pedagogy and Symbolism: Vico, Cassirer, Piaget, Bateson.” Educational Philosophy and Theory, vol. 44, no. 8 (2012): 878-891.

Pompa, Leon. “Imagination in Vico." In Tagliacozzo, ed., 162-170.

Ricuperati, Giuseppe. "A Long Journey. The Italian Historiography on the Enlightenment and Its Political Significance (1890-1990)." In Historiographie et Usage des Lumière, edited by Giuseppe Ricuperati, 232-260. Berlin: Arno Spitz, 2002.

Robertson, John. "Political economy and the 'feudal system' in Enlightenment Naples: outline of a problem." In Butterwick, et al., eds., 65-86.

Rockmore, Tom. "A Note on Vico and Antifoundationalism." New Vico Studies, vol. 7 (1989): 18-27.

Rotenstreich, Nathan. "Between Participation and Constitution." In Otto and Viechtbauer, eds., 87-98.

Stone, Harold Samuel. Vico's Cultural History: The Production and Transmission of Ideas in Naples 1685-1750. Leiden: Brill, 1997.

Tagliacozzo, Giorgio, ed. Vico: Past and Present. Atlantic Highlands, NJ: Humanities Press, 1981. 
------- and Hayden V. White, eds. Giambattista Vico. An International Symposium. Baltimore: Johns Hopkins University Press, 1969.

Trabant, Jürgen. Vico's New Science of Ancient Signs. A Study of Sematology. Translated by Sean Ward. New York: Routledge, 2004.

Verene, Donald Phillip. The New Art of Autobiography. An Essay of the Life of Giambattista Vico Written by Himself. Oxford: Clarendon Press, 1991. 